\title{
Vulnerable Territories: The Perpetually Shifting Edge.
}




\section{Vulnerable Territories:}

The Perpetually Shifting Edge.

Joseph Wellwood

A 120-point thesis submitted to the Victoria University of Wellington in partial fulfilment of the requirements for the degree of Master of Architecture (Professional)

Victoria University of Wellington School of Architecture 2020 


\section{Vulnerability}

"the qualitity or state of being exposed to the possibility of being attacked or harmed, either physically or emotionally"

in danger - peril - in jeopardy - at risk endangered - unsafe - unprotected 


\section{Abstract.}

New Zealand's coastline is rapidly receding. The increased threat rising sea levels continues to erode

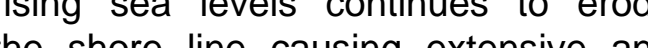
the shore line causing extensive and irreparable damage to thousands of communities and the kiwi dream of living near the ocean.

With global temperatures continuing to rise, all of our coastal communities are at risk. The current measure of response to this issue is through managed retreat the removal and relocation of all 'at risk' buildings in coastal hazard zones. While this approach is successful in preserving the physical structures, it remain an undesirable solution that forces homeowners to abandon their community and the coastline for the safety of higher ground. The retreat is hampered among debate within the effected regions as the forced detachment of long standing communities often results in the loss of 'sense of place' that living within coastal community enables.

This thesis proposes that Haumoana in Hawkes Bay offers the fitting location to introduce an alternative coasta community model that actively responds to the impending hazards whilst retaining the societal poetics. Situated just south of the nearby communities of Te Awang and Haumoana, two of the most at-risk coastal regions in New Zealand that are currently facing the prospect of dismantement. The site was specifically chosen due to the fact that erosion is chosen due to the fact that erosion is predicted to diminish hall its usable will investigate the potential risks to the respective coastline, the role that this would play in an adaptive community and the possible design options that an respond and enhance a future sustainable landscape.

This thesis argues that a coasta community can be designed to actively adapt and respond to the threat of erosion rather than being dismantled hrough retreat; that by adopting design principles that protect the land on which they are placed, the coastal hazards of prion an region can be lessened; and that chiced whilst retaining the can be place' that coastal community's exhibit.

The thesis proposes that this can be chieved by incorporating and reinforcing natural features of the coast into the architectural design at various scales accommodating for, and adapting to the imminent threat of erosion; and by invoking principles of sustainable design in company with adaptive planning and in company with adaptive planning and resilent design, thereby pushing the tandards of coastal planning beyond ypical practice. 


\section{Haumoana.}

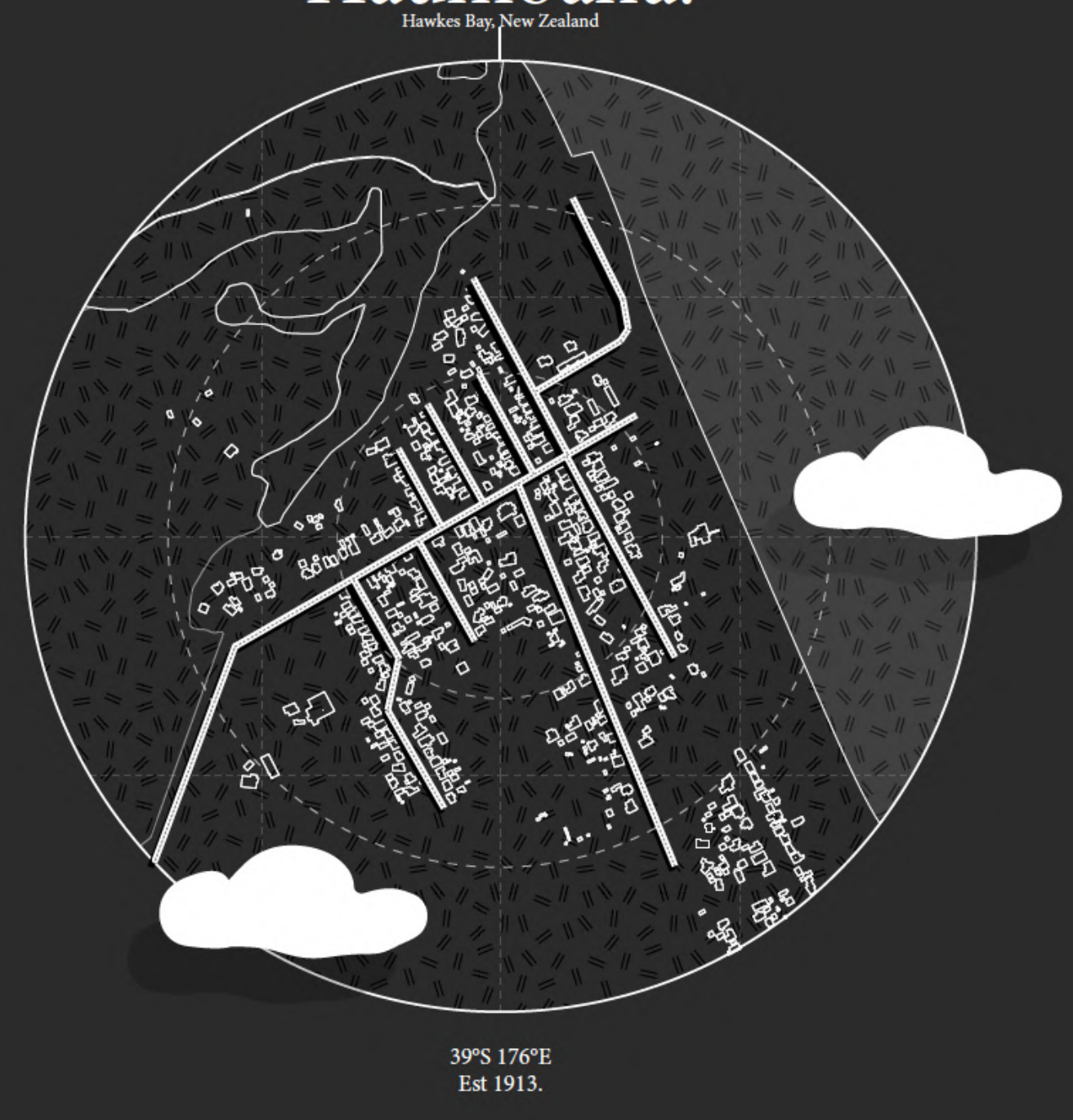

\section{Preface.}

\begin{abstract}
$\mathbf{T}_{\text {b }}$
his project exists in the context of conceptual architectural design. It critiques and explores the existing built environment, making explicit remarks towards issues such as climate change, sustainability, landscape preservation and methods of coastal habitation.

It has come about through the observation of the many cherished coastal New Zealand community's that have become exceedingly threatened by the product of sea level rise.

The title of this thesis, Vulnerable Territories, reflects on the fact that the built environment often neglects how delicate, dynamic and extrodinary some of these places are, and the damage that innapropirate buildings can do to them.
\end{abstract}




\section{Acknowledgements.}

I would like to thank my friends, for the last five years of memories. The people that I am privileged enough to be surrounded by have helped me in more ways than I can express.

Most importantly, I would like to thank my family.

To my parents who have shown unconditional encouragement and support throughout the last five years of study, it goes without saying that i could not have done any of this without your help.

And to my siblings, who have unwittingly driven me to continually uphold a similar standard of

motivation, persistence and achievement that they

have attained in their own pursuits of passions and professional endeavour's.

\section{For everything}

Thank you all. 


\title{
Contents.
}

\author{
00 pi-xiii $\begin{gathered}\text { Vulnerable Territories. } \\ \text { Preface. }\end{gathered}$ \\ 01 p1 Conflict of the Beach. \\ Introduction. \\ 02 p19 Architectural Mutualism. \\ Required Response. \\ 03 p41 The Saying of Things. \\ 04 p71 Affirmations Of The Human Spirit. \\ 05 p85 To Settle In The Landscape. \\ Conceptual Design. \\ 06 p119 Sentiments In Man.
07 p137 Of The Environment. Final Design. \\ 08 p187 Of The Environment. \\ Conclusions.
}




\section{$\begin{array}{llllllllll}00 & 01 & 02 & 03 & 04 & 05 & 06 & 07 & 08\end{array}$}

CONFLICT OF THE BEACH. 
"The real conflict of the beach is not between sea and shore, for theirs is only a lover's quarrel, but between man and nature. On the beach, nature has achieved a dynamic equilibrium that is alien to man and his static sense of equilibrium. Once a line has been established, whether it be a shoreline or a property line, man unreasonably expects it to stay put."

Introduction.

| vulnerable territories |

A I large majority of New Zealand's urban development
has prioritized coastal areas as has prioritized coastal areas as
desirable landscapes, and the desirable landscapes, and the values along the coastal edge has reinforced the strong demand for further development (Cheyne \& Freeman, 2006, p. 105). Induced by anthropogenic climate change, sea level rise and resulting events such as erosion and inundation remain the most pressing obstach to this to this coastal inhabitation. These coastal events are only perceived as hazardous when they begin to impact the human occupation of a region. The grounded structures that humans erect often fail to consider the shifting dynamics of the ocean, in the perception of inhabitants, these dwellings seemingly define where the coastal edge ought to remain coastal edge ought to remain (Ricketts, 1986, p. 197)

As the development of homes and communities persist in the path of these hazards, three broad responses arise as mitigation options; to resist, retreat or adapt (Refer pg.10). Historically protection techniques were seen as the desired response to the prominent coastal hazards, the pronstruction of barrier structures and the imple and the implementation of soft engineering techniques to slow or halt any edge deterioration Cooper \& McKenna, 2008, p. 296). However, it has been recently recognised that hese common methods of protection are not only financially unreasonable, but regularly have an adverse repercussion on both the immediate and adjacent coastal environments (ReinenHamill, Clode, \& Daykin, 2009, 1). More recently, New Zealand egional councils are in of maned retreat, the of managed retreat, the design of communities for future relocation of at-risk structures inland away from adverse effects of coasta hazards (NZCPS, 2010, pp. 24, Policy 25c). This retreat is hampered with debate as whilst it remains effective in preserving the built environment, it often eventuates in the disbandment of communities through the decline of residents and coastal property, resulting in a loss of connection (Owen et al. 2018, p. 10)

"The way managed retreat is currently implemented in coastal New Zealand seems less about retreat and rather more about displacement

(Bloomfield, 2018, p. 558)
The continued effect of sea level rise and its associated coastal hazards such as erosion and hundation is a well-established management problem for coastal communities around the country. The fore mentioned resistance option positions itself on artificially manipulating nature (place) to protect architecture (built environment), whereas the retreat option focuses on protecting architecture through abandoning nature. With aconclusive mitigation preference still lacking, this thesis argues that management of the coast needs to take a more nature centric approach, embracing innovative strategies of adaption to enforce a mutualistic relationship where architecture and the built environment stand as a tangible meeting point between nature and humans.

It is with this idea in mind that I have framed my design-led research, with the intended objective of exposing a designed solution where architecture and nature can cohabit place harmoniously, where the built environment is sympathetic to the vulnerable landscape, thereby allowing nature to retain its freedom whilst preserving the luxury of coastal occupation. 


\section{Research Methodology.}

A itself in the realm of scientific plausibility, and expresses itself through the poetic notions of its response.

As such, this project begins by implemented in response to similar conducting qualitative research, issues, their design principles and primarily through the exploration, the justification for such methods. observation, and analysis of This is followed by modern the chosen site, its issues, and examples of architectural designs

the historic responses that are that follow similar principles

Understandably, there is a potentially adaptable to similar significant lack of grandiose locality.

theoretical doctrine of a poetic nature in regards to the scientific plausibility of the subject, and as a result, this thesis will follow the model of 'grounded theory'. A model that:

By initially and systematically xploring the reports and data that provide substantial groundwork for a designed intervention to establish itself on, a more esoteric response can be explored and "...allows the researcher to elements of feasibility with develop a theoretical account of continuous reference to elements the general features of a topic while continuous reference to elements simultaneously grounding the account in empirical observations or data" (Martin \& Turner, 1986, p. 141) search

The process of design then follows the adaption of all of the principles that have proven effective in various scenarios from these case studies, assessing how similar techniques can be applied to a ew Zealand context and the chosen site in particular.

This results in an emergent design method, maintainin new ideas and findings made This thesis analyses historic revisiting discoveries made at the architectural techniques that were beginning of the process.

\section{Scope.}

T 1 his thesis will develop one coastal New Zealand site as an exemplary design model, following an approach that can be replicated and adjusted for simila regions elsewhere.

The research focuses on the approach and justification for a new method of coastal habitation in New Zealand, encouraging the implementation and assessment of unconventional building techniques that respond empathetically to the highlighted issues and site.

Some limitations of this work that are beyond the scope of the investigation are that there are no considerations towards such things as detailed structural analysis, restraints due to economic viability or resource consent obligations.

The project is of theoretical nature and is intended to remain a speculative and poetic excin that is based on the premise of inciting conversation about the changing conditions and requirements of continued coastal habitation.

\section{Structure.}

Chapter 01 - Introduction

Explores the selected region and categorises the highlighted hazards that effect the built environment along with the typical responses that have been implemented historically.

Chapter 02 - Chosen Response

Justifies the technique that has been chosen for exploration and further chopment, analysing wher development, analysing whas has be adapted to site.

\section{Chapter 03 - Site Analysis}

Introduces and explores a refined and specific site that is deemed suitable for a designed intervention to use as a vessel.

Chapter 04 - Design Considerations Investigates circumstances that need to be considered throughout the to be considere
Chapter 05 - Conceptual Design Chaduces and develops a conceptual design example that follows the outlined design considerations, then reflects on the success of the intervention.

Chapter 06 - Developed Masterplan Revisits the scope of the project and adapts communal product.

\section{Chapter 07 - Final Design}

Outlines the decisions behind the final design and what effects suc decisions have on its surroundings.

Chapter 08 - Conclusions

Reflects on the nature of the problem the steps that have been taken and the limitations of the investigation. an impoctant argument and project is continue in the future. 


\section{Haumoana.}

A an abundance of quintessential coastal regions in New Zealand that are exceedingly vulnerable to the fore mentioned coastal hazards, many of which would function as a suitable vehicle for this design-led research to take place. However, throughout the initial research investigation of intial research investigation of the region that is consistently the region that is consistenty highlighted as one of the most
at-risk in the country is the southern Hawkes Bay coastline, specifically the small community of Haumoana.

Haumoana is considered on of New Zealand's 'hot spots' of community vulnerability to coasta hazards (Kench \& Dickson, 2018 p. 1). The town, located near the southern end of the gravel barrier beach stretching between Napier to Cape Kidnappers, is home to to one of the fastest deteriorating country. It has cubjected to extensive rosion since the 1931 Hawkes Bay Earthquake resulted in the alteration of the coastal system along the 'cape coast' due to tectonic uplift (Bloomfield, 2018, p. 556). Since then the community has consistenty battled with the natural forces of batled wh the natural forces of the ocean, implementing hard engineering techniques such as the construction of concrete sea walls and groyne in an attempt to protect their homes from the everrising waters.

With these hard engineering techniques proving costly and adversely less effective than predicted, a large number of the Haumoana community are now facing the 'managed retreat' option of abandoning properties to the mercy of the tide and relocating their homes away from the coastline, an approach that is heavily contested among the is retreat approach is not disputed for most logical, such as the loss of most logical, such as the loss of land or home, but for the more poetic notion of attachment of place (Gudsell, 2016). Residents are less concerned about the physicality of their property and more about the cherished values, memories and experiences that the Haumoana community has catered for, as climate change commentator Jeff Goodell states:
"But they love where they live and the whole notion of getting up and going somewhere else is very hard... Even people who understand climate change still think sea-level rise is a slow, gradual thing and they can build a seawall that will be fine for $X$ number of years and this is a remedy for the problem." (Blundell, 2018)

Unfortunately, it is already nevitable that many of the home will have to be relocated due to how immediate the threat from the sea is, and with the homes displaced, the community is under threat of disbandment. However it is for this purpose that the is optimal circumstances for this design-led research portfolio, this thesis proposes that although they may have to abandon their homes, they do not have to abandon their community.

This proposal suggests that a new community design can be established to allow for the continued habitation of the Haumoan coastline. It suggests that the exp coastine. It suggests that the exploration of an adaptive model that harmonises with the dynamic environment is essential to retaining the place attachmen and values of the region, even in the face of coastal hazards. 
Coastal Flooding

Coastal flooding can range from 'nuisance events' to widespread inundation, and with the sea rising, the latter is becoming increasingly regular. Flooding due to rising sea is expected to not only to originate from the coast, but is predicted to increase the duration and extent of river floods also (Parliamentary Commissioner for the Environment, 2015, p. 28 ). As the sea continues to rise coestal land and communities will experience more frequent and severe flooding, a hazard that will severe flooding, a hazard that will
cover more land, last longer and cover more land, last longer and rise.

\section{Coastal Erosion}

Although erosion (and subsequent accretion) is a natural process of the coast that has been happening for thousands of ground and surface ponding, years, as the sea rises, erosion and the increased threat of will undoubtedly increase around liquefaction in earthquakes the New Zealand coast. As high (Parliamentary Commissioner energy storm waves rush further for the Environment, 2015, P.

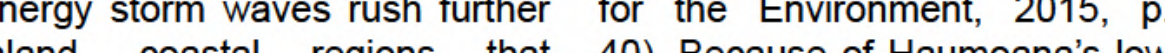
inland, coastal regions that ref lying water table, much of the fore surges are becoming much more mentioned flooding hazard will usceptible to the repercussions come directly from the ground, of erosion. Thus regions such and will not be able to retract back as Haumoana, that are already into the soil for a much longer heavily prone to the effects of period of time.

erosion, are likely to erode faster Parliamentary Commissioner for the Environment, 2015, p. 38)

\section{Coastal Groundwater}

The effects of flooding and erosion are often clearly evident, however the problems of ground water are seldom evident immediately. High ground water due to sea vel rise can lead to extensive damage to infrastructure and the built environment, boggy

With this prediction by both the IPCC and PCE that sea level rise will not falter for the reasonable future, it is critical for the continued habitation of the coast that a habitation of the coast that a designed solution be identifed that addresses and responds to these three hazards and the associated disturbance that they will have on both the natural and built environment.
$I$

n its most recent 2013 report, report highlights the three types the Intergovernmental Panel on of coastal hazard that will directly Climate Change (IPCC) outlined affect New Zealand by rising sea, the seais predicted to rise between these are:

$60 \mathrm{~cm}$ and $100 \mathrm{~cm}$ in the course of

the next century with the former + Flooding along coast where sea being the rise under a 'stringent flows over low-lying land.

mitigation' strategy, and the latter + Erosion that occurs when waves under a 'very high greenhouse gas and currents eat away at 'soft' emission' scenario (The Working Group I, 2013, pp. 1181-1182).

The unavoidable sea level rise is expected to exponentially aggravate the coastal hazards of New Zealand

The Parliamentary Commissioners Report for the Environment (PCE) shorelines.

+ Groundwater that can be affected in two ways - water tables can rise and fresh water can become saline. the Environment, 2015, p. 23)
(Parliamentary Commissioner for
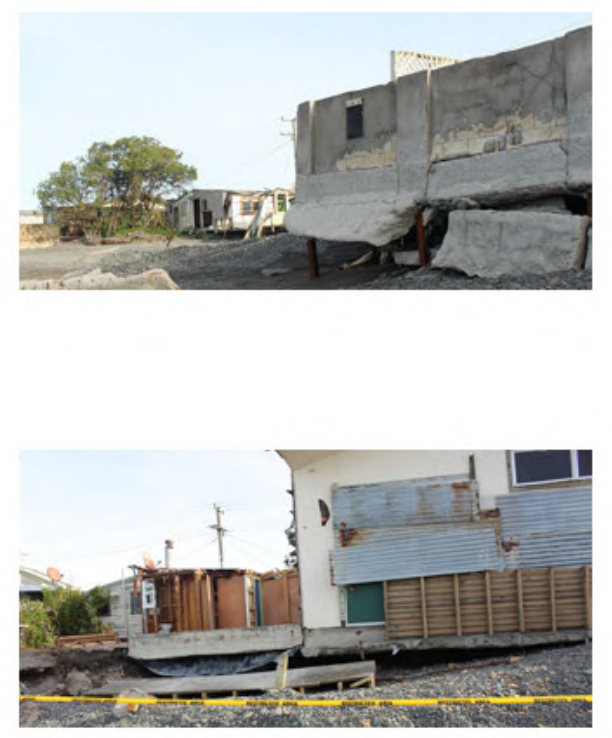

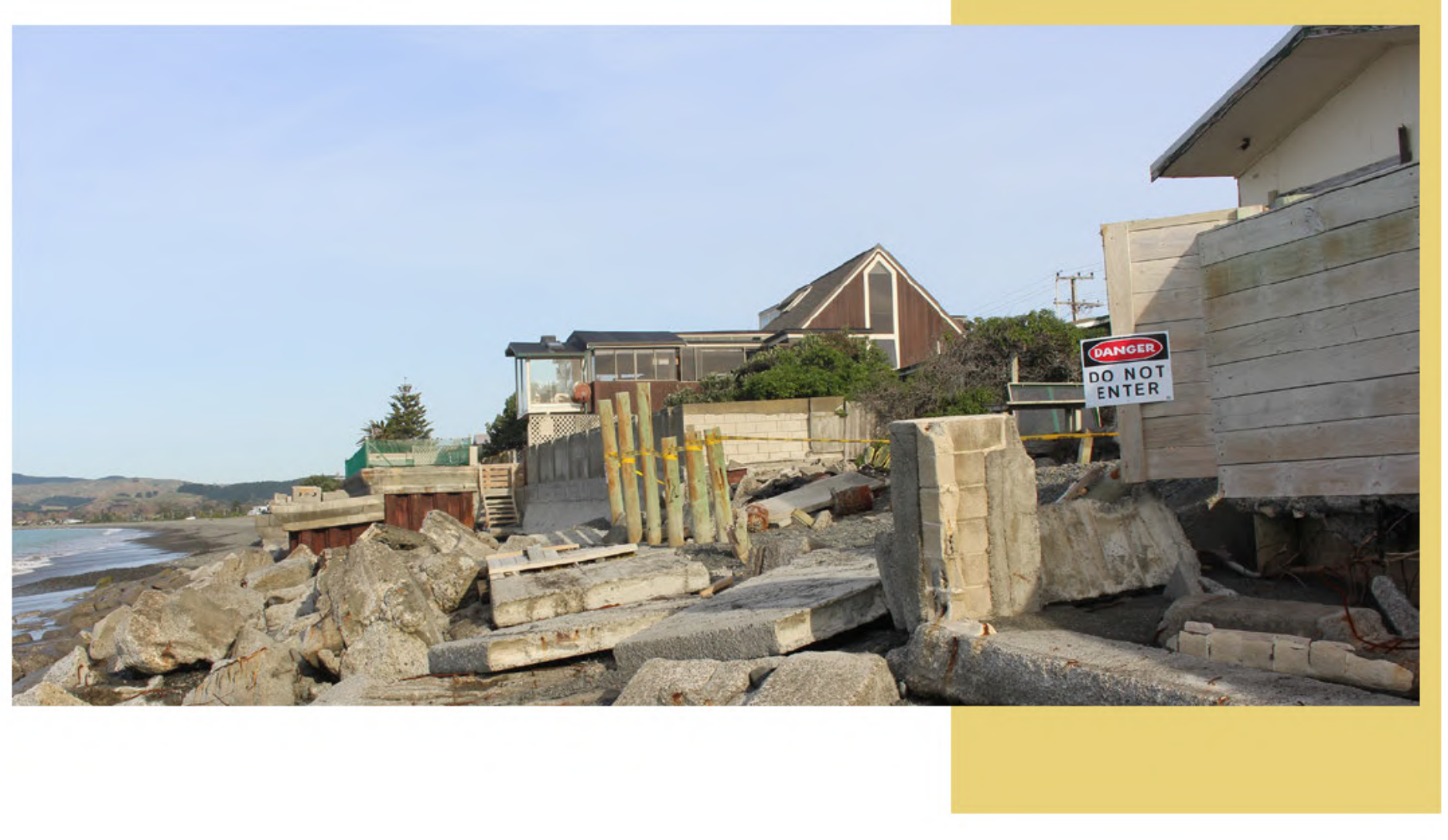


The Human Issue.

\section{W}

the area comprises or an area of few natural features, all of Hawkes Bay's coastal edge possesses some degree of natural character. The procedure under the [1991] Resource Management Act (RMA) is to actively explore protection of the features which amplify a regions natural character (Resource Management Act, 1991 , p. 62), and whilst they themselves do not define what 'natural character' is or is not, the [2014] Hawkes Bay Regional Coastal Environment Plan (RCEP) takes the consideration of several Environmental Court decisions to assist the interpretation. The

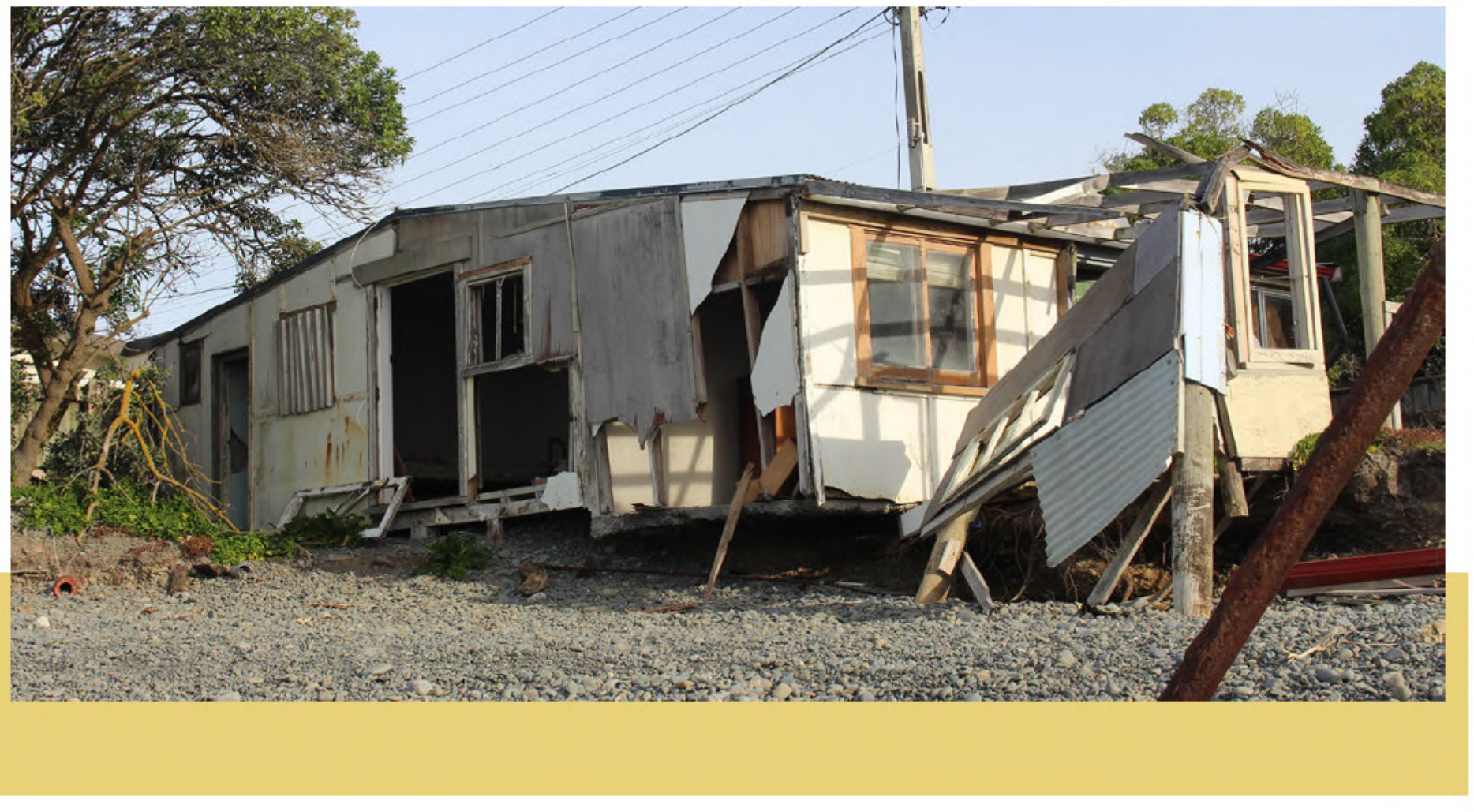

summary of which focalize on egional attributes as criteria, hese attributes to an areas identity include "outstanding of the landscape, reas of significant indigenous egetation and significant habitats of indigenous fauna and ecological and hydrologica ystems" (HBRC, 2014, p. 12). According to this management plan, under the titled section of 'Matters of National Importance', the report highlights the regiona and development, stating that:

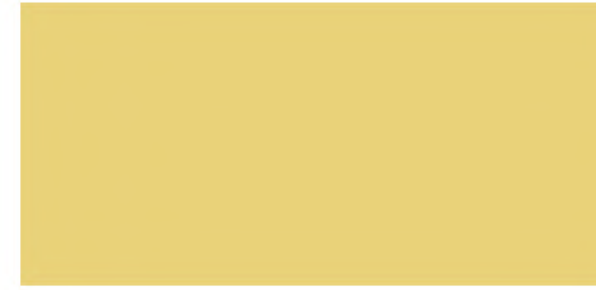

'The coastal environment's natural character is being modified and adversely affected hrough inappropriate subdivision use and development" (HBRC, 2014, p. 11)

"Inappropriate subdivision, use and development may degrade the physical integrity and aesthetic values of outstanding aestic within the coasta (HBRC, 2014, p. 13)
Such development can be observed throughout the Haumoana communty, where mercy of the ocean. Historically, cost houses have developed oval time with a stable sea in withconstuctionandinfrastructure rooted heavily in the ground. This rooted heavily in the ground. This model of building demonstrates the fact that majority of human intervention in the region has not considered its contextual locale. Dwellings have been constructed in the same manner as if they were in town, and consequently, they have become a logistical burden as now the commitity and council struggle with the resistance to the natural forces $A$ fragile and finite resource, the the coast. These immense natural character of the coastal fructures of permanence have environment is a vulnerable proven devastating to both the territory that must be protected physical integrity and the aesthetic from irreversible alteration or values of the coastal edge, with damage. To cohabit a dynamic many falling into disrepair and environment such as the coastal bandonment. edge requires a precautionary approach applied to the built environment, one that differs greatly from the prevalent mode of habitation. This design-led research portfolio seeks to uncover an intervention that harmonises the interaction between man and nature by protecting and and rature by protecting and amplifying the Haumoana regions 


\section{Research Aims.}

Enable enhanced occupation of sites that are vulnerable to coastal hazards.

Establish an innovative designed solution that allows the continued habitation of the Haumoana coastline.

Demonstrate a mutualistic relationship between nature and architecture

Retain the 'natural character' of Haumoana's coastal edge.

Use architecture as a tool to harmonise the interactions of man and nature.

\section{Design Objectives.}

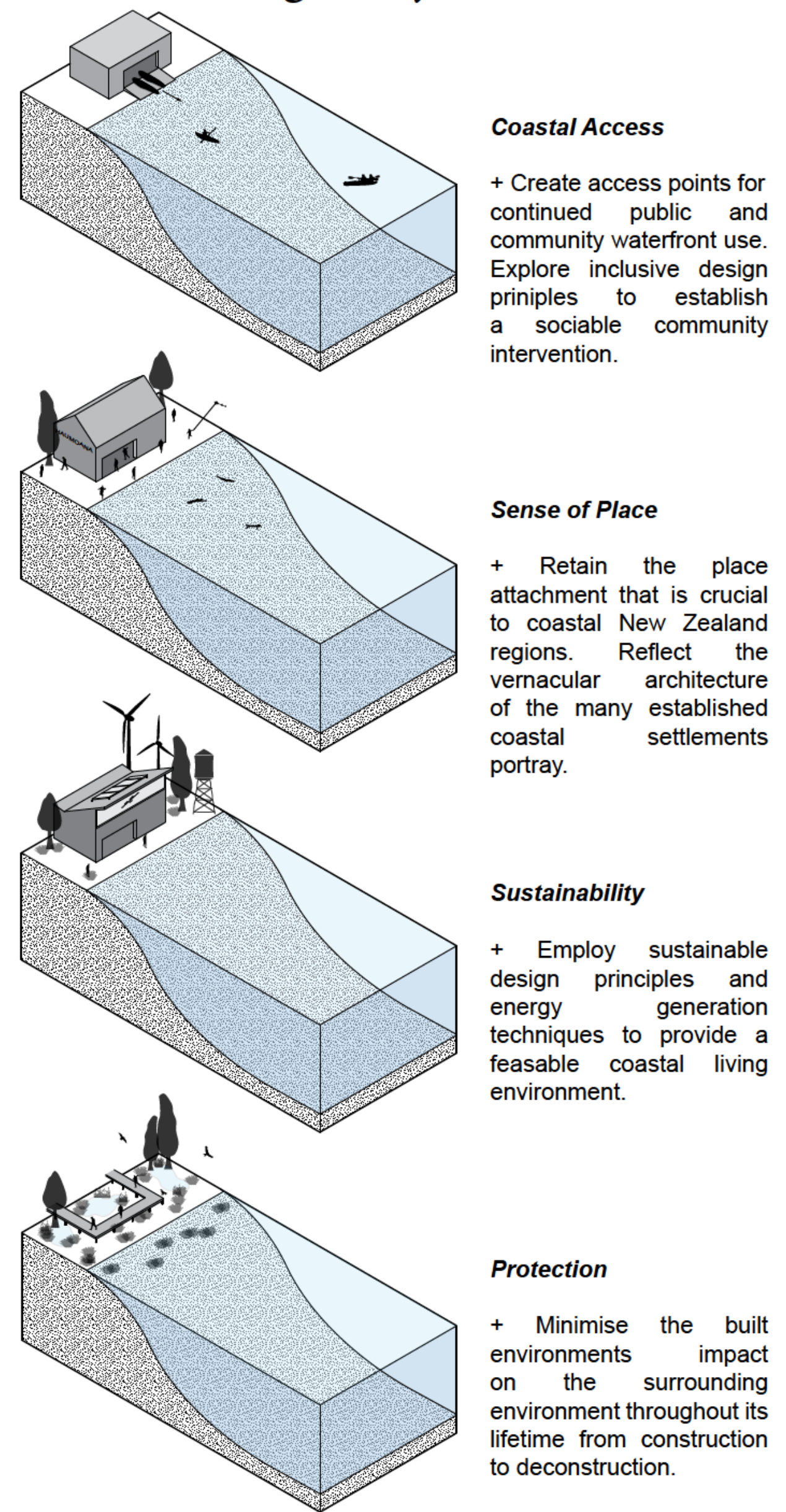




\section{$\underset{\text { Gyprding Against Sea Level Rise }}{\text { Typical Responses. }}$}

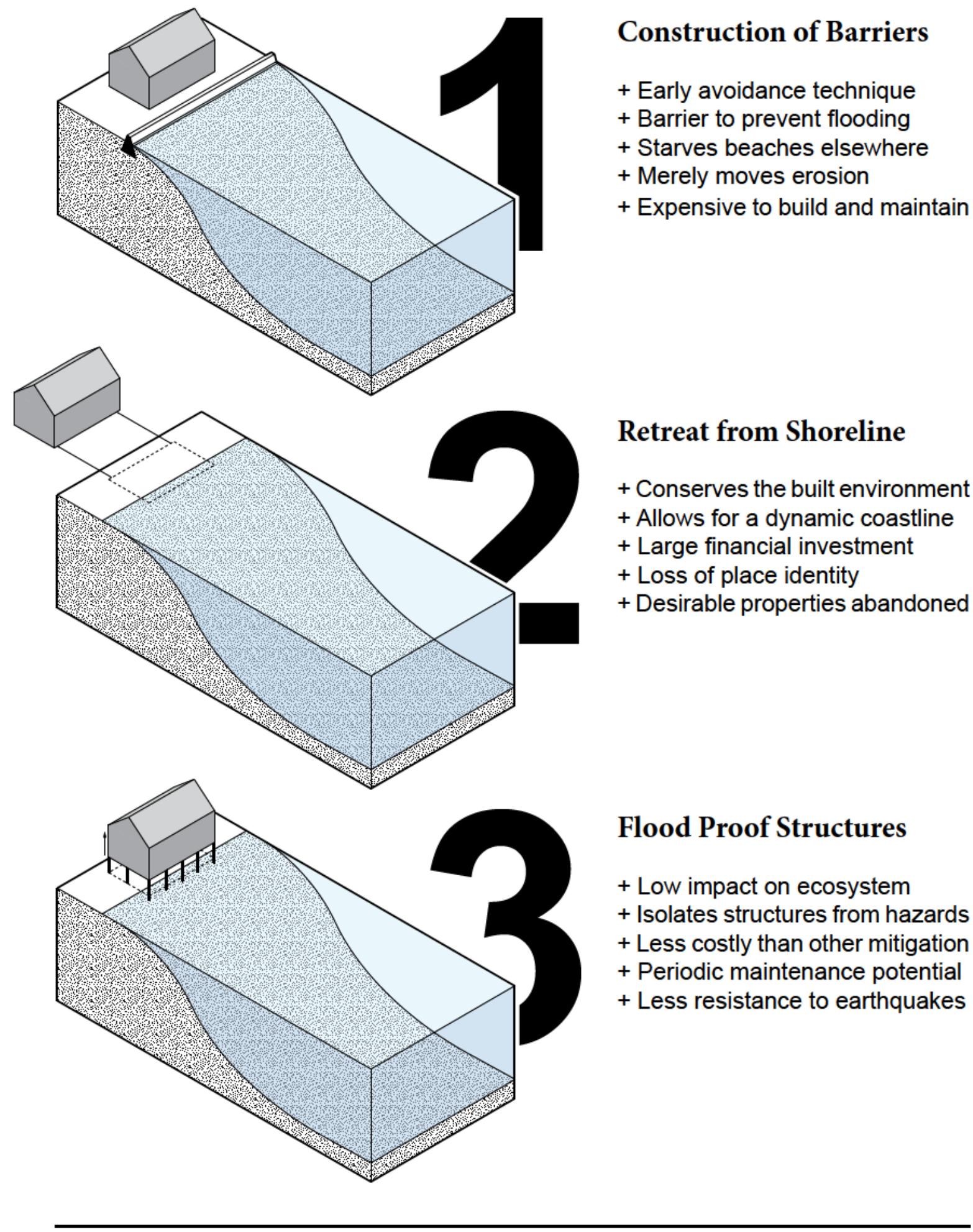

Information courtesy of FEMA
(Federal Emergency Management Agency, 2007, pp. 55-83)

\section{$+$}

This content is unavalible. Please consult the figure list for further information.

Haumoana.

Guarding Against Sea Level Rise

\section{Fig 1.03.}

\section{Construction of Barriers:}

As a result of the major 1931 Hawkes Bay Earthquake and subsequent sediment shift, the southern Hawkes Bay coast line has continually been constructing and implementing barriers through the means of hard and soft engineering techniques to resist the eroding coast. These include sea walls, groynes, and beach and gravel nourishment (REF). Whilst the hazard from the (REF). Whilst the hazard from the
coast was effectively mitigated for the immediate future, over time the barriers have proven to fail. The powerful storm surge and resulting erosion of the coastal edge has diminished the barriers to the point where many have become completely ineffective or destroyed entirely (Fig 1.11).

\section{Retreat from Shoreline:}

The current recommendation from the Hawkes Bay Regional Council is for the Haumoana region to undergo the option of 'managed retreat'. This measure refers the retreat or relocation of settlements and infrastructure out (Fig (Fig 1.12). The proposal for retreat is controversial in the Haumoan region, in particular the affected orstandably hold some of the strongest opposition this management plan as ften results in the resident's involuntary removal from the coast and the subsequent community.

\section{Flood-Proof Structures:}

Flood proof structures ar buildings that are designed to accommodate for the predicted risk of flooding. With techniques such as floating or amphibious structures that adjust with the alternating water levels, sealable buildings that aim to barricade the water and prevent any seepage, and building on poles to raise the ground level of a structure above the design water level.
The technique of flood proof structures is the only approach that the built environment of Haumoana has not employed in response to the imminent coastal threats. This thesis proposes that to retain the continued habitation of the Haumoana coastal edge, a flood proof building technique must be explored with regards to both individual dwellings, and community amenities. It proposes that a flood proof design would react to the coastal hazards in a more dynamic way than the barrier method, and would have the ability to retain the place attachment that is lost when undergoing the 'managed retreat' method 


\section{Flood Proof Structures.}
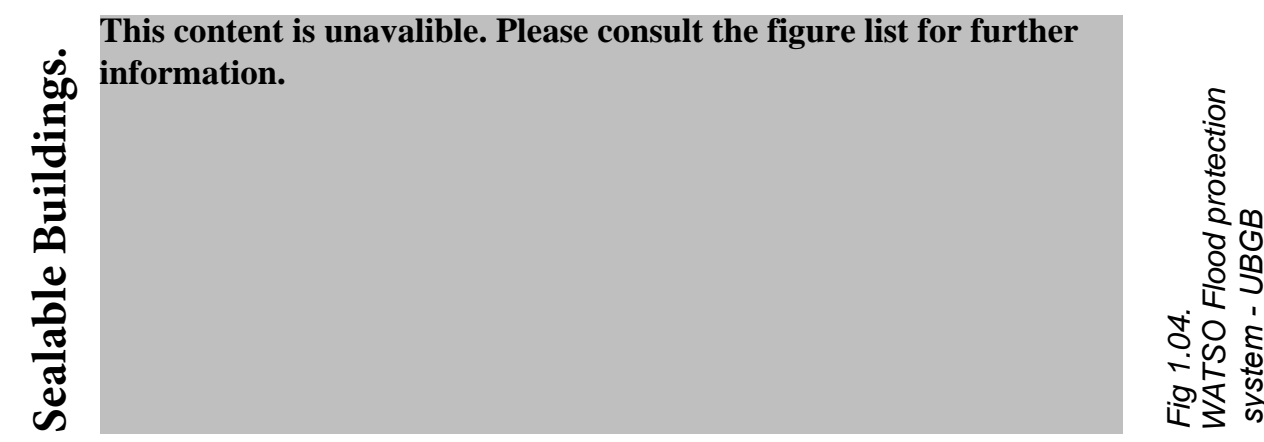

The sealable building technique refers to actively making the exterior shell of a building waterproof to prevent any water entering in the event of a flood. In case of a flood, the building will not be damaged by water so typical operations of the building

can usually resume promptly - Requires continued maintenance Allows for instant operation after hazard

+ Very cost effective

+ Minimal alterations to existing building

- Does not allow continuation of hazard after the water has subsided. However the design relies on the water subsiding, and would not be effective if the water level continued to raise.

$$
\text { 总 }
$$$$
\text { This content is unavalible. Please consult the figure list for further }
$$$$
\text { information. }
$$

es continued maintenance

Response rather than mitigation

\section{Flood Proof Structures.}

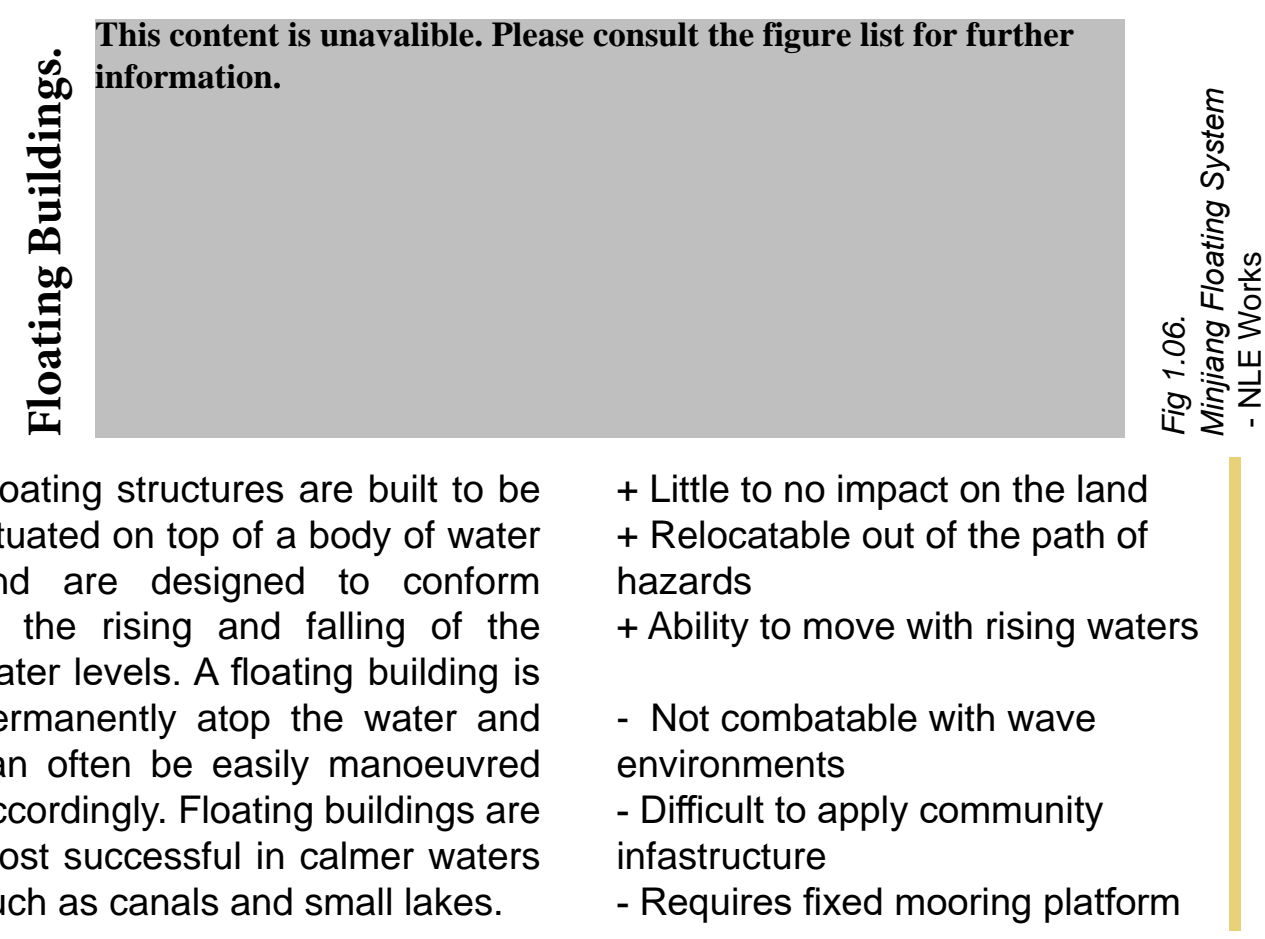

As opposed to the floating building technique, amphibious buildings are designed to be situated above the water and are designed to float once the water rises. They are often fastened to mooring posts and rest on concrete foundations when the water level is low. They are restricted to vertical movement with the water on the fasteners to moring rest the fasteners to moorings restric the motion caused by water.

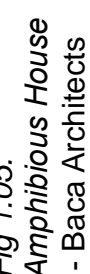

+ Ensures building and inhabitants safety

+ Allows for occupation of vulnerable site

+ Minimal visual difference in

homes

- Difficult in salt water conditions - Heavy on the land

- Short term solution to a short term issue

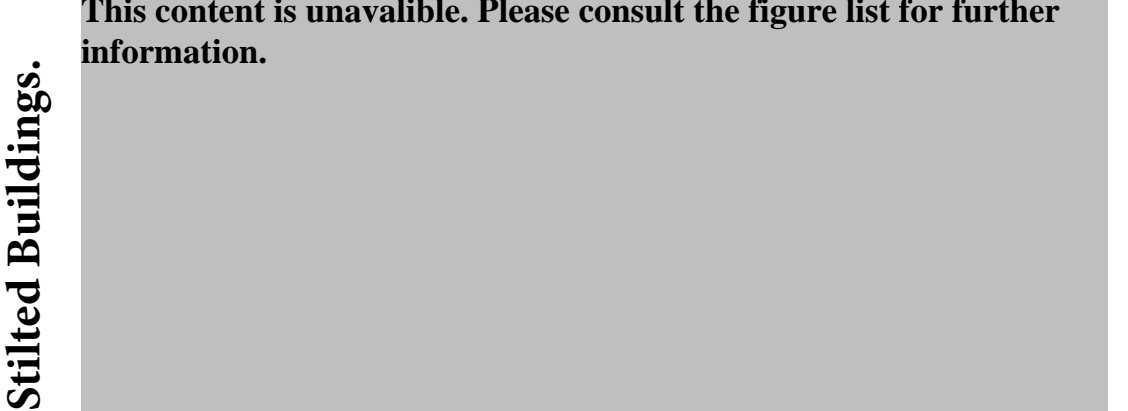

Raising a building off the ground allows for any water that could be a potential threat, to pass freely underneath. The poles that the building sit on provide a strong foundation and separate the built form from the hazard of the water.

+ Minimal impact on the land + Allows water to retain dynamics structure

- Must seperate infastructure from issue

- Requires periodic maintenance - Often more exposed to greater hazards

.



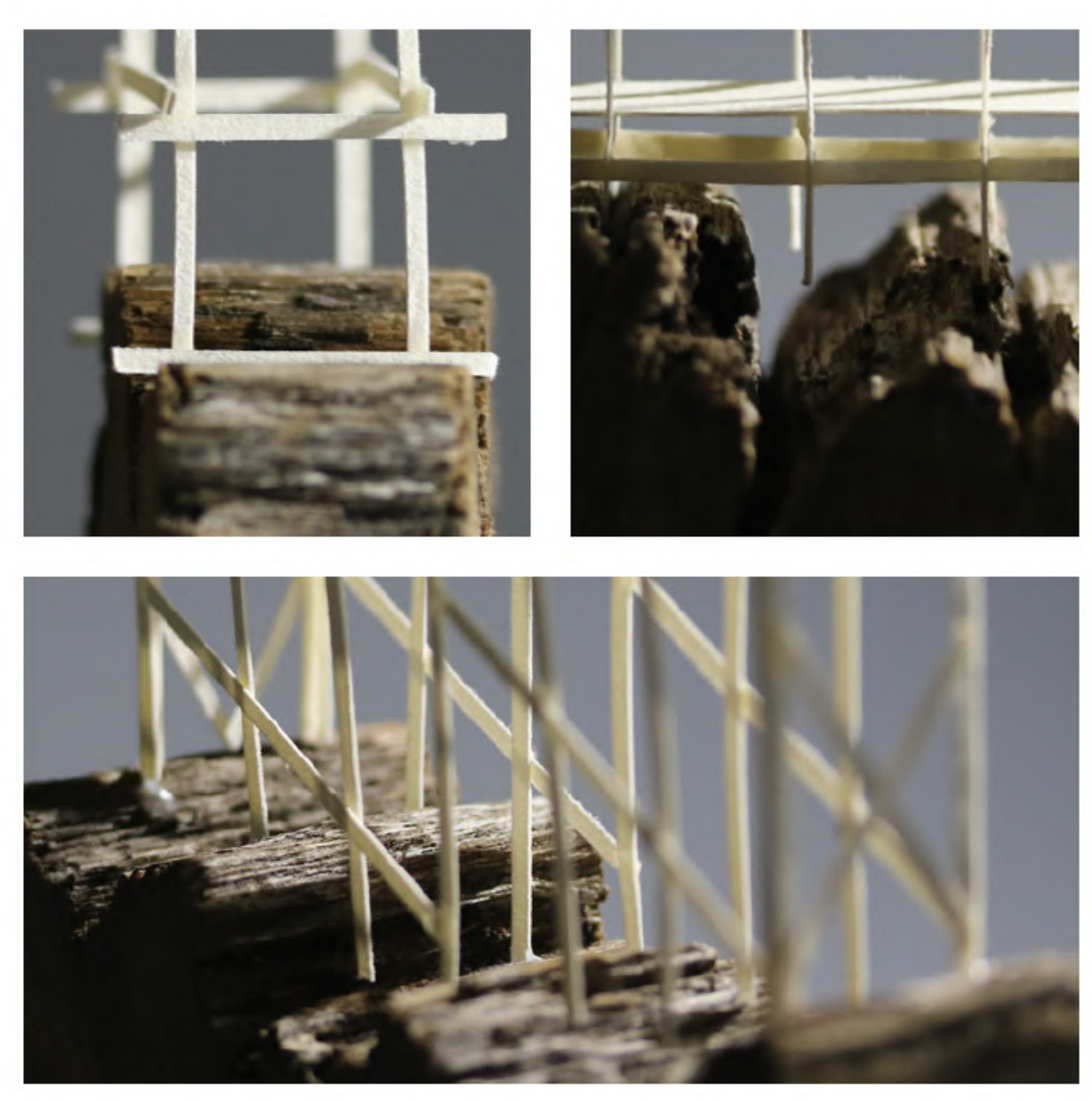

ARCHITECTURAL MUTUALISM.

required response 
"Mutualistic architecture embraces complexity. It cannot be a simple system because there are too many processes at work and to call it a simple system is to ignore this. It is because of this complexity that mutualistic architecture is in a unique position to reestablish the natural presence and its non-man made physical characteristics in the built urban landscape and establish a sense of harmony between the two. In this the when the effects of our actions on the natural world are becoming increasingly evident, when the effects of our actions on the natural world are becoming increasingly evident, it is necessary for architecture to embrace the complexity, diversity and uniqueness that exists between built and natural form."

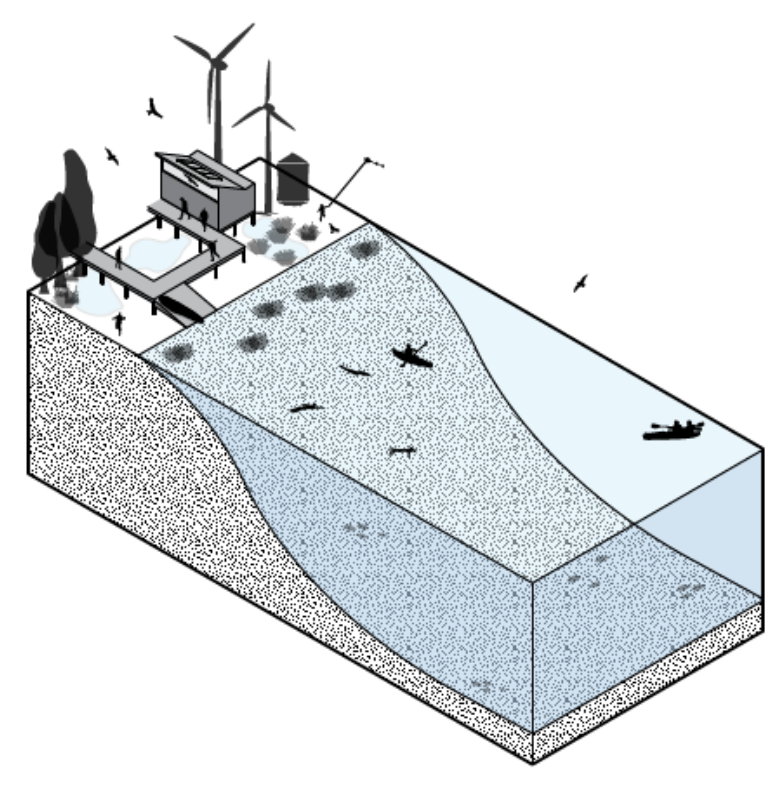

\section{Required Response.}

Stilted Architecture

$\mathbf{T}$ hroughout the previous
investigation process, it has appropriate response to the segregates and unifies the highlighted issues surrounding interactions of humans, nature, the continued habitation of coastal and the built environment. With the continued habitation of coastal and the built environment. With the strategy of elevating buildings of continued coastal occupation, using the technique of stilted while natural processes and architecture. shifting dynamics of the coast are The technique succeeds in approach stands as the most satisfying many of the underlying applicable response to this ever principles that this design led growing issue.

research to follow Elevating the built In such a scenario, the buitt the felicate environment plays a citical iole landscape has the potential to in bringing these two forces, in bringing these two forces, allow for humans and nature man and nature, together in a to occupy the same territory's, mutualistic manner, an essential maintaining the ability to interact balance must be obtained in order with one another, simultaneously to accomplish true architectural granting the two the freedom to mutualism.

operate how they see fit in their 


\section{A Historic Technique.
Stited Dwellings.}

\section{$\mathbf{W}$} separate human from water is one
of the fundamental principles of shelter. On the contrary, all life on earth has an intimate relationship with water, as a species we have long depended on water, it has forever prevailed as a crucial source of nourishment.

The conflict between the need to live contiguous with water for nourishment, and the need to be detached from water for dwelling detach compelled adaption of the bult environment to conform to man's needs. Humans ultimately discovered a building technique
that allowed them simple travel

This content is unavalible. Please consult the figure list for further iffortion
Tonlé Sap.

$\mathbf{L}$

anded in central Cambodia, biodiversity that serves as one the great lake of Tonlé Sap lies of the world's largest fresh-water within a geological depression in fisheries. On the perimeter of the vast floodplain of the lower this lake, around 100,000 people Mekong River. Tonlé Sap is a inhabit the over 150 mixed village seasonally inundated freshwater containing floating homes as well lake and as such, community as homes elevated on eight to ten habitation of the lake has adapted metre high stilts (Kuenzer, 2013, outstandingly to the natural p. 29). The inhabitants of the environment (Kuenzer, 2013, p. villages have adapted to the water 30). The vernacular buildings of and stilted environment perfectly, the great lake stand as incredible houses are built densely close to examples of how individual stilted one another, with the little space dwellings can be intertwined between functions as public roads do form a dynamic community and meeting places in theads and meeting places in the dry ecosystem. season, and waterway navigation in the wet (Sithirith, 2007, p. 18).

With an economy centralized around the fishing industry, the lake is home to exceptional

This content is unavalible. Please consult the figure list for further informatio
This content is unavalible. Please consult the figure list for further information. है Please const thavalible. for funsult the figure list

and river environments to be imposing on dwellings(Chan \& Parker, 1996, p. 320) 


\section{Precedent Study 01.}

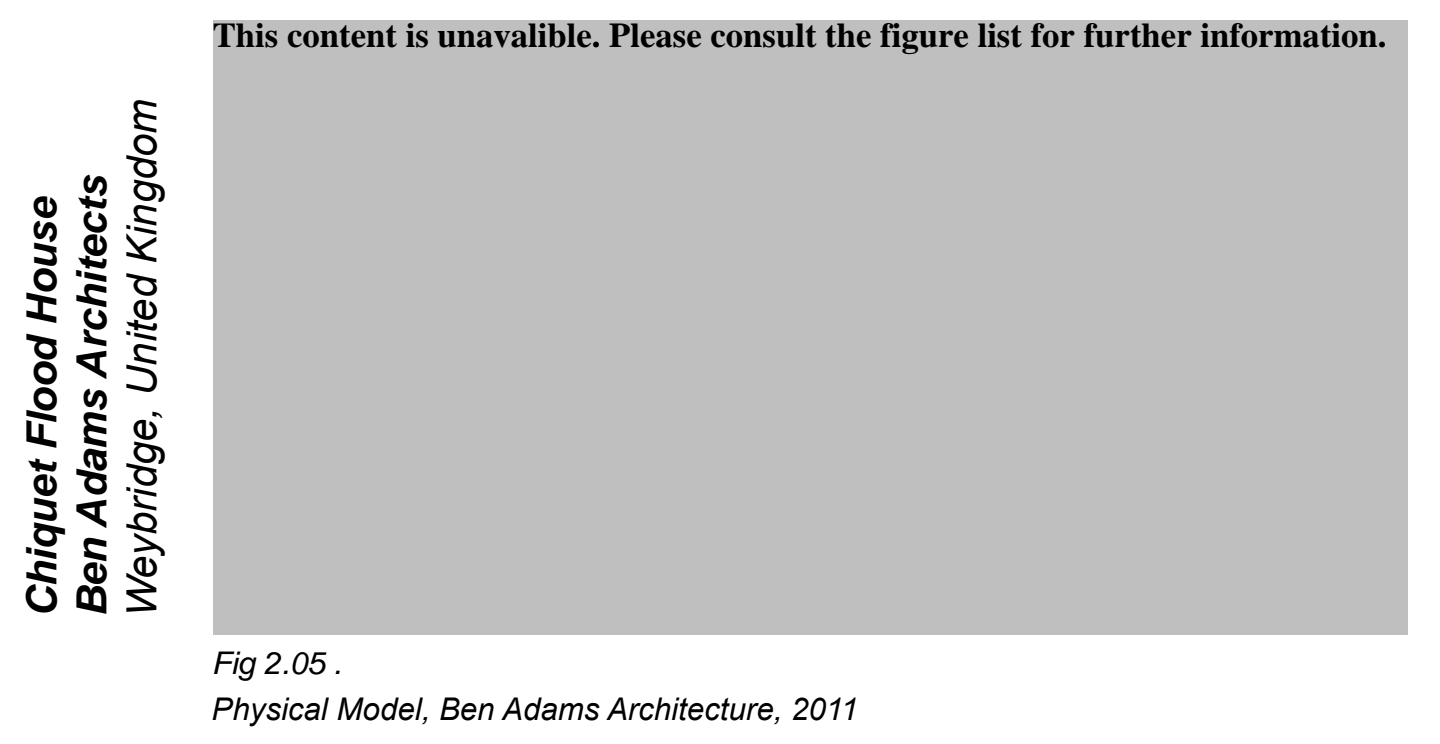

$\mathbf{T}_{\mathrm{r}}$ was designed by Ben Adams Architect's in a manner that celebrates its captivating site on the banks of the River Thames in Weybridge it is situated on the greenbelt on the surrounds of the river, a primary floodplain of the river, a primary floodplain that becomes overrun by the river on average twice a year and can remain waterlogged for weeks at a time.

extent of the Thames and into the open spaces of Hamm Court.

The mass of the house is minimised through the formal restraints of the site, the low roo line on the river side condenses its visual impact while the ascendis forms on the road side diminish the impression of volum dimish the impression of volume. It being a long slender building results in the majority of the mass remaining hidden from the primary viewing The form of the house is positions at either end. The plan centralized around the constraints of the house manages to conform of the extraordinary site, with to the exterior conditions whils the river being the major driver still maximising any natural light for most design decisions. Most through roof lights along the length notably, the design is lifted more of the house, leading the occupant than two meters off of the ground towards the river.

by a series of concrete and steel

posts, raising the occupation This simple, yet astute home areas above any potential flood becomes light on the land, not level. This elevation allows for only through the application the ground floor to become the of stilts detaching form from 'piano nobile' of the house, with site, but visually through the heightened views across the conscious regard of its contextual environment.

\section{Relation to Design.}

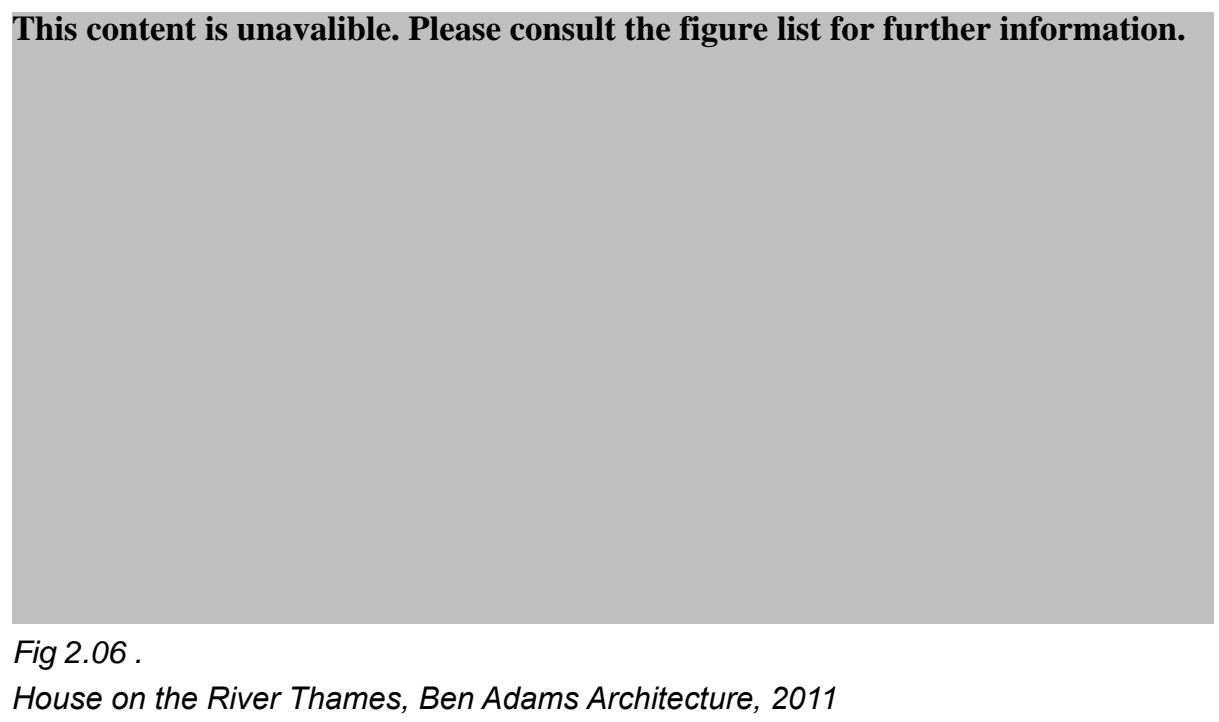

+ Respect of contextual environment, both physically and visually

$+\quad$ Stilted construction in response to inundation hazard

$+\quad$ Challenges of site highlighted within design features Sensitive site leading to sensitive design

Simple, essential design axiom 


\section{Precedent Study 02.}

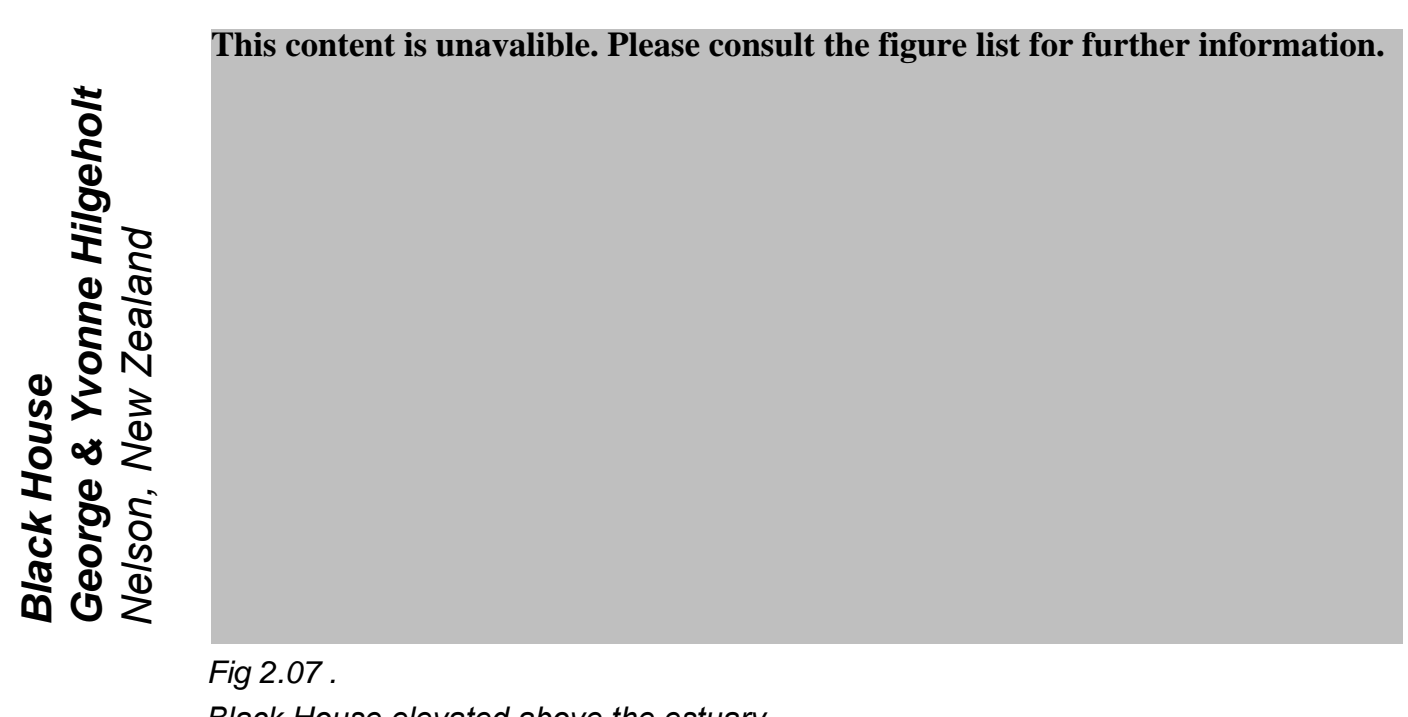

Black House elevated above the estuary

\section{Relation to Design.}

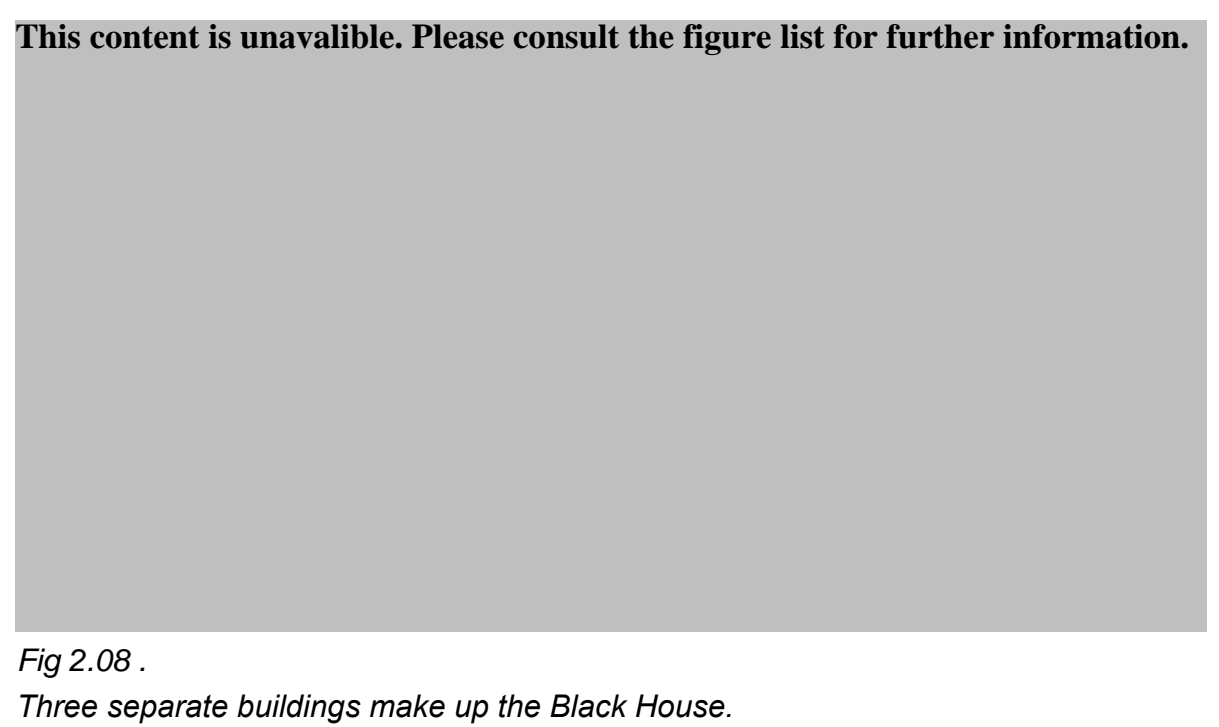

+ New Zealand example of stilted construction on vulnerable territory + the foundation supports. Even with the stilts, the warming and sea level rise means that the building may eventully still be in danger of damage, and Hilgeholt acknowledged this by designing for impermanence. The designing for impermanence. The were all extensively designed so if need be, they could be craned onto the back of a truck and relocated.

was a crucial consideration that had to adhere to the morals of the entire build. To combat any opportunity for the waste to enter the water table, the entire sewage system was elevated on a sand bank, fitted with an ecofriendly, gravity fed scheme that requires no power and minima maintenance, needing only be cleaned every three to five years. The innovative design transforms a seemingly undesirable and complicated site into an idealistic platform for a beautiful home, it becomes an exemplar of how any challenge of site can be reestablished and exploited as an opportunity to develop into an of the most astonishing into one the design. vibrated into the softer estuary With the fragile nature of the ground, a technique that required estuary's ecosystem, the safe no removal of earth, proving faster, management of the sewage more sustainable and more cost system and waste water disposal $+\quad$ Emphasis on designing to the requirements of site

Adapting weaknesses into opportunities

\section{Carefully thought out infrastructure}

Sustainable and affordable design

Light on the land 

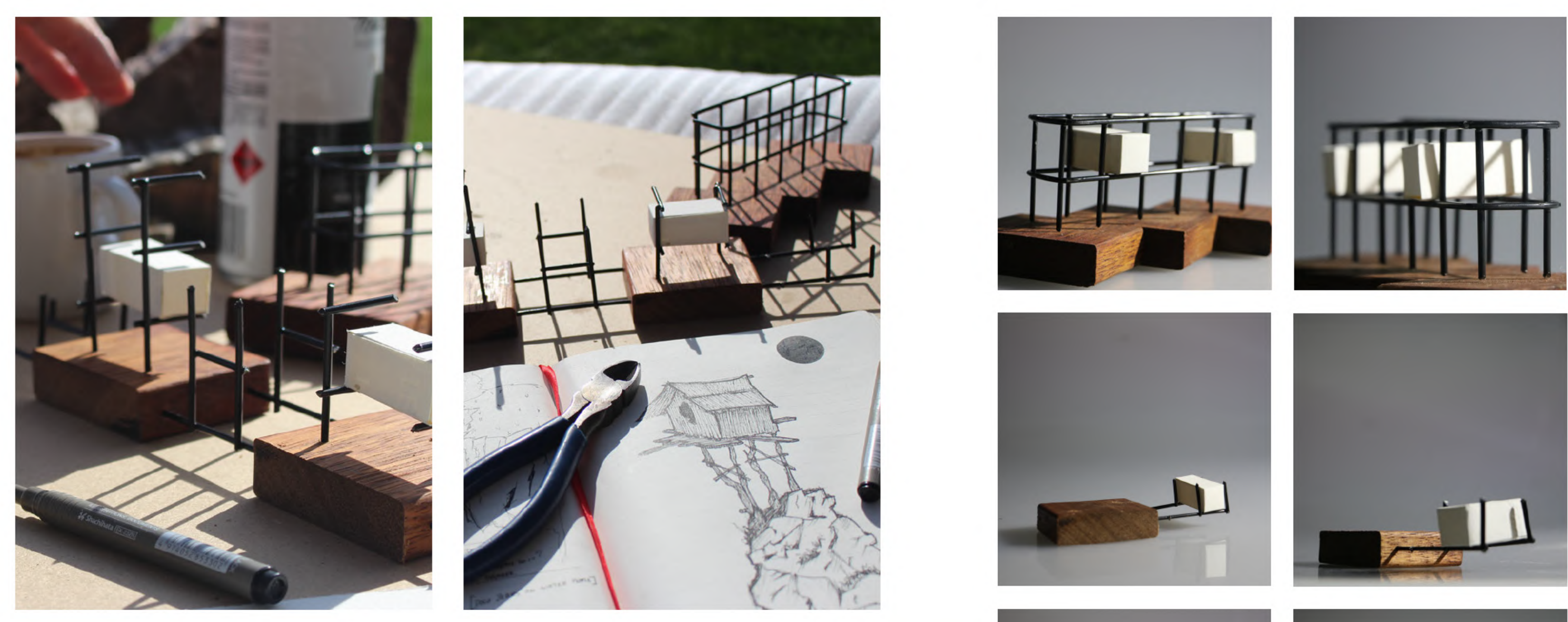

$\{01\}$
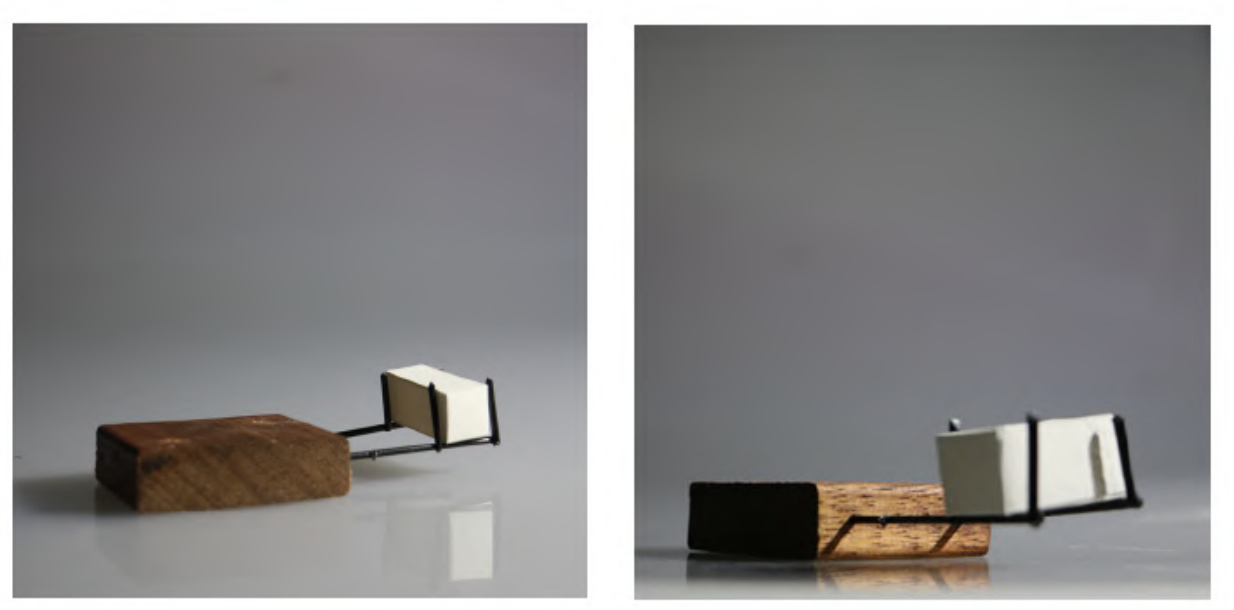

$\{02\}$

\section{Design Experiments.}

01
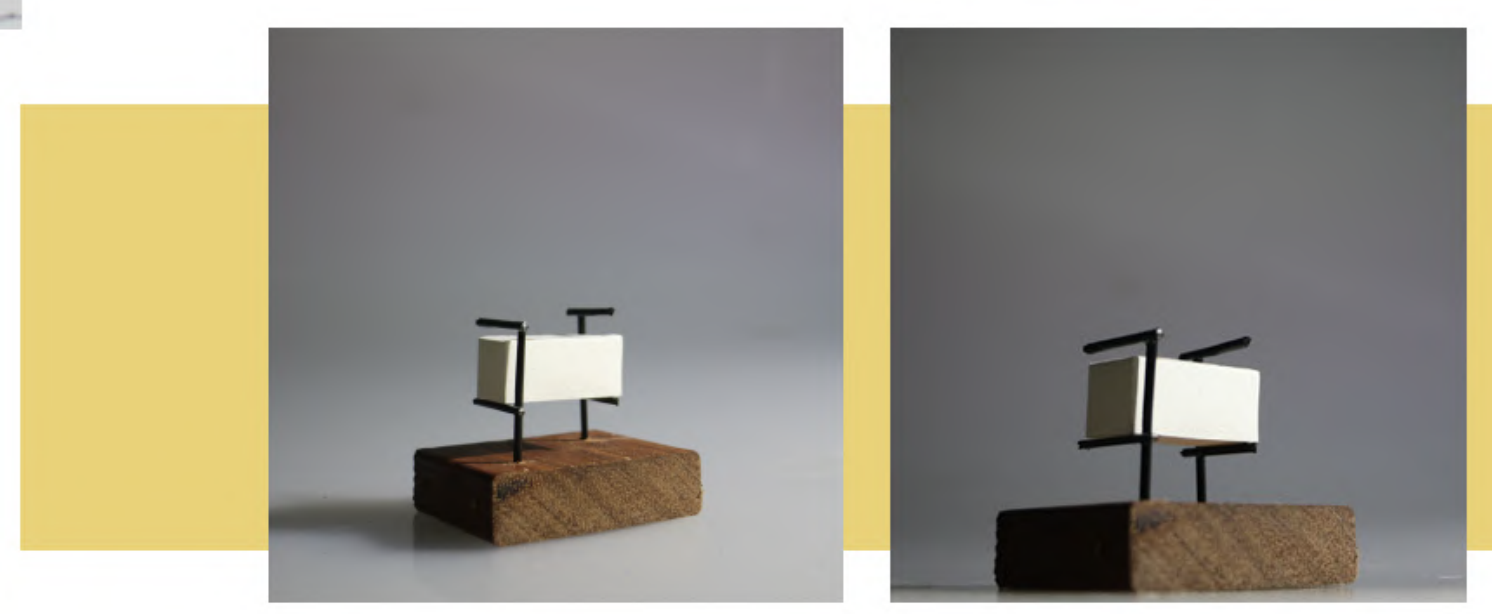

the simple stilt 
$\{04\}$

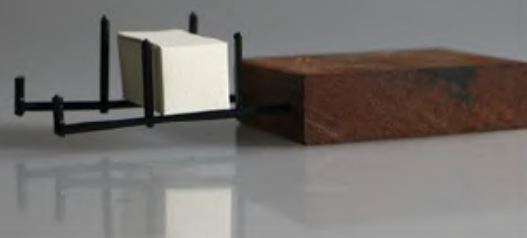

$\{05\}$

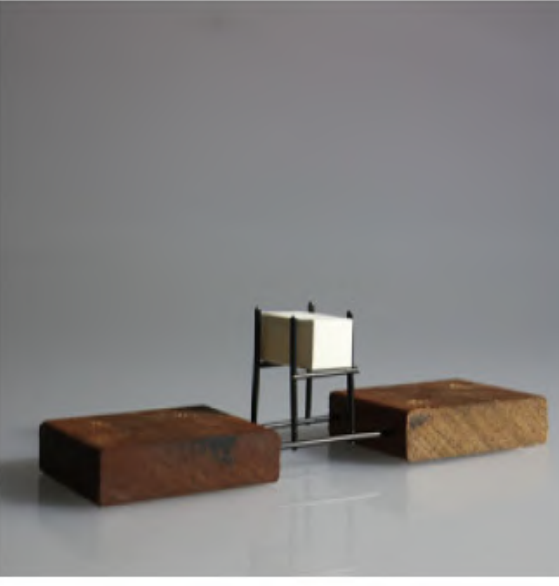

$\{06\}$
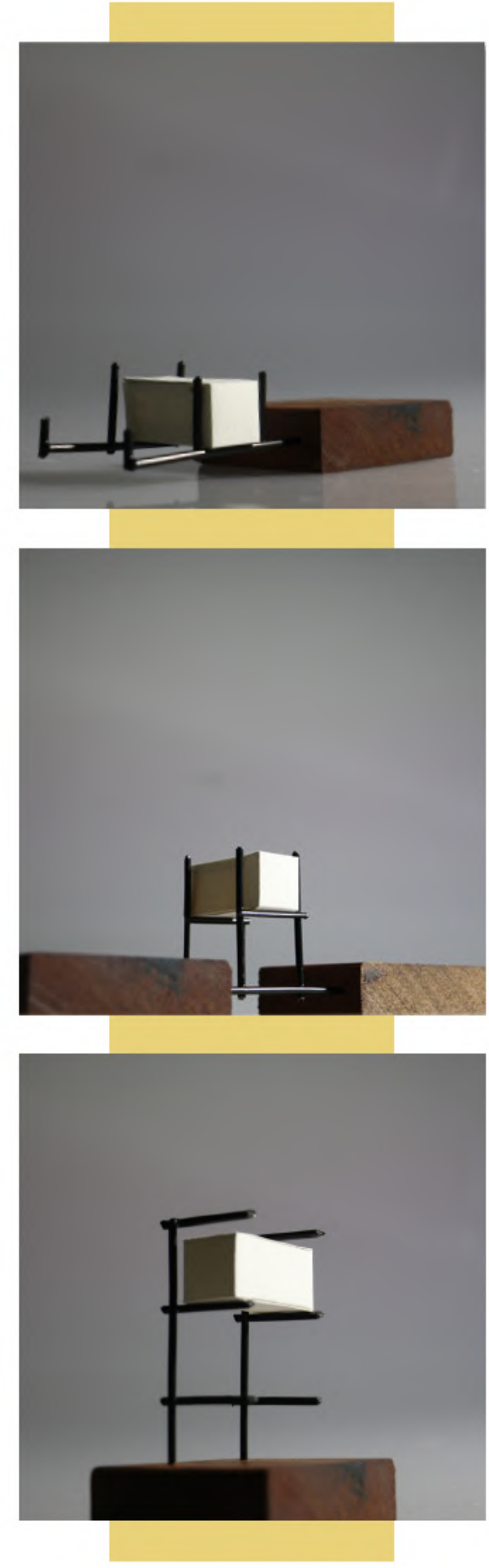

$\{07\}$
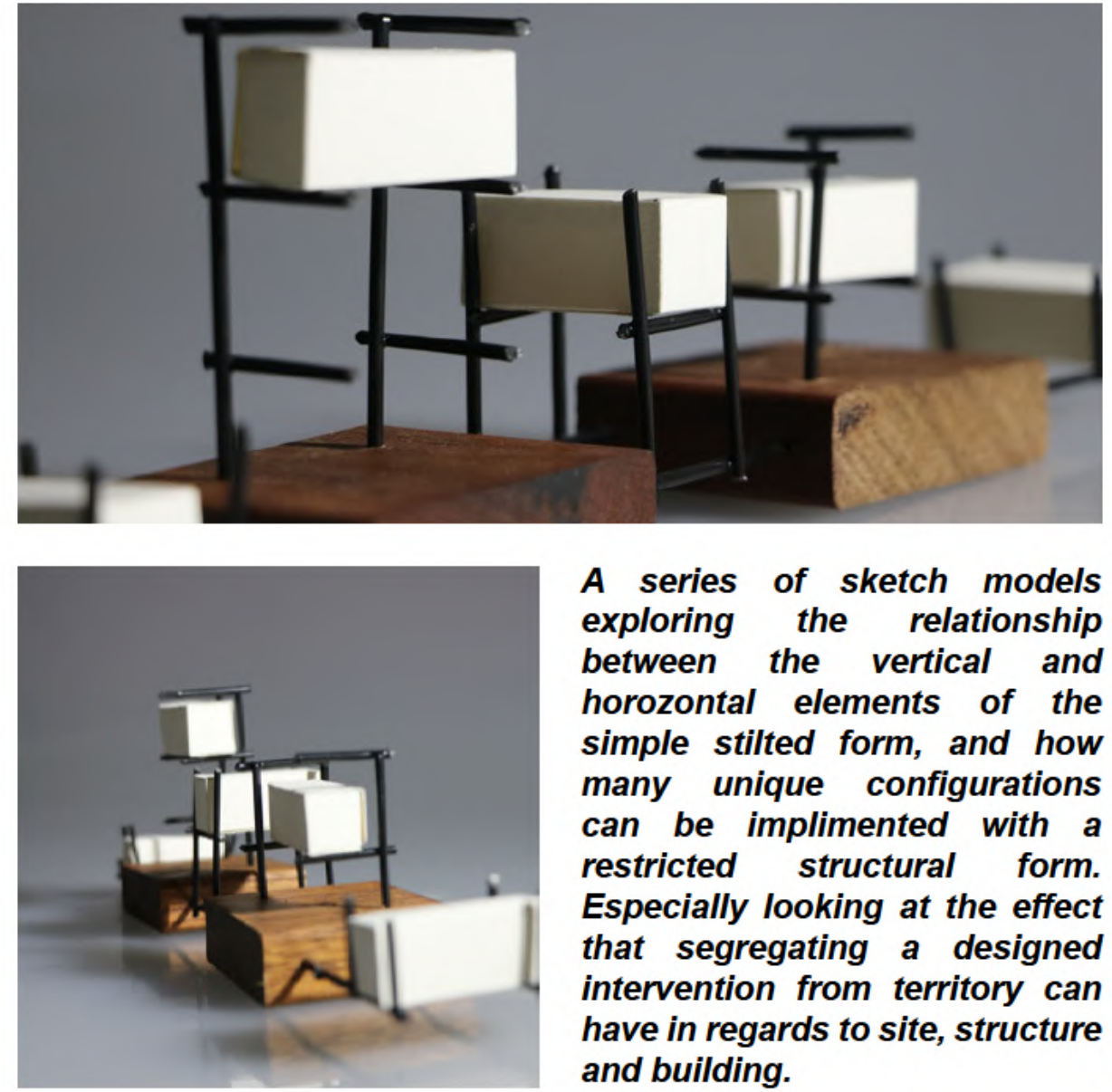

A series of sketch models exploring the relationship between the vertical and horozontal elements of the

simple stilted form, and how many unique configurations can be implimented with a restricted structural form. Especially looking at the effect
that segregating a designed that segregating a designed intervention from territory can have in regards to site, structure and building.

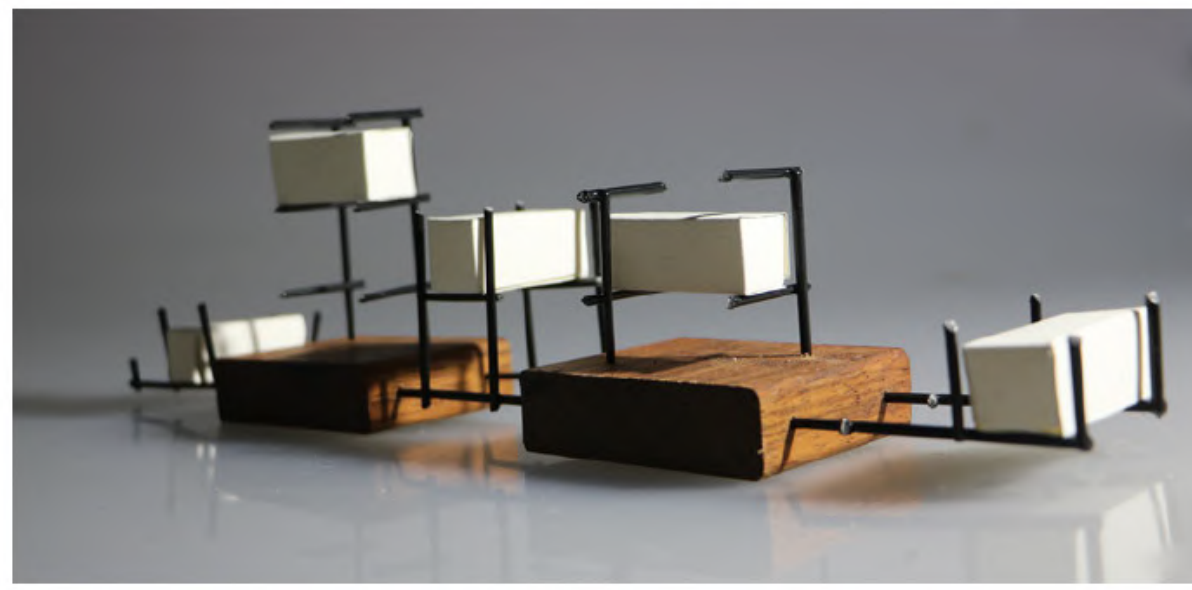



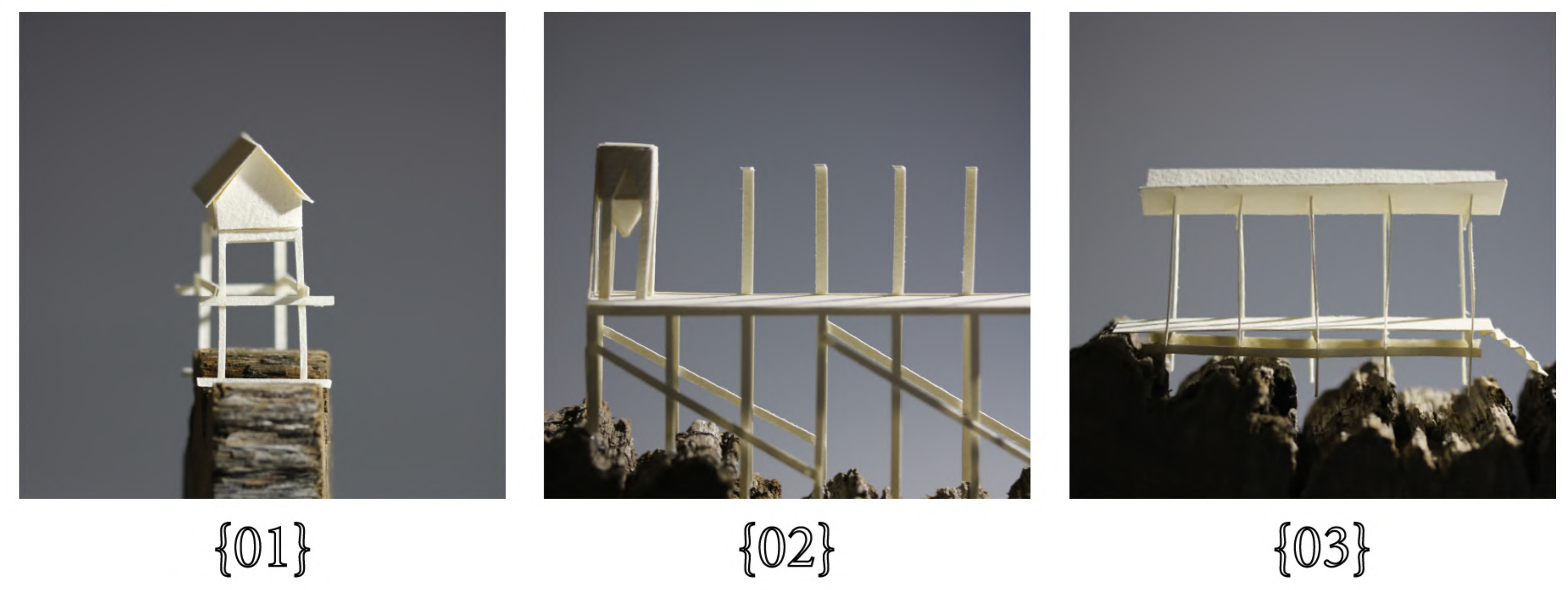

\section{Design Experiments.}

02

the relationship of habitat and territory. 
Vulnerability.
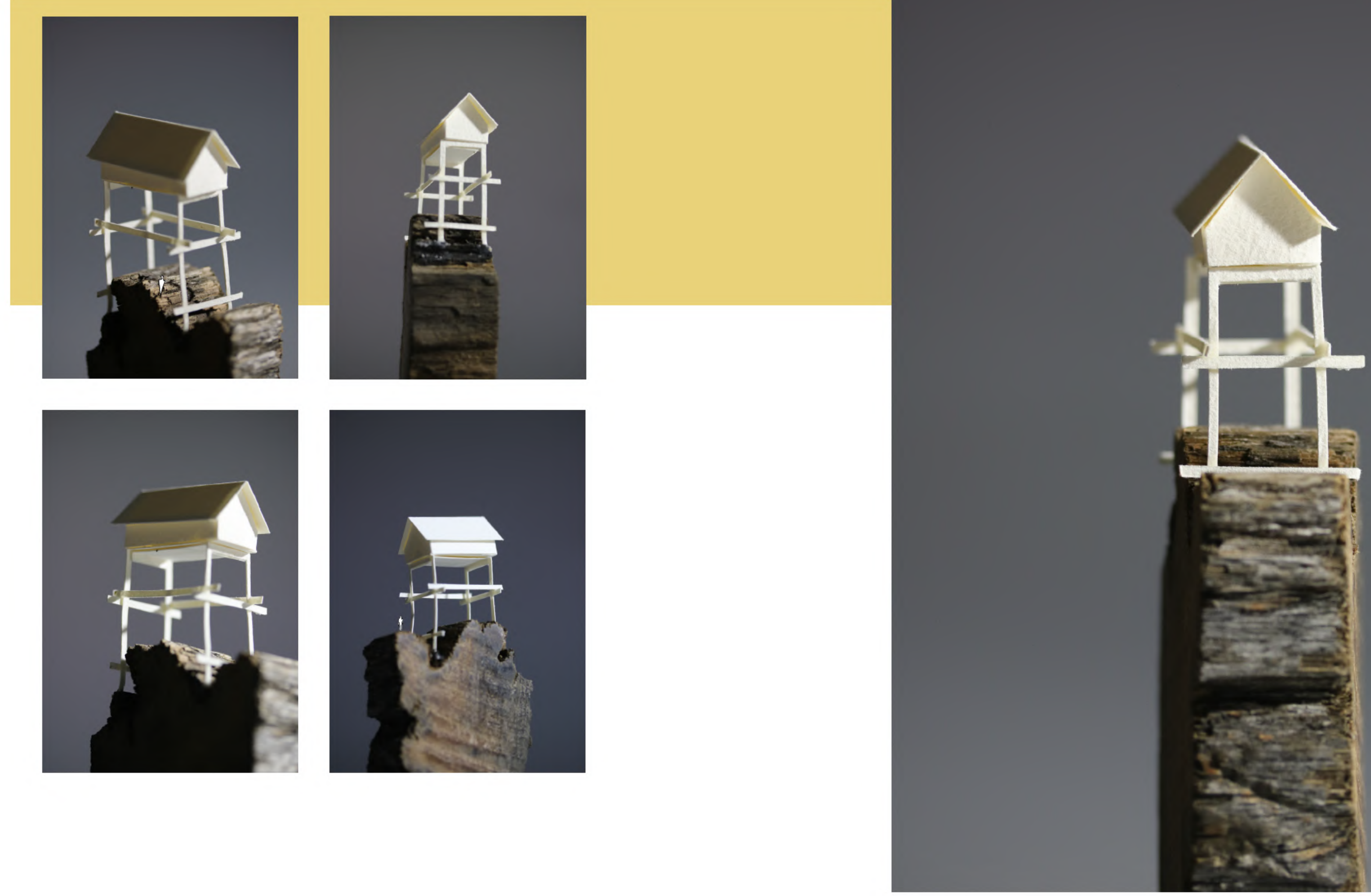

$\{01\}$

$\{01\}$ 

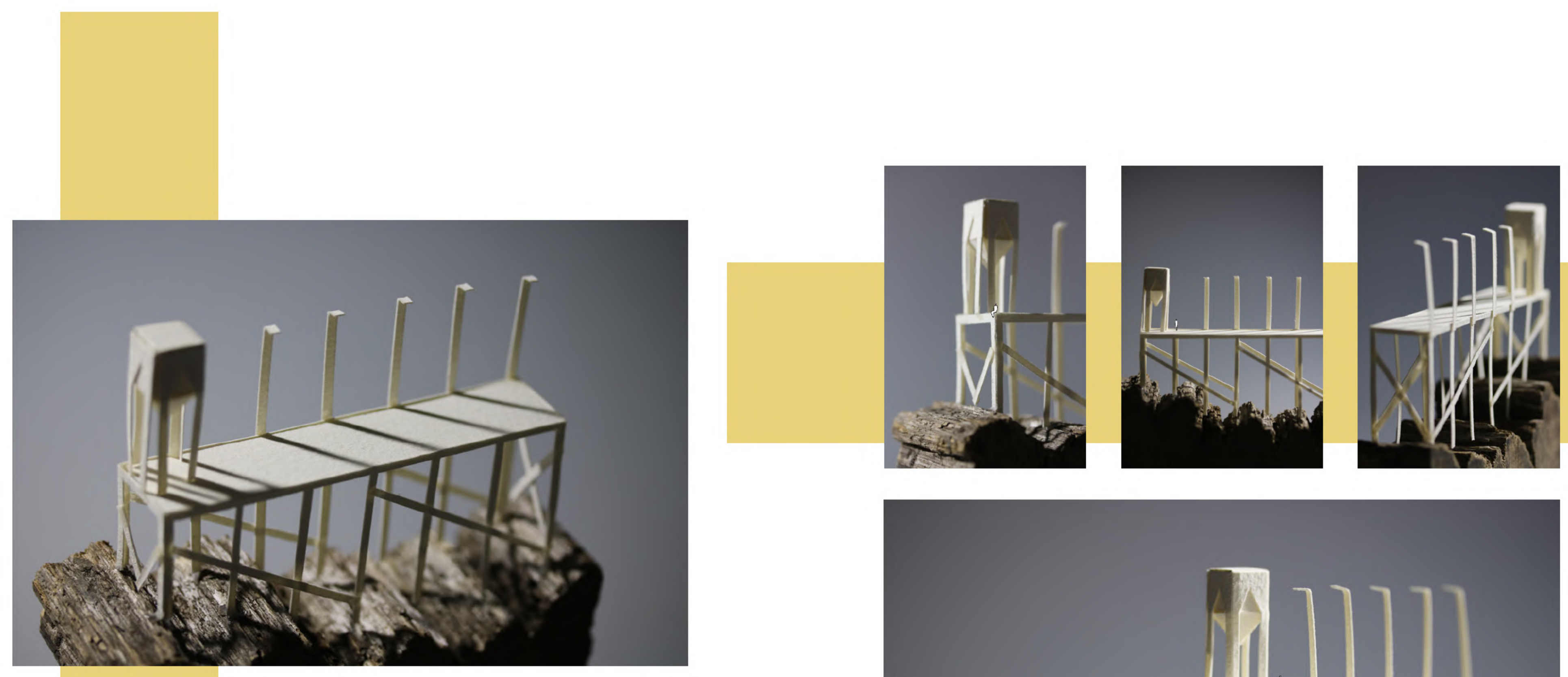

"What could architects do to turn these instant cities into affirmations of the human spirit? Architecture is about planning. How can architects plan for the unplanned, for the unpredictable?

Exactly..."

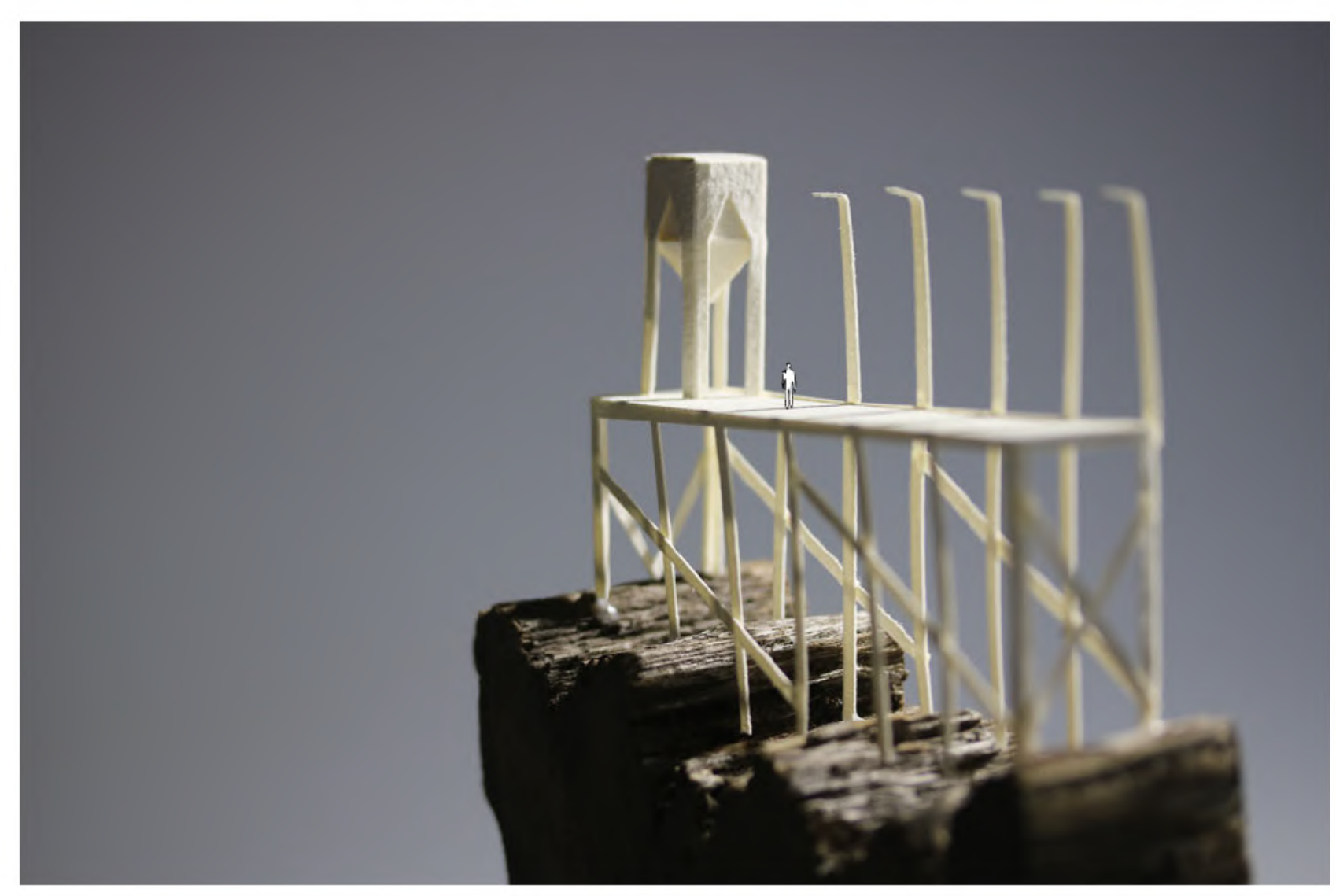

$\{02\}$

$\{02\}$ 

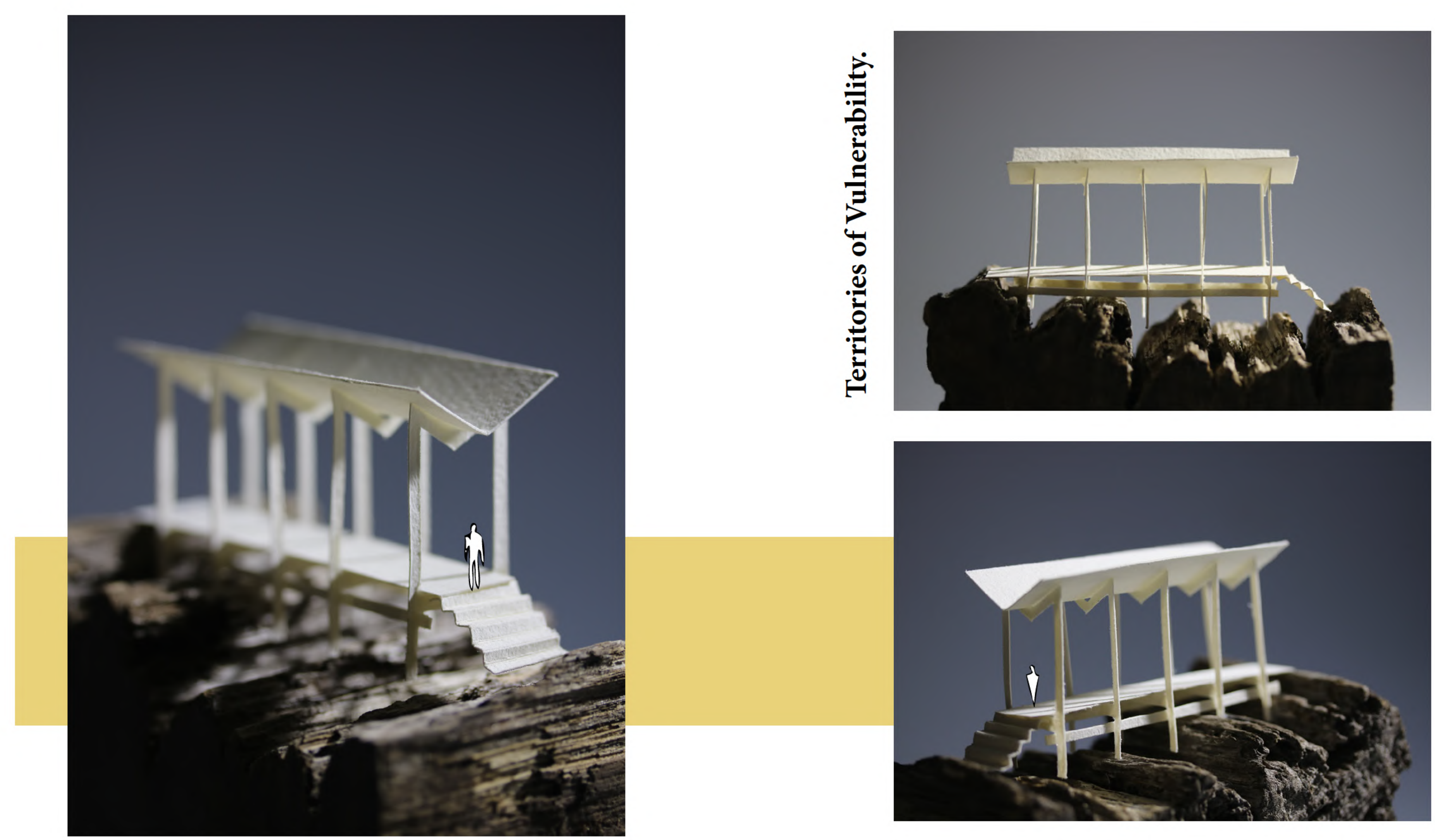

$\{03\}$

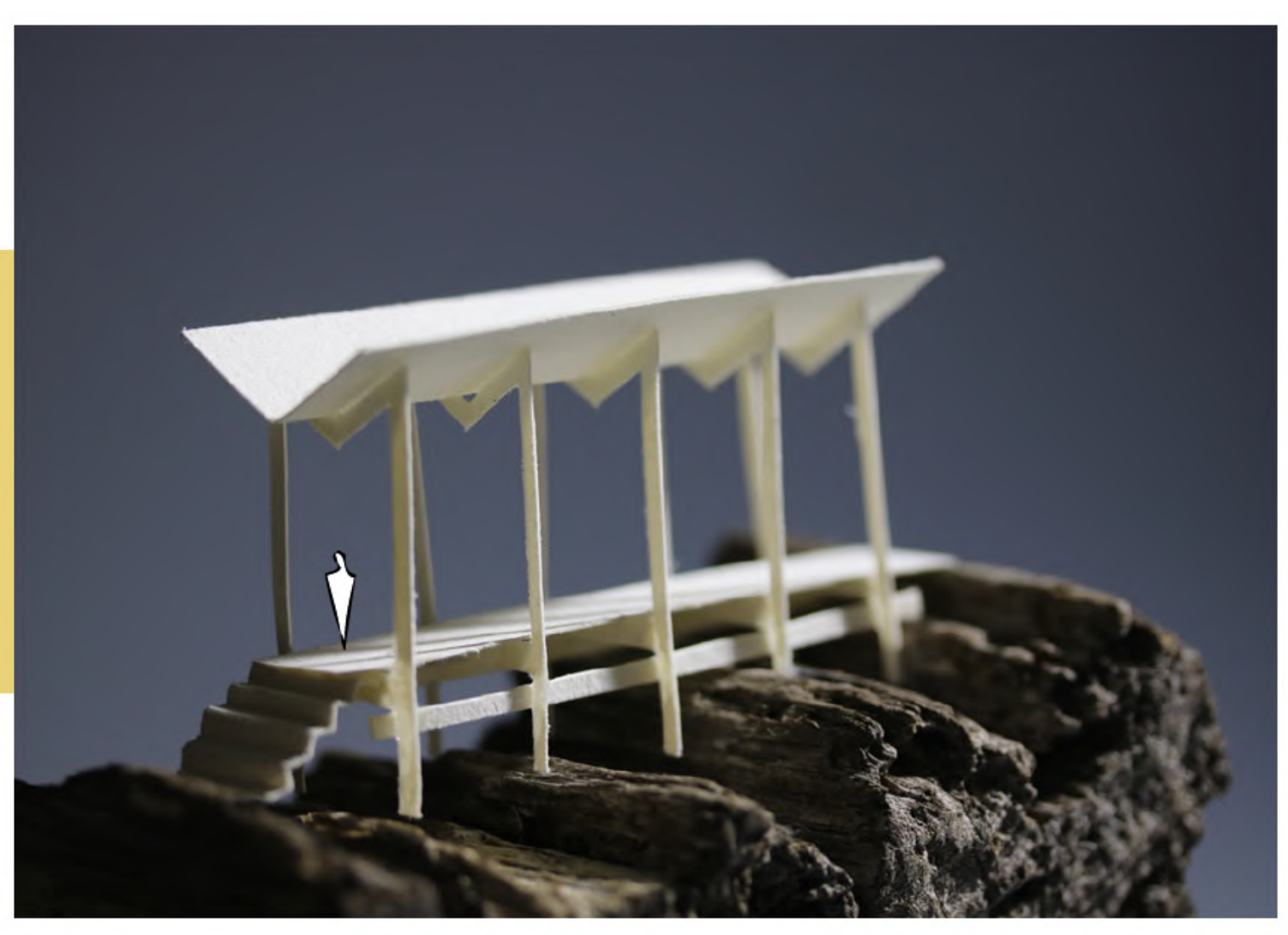

$\{03\}$ 


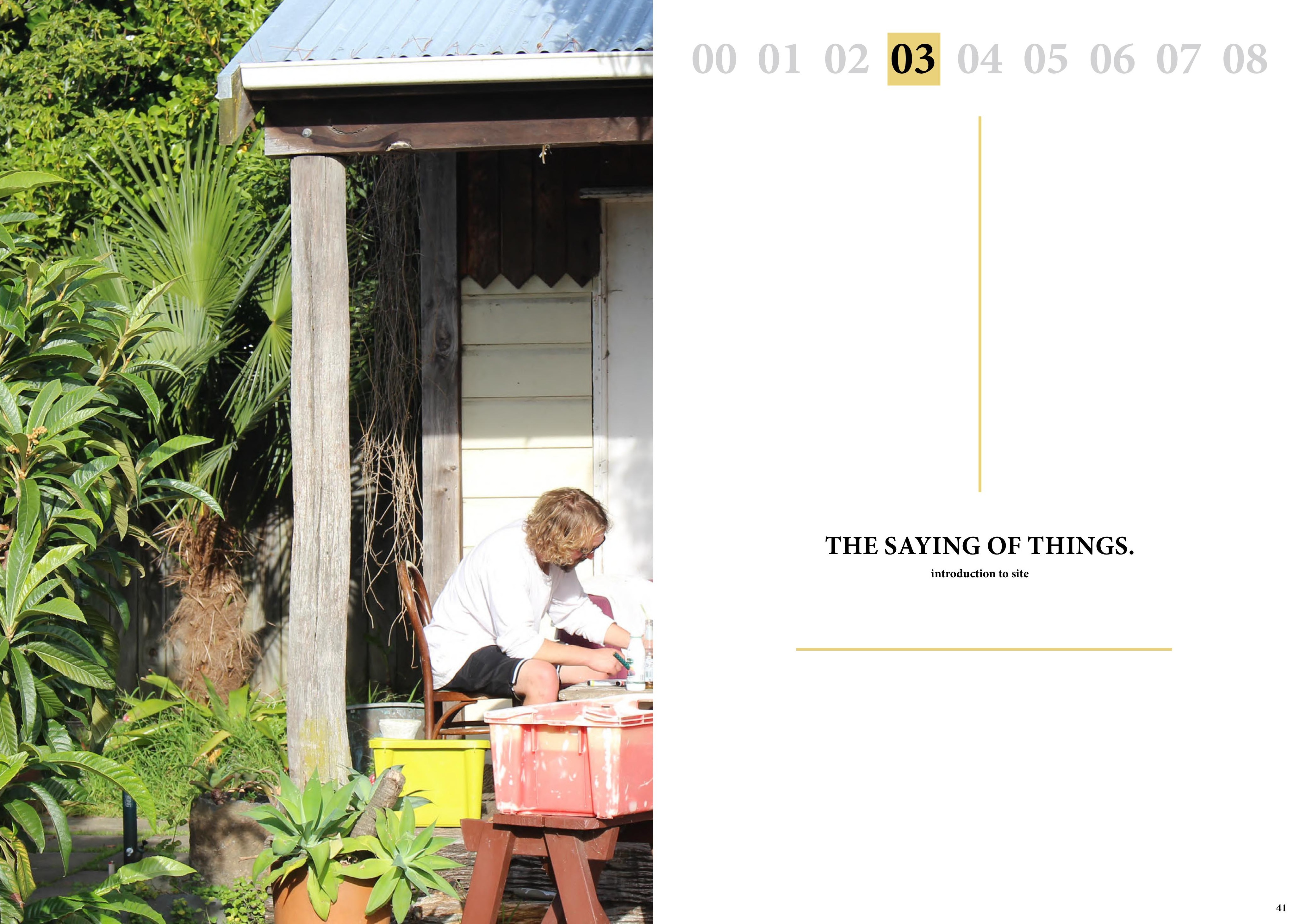


"A work of architecture does not exist in a vacuum, but in the world of things and human beings, and reveals this world as what it is. Thus it helps man to dwell poetically. Man dwells poetically when he is able to 'listen' to the saying of things, and when he is capable of setting what he apprehends into work by the means of the language of architecture."

\section{The Community. \\ haumoan region}

$\mathbf{T}_{\mathrm{r}}$

Haumoana coastline is a quintessential coastal New Zealand community, it is a vibrant and social region, forging a eputation as a mecca for creative arts. Well known throughout Hawkes Bay for its beautiful beaches, winery's and surfing spots, Haumoana is a common weekenders spot for locals and is often buzzing with activity.

With a total of roughly 2,256 permanent residents, the village is home to a school, many varying artists studios, a general store and a Presbyterian church, any needs beyond what these cater for are easily obtained, with Hastings city only $10 \mathrm{~km}$ away.

The region is part of the Heretaunga Plains and as such, predominantly comprises of low lying flat land, but is in close proximity to the arge hills of Cape Kidnappers to the southwest. It is part of three sister communities along the same stretch of Hawkes Bay coastline, the other two being Te Awanga and Clifton, both also incredibly susceptible to the highlighted coastal hazards.

The people of the Haumaona region, being encouraged towards the method of managed retreat, would immens from an adaptive approach to from an adaplive approach to coastal habitation that allows them to continue to remain their cherished community.

As one of the main design principles is to be light on the land the intention is to not interfere with the natural processes of the environment, because of this, the selection of site is not restricted by stability of location. The project welcomes a region that is close to the Haumoana community, but notably exposed to the expressed coastal hazards.

By selecting a potentially more difficult site based on these conditions, the intervention will be forced to be over designed, ensuring that the process can be potentially replicated in similar regions around New Zealand.

Throughout this chapter the Haumoana region will be further studied to find the perfect site for the design process to begin. 


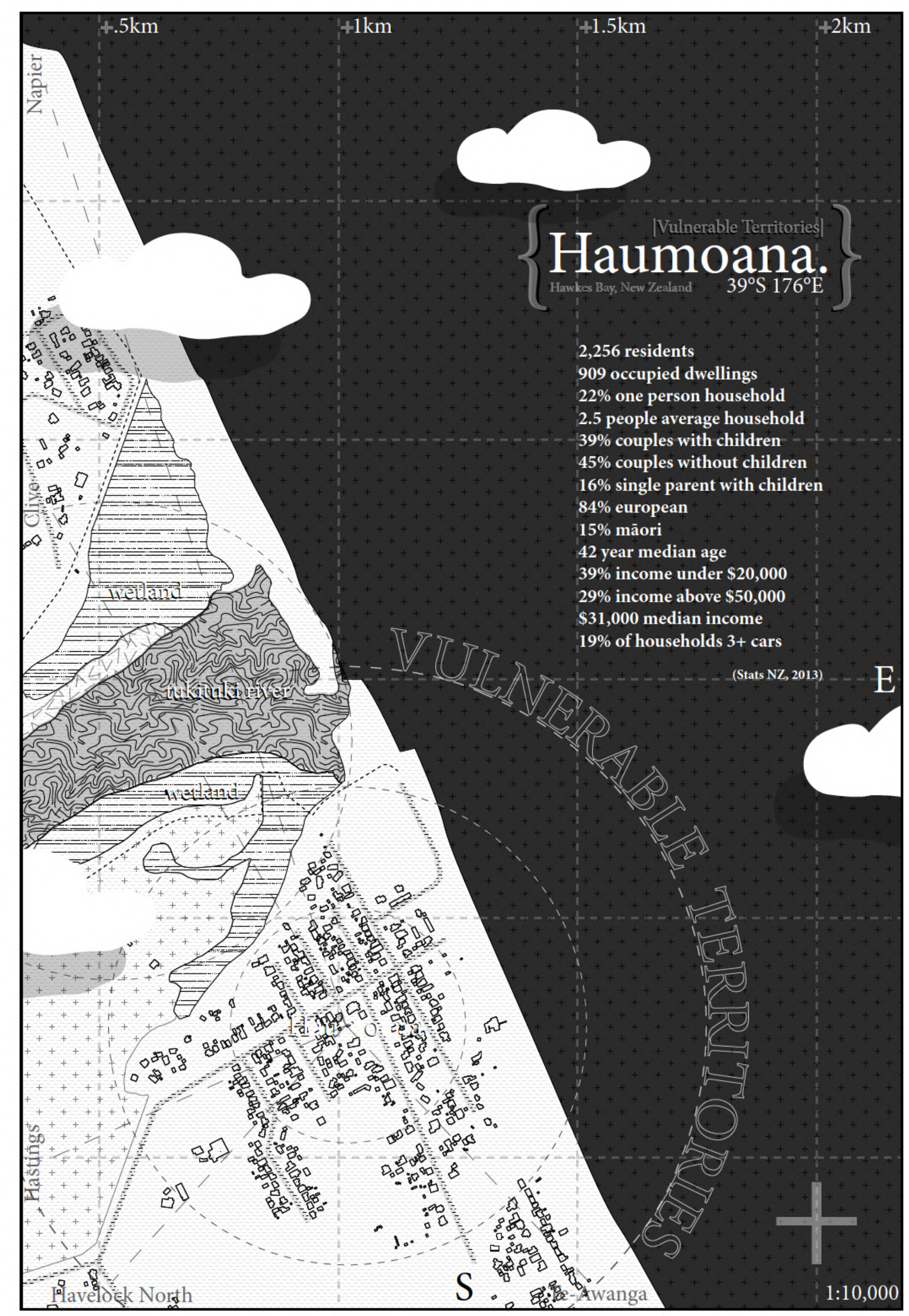

$+$

Architypes.
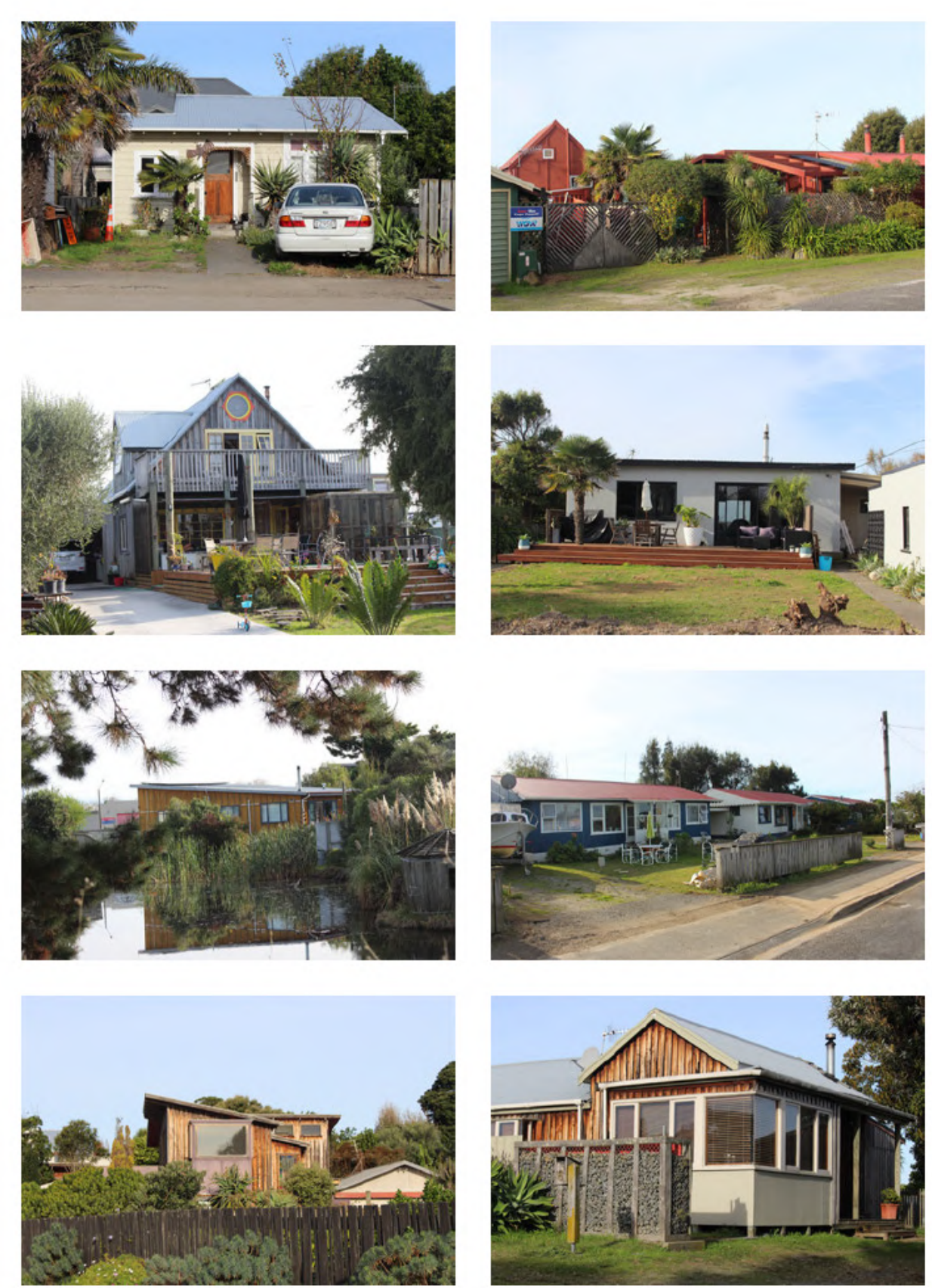

Haumoana exhibits it's relaxed coastal atmosphere throughout its built environment, with the majority of dwellings being modest homes of simple construction, surrounded by lush tropical plantings. The most celebrated houses are those that encapsulate the fundamentals of the humble kiwi bach.

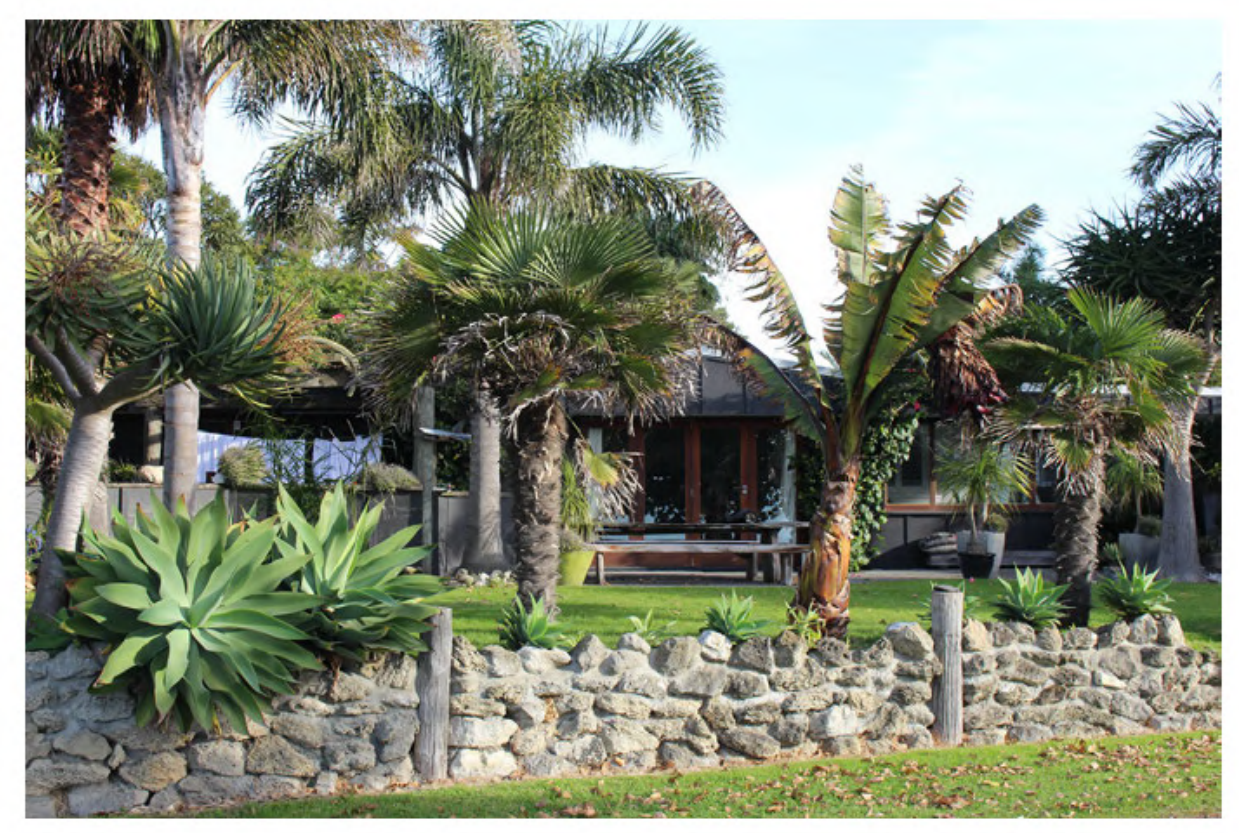


Regional Conditions.

hawkes bay

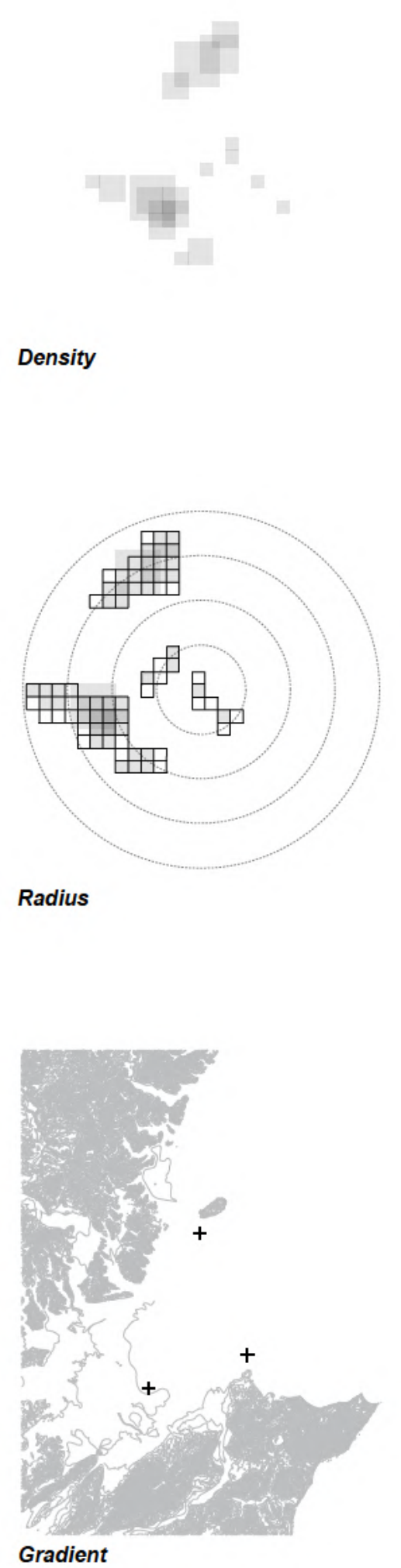

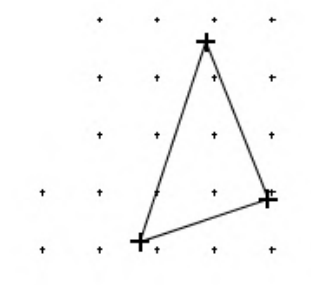

Nodes
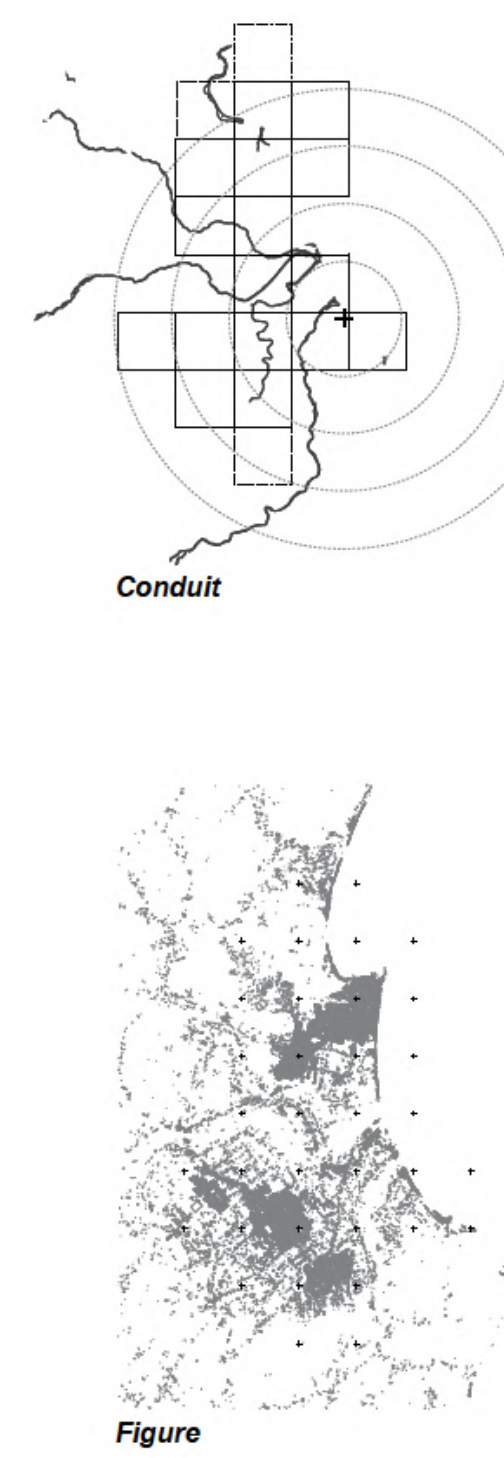

Region Extent.

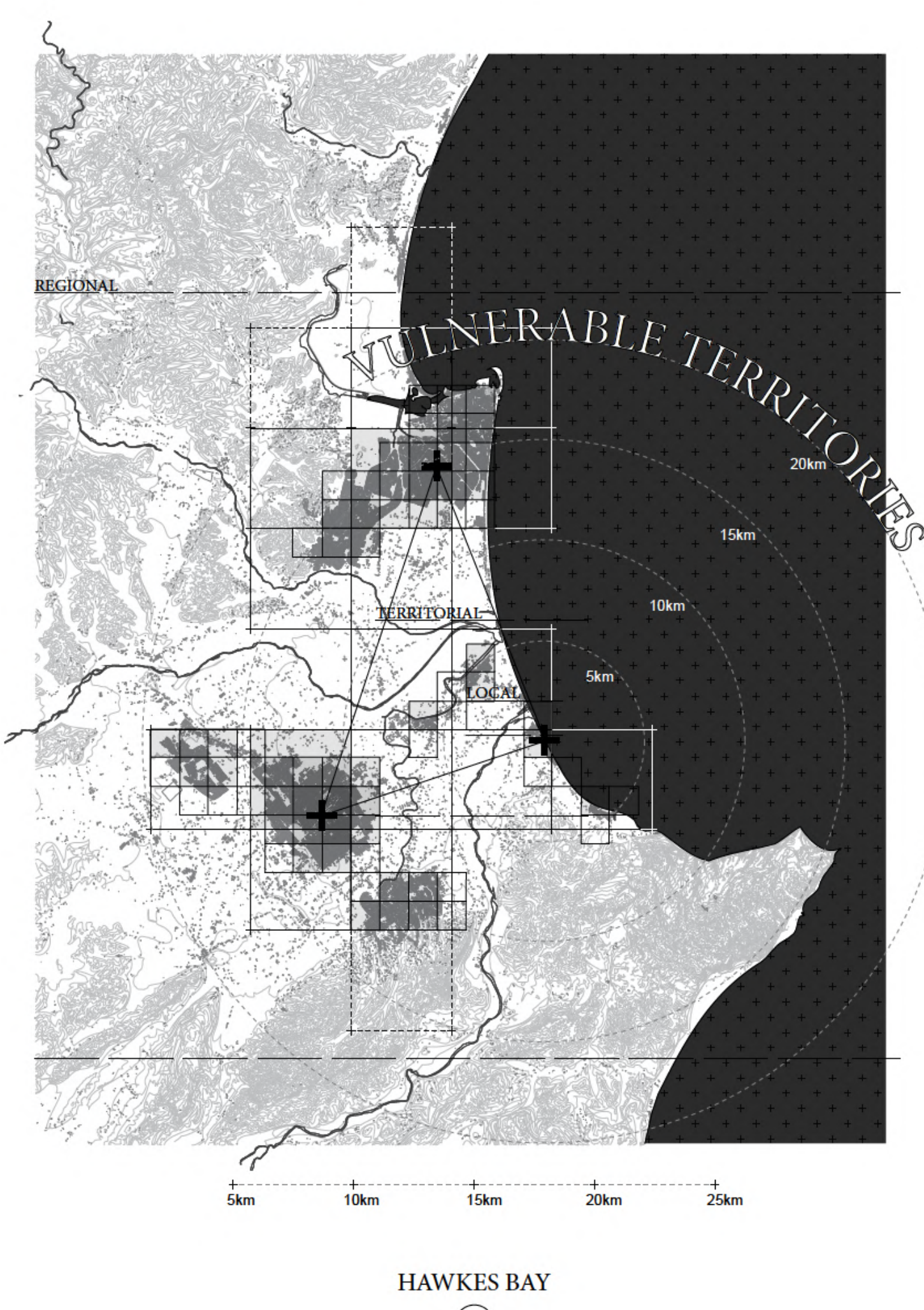

(1:250,000 


\section{Regional Extent.}

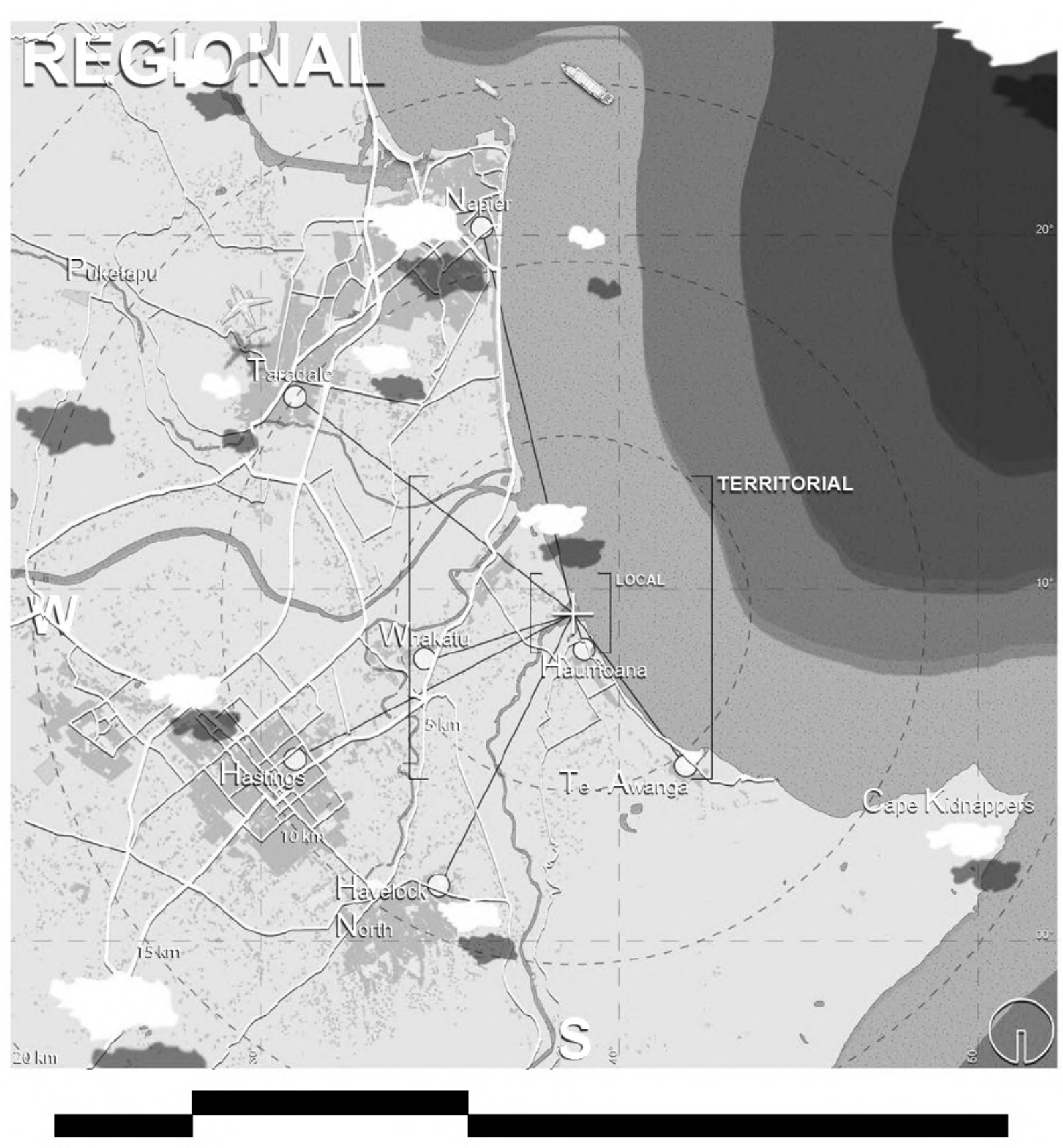

Hawkes Bay.
Territorial Extent.

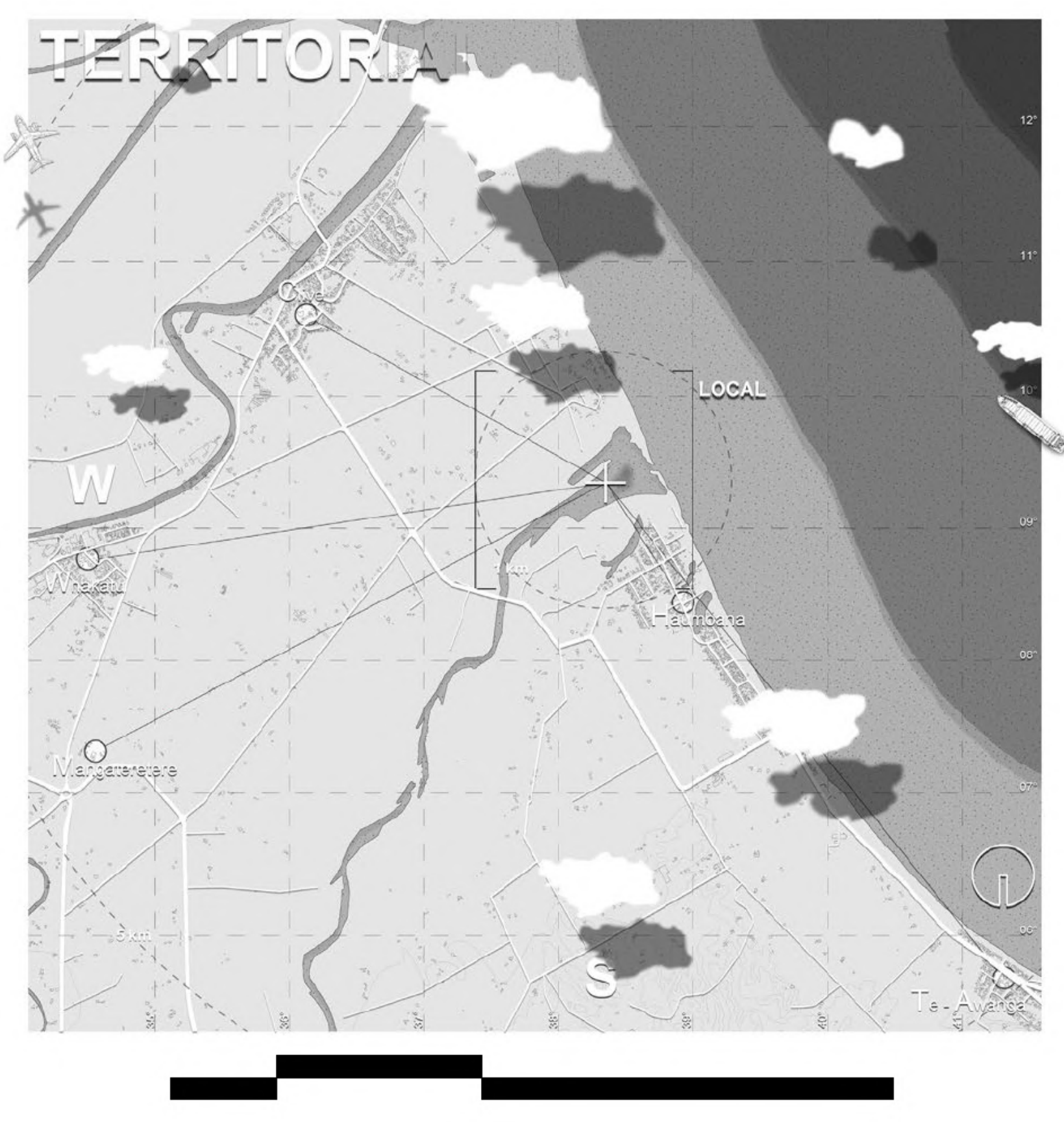

Haumoana. 


\section{Local Extent.}

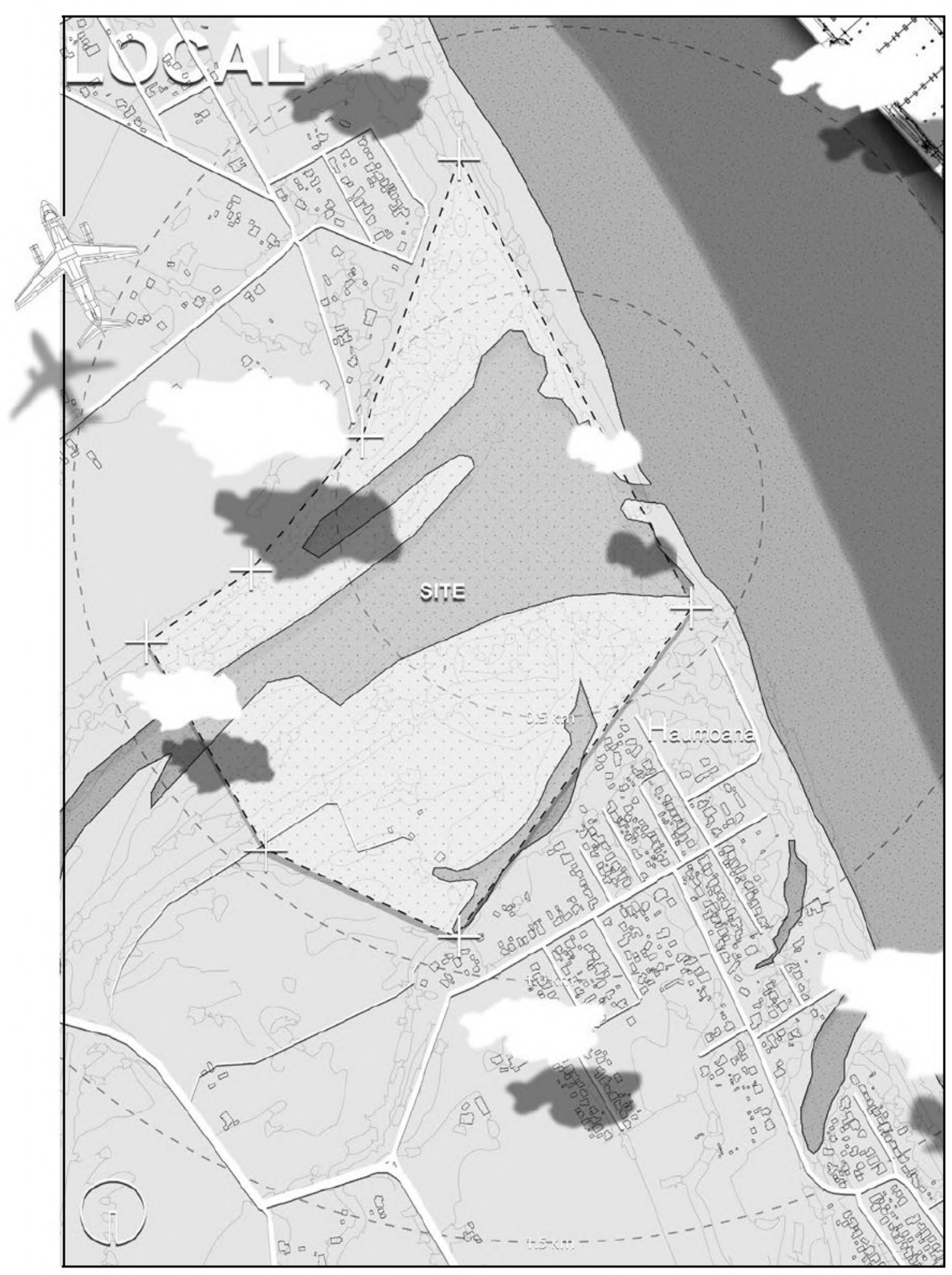

Tukituki River.

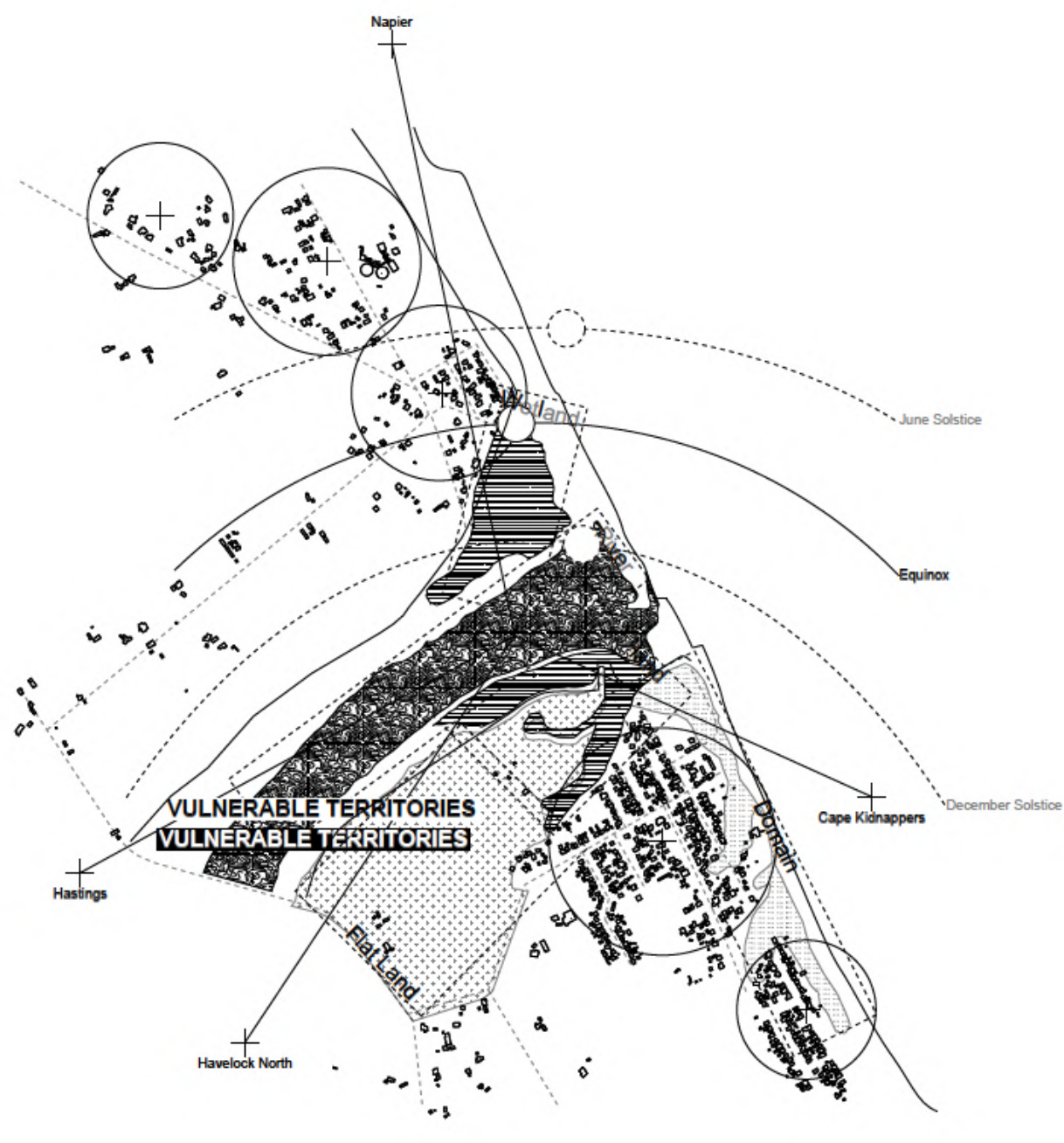

The Legend of the River.

$\mathbf{F}_{\text {or }}$

Fo Marori, the connection According to legend, there was and water is a basic once a large lake that covered the tenet, when Māori meet for the Ruataniwha plains, this lake was first time, each is asked 'Nō wai the lair of two enormous taniwha. koe?' (Where are you from? From

where do your waters flow?). The One day a young boy fell from Tukituki awa (river) has long been a cliff into the lake, the taniwha essential to the different hapu fought a vicious quarrel between (tribal clan)that have residedalong them as to who would get this its banks, serving as a highway appetising food. The wild thrashing that interconnects varying whānau of their tails in this fight is said to with each other along this 'river of of cut through the eastern hills and villages' (HBRC, 2012, p. 14).

the lake gushed out, forming the Waipawa and Tukituki rivers of The river originates from the today. The name Tukituki means Ruahine ranges and flows over "to demolish" and is thought to the Ruataniwha plains before refer to the destruction of the lake wandering northeast to the mouth mentioned in the story (Grantof Waipureku (the meeting of Taylor, 1996).

waters), eventually flowing out into Te Moananui a Kiwa, the great ocean (HBRC, 2012, p. 14). 


\section{Tukituki River Mouth.}

site selection

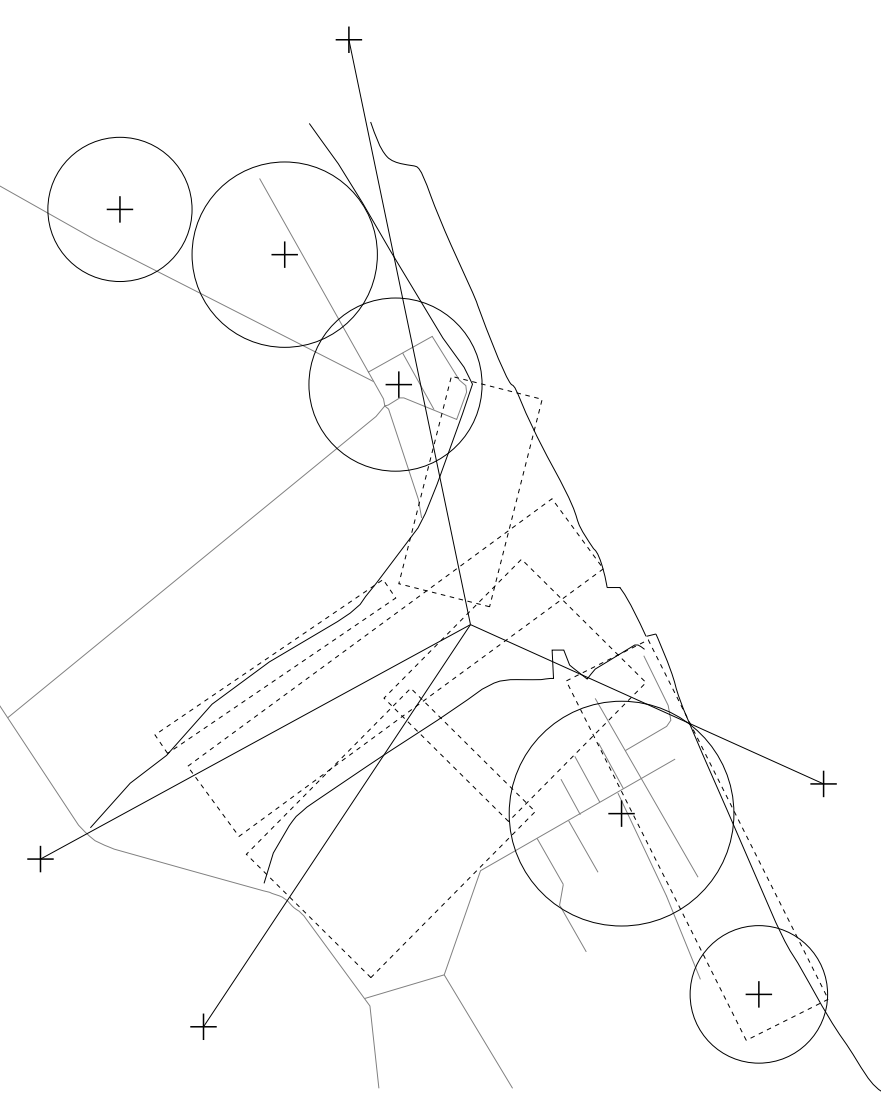

$\mathbf{T}$

1 he Tukituki river mouth is a This barrier and estuary territory of vitality, it is a central system ensures that the river hub where humans and nature mouth remains a mild coastal can occupy space mutualistically environment even though it is without interference. adjacent to a turbulent sea.

The mouth of the river itself is Because of this, the river mouth surrounded by curious natural is one of the most stable regions features. Over time, the forces along the coast. A built intervention of the river and Pacific Ocean would benefit being located at this pushing against one another river mouth as while it epitomises has created a soft gravel barrier coastal living, it remains protected segregating the gentle flowing from the immediate hazards of the water, and the powerful ocean sea.

water, and the powerful ocean

surge. With this barrier in place,

the mouth of the river slows down, It is for these reasons that the river seeping over the land and creating mouth and the surrounding region the estuary plains on the northern has been chosen as the optimum

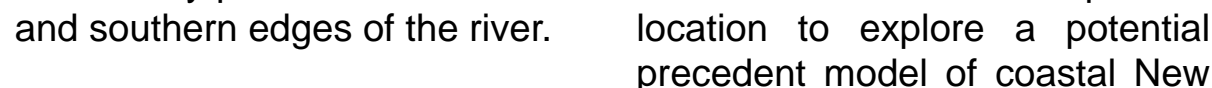
Zealand habitation. 


\section{The Estuary.}

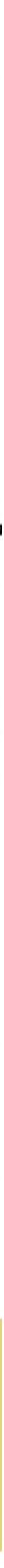

$T_{\text {m }}$

Tukituki estuary is a Under the Hawkes Bay Regional biodiversity hotspot, providing Coastal Plan (HBRC, 2014, p essential habitat to the local 197), the estuary is recognised fish, birds and spawning as a significant area and is whitebait. Further cherished by recommended for protection under the Haumoana community, the the Department of Conservation's estuary provides a pristine natural Protected Natural Areas Program. system for the public to enjoy, with For these reasons this body of walking and cycling trails weaving work will avoid any undertaking an a stopbank to allow the public estuary and its natural processes. 


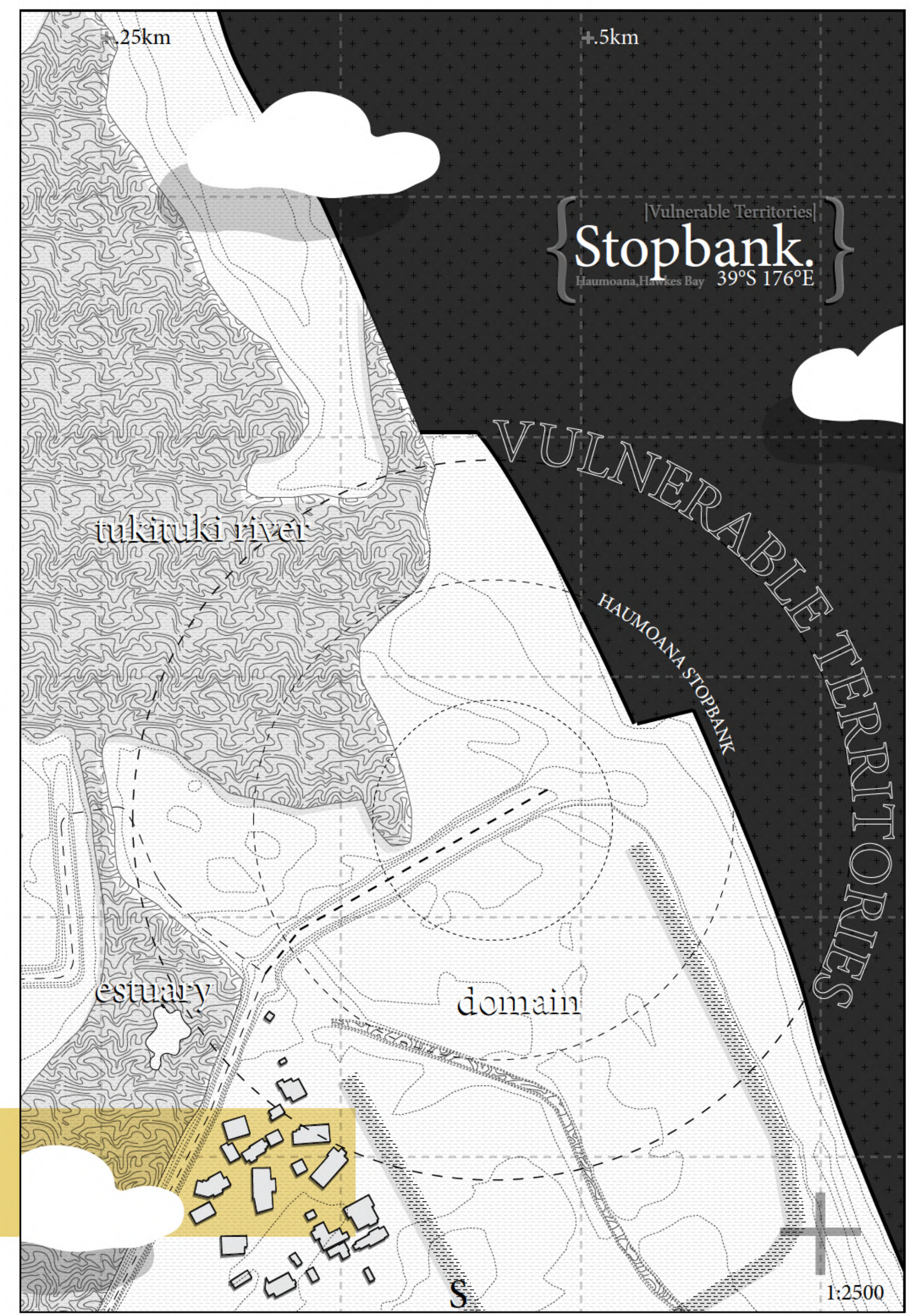

\section{The Stopbank.}

he stopbank of focus lies Due to its proximity to the ocean on the southern boundary of the and river, the stopbank is heavily Tukituki River, and the northern exposed to the highlighted hazards edge of the Haumoana community. associated with sea level rise, but While the bank runs a great length retains the advantage of inherit along the river, this proposal is strength through shear mass and primarily interested in the eastern calculated design when compared most end of the bank, where the to the surrounding environment of wetland, low ground and

of wetland, low ground and

Designed to separate the iver from the nearby houses of the path that serves as a walking Haumoana community, the four and cycling trail utilized by the meter high stopbank is one of the public in a network of connected most sympathetic flooding hazard paths that span the majority of mitigation methods. In its simple the Heretaunga Plains. Through construction of mounded earth, this, the simple path is a too the stopbank allows for vegetation that connects the stopbank and and physically melding the bank the populous of Hawkes Bay, into the surrounding landscape often serving as a destination for compassionately. weekend recreational activities for people from all around the region
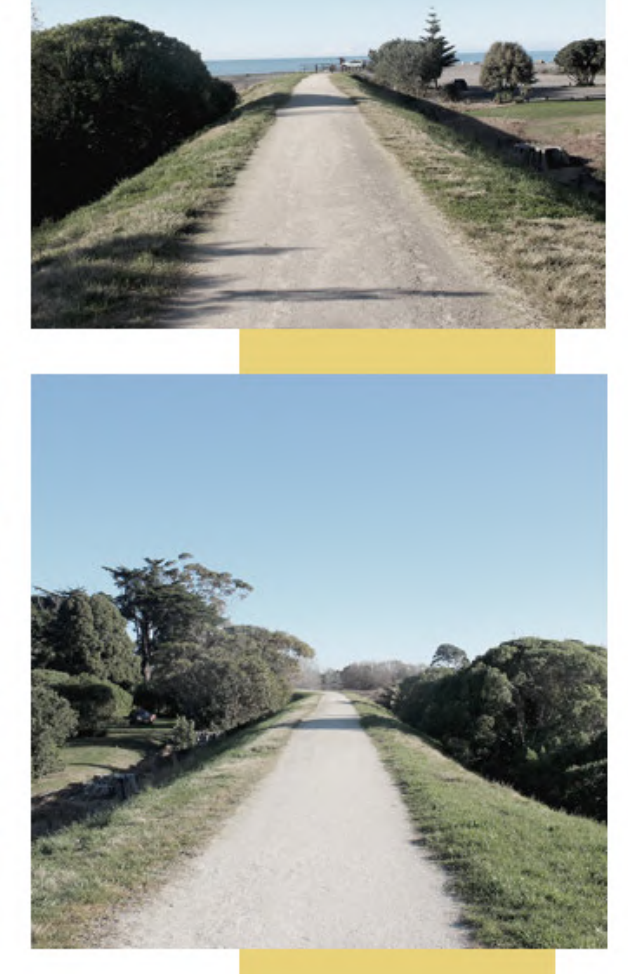


\section{An Artifical Natural.}

\section{\{Man and Nature\}}

\section{O} represents the tangible meeting point between man and nature, it allows for man to occupy land a great deal closer to the desirable landscapes while allowing the natural proceedings of the river to take place. Stopbanks are typically situated a fair distance away from the extent of the river self, as to only interfere with its natural process during a flooding event.

Although it is a man-made artificial barrier, the presence of the stopbank can be perceived as almost natural due to the simplicity of its form and the organic relationship it seems to have with the surrounding environment, its design being sympathetic to the natural environment by replicating the natural features and passive the natural features and passive
Site Selection.

\section{$\{$ Man\}and\{Nature $\}$}

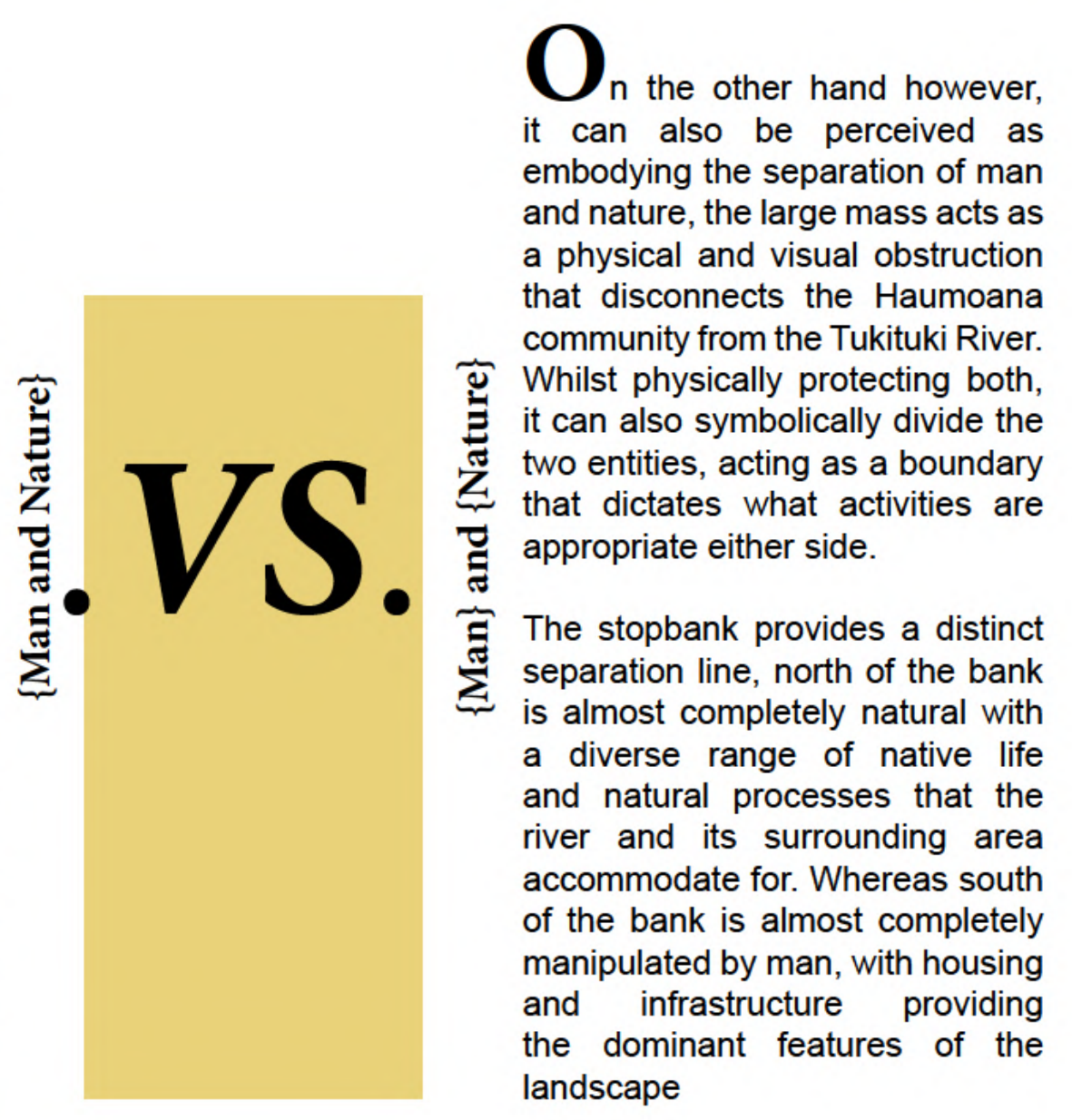

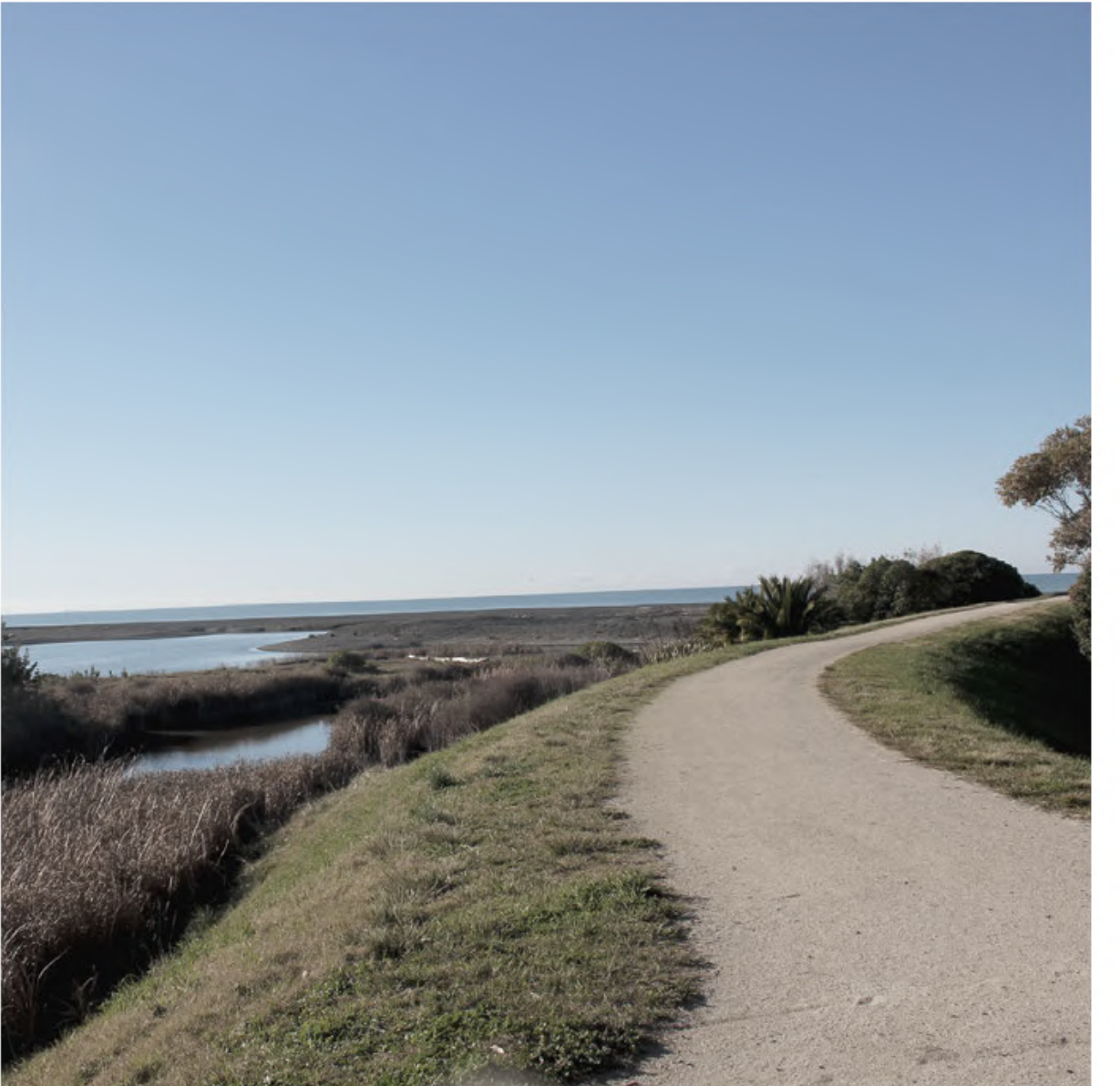

$\mathbf{T}_{\mathrm{n}}$

The Haumoana / Tukituki hazards, where man, nature, and stopbank is a territory where man architecture can potentially coand nature adjoin, acting both as a habit place harmoniously.

tool of separation and unity. While it stands between the community This thesis aims to use the stop and the river, it simultaneously bank as a means to further obscure brings the two closer together. the boundary of man and nature by implementing a designed Considering these conditions, architectural intervention that the stopbank presents itself as portrays a mutualistic relationship the optimal location to explore between the artificial and the continued coastal habitation natural.

in the path of the highlighted
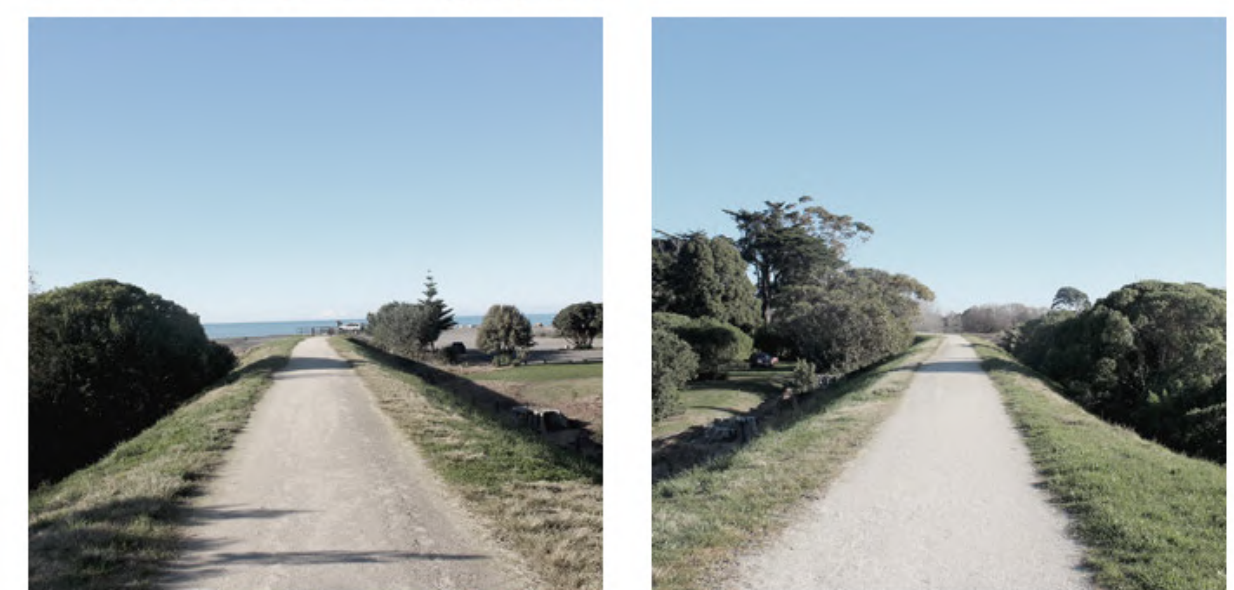


\section{The Spine. \\ Intergrating the Riverbank.}

$T_{\text {ne }}$

stopbank, constructed for the continuation of coastal with strength in mind, provides habitation

the perfect anchor point for the

community design to branch out This project will exploit the inherent of. Running perpendicular to the strength that the stopbank provides ocean, and also protected by the against the threat of rising water

soft gravel barrier beach at the by adopting it as an anchor point

itself as the perfect foundation base themselves.

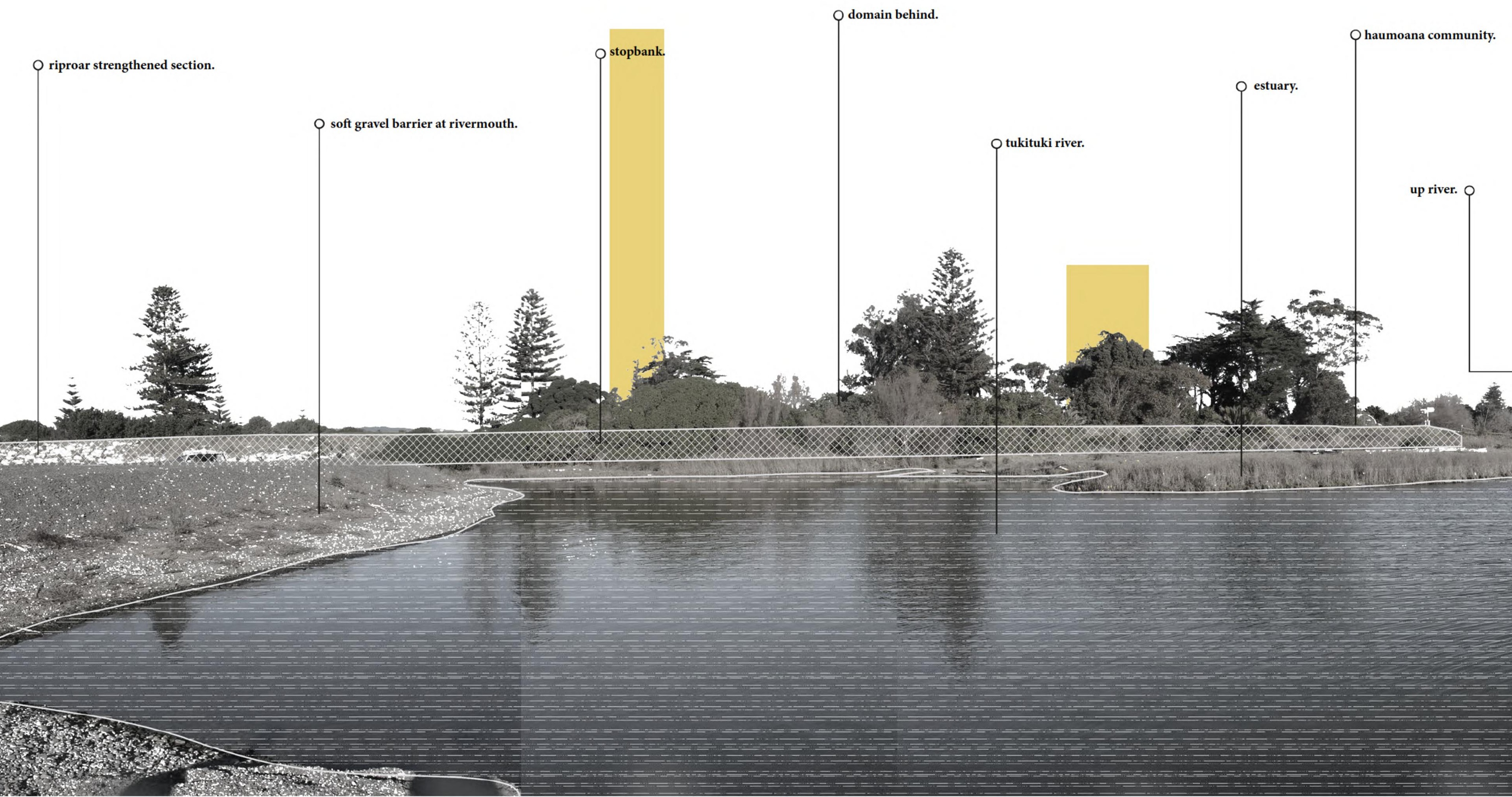



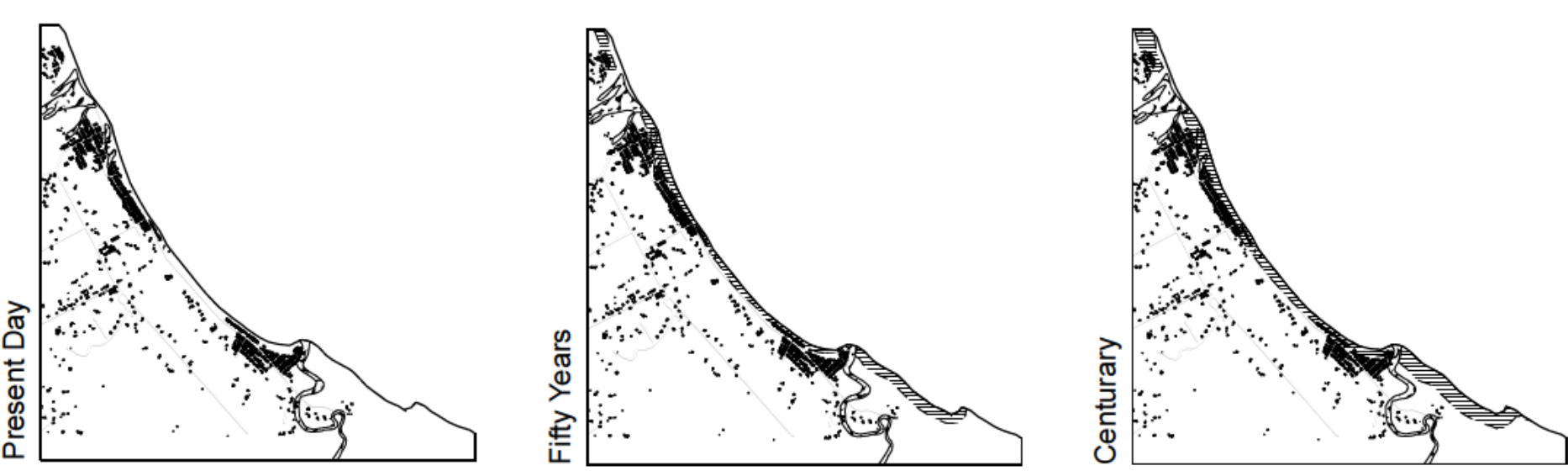

This content is unavalible. Please consult the figure list for further information.

Erosion.

$\mathbf{E}$

Erosion is a gradual, yet The gravel barrier beach is a much persistent threat to the site. It can easier landmass for the ocean be detrimental to the land on which to erode, with the soft gravel it effects, destroying anything in its freely moving under the power path and permanently weakening of the ocean. However with the any human or natural defences. opposing force of the river, there The main two being the stopbank will essentially always be a gravel and gravel barrier beach. barrier at the river mouth, but the mouth itself has already begun to a man made flood move up stream.

defence, is fortunate enough to

be perpendicular to the churning This means there will always be

waves of the Pacific Ocean. For an accessible, and fairly strong

this reason, the erosion will eat landmass alongside the bank away at it lengthways, slowly as to assist in protecting it from opposed to the speed it would the ocean, but once the gravel be if it was parallel. The end barrier moves along the length of of the bank has already been the bank, any original stopbank of the bank has already been the bank, any original stopbank
strengthened temporarily resist exposed to the waves will quickly the threat of erosion, a technique deteriorate.

that can be implemented along

the entire stretch of bank.

Erosion. 

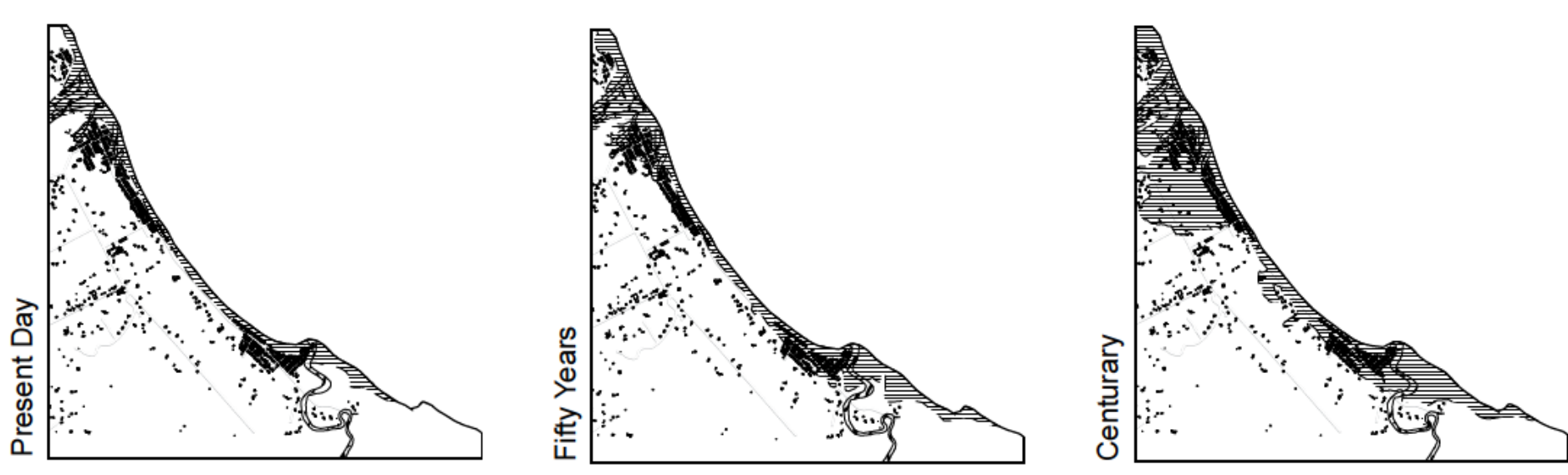

\section{Innundation.}
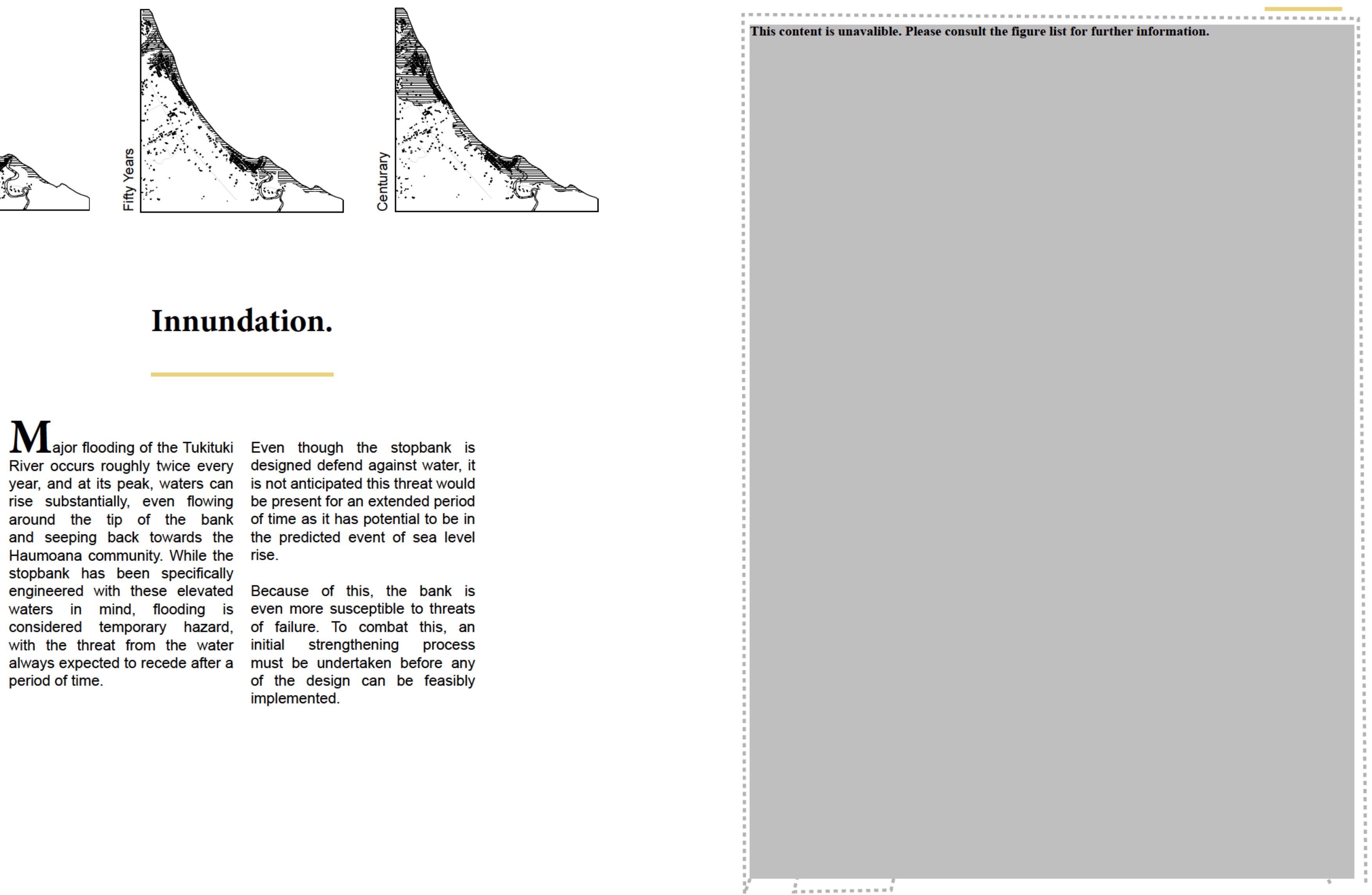

Innundation. 


\section{Current Threats.}

the unprotected stopbank
Underflow.

When water permeates the sand deposits underneath the stopbank, and rises to the surface on the other side. With the expected future of the Tukituki stopbank being completely surrounded by water, the largest issue with underflow is the potential damage to the integrity of the internal bank structure.

Overtopping. When water levels rise higher than the designed intention, spilling the designed intention, spilling
over the top of the bank. Even with the projected sea level rise of $1 \mathrm{~m}$, the projected sea level rise of $1 \mathrm{~m}$, the Tukituki stop banks existing
height of $4 \mathrm{~m}$ is substantial enough to deter overtopping.
Slumping. When the weight of the contained water pushes over the top of a stopbank by scouring out a weak point. If the projected level of water reaches within $1 \mathrm{~m}$ of the top if the bank, slumping could prove an enormous issue, especially when water is expected to reside both sides of the bank.

Toe Scour.

Wave action erodes away the toe section of the stopbank, causing slipping infill from the top and resulting in the integrity of the bank resulting in the integrity of the bank to be weakened. This is the issue
of most concern for the Tukituki of most concern for the Tukituk
stopbank as with the ocean rising comes a substantial threat from waves.

Underflow.

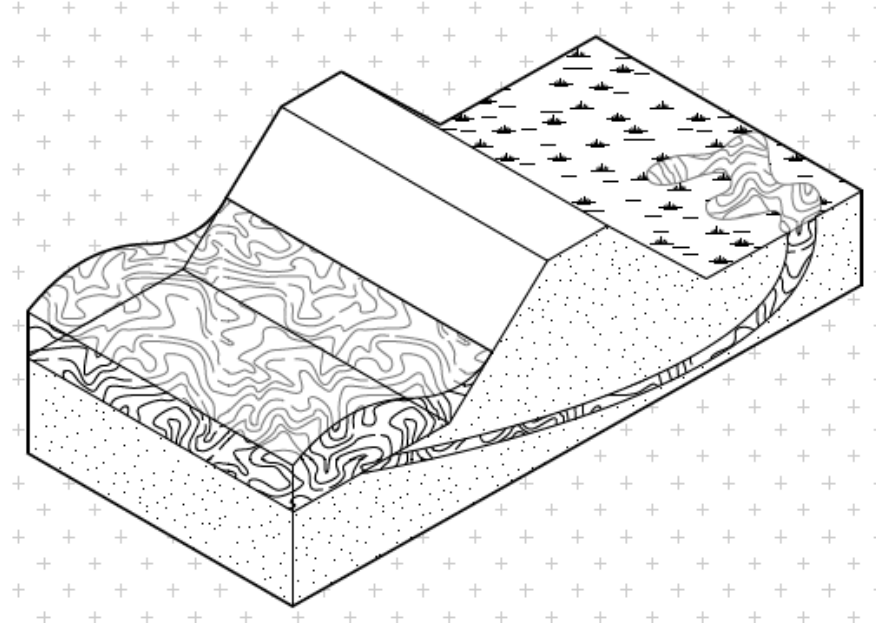

Toe Scour.

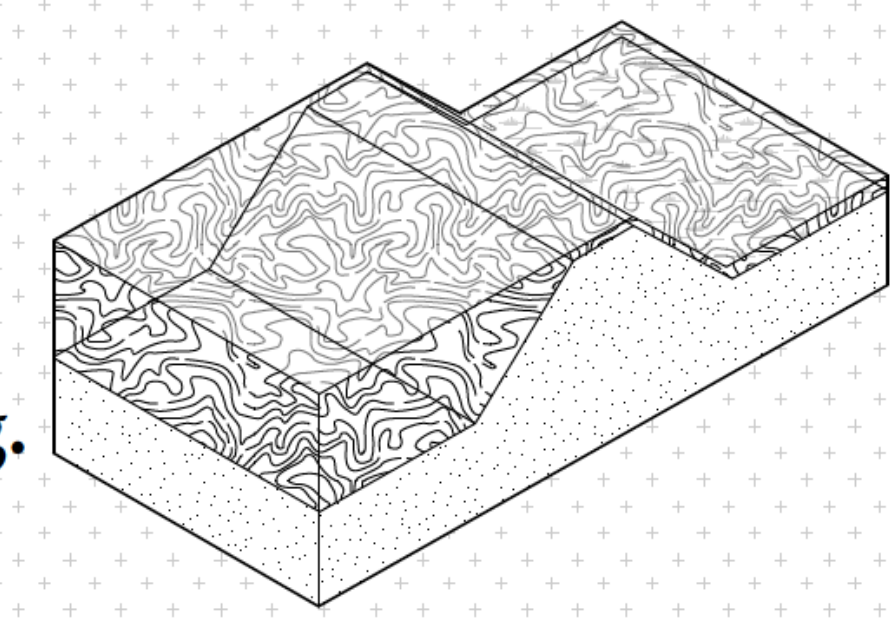

Slumping.
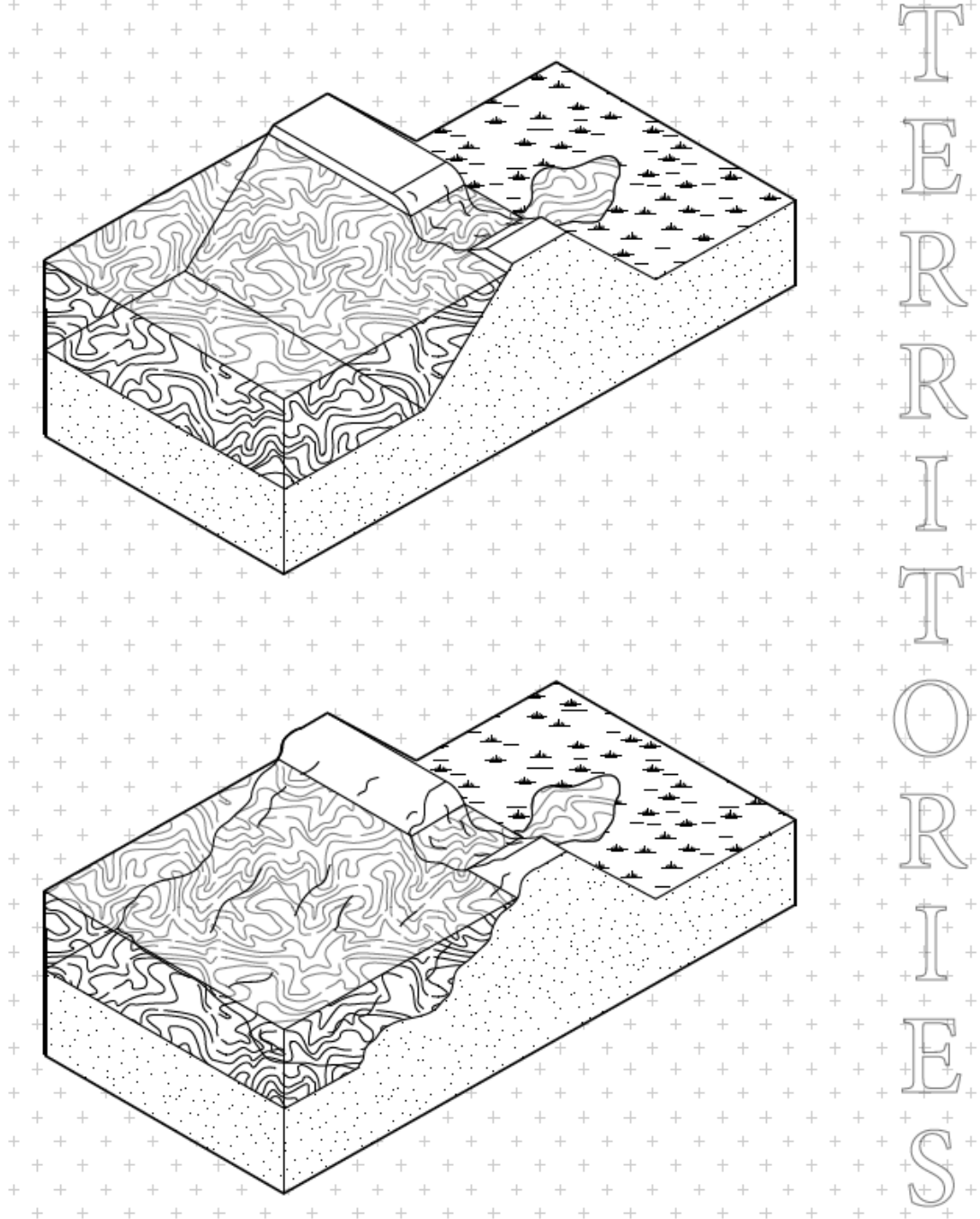


\section{Preliminary Design.}

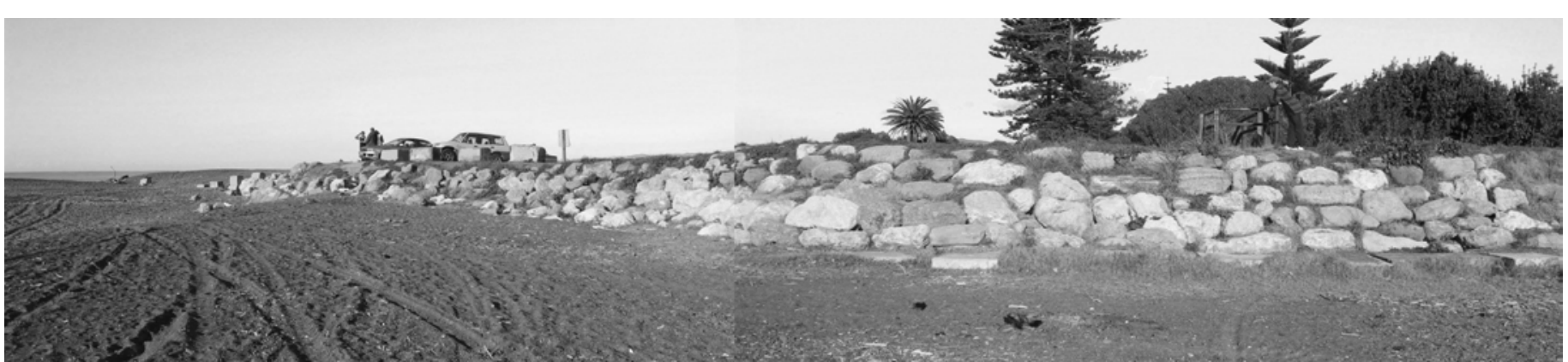

Tip of the Haumoana / Tukituki stopbank. Image by Author
$\mathbf{T}_{\mathrm{t}}$

he primary concern for the Tukituki stopbank in relation to the degradation of the base of the bank leading to failures along stopbank must be strengthened before design can be considered. The most common methods of strengthening that could be applied to the Tukituki stopbank include:

Concrete barriers or Concrete gether on a bedding layer (fig causing erosion (Ministry of 3.40). The interlocked mass Environment, Lands and Parks, provides sufficient resit to uplift, 2000, p. 3). They are particularly but this lack of permeability can effective in wave environments as ead to pore pressure build up the stones act as a natural energy in the bank leading to slope dissipater and the filter layer allows instability, additionally the surfaces pore pressure to dissipate without the . c causing erosion. Furthermore, the phat continues to protect the toe

Gabion baskets that are designed as flexible gravity barriers to resist
scour (fig 3.03). However the scour (fig 3.03). However the
baskets are ineffective in coastal environments due to the corrosion of the tie wires or the abrasion from gravel riverbeds, resulting in the baskets contents unravelling boulder system along the toe of to protect the toe against scour measure. As such, the Riprep will structural failure is Toe Scour, (Britton, 2014, p. 47)
However the most appropriate even if a scour hole develops, intervention for the Tukituki said hole, preventing any furthe stopbank is to implement a Riprap damage (Britton, 2014, p. 51). the bank on either side (fig 3.02). This method has already been Riprap comprises of natural rock applied to the tip of the bank that laid over a granular filter layer and is closest to the ocean, and has provides the ideal armour material proven to be an effective defence The procigned inent of Riprap is besure. As such, the Riprap will The designed intent of Riprap is be continued on both sides of the that the stones provide designed reinforces the base of the bank, intervention.

\section{Fig 3.02. Riprap System}

This content is unavalible. Pleas consult the figure list for further information.

This content is unavalible. Please consult the figure list for further information.

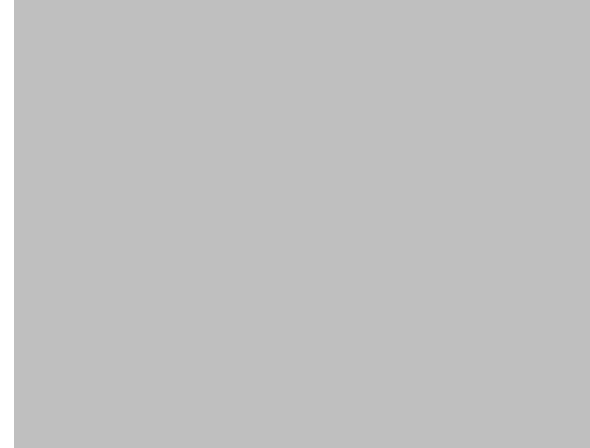

Fig 3.03. Gabion Basket System 

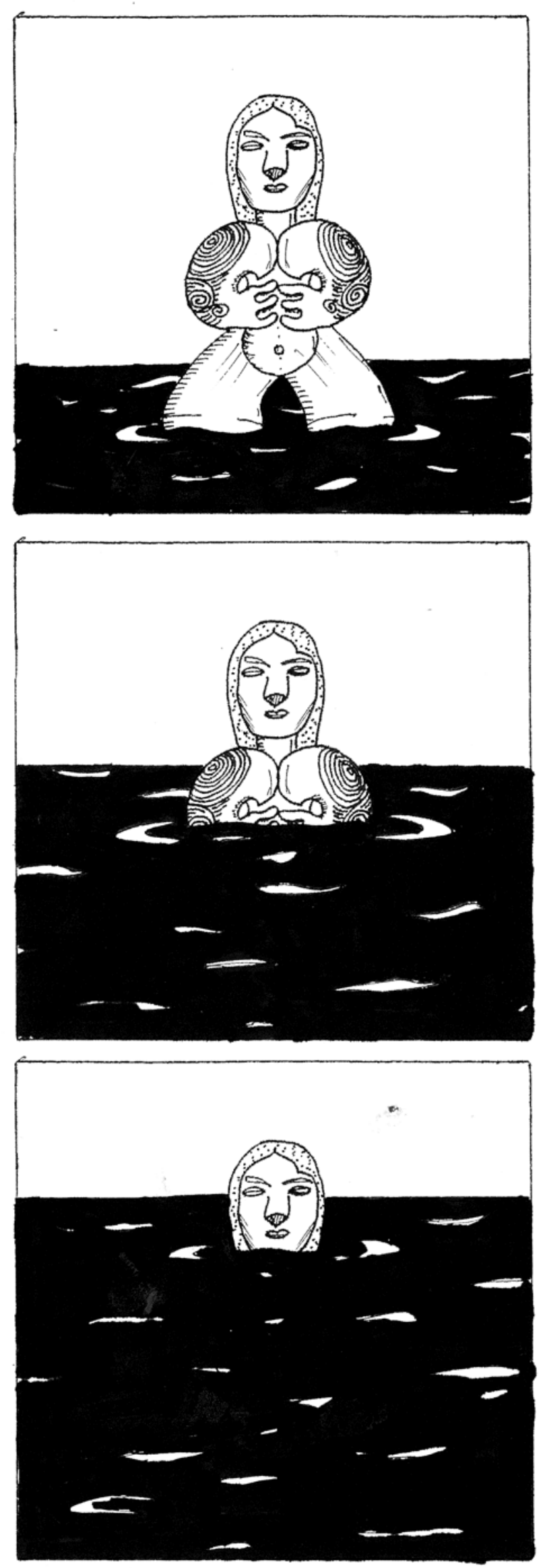

\section{AFFIRMATIONS OF THE} HUMAN SPIRIT

design considerations 


\section{Design Considerations.}

"...the hastily constructed communities of urban dwellers displaced by catastrophes of both human and natural origin - war, economic disaster, hurricane, and earthquake. After all, where was the role for architects in them? What could architects do to turn these instant cities into affirmations of the human spirit? Architecture is about planning. How can architects plan for the unplanned, for the unpredictable? Exactly...."

$\mathbf{T}_{\mathrm{m}}$

his chapter explores the preliminary considerations of this design-led research investigation.

It begins with exploring design

considerations surrounding both

the built and natural environments

with particular emphasis on the

Proposed Hastings District Plan

and the objectives and policies

that it outlines.

Alongside these considerations, are the established values of the

Haumoana region, documented in

a Hawkes Bay Regional Council

report (HBRC, 2012, p. 16). The

values have been collected and

generalised into four easy to

understand categories:

\section{Economic Values}

+ Long term economic growth

+ Flexibility

+ Employment Opportunities

+ Tourism

+ Reliable water supply
Social Values

+ Drinking water needs

+ Swimming and fishing

+ Passive enjoyment

+ Food gathering

Public access

+ Lifestyle

Cultural Values

+ Mauri - the life force

+ Wāhi tapu - scared places

+ Tikanga - protocols

+ Manaakitange - being good

hosts

+Te Reo - language

+ Taonga - highly prized things

Matauranga Mãori - knowledge

+ Mahinga kai - food gathering

Ecological Values

+ Healthy ecosystems, life

supporting capacity

+ Biodiversity

+ Native fish habitats

+ Trout habitats

+ Fish passage
Many of these values coincide with the objectives displayed in the District Plan, and will be considered throughout the design process.

The project then briefly explores some existing architectural projects in regard to program,

typology and form, highlighting what they demonstrate that this project aspires to draw influence from.

Overall the design aspires to display a mutualistic design, one that benefits both the built and natural environments while accentuating the natural character of Haumoana. 


\section{Built Environment.}

\section{$T$}

me first goal of the design is maintain the residents of the existing community, this means providing a minimum of 10 dwellings to replace those that are deemed essential to be relocated away from the coastline.

Secondly, the design will aim to ollow some of the pre-established council objectives highlighted in the Proposed Hastings District Plan, in particular:

"To minimise the adverse effects of developments created by excessive building scale"

(Proposed Hastings District Plan, HTRP5)
"Provide for non-residential activities which are compatible in scale, intensity and character within the Haumoana - Te Awanga Residential Zone" (Proposed Hastings District Plan
2013, Chapter 11.2.3, Policy HTRP6)

The first policy refers to the existing community's perception of residential amenity, private and open space and private It highlights how the built environment that does not acknowledge its locale can be detrimental to a region such as Haumoana, stripping it of its uniqueness and appeal. This thesis will endeavour to follow the

\section{Natural Environment.}

established dialect of the existing built environment in Haumoana, with particular emphasis on scale and style.

The second policy refers to the social synergy of the region Haumoana is already home to many arts and craft galleries, winery's and other visito attractions that contribute to the unique character of the community. With the site already situating Sif on a prominent Hawkes Bay beach, and being intended to be at the very end of a very popular weekend cycle trail, the design will atempt to provide a space will attempt to provide a space where the unique character of the community can gather togethe and be on display to the general public.
$\mathbf{O}$ the well-established Droject is ensure the outcome of design

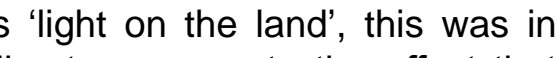
direct response to the effect that the traditional method of building on New Zealand's coastal edge has had on the environment. Buildings consisting of heavy concrete foundations and deeply rooted infrastructure have proven harmful to the landscape and have become a troublesome logistics exercise when they are left to the mercy of the tide.

This project aspires to adopt a new approach to the built environment on coastal New Zealand sites, one that strives to:
Protect the landscape features and character of the Tuk Tuki Special Character Zon y controlling or restricting (Proprate land use activities" Plan, 2013, Chapter 5.4.3, Polic TTP2)

\&

"Provide for the subdivision of Lifestyle sites in the Tuki Tuki Special Character Zone which maintains the openness of the landscape and the existing low density of housing." Proposed Hastings Distric

Plan, 2013, Chapter 5.4.3, Policy TTP5)
Adverse building practices has the greatest potential to threaten the natural character of the Haumoana region, and with the intent to establish a new community region, the minimization of impact on the surrounding environment is of absolute priority. Nonetheless, one of the most beneficial aspects of the stilted building technique is that it minimises the impact of any potentially adverse construction to just the posts that holds it above the ground, allowing and natural process of the landscape to continue without too much interference. 


\section{Programmatic Precedent.}

\section{Eco Village.}

This content is unavalible. Please consult the figure list for further information.

$\dot{0}$
$\dot{0}$
ì

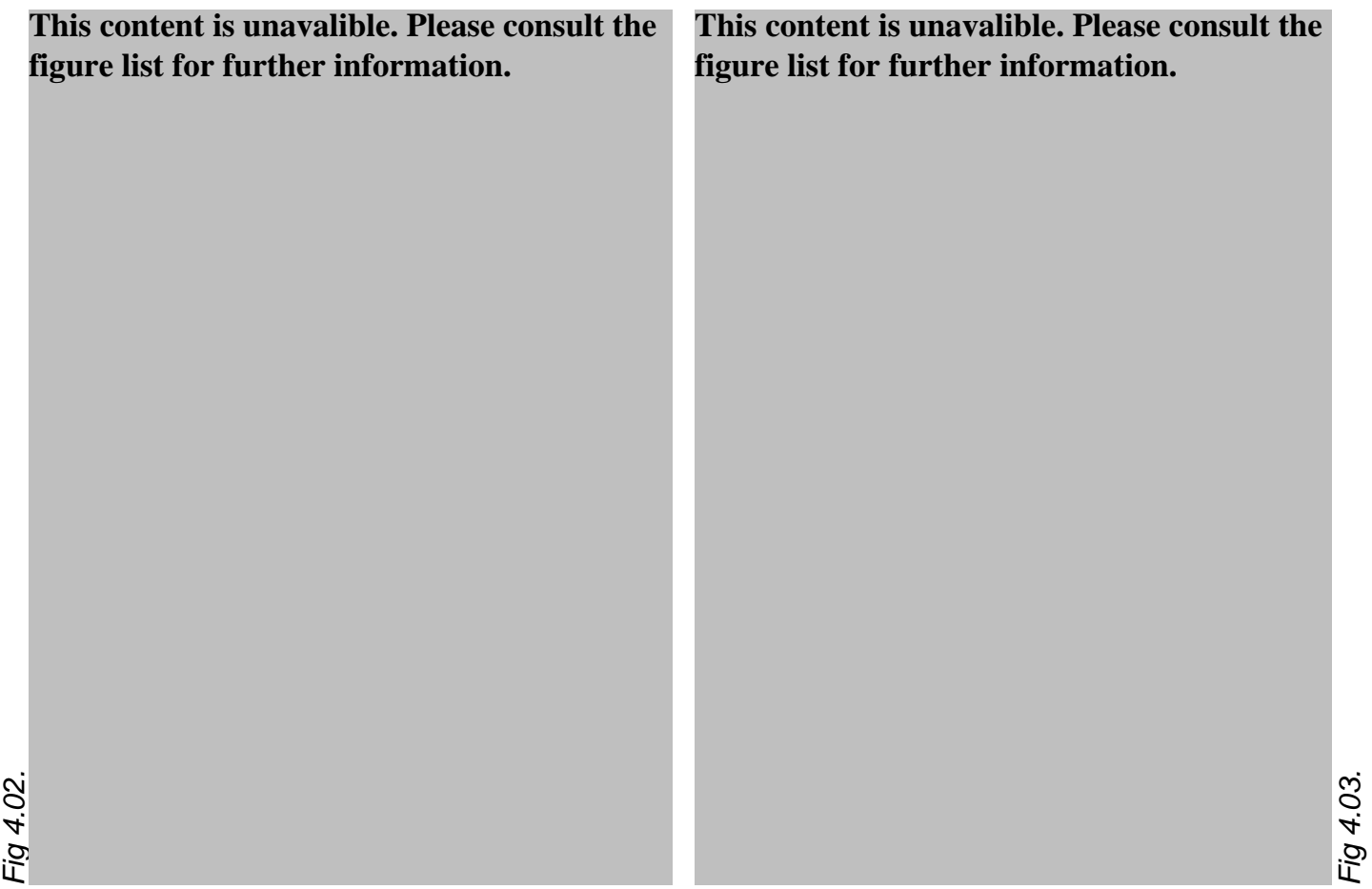

$\mathbf{T}_{\text {he }}$

ReGen Village is an desires to tackle. While the design integrated neighbourhood design is not intended to be completely that follows a 'waste-to-resource' self-sufficient and off the grid like approach to a sustainable RenGen Village, it does aspire community. to enforce good practice when it With a heavy focus on self functions. A productive community sufficiency, the RenGen Village that has the capibility to produce encapsulates a utopican example food and resources.

of the ambitions that this thesis 


\section{Typology Analysis. \\ A New Zealand Vernacular.}

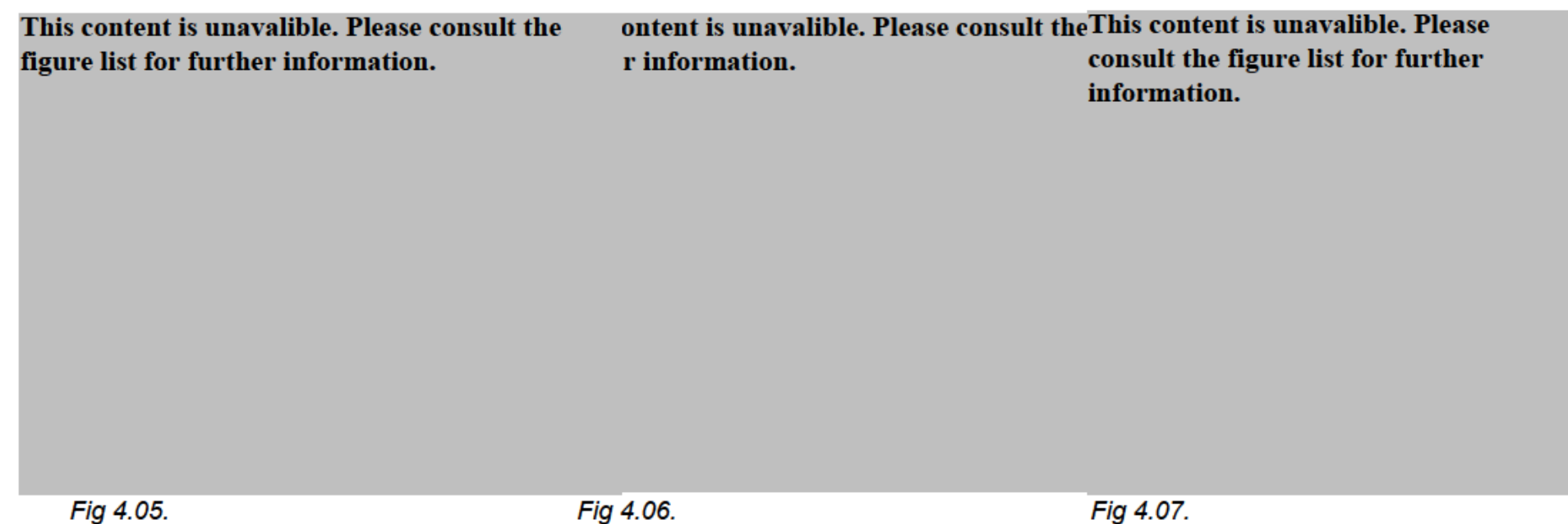

$\mathbf{T}_{\text {ras }}$

We New Zealand bach is from the busy day to day life of the depiction of the bach a more than an architectural bigger city living.

expression, it is a cultural icon.

They are best known as home Bach's have had such a profound

built weekenders that reject the impact on New Zealand society

values of traditional homes, that they have become the kiw

dwey are uncomplicated, modest vernacular, with their embedded

function, setting and materiality reflect the humble and content

(Wood, 2000, p. 44)

nature that the residents of $\mathrm{New}$

Zealand are known around th

Fig 4.07

For many New Zealanders, they world for.

have become a 'site of memory'

(Kearns \& Collins, 2006, p. 227), Being a coastal community, much

a place that is associated with of the built environment in the

relaxed family holidays, an escape Haumoana region already reflects region that diverged from this, would undoubtedly be disputed For these reasons, this thesis aims to adopt the principles and values of values of the vernacular bach and the proposed design.

\section{Modern Precedent.}

The Kiwi Bach
This content is unavalible. Please consult the figure list for further information.

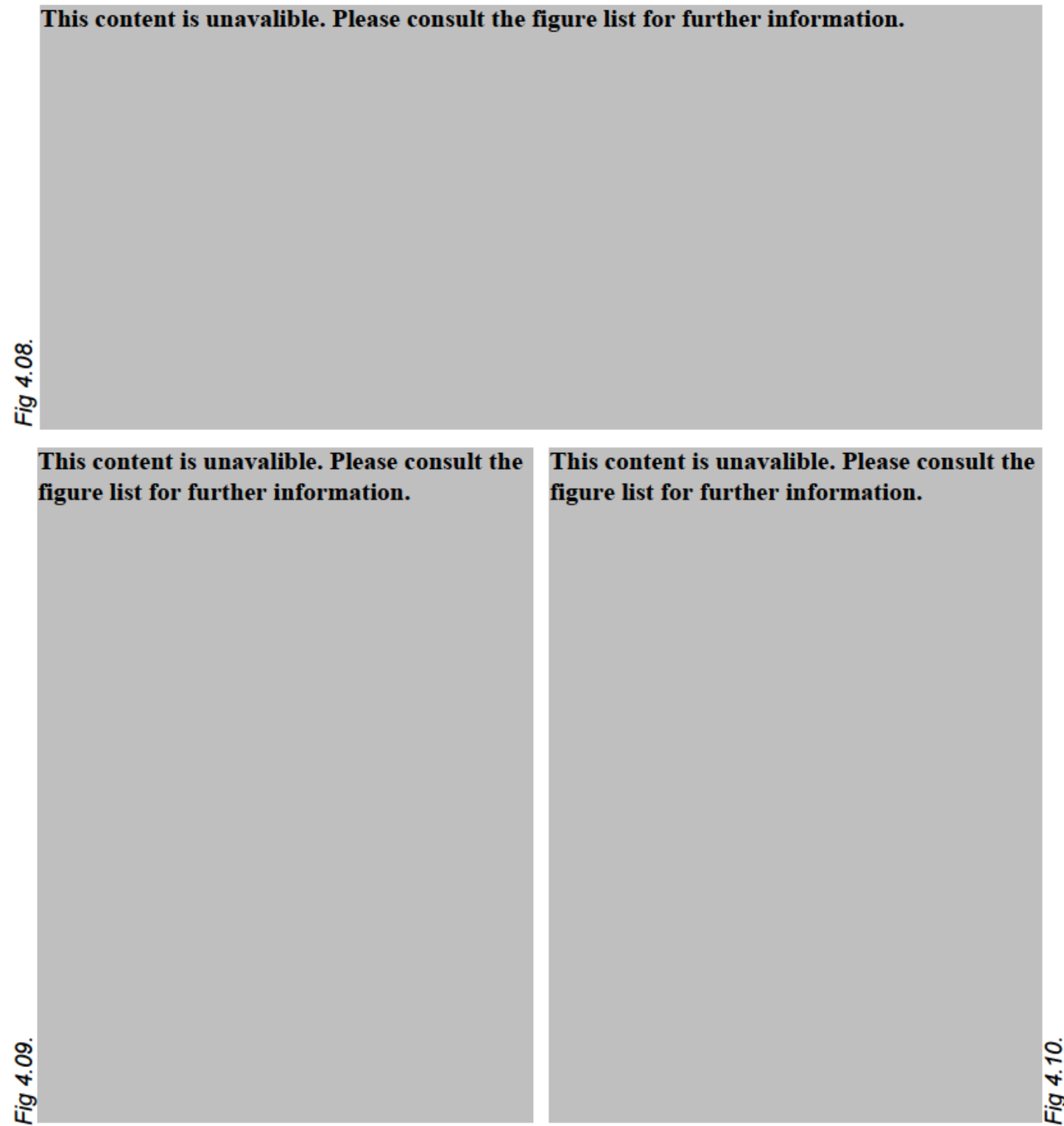

Although modern bach's are often As with Crosson Architects 'Hut on
much more comfortable than the Sleds', a design that pays homage to
traditional vernaculars, the underlying the vernacular bach, but enhances
principles often remain evident. By user experience by allowing the
combining our modern technologies, luxury's of modern materials. This
building materials and design attitudes self-contained, semi permanant design
with the basic principles that makes embodies the design intent of this
the bach such a cultural repository, project, with its simple yet powerful
the modern bach presents itself as the presence and its use of honest and
pinnacle of coastal architecture. 


\section{Design Precedents.}

Structural Elegance.

This content is unavalible. Please consult the figure list for further information.

交

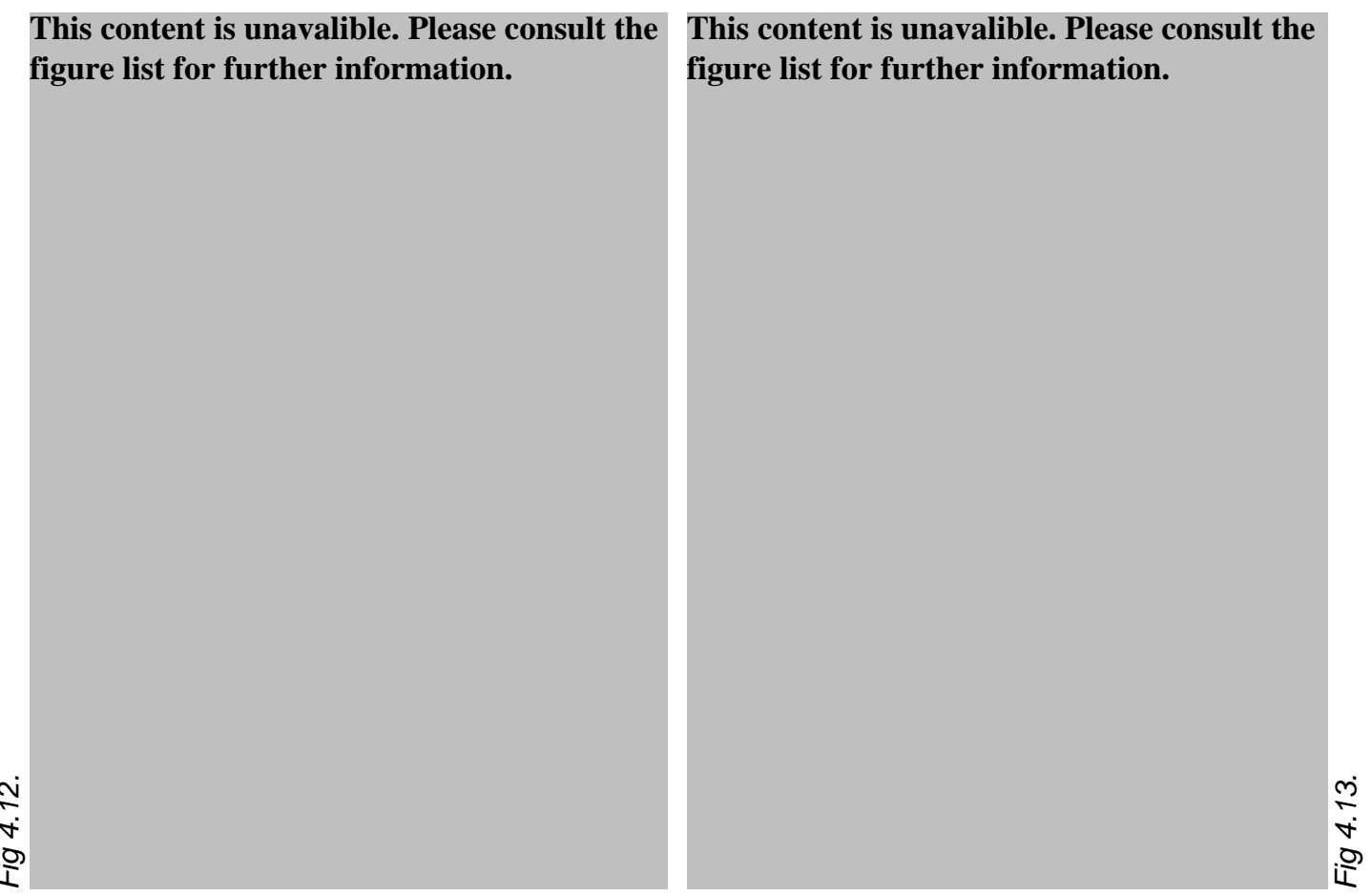

This content is unavalible. Please consult the figure list for further information.

$\frac{i}{i}$

Exposing and expressing structure
This content is unavalible. Please consult the figure list for further information. 


\section{Design Precedents.}

Humble Strength.

This content is unavalible. Please consult the figure list for further information.

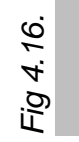

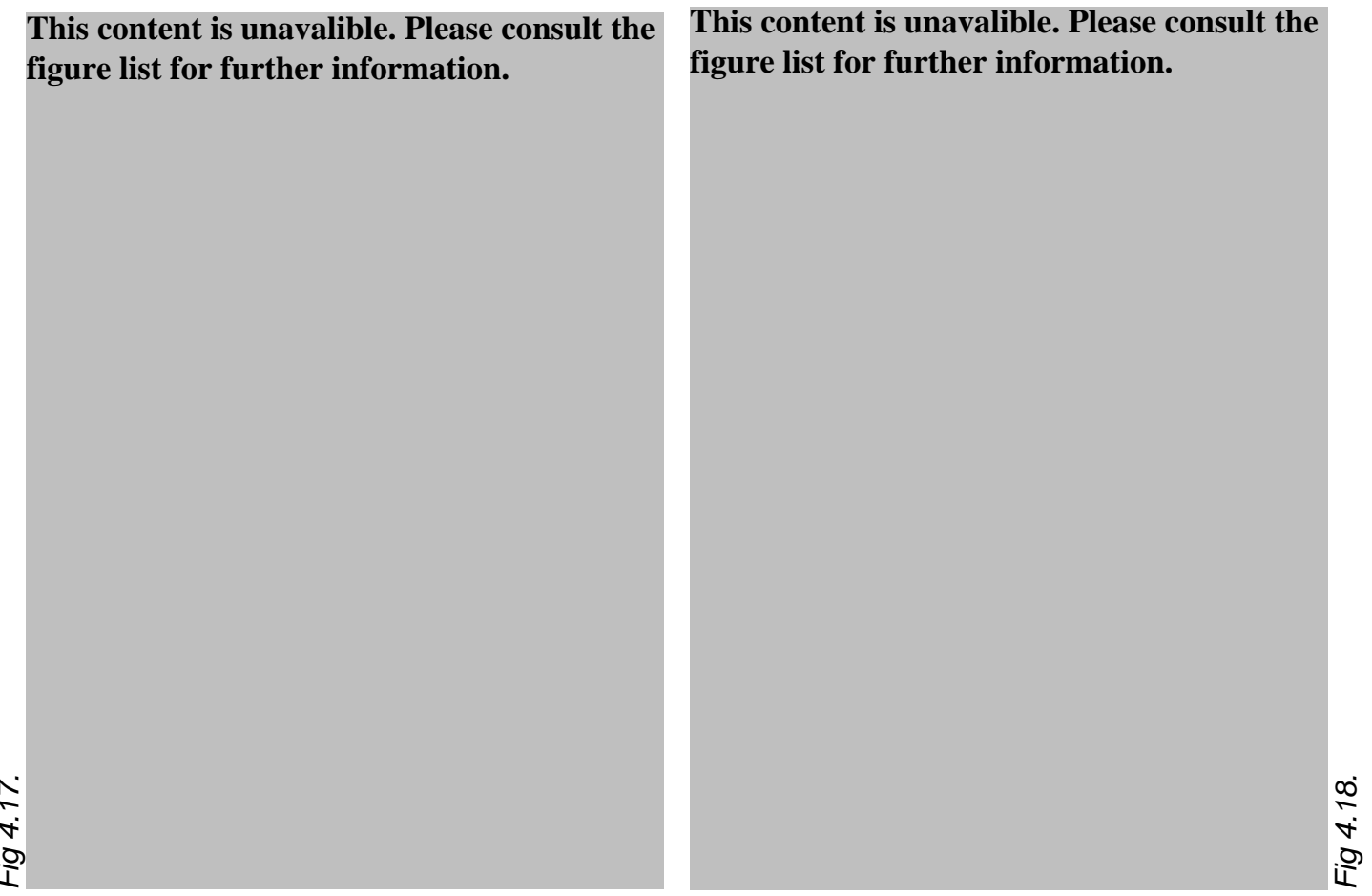

This content is unavalible. Please consult the figure list for further information.

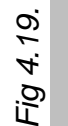

This content is unavalible. Please consult the figure list for further information.

Dennis Andernach

Landschaftshäuser | "Landscape for Houses”| Caspar David Friedrichs 


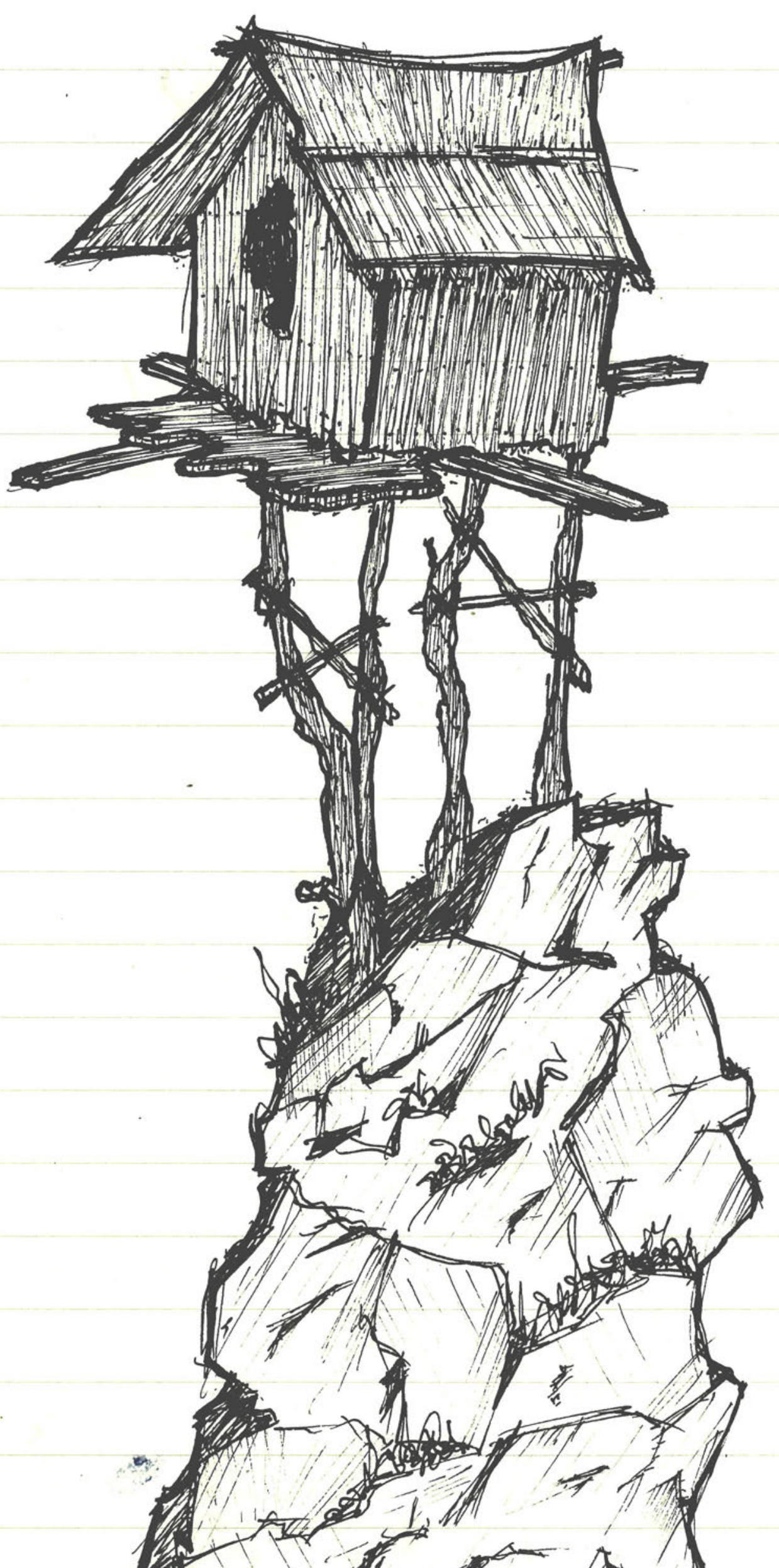

$\begin{array}{lllllllll}00 & 01 & 02 & 03 & 04 & 05 & 06 & 07 & 08\end{array}$

TO SETTLE IN THE

LANDSCAPE 


\section{Conceptual Design.}

"To settle in the landscape means to delimit an area, a place. We stop our wandering and say: Here! Then we create an 'inside' within the encompassing 'outside'."

\section{$\mathbf{T}_{\text {he }}$}

formal and structural techniques principles that are complimented at multiple scales that follow by the Zinc Mine Museum's

the established precept of the elegance and honesty of structure and the humble strength of simple, bold forms that are illustrated by The underlying principles of each Dennis Andernach individual design will follow that of
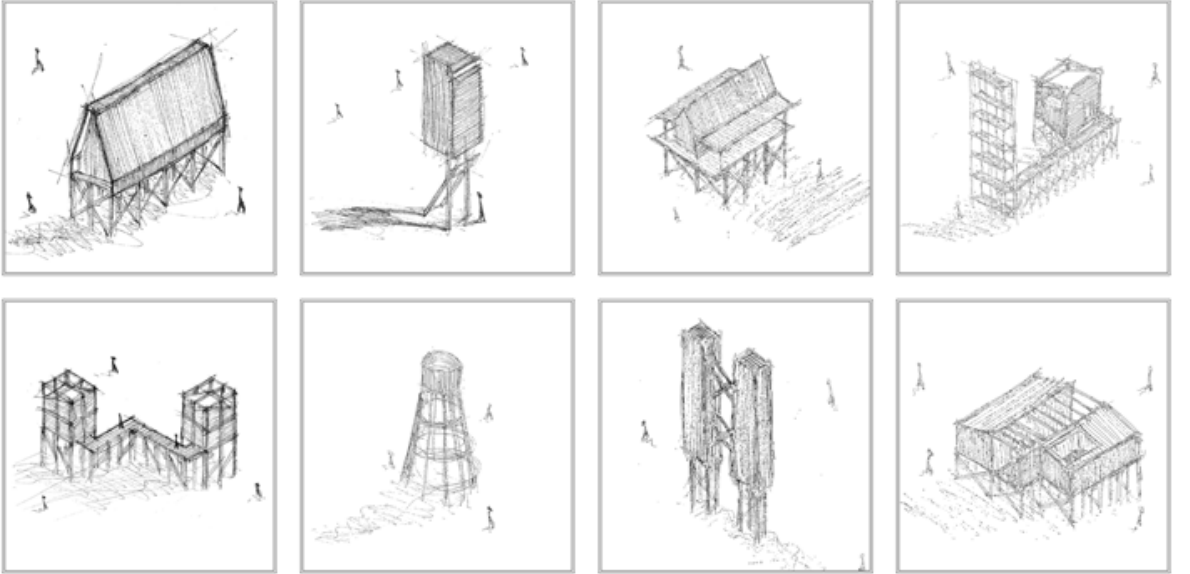


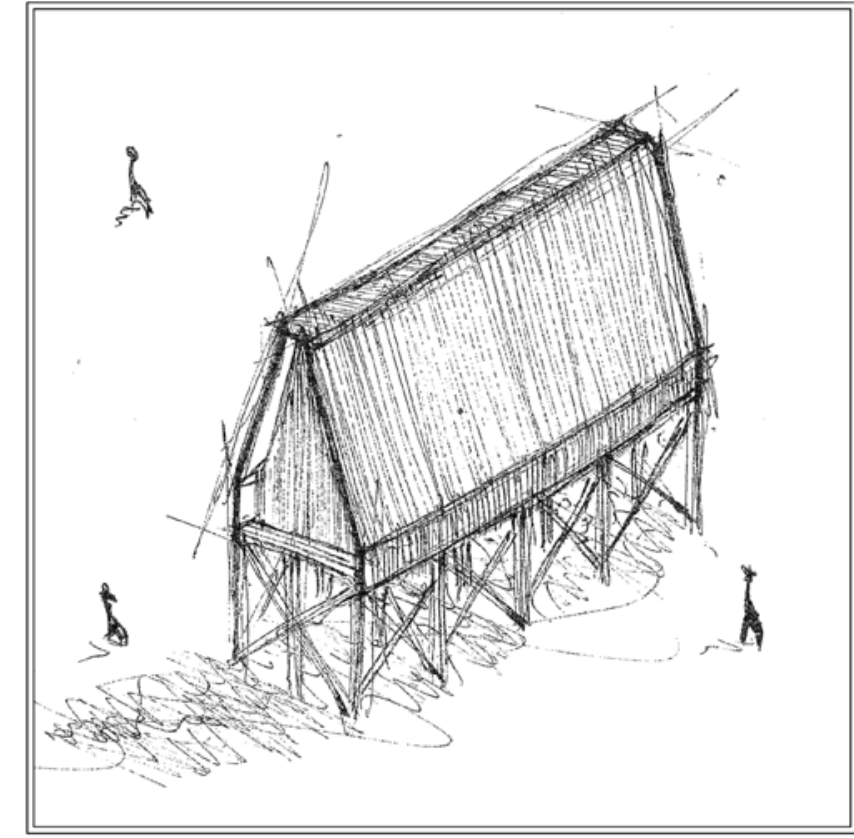

01

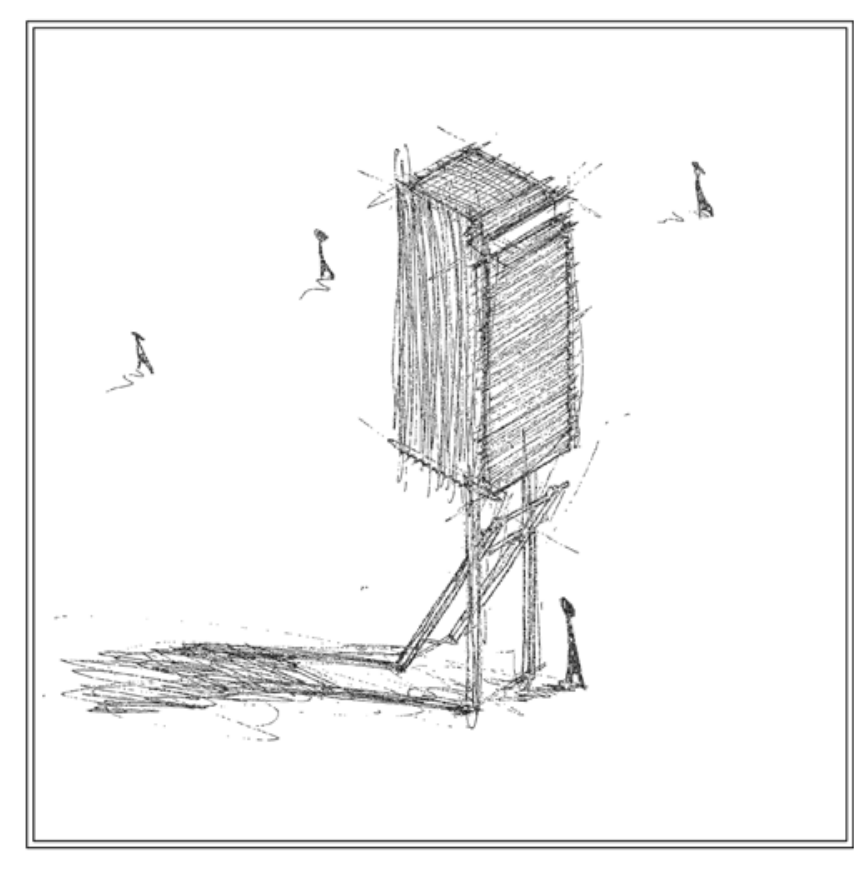

02

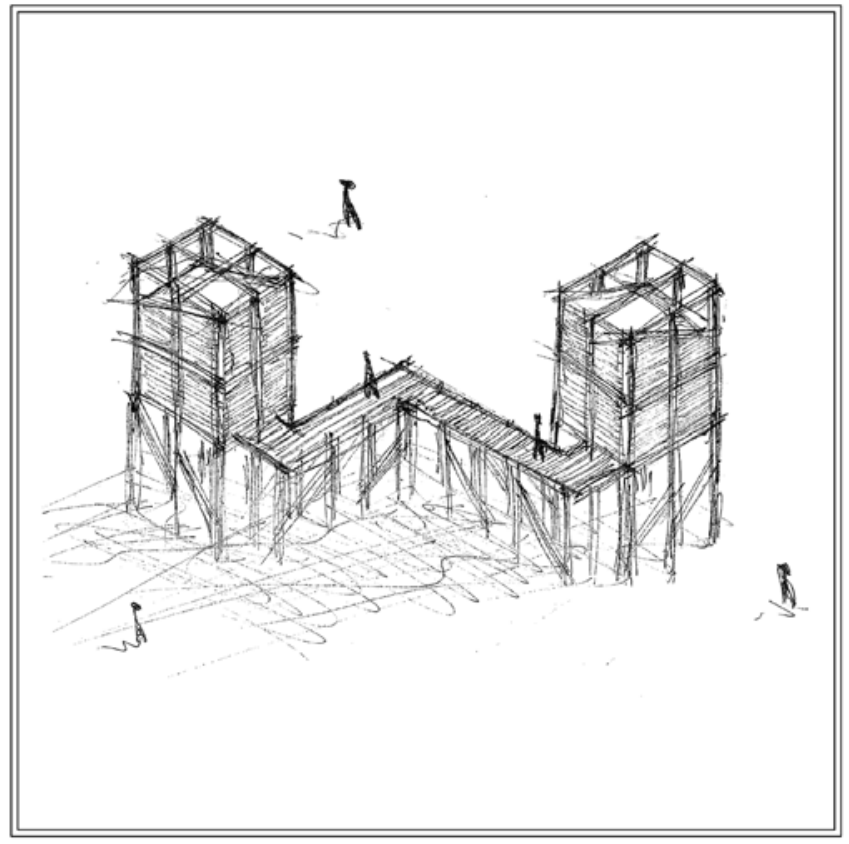

03

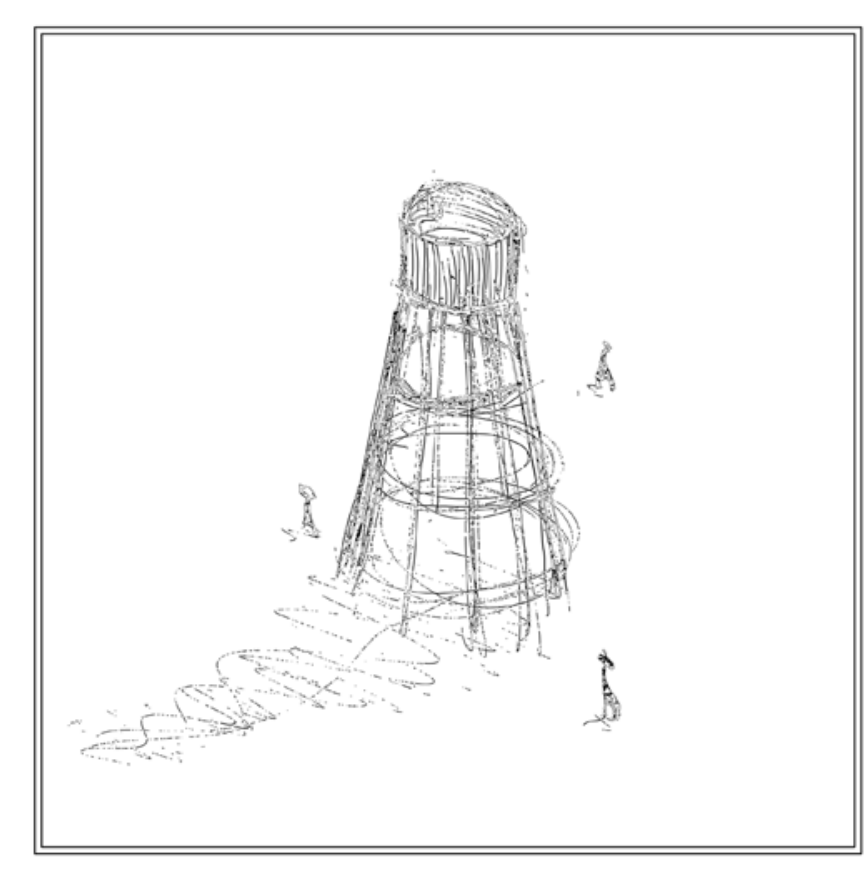

04 


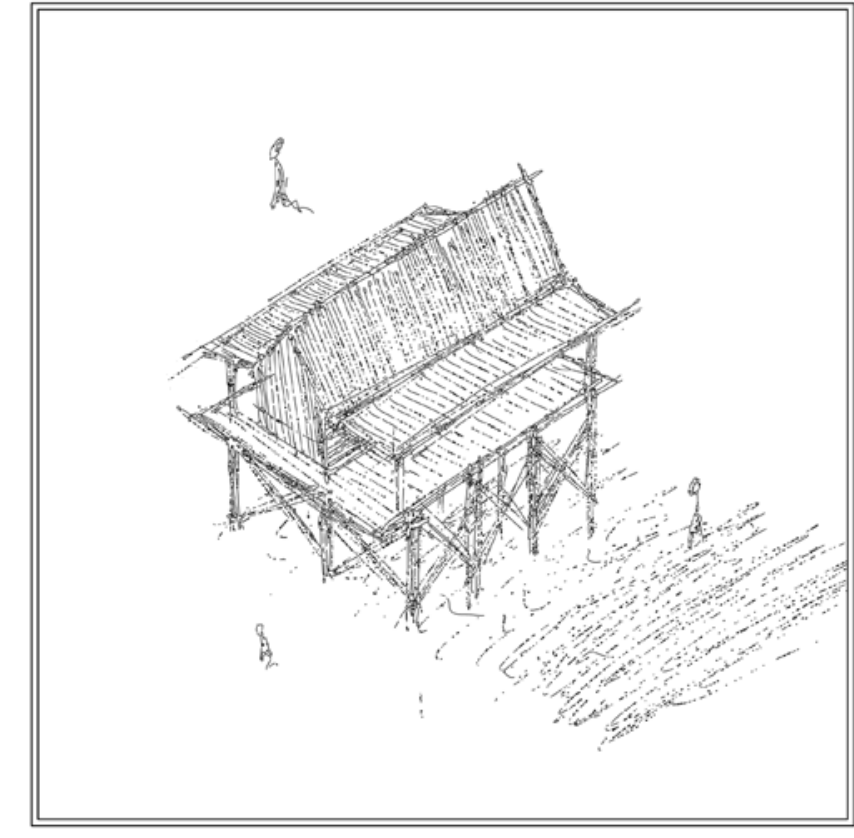

05

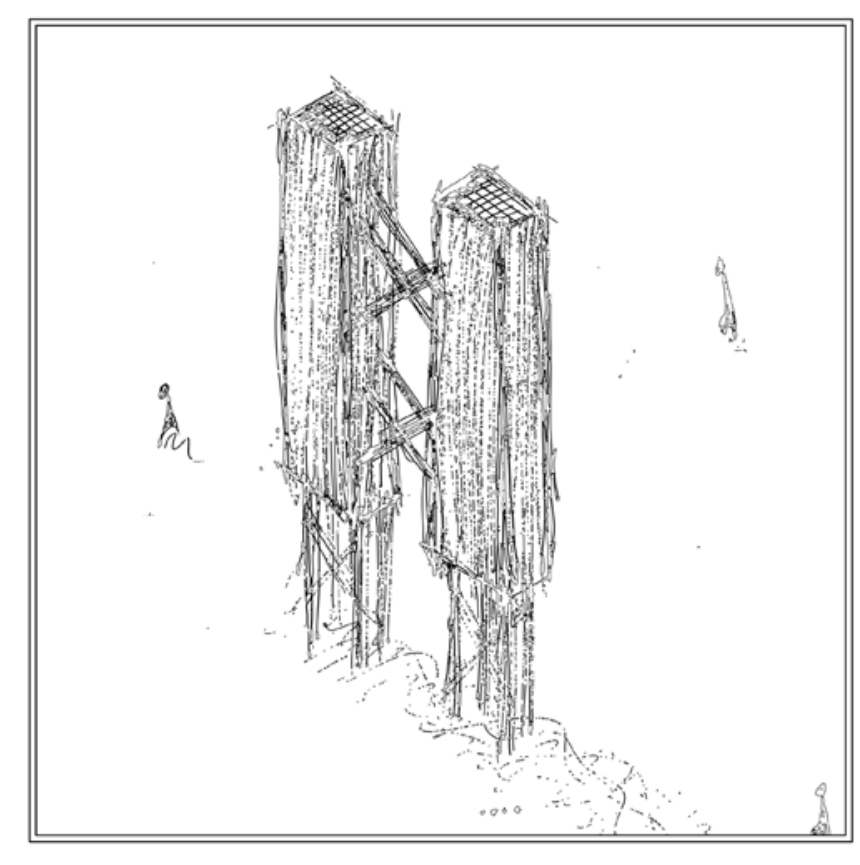

06

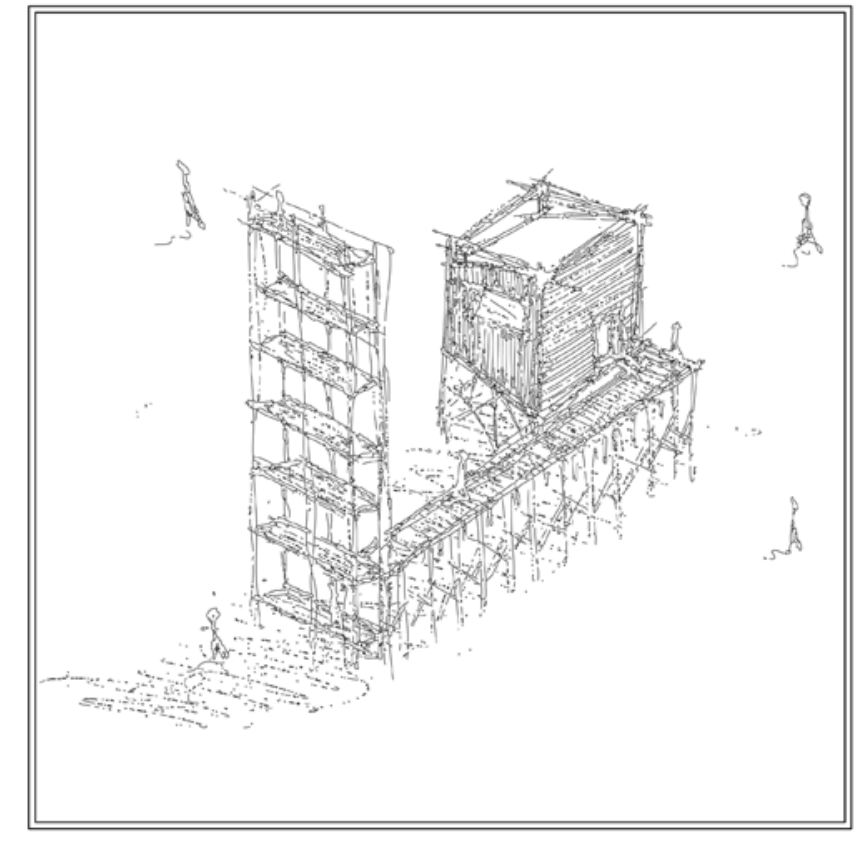

08

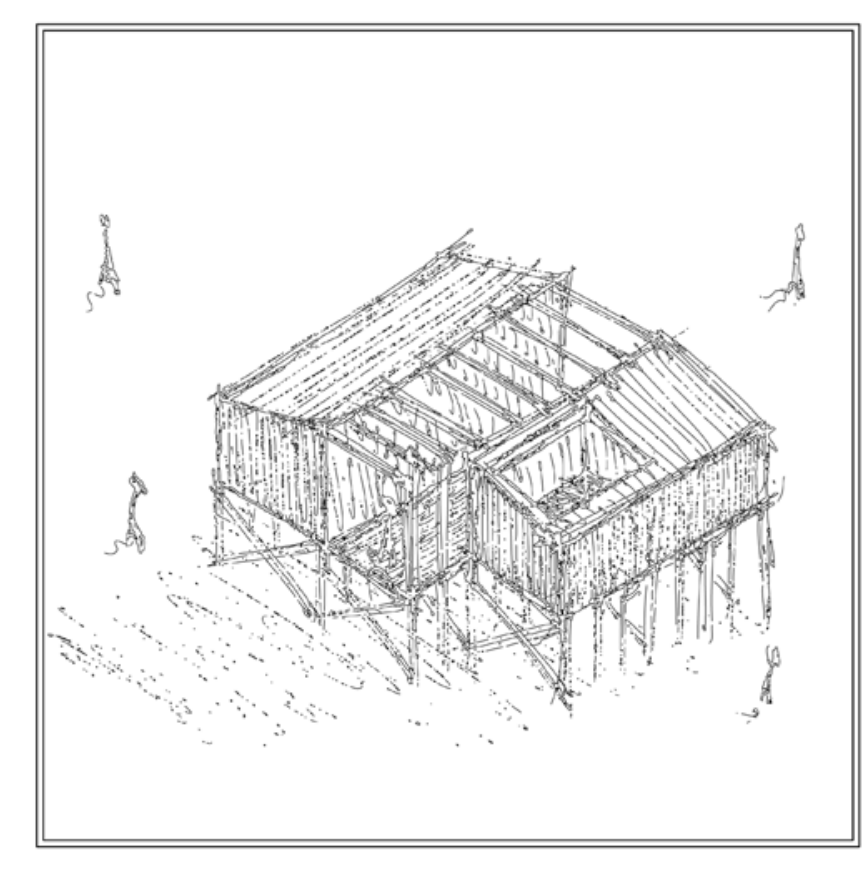

07 


\section{A Landscape of Prototypes.}

Structural Elegance Humble Strength.

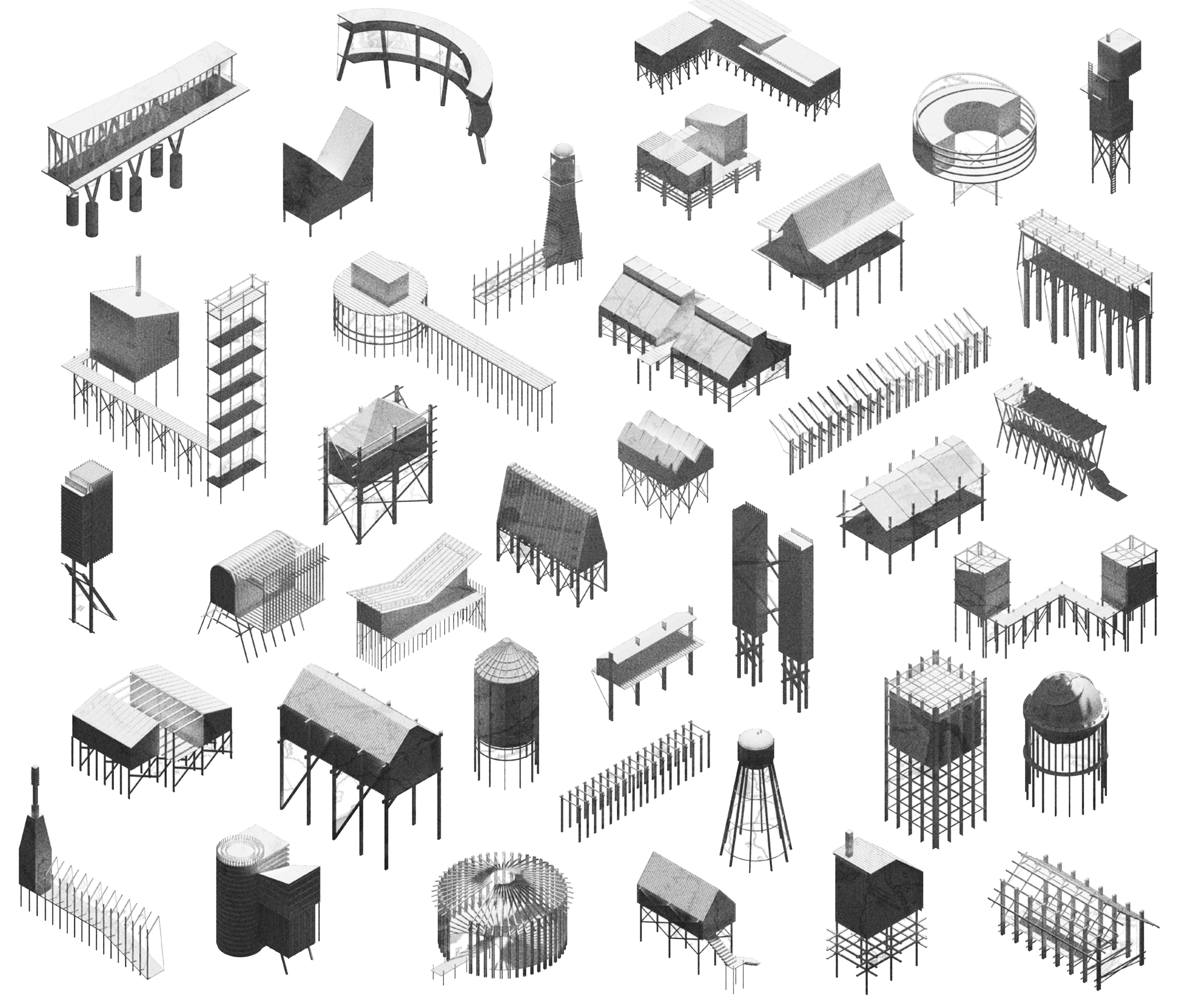




\section{Developed Design.

\author{
contextualisation
}

W was rooted as a formal exploration setting out to add and examine of the underlying design hints towards potential structure, principles, this next stage looks materiality and textures.

to contextualise the interventions

onto the stopbank itself.

The series of designs are adaptions of the conceptual forms (deve

A series of six buildings have been shaped chosen to explore further, three of each, exploring the liveability dwellings and three community of such buildings and how they buildings. The designs are respond to site.
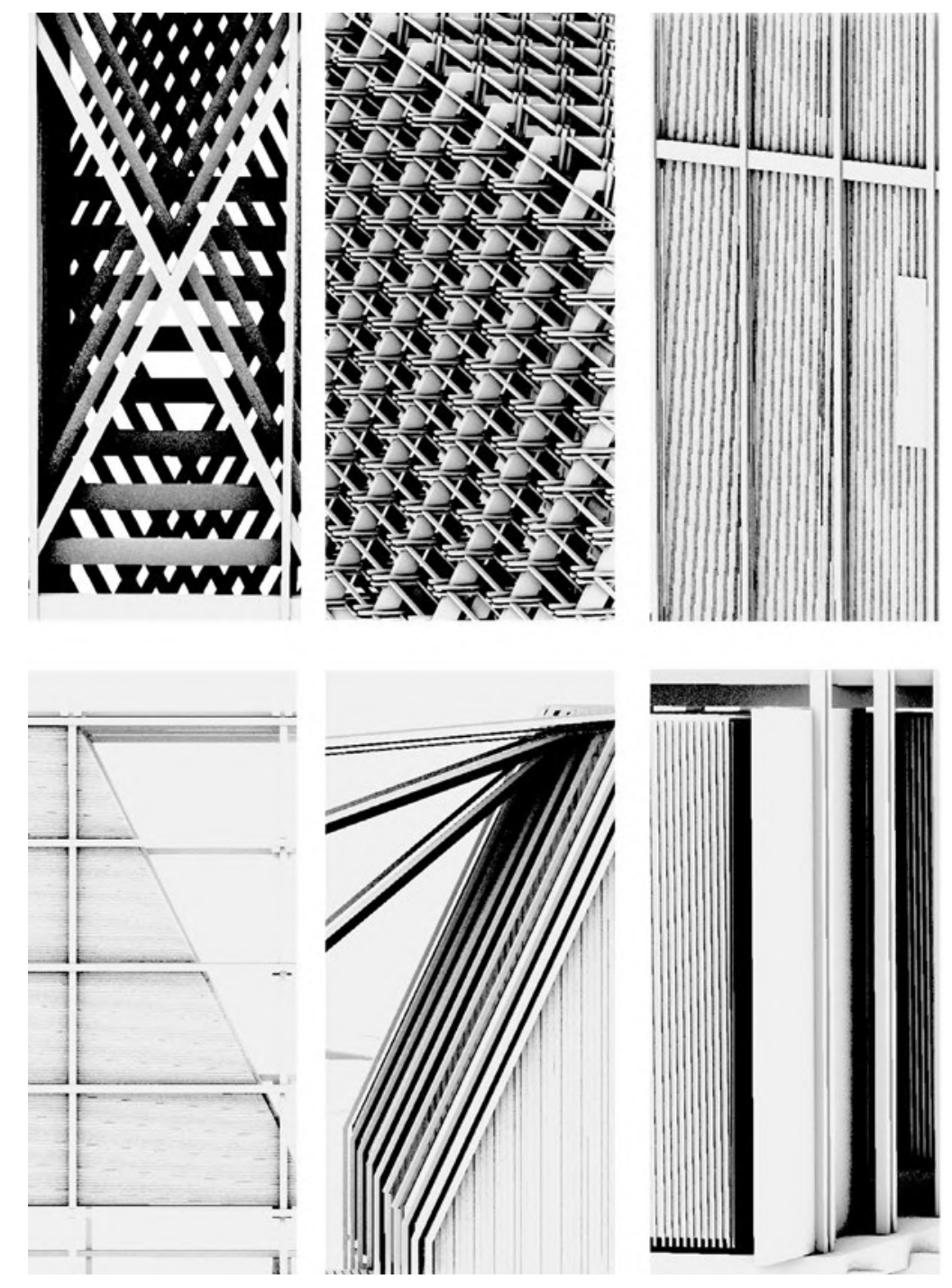


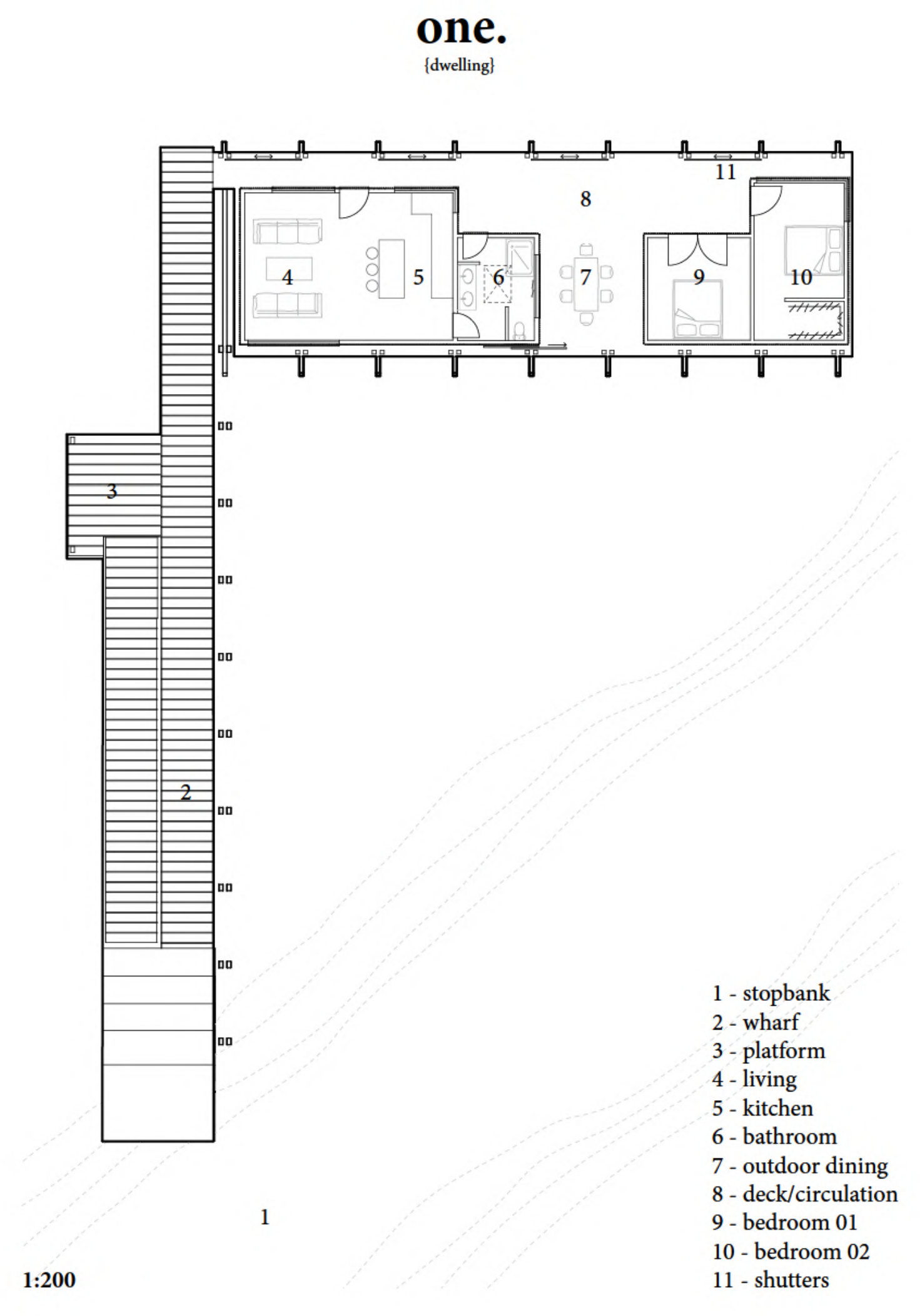


$+$

two.
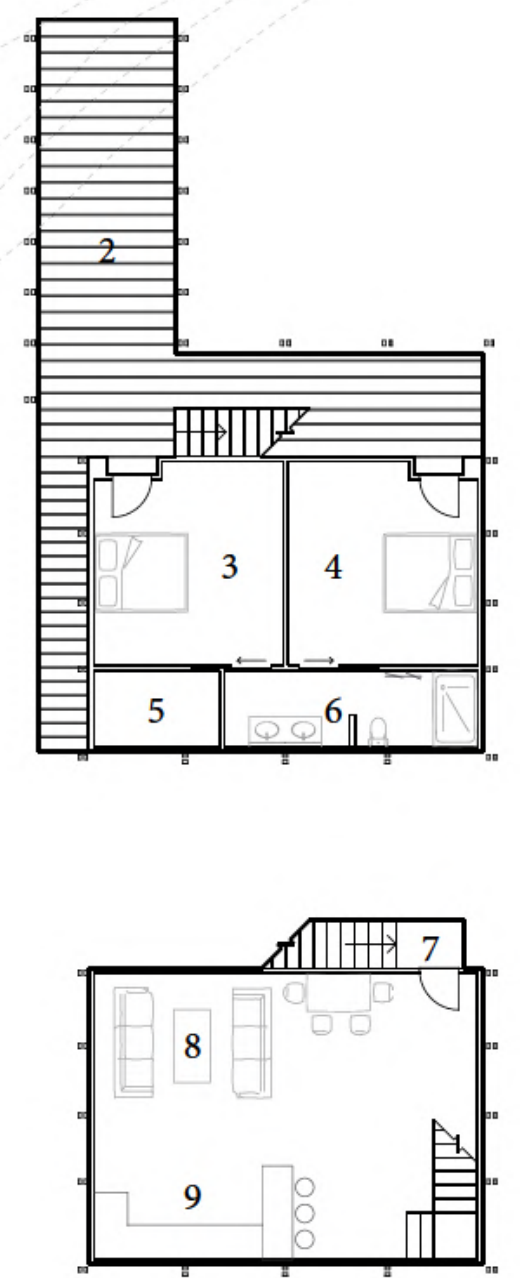

1:200
1 - stopbank

2 - wharf

3 - bedroom 0

4 - bedroom 02

5 - storeroom

6 - bathroom 01

7 - main entrance

8 - living / dining

9 - kitchen

10 - master bed

11 - master be

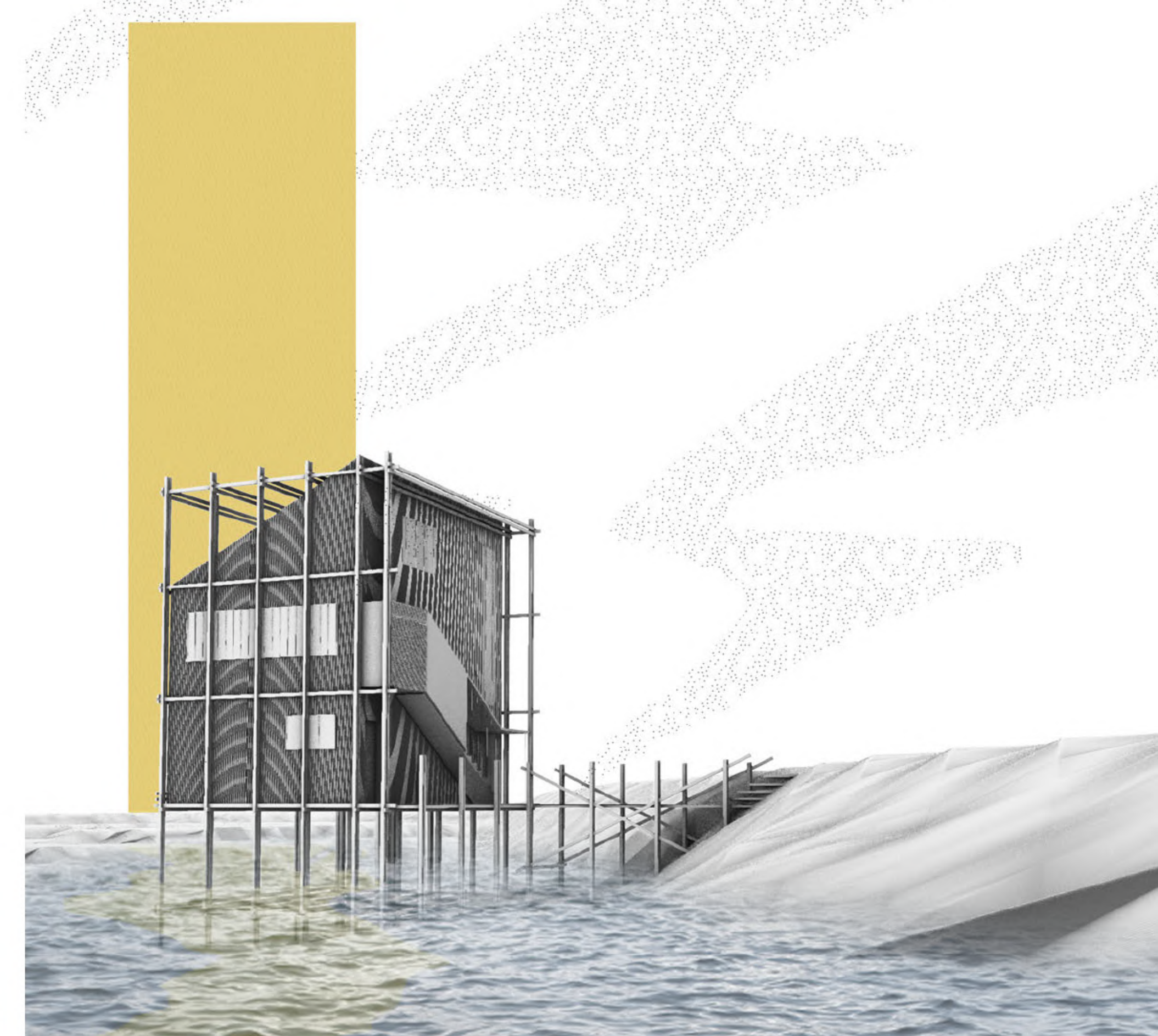


three.

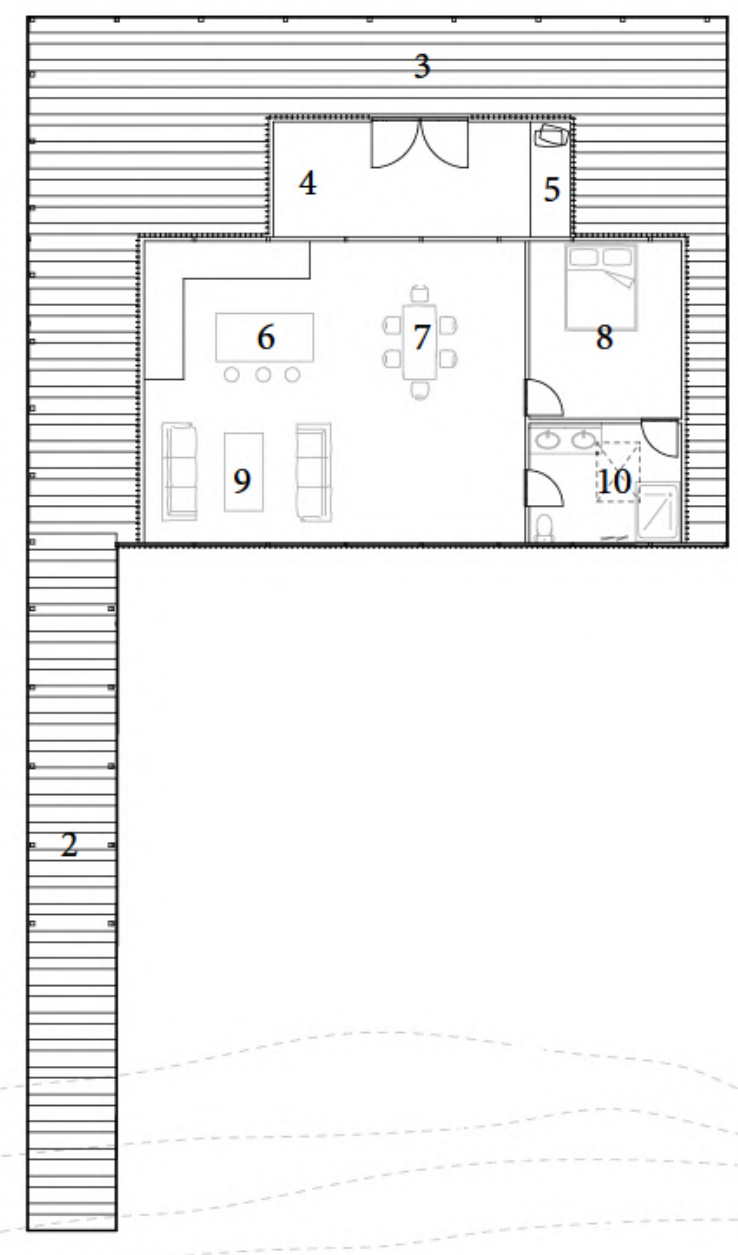

1 - stopbank

3 - deck

4 - sun room

6 - kitchen

7 - dining

7 - dining

8 - master
9 - living

10 - bathroom

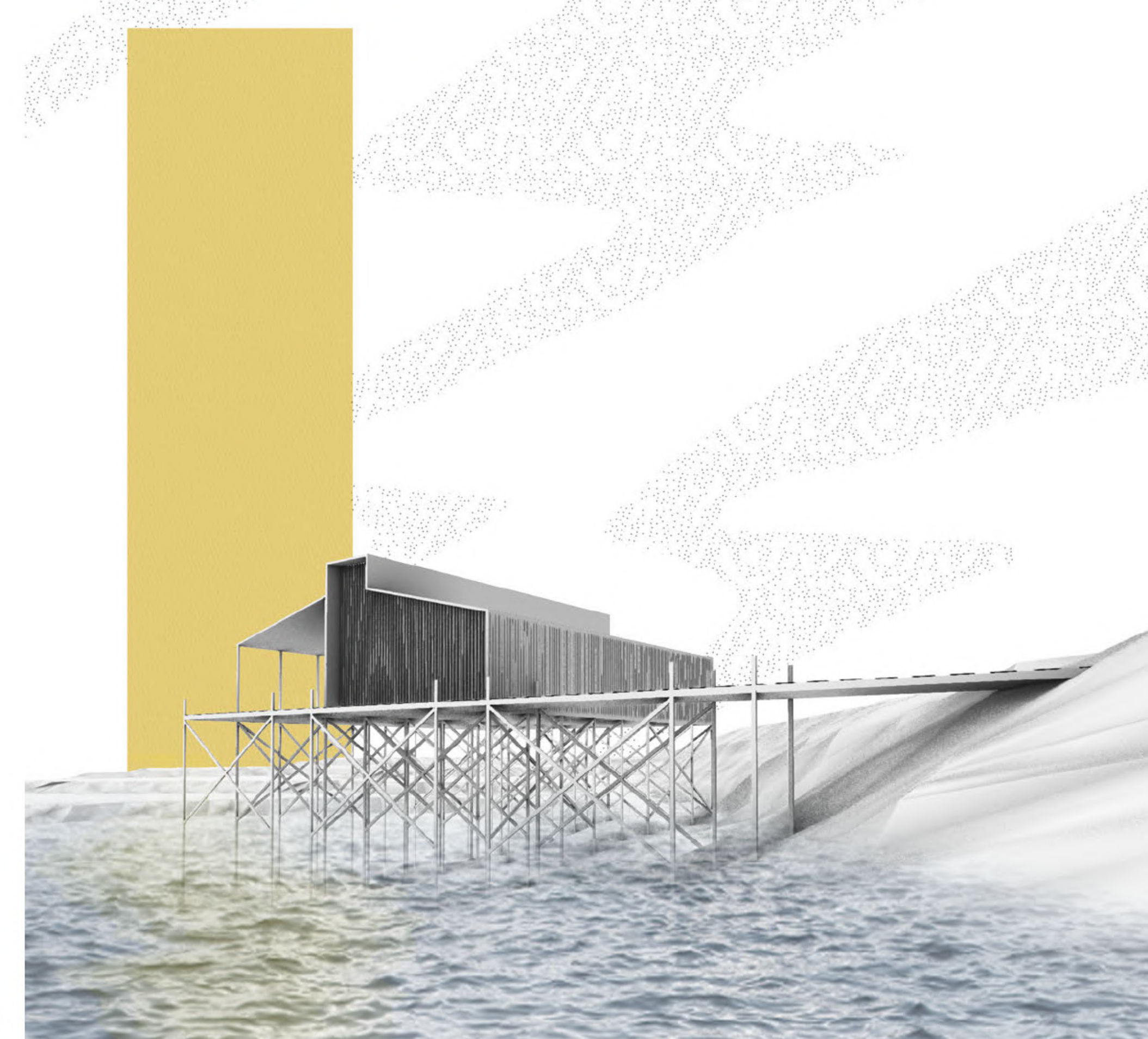


$+$

\section{four.}

\{community building\}

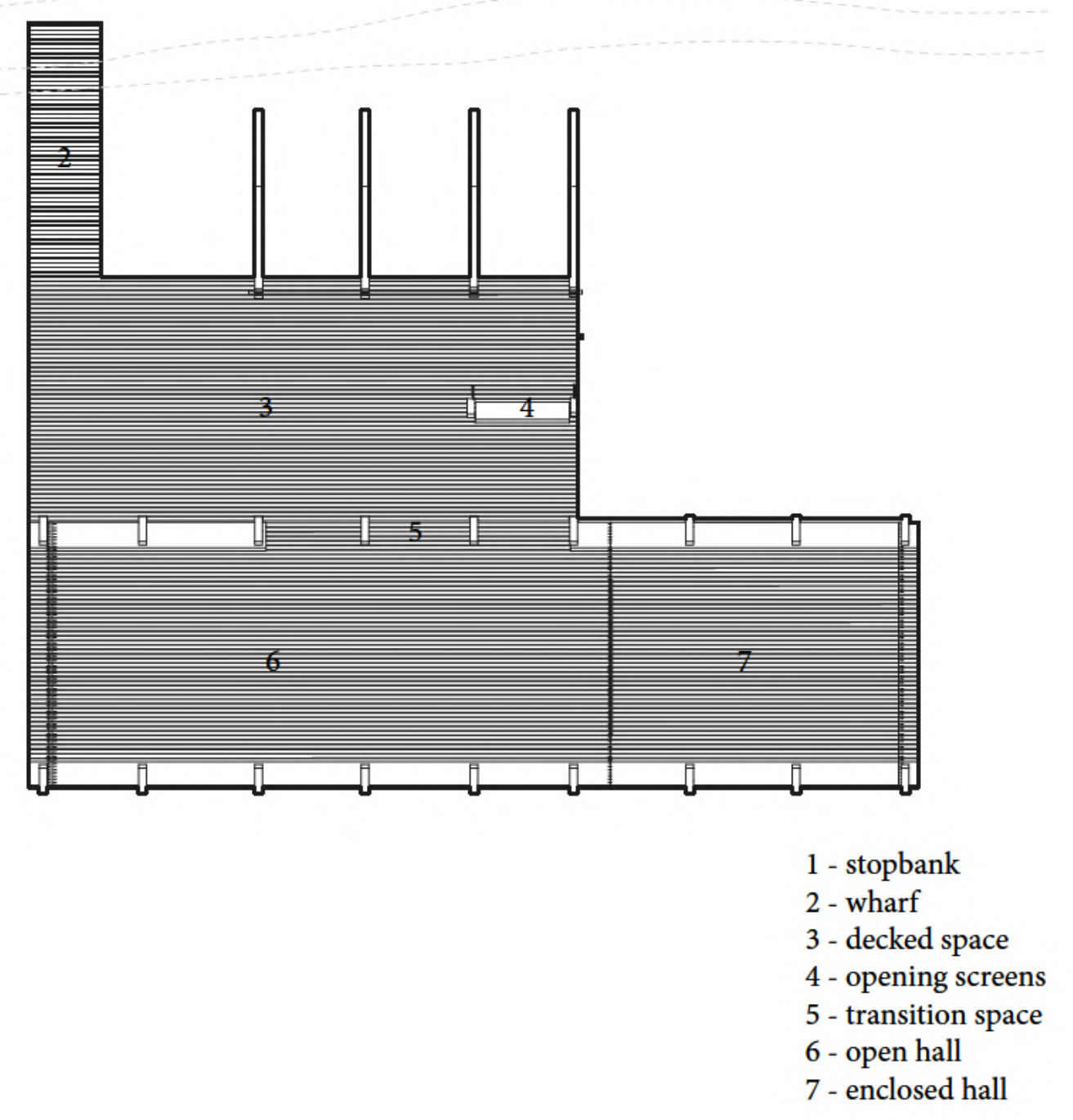

1:200

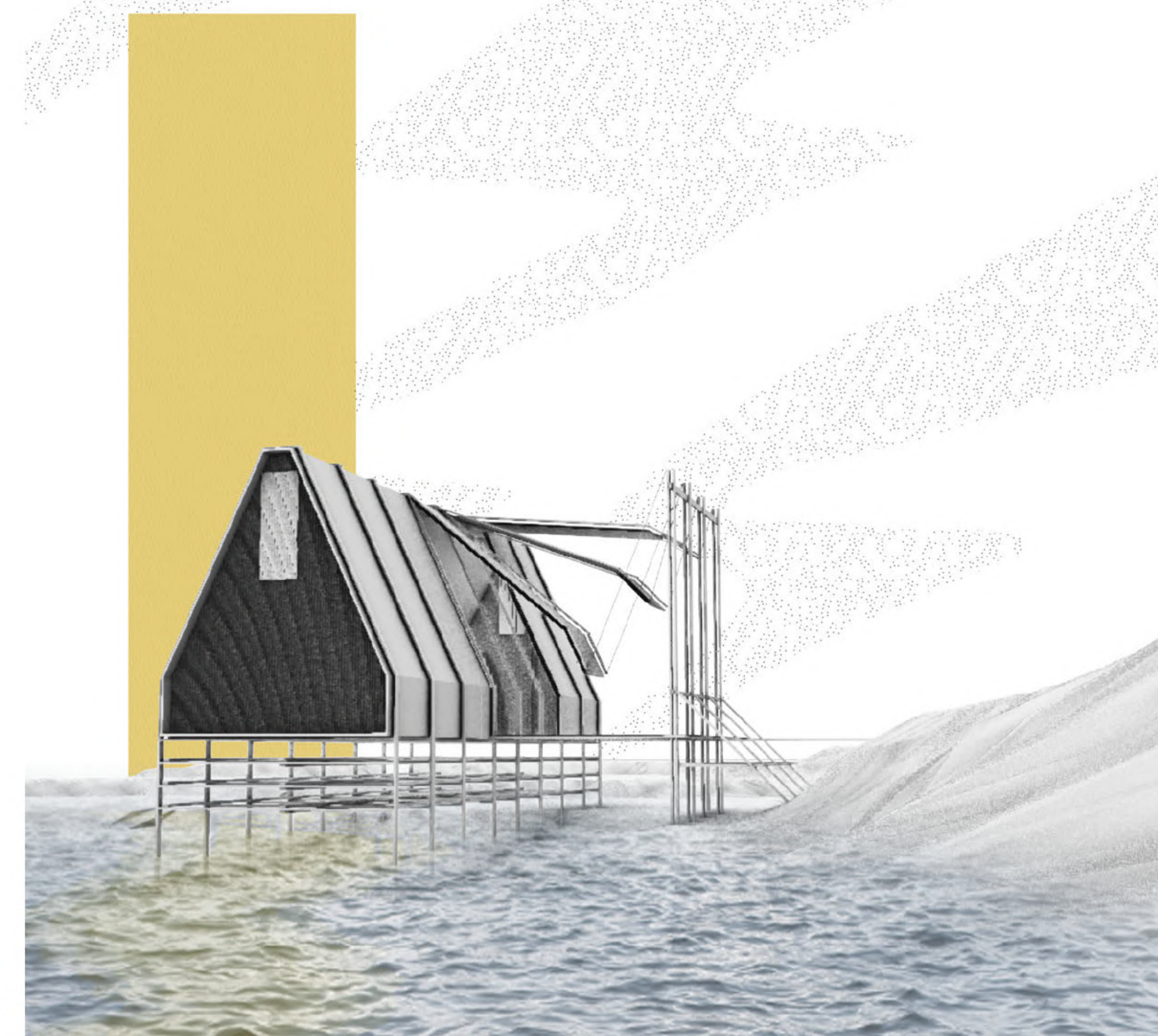


five.

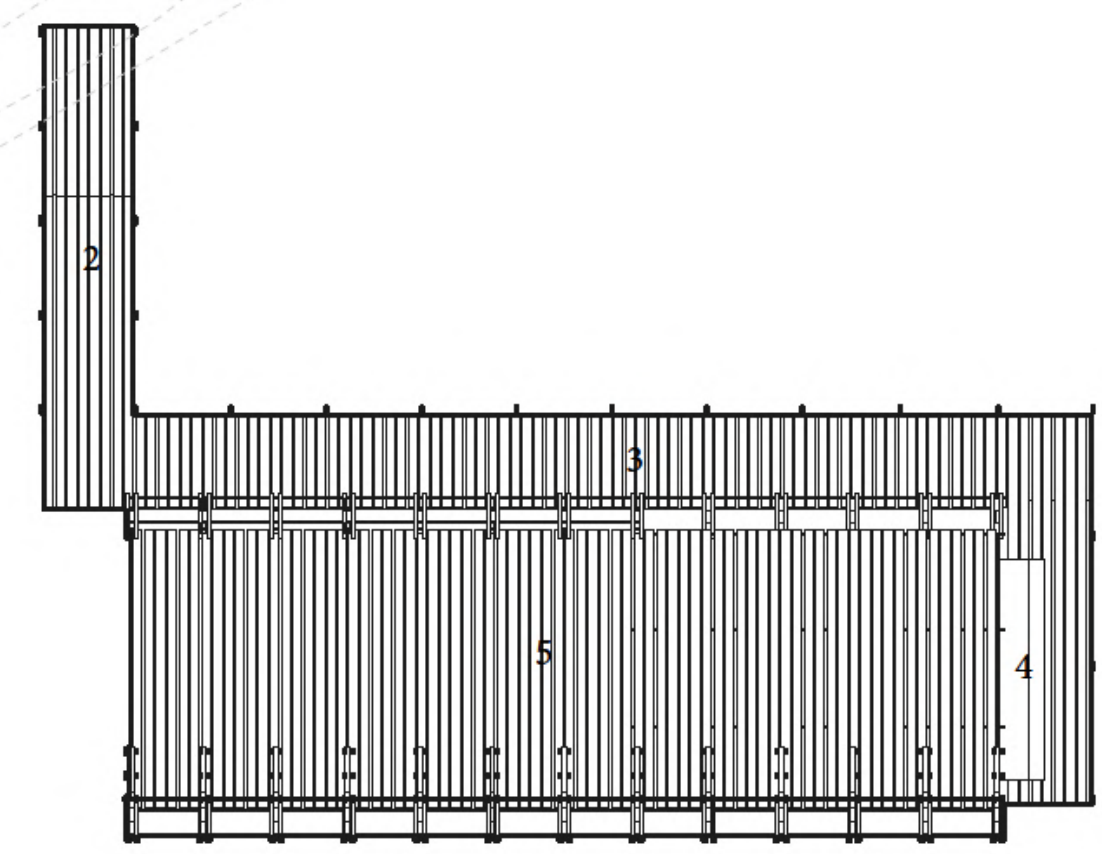

1 - stopbank

2 - wharf

3 - boardwalk

4 - open entrance

5 - cultivation

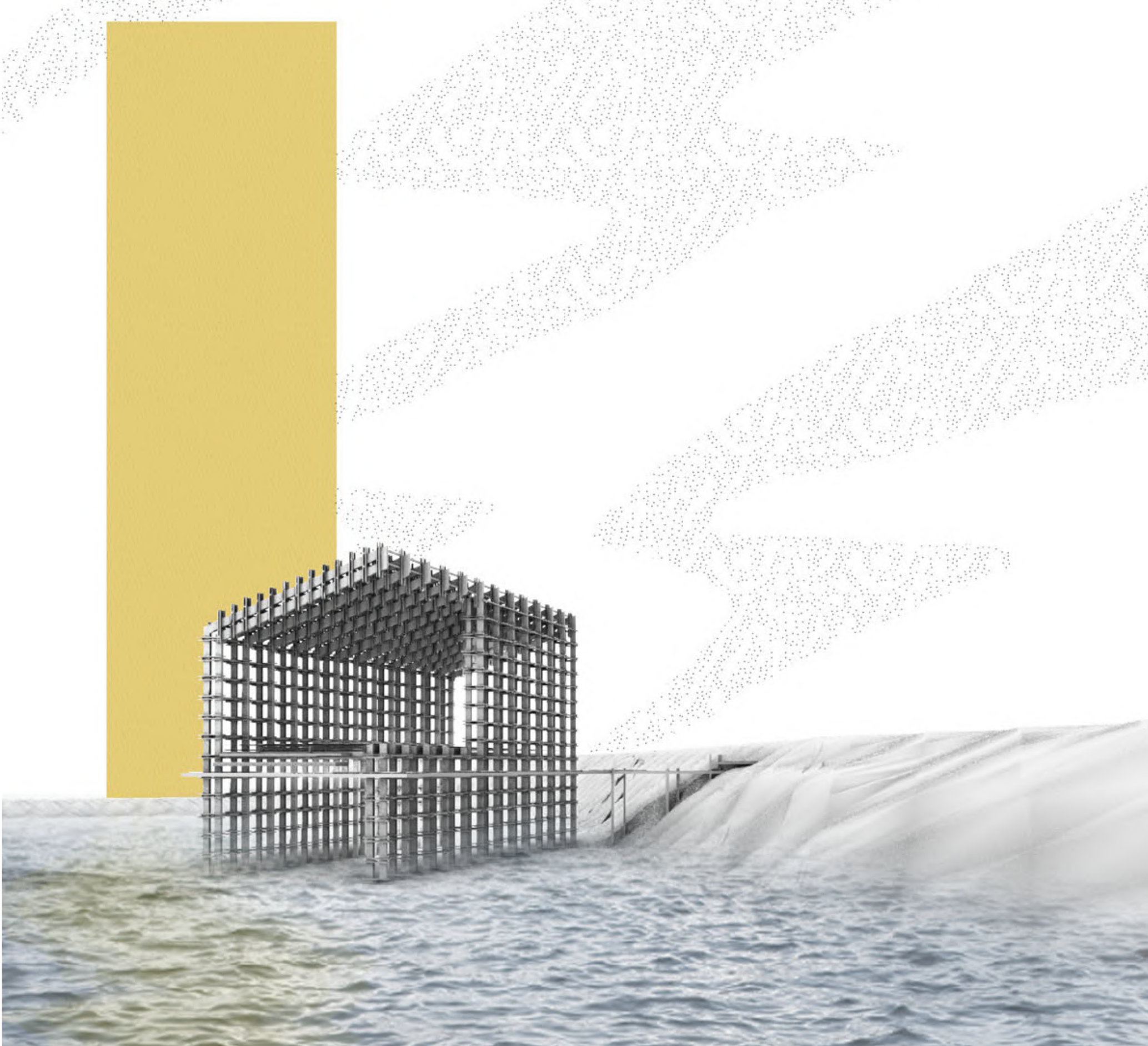




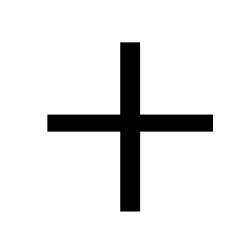

six.

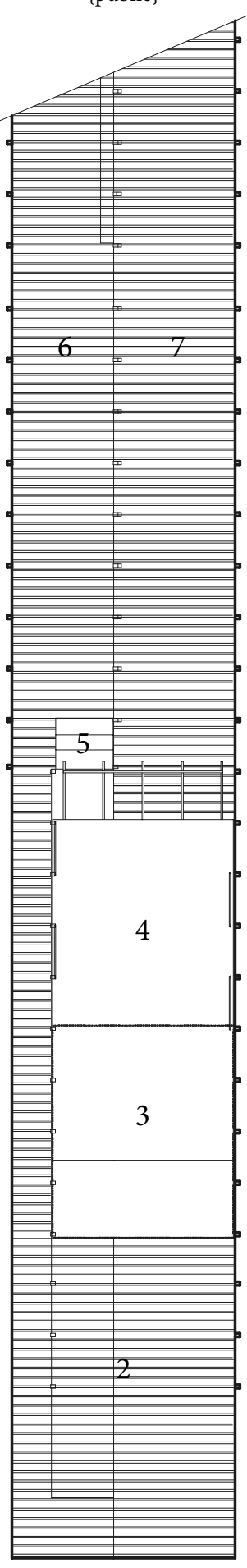

1:200

1 - stopbank

2 - wharf

3 - wharf dwelling

4 - dwelling deck

5 - stair

6 - low pier

7 - high pier

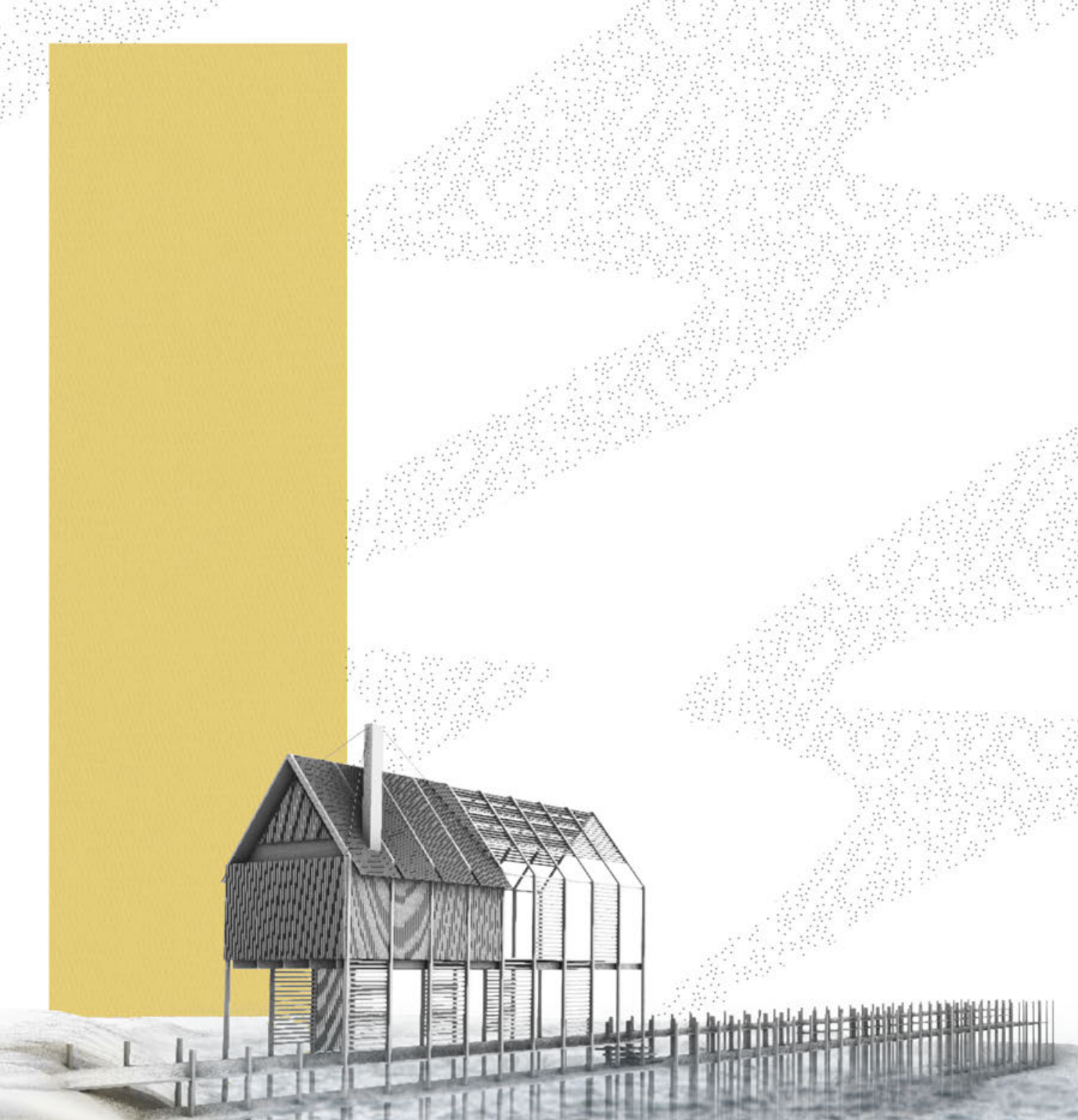


Physical Model.

developed design.

A 1:200 scale model exploring the A 1200 scale motween architecture

and site, atop a 1:20 scale model

of the timberpost structural model

with a traditional asian accent on the a traditonal asian accent on the decking joists.
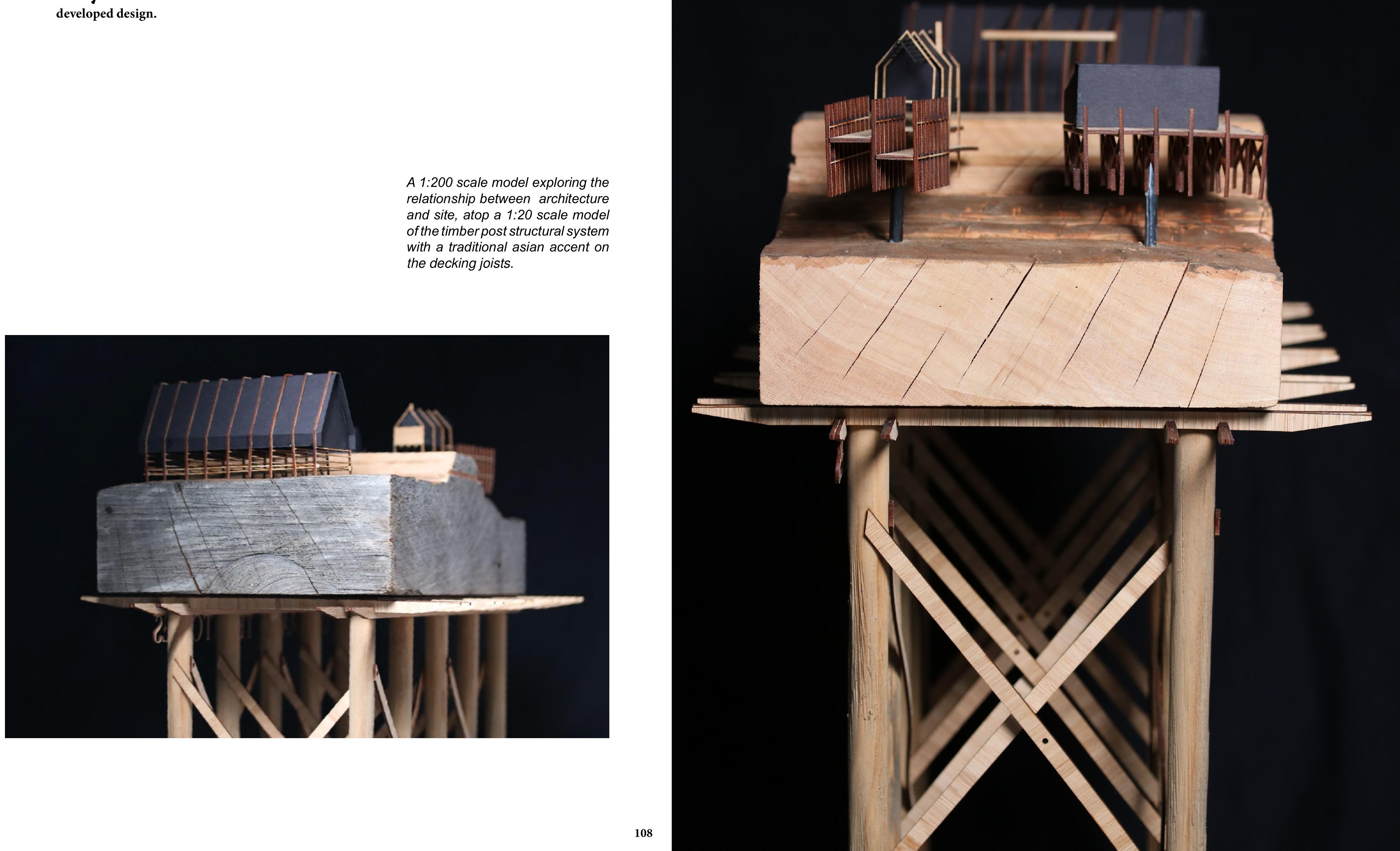

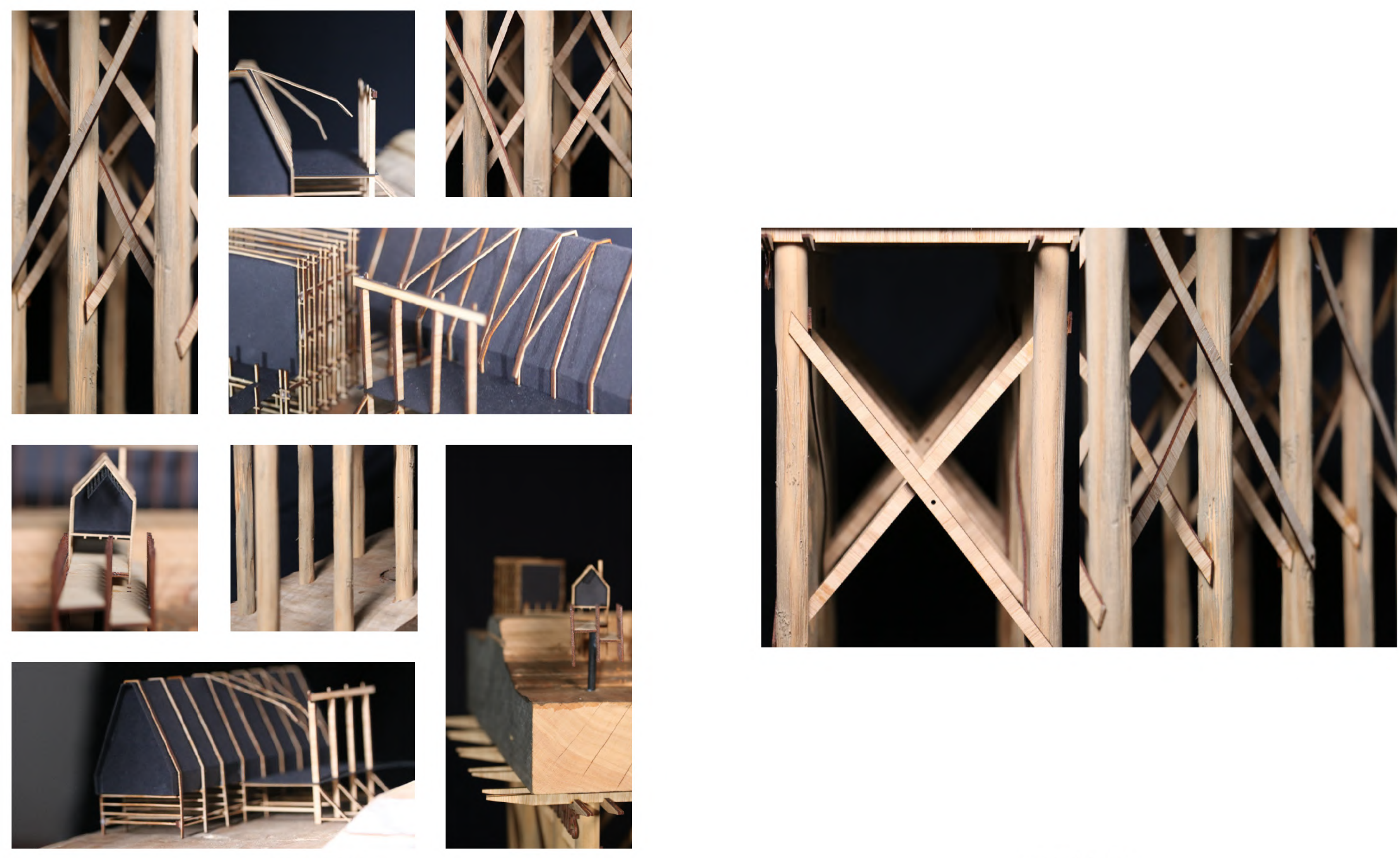

humble strength.

structural elegance. 

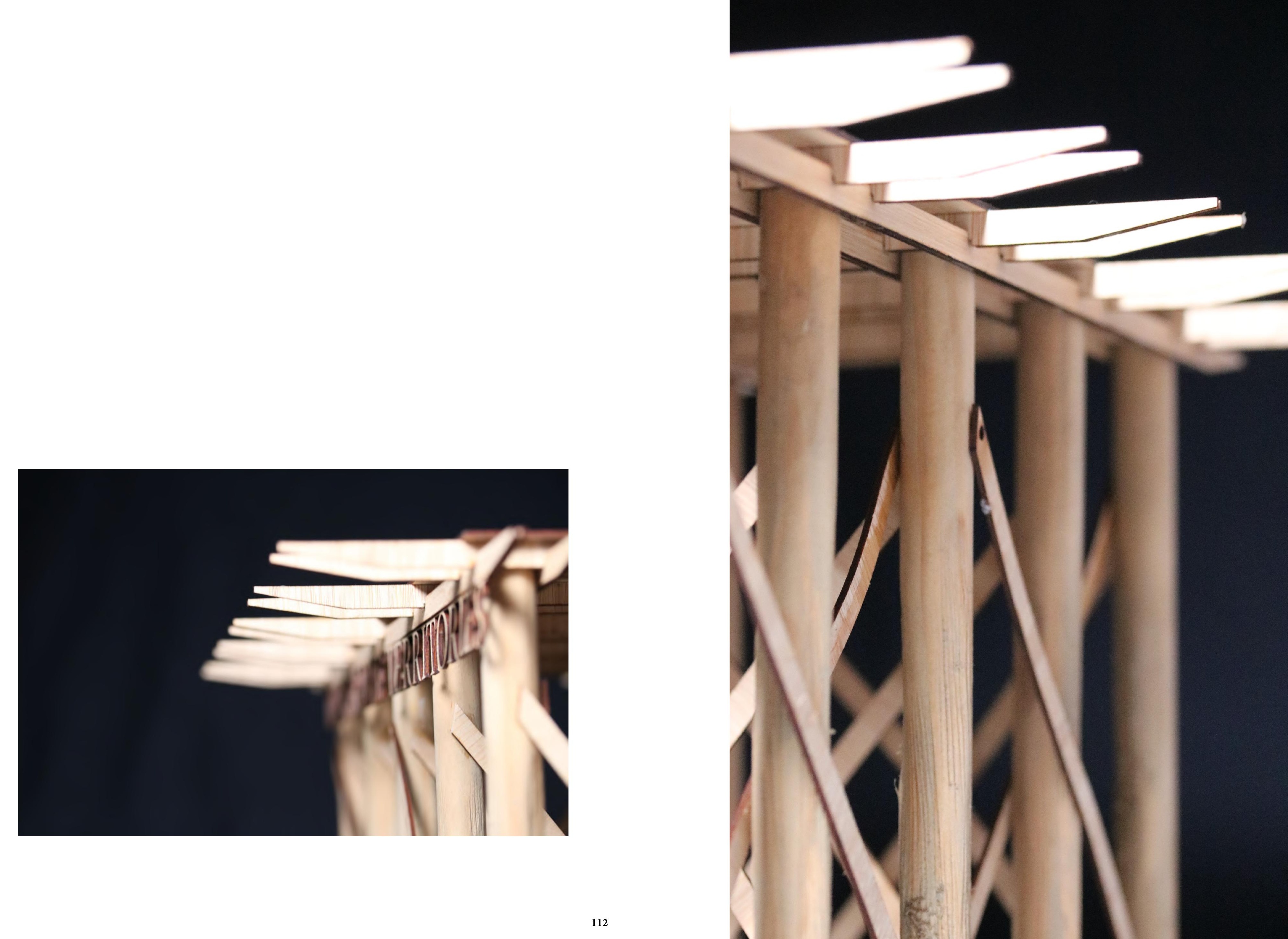


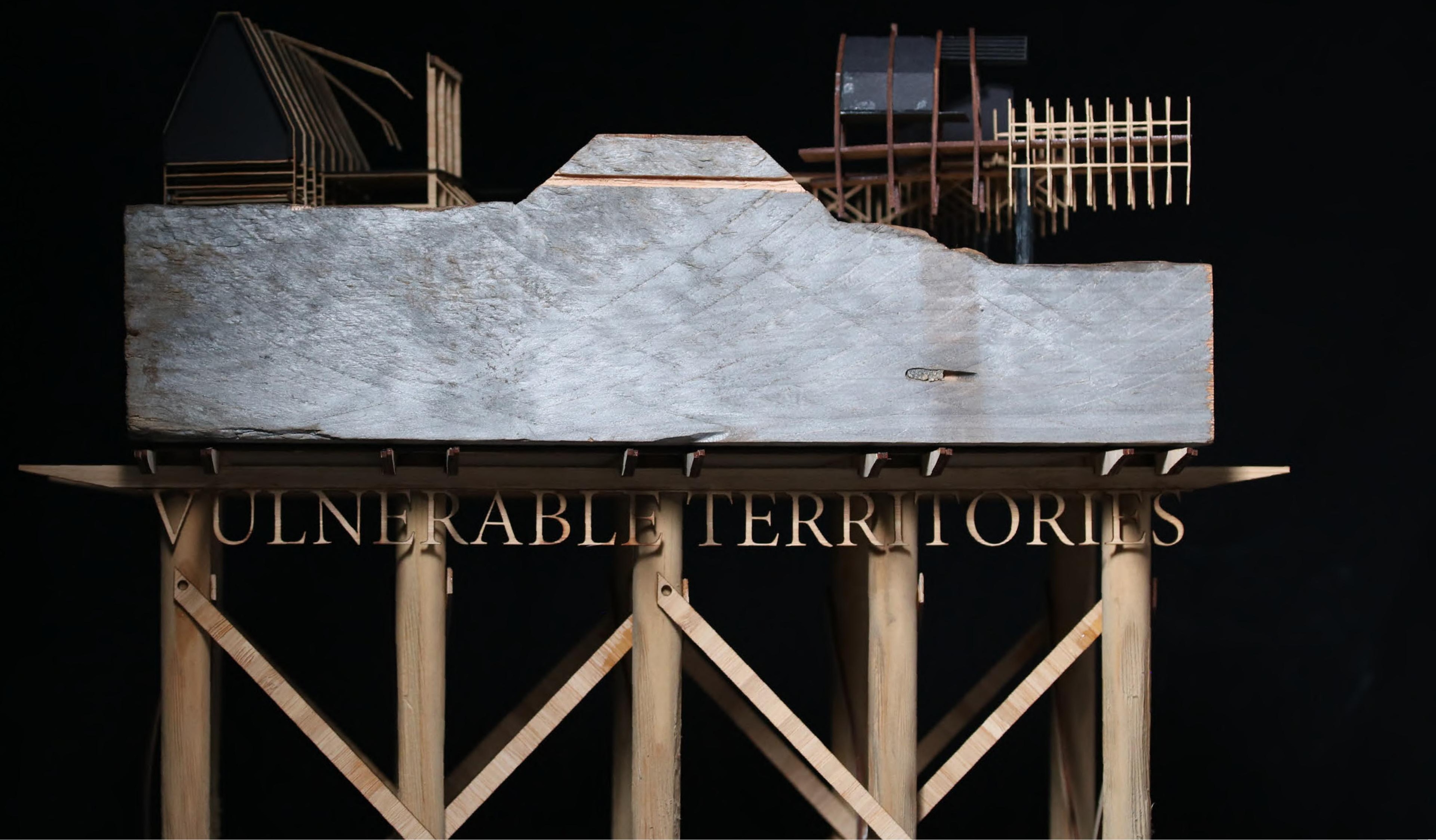




\section{Issues Arisen.}

$\mathbf{T}_{\text {his }}$

his preliminary design outcome has resulted in the design of individual dwellings that are anchored from the stopbank, structural techniques.

As segregated designs, each stands as a successful speculative intervention that positively responds to the physical design principles of site. However as they principles of site. However as they were designed individually, it has proven challenging to tie them
together.

While the physical model begins to employ the stopbank to integrate the various building together to test their potential relation, they remain detached, relying on the stopbank for any connection to each other and environment.

It has become apparent that while this design is conceivably easible and effective as individual buildings, it is when they are applied simultaneously and the stopbank is populated. that the concept essentially becomes a mere collection of private dwellings that are elevated above the ground. Most noticeably, the scheme seems to almost neglect any appreciation of the intangible design principles such as 'community' and 'sense of place' that was discernibly critica throughout the initial study of the region.

\section{Combination.}

Conceptual representation of what a potential community like design would look if the idea was continued to be developed solely relying on the stopbank.

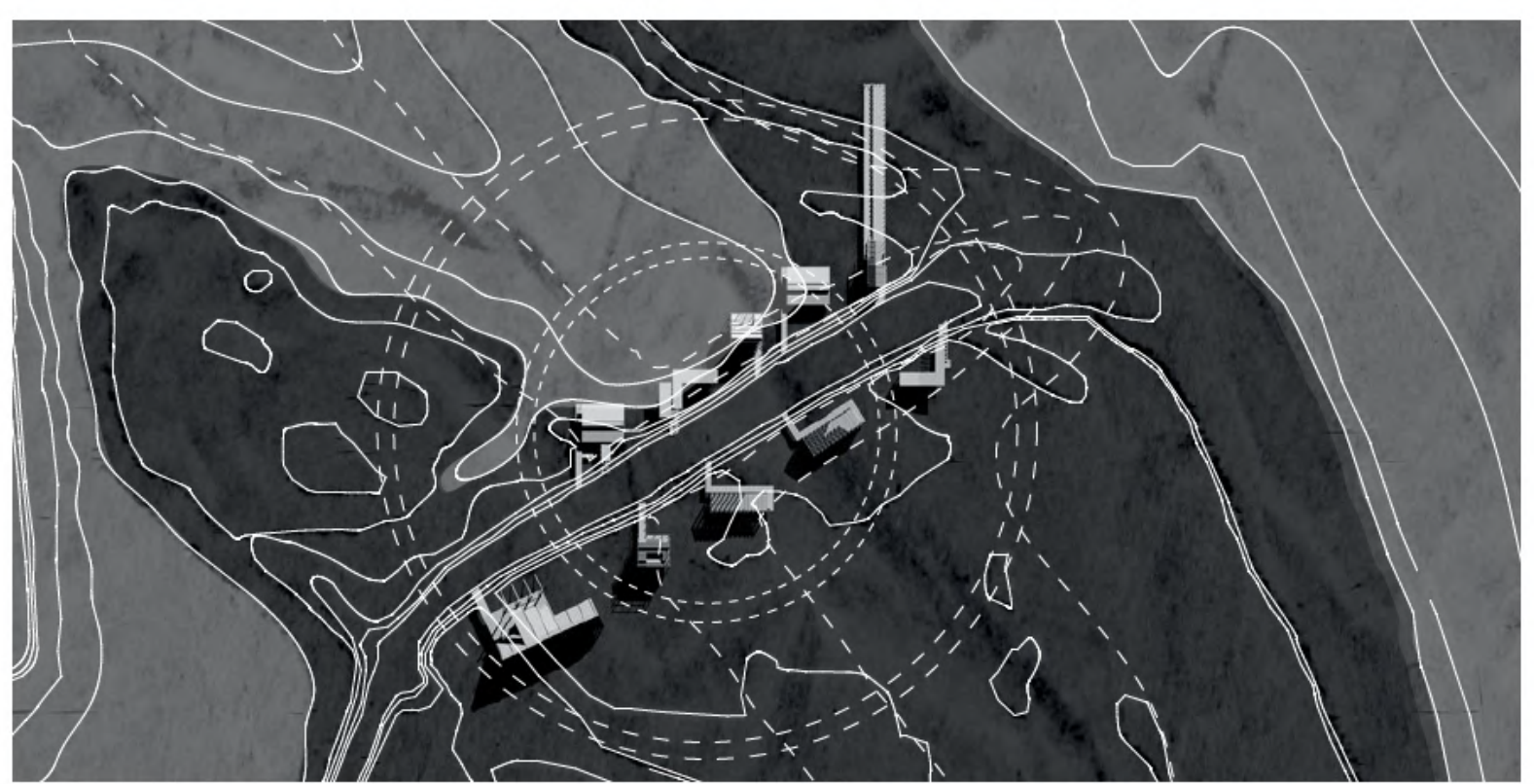

Whakataukī.

[to utter a proverb]

\section{Nā tō rourou, nā taku rourouka ora ai te iwi}

"With your food basket and my food basket the people will thrive"

T

hakataukī encapsulates the notion that while working in this design must adopt a more isolation might result in survival, significant focus on communal working together can take design outcomes, how the design people beyond survival and onto functions as a whole and how prosperity.' (Berryman \& Ford, each aspect can benefit another. 2014, p. 1)

\section{Moving Forward.}

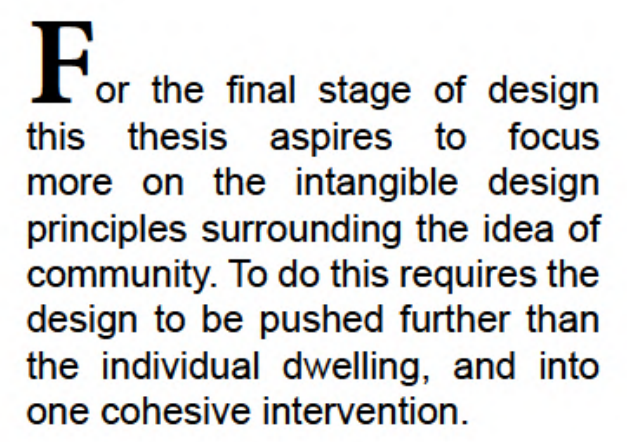



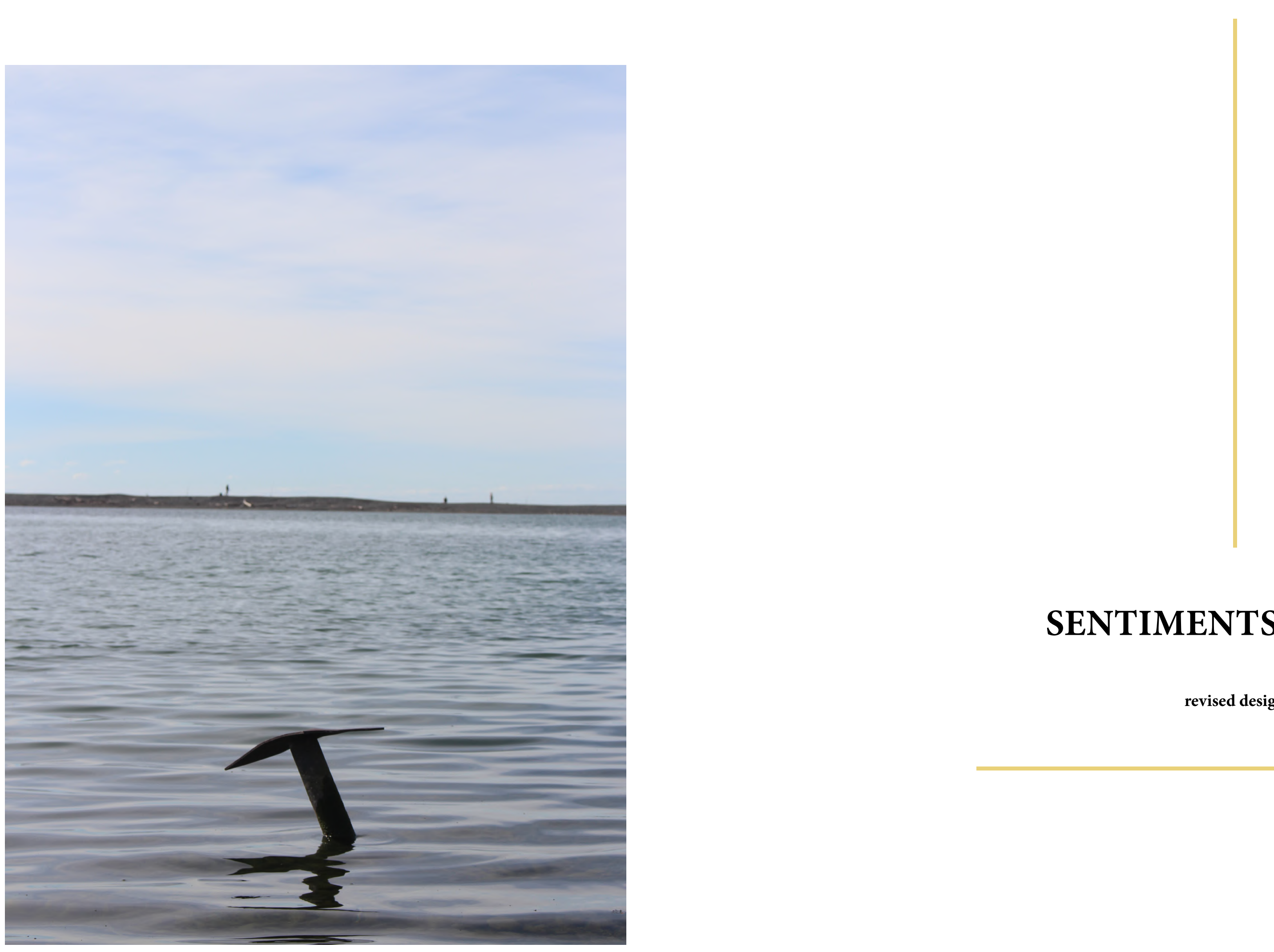

SENTIMENTS IN MAN

revised design 


\section{Introduction.}

| developed design |

\section{A}

Is established, for this design A collective design outcome has to develop further, requires it to become a more inclusive intervention. The conceptual design has relied too much on the stopbank to tie the community together, a job that this thesis argues the built environment should be responsible for.

To Achieve this, an almost entirely wharfed design, housing all community functions will be explored. The intent in doing so, is to allow the design to tackle the intangible aspects of the the intangible aspects of the community, whilst further pushing the capabilities of an architectural intervention.
A collective design outcome has and experimented with to explore A cotential to make the design the full potential of a stilted more catalytic example of community.

coastal iving, and less reliance n the stopbank that is specific to Haumoana will only reinforce this further.

To do this, the stopbank will remain an anchor for the structure of the design, but the functions of the community will not rely on rather the built environment will employ a completely stilted, herfed design to act as a vehicle or all community functions.

With the freedom of moving away from the bank, the desig also becomes unfastened by the limitations of the stopbank. As such, the scope can be increased
This chapter focuses on developing a masterplan that satisfies the established requirements of a collective design.

The chapter begins by observing and analysing existing communities that operate with similar environmental conditions.

Then, by revisiting the analysis of site with a greater consideration of a fully wharfed design that will extend away from the stopbank itself, a developed master plan that follows some of the traditional principles can be uncovered and reflected upon. 


\section{Traditional.}

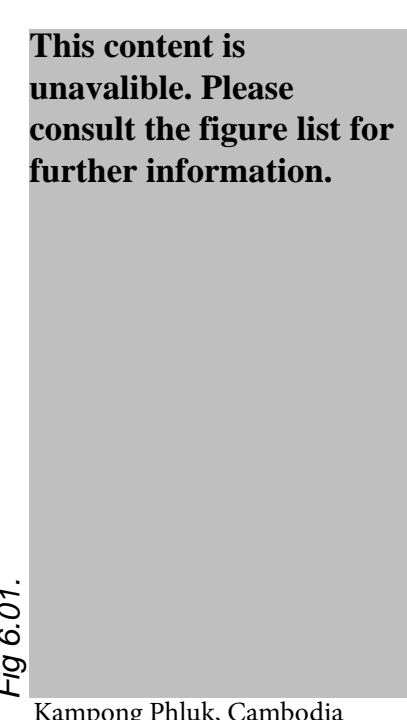

\section{Kampong Phluk, Cambo}

unavalible. Please

consult the figure list for

further information.

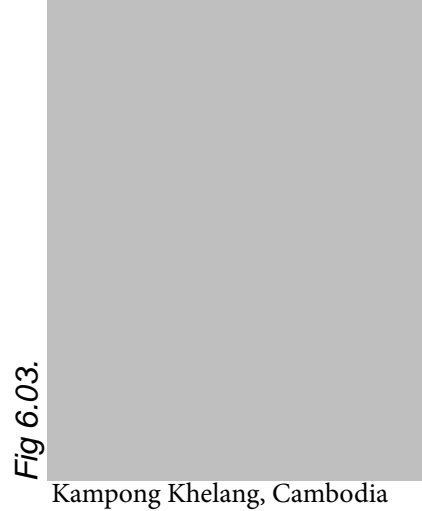

This content is

unavalible. Please

consult the figure list for

further information.

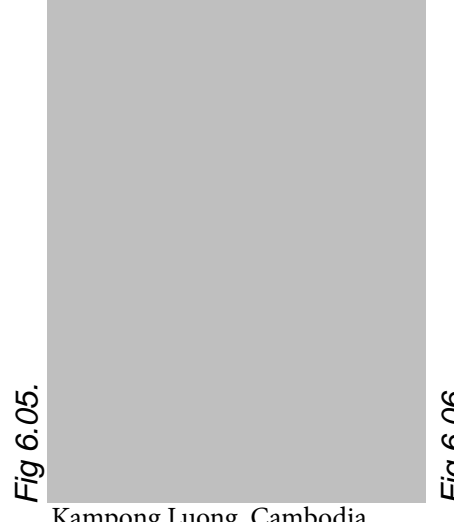

This content is unavalible. Please consult the figure list for further information.

1
8
0
0
0

This content is unavalible. Please consult the figure list for further information.

1
0
0
0
$i$

This content is unavalible. Please consult the figure list for further information.

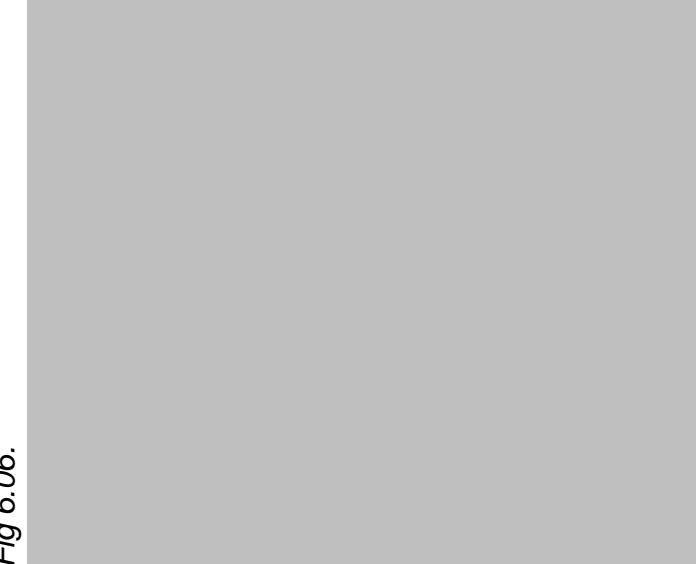

\section{Traditional.}

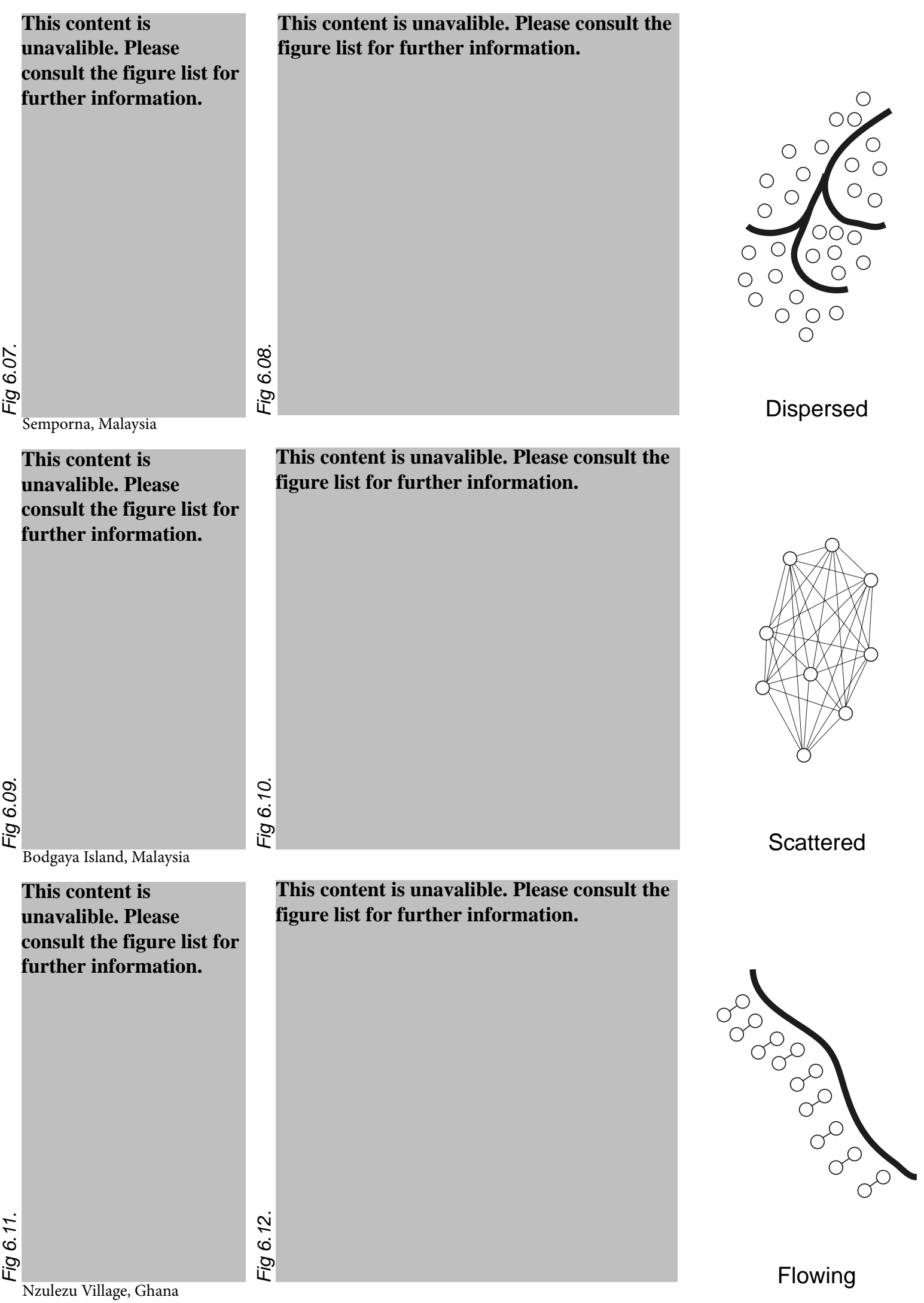

Fanned

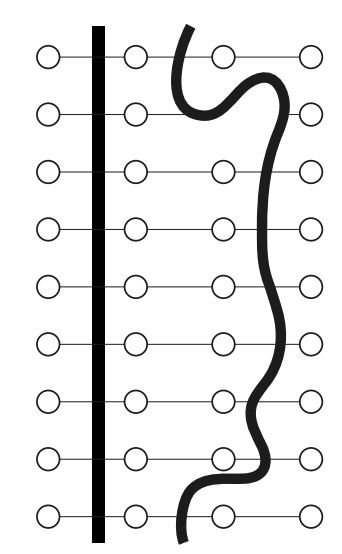

Symmetrical

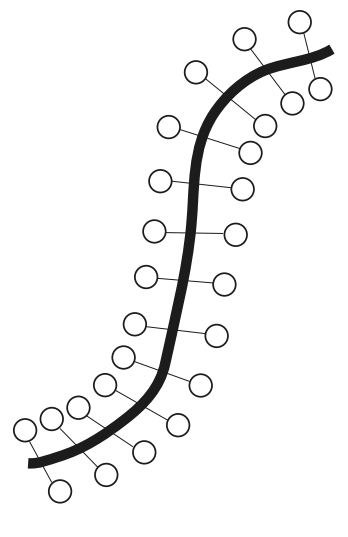

Splayed

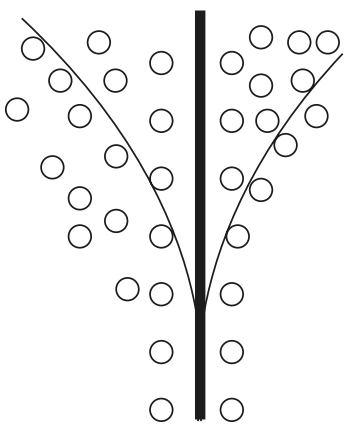

Nzulezu Village, Ghana 


\section{Master Plan.}

Key Site Condition
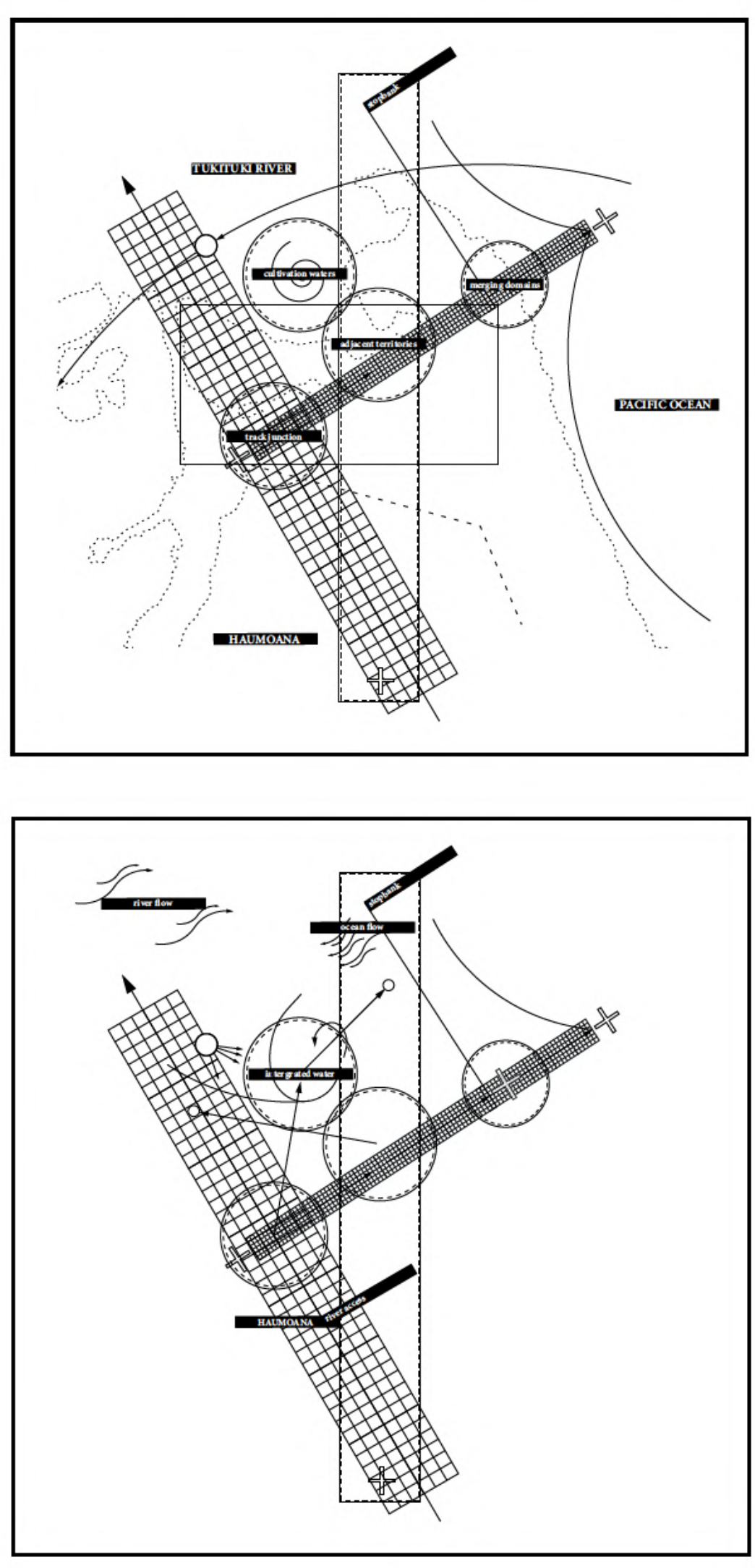

In discovering that the initial strategy of solely building off of the stopbank was inadequate for the scope of what this thesis aims to achieve, and that expansion is necessary. It broadens the potential impact that humans have on the natural environment and vise versa. Architecture will and vise versa. Architecture will whether that impact will be whether that impact will be of positive nature, or negative.

To begin with, it is necessary to re-visit the analysis of site with a larger design concept in mind. With the intent outlined to expand the scheme into a predominantly wharfed intervention, much more of the aquatic environment will be utilised, and this analysis intends to uncover the optimum method of doing so.

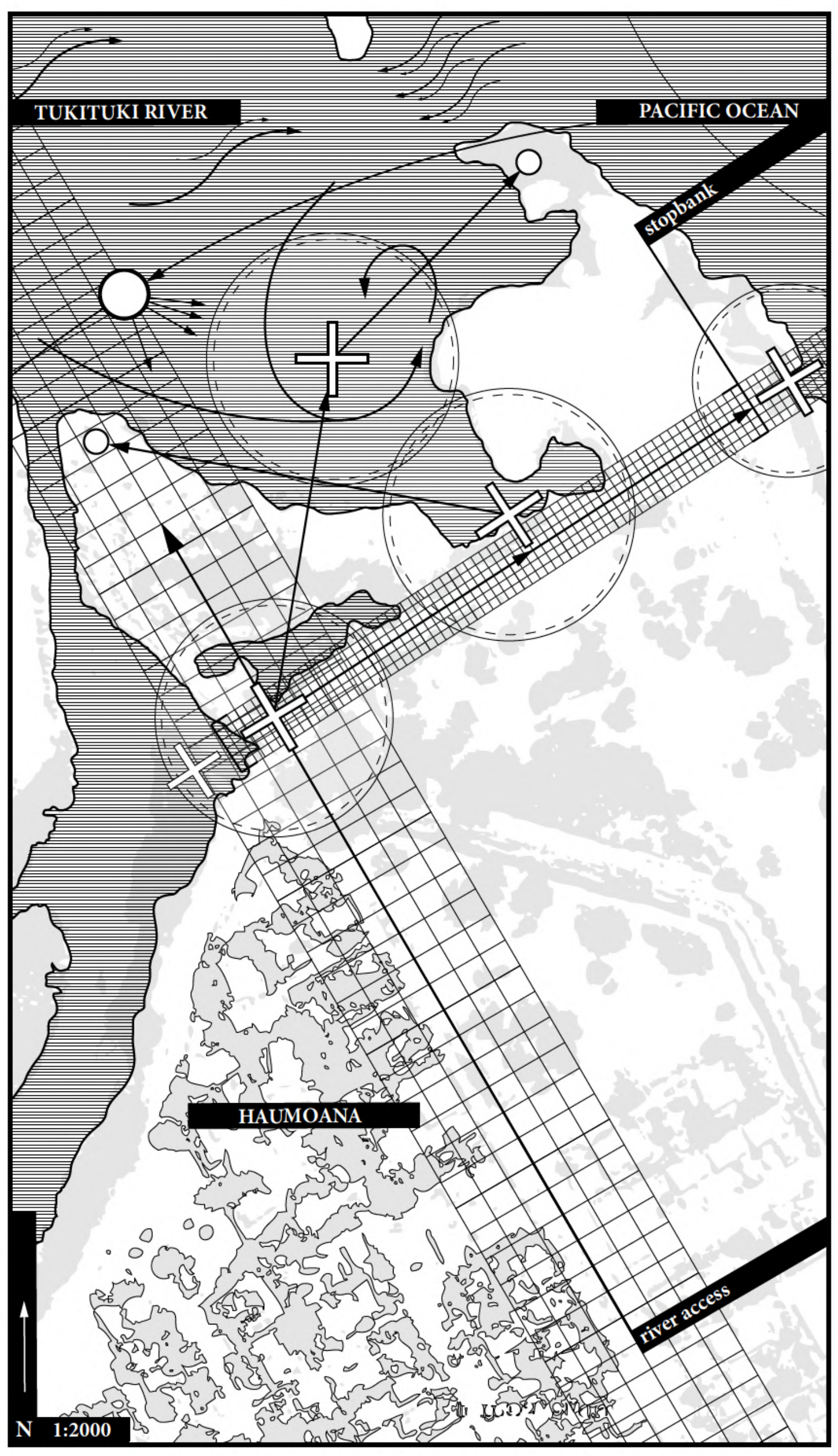




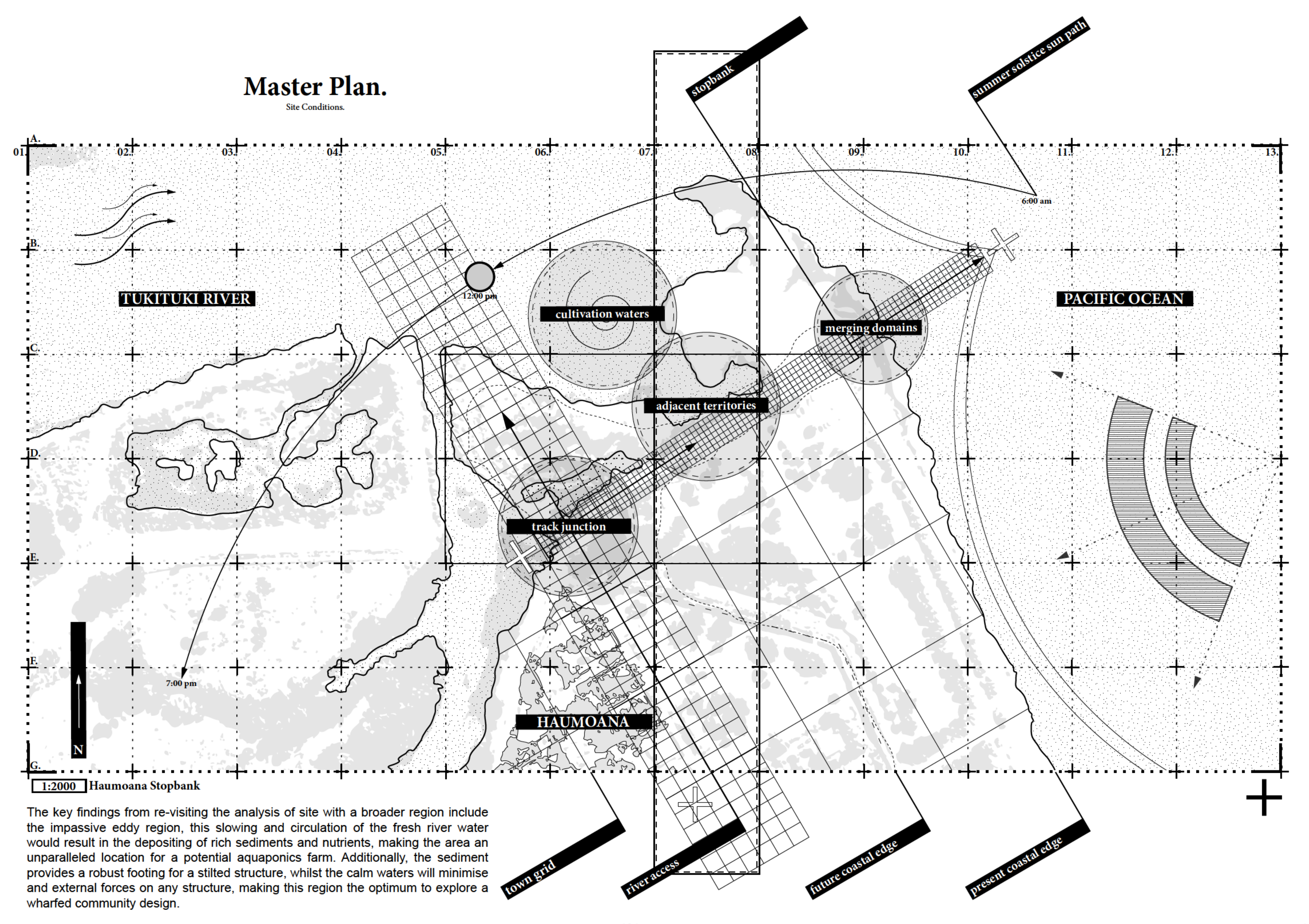




\section{Master Plan.}
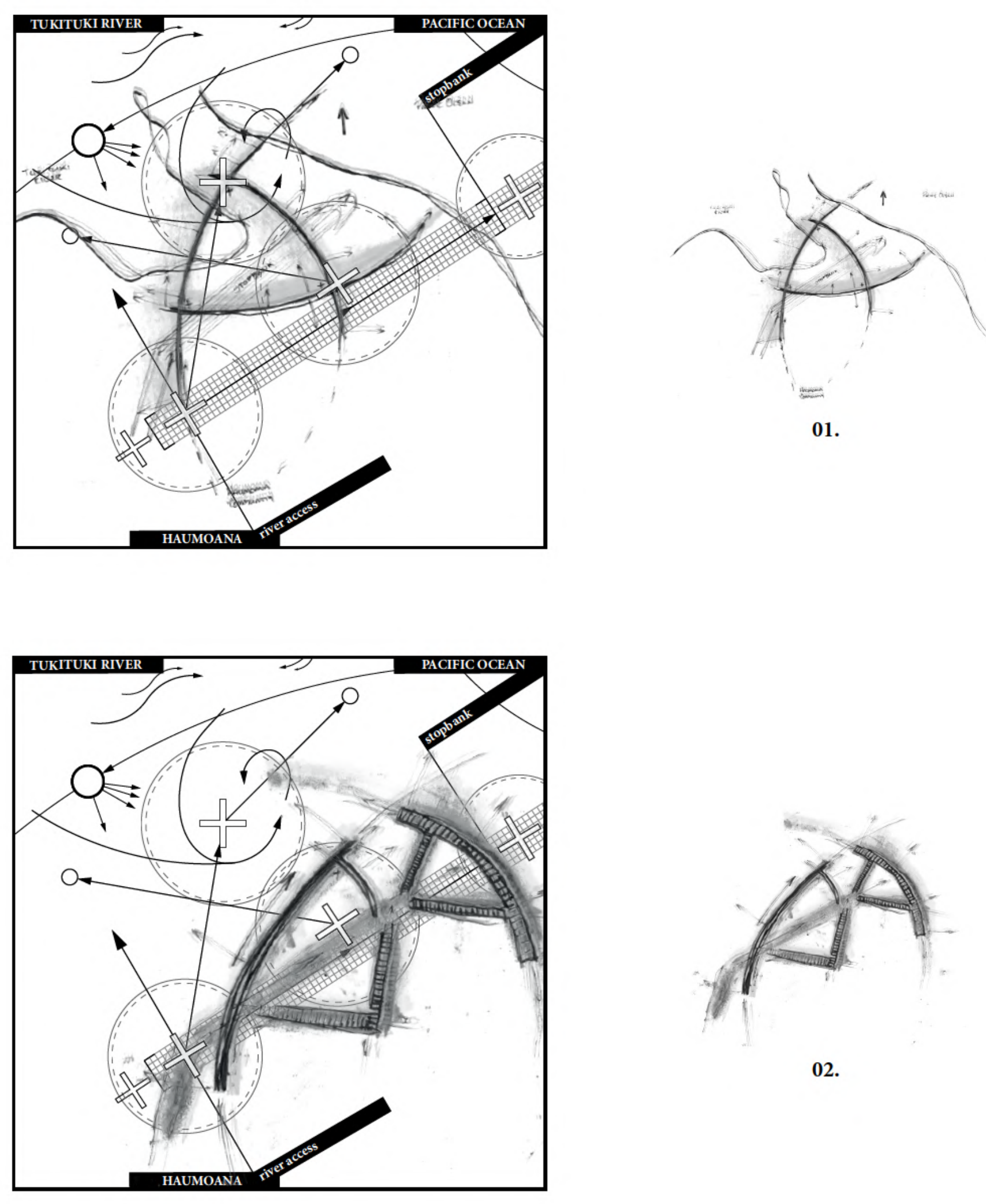

02.

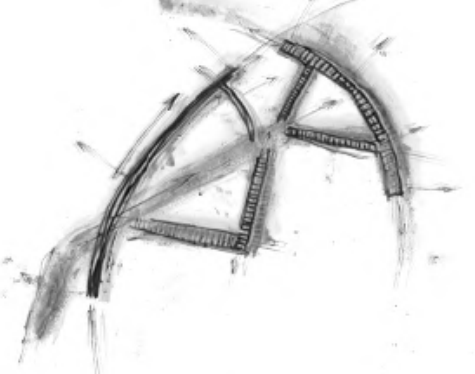

The arm and stopbank act as focal points that emphasise directionallty, they will become passage ways to the various communal functions branching off.
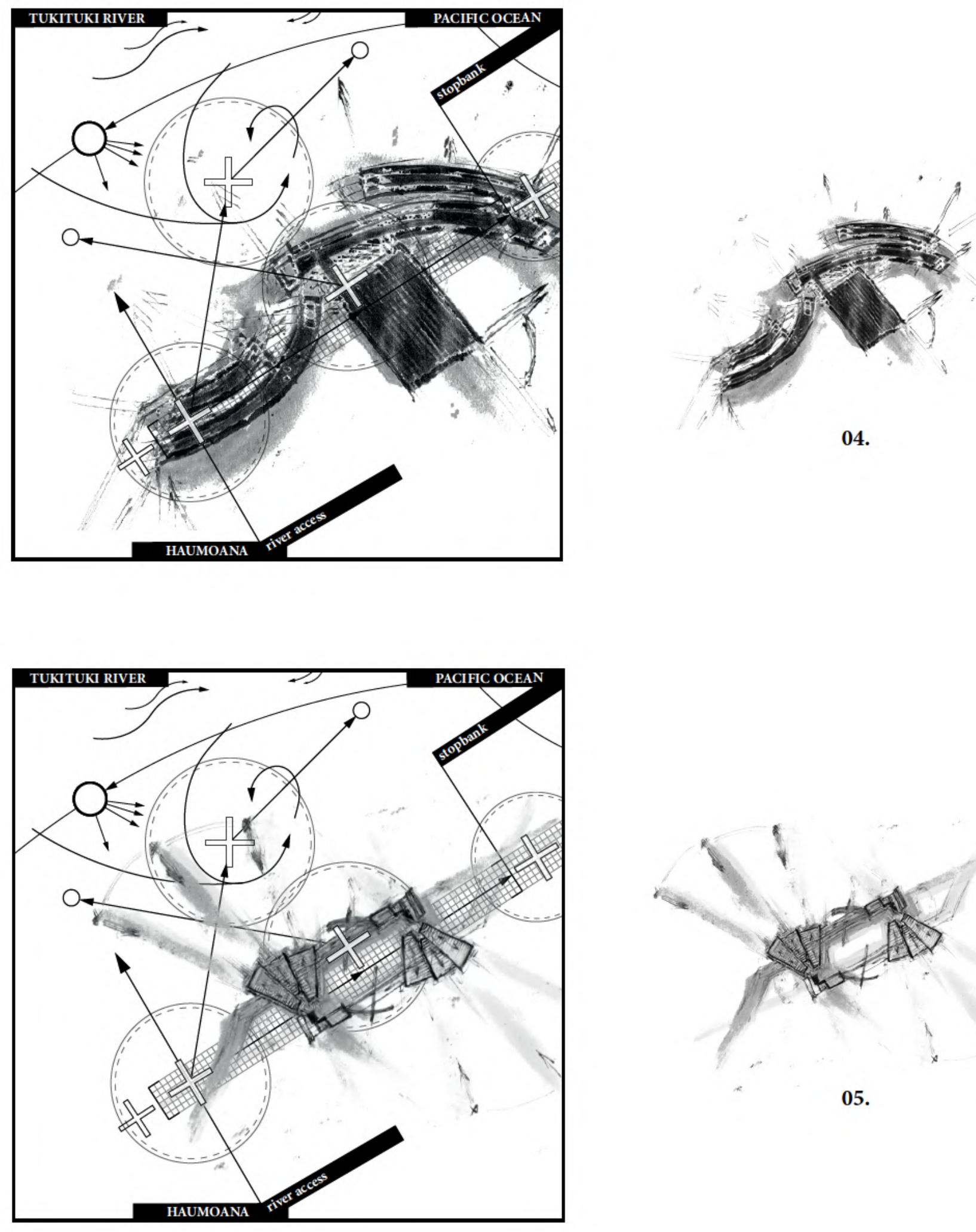


\section{Master Plan.}

Developed Wh
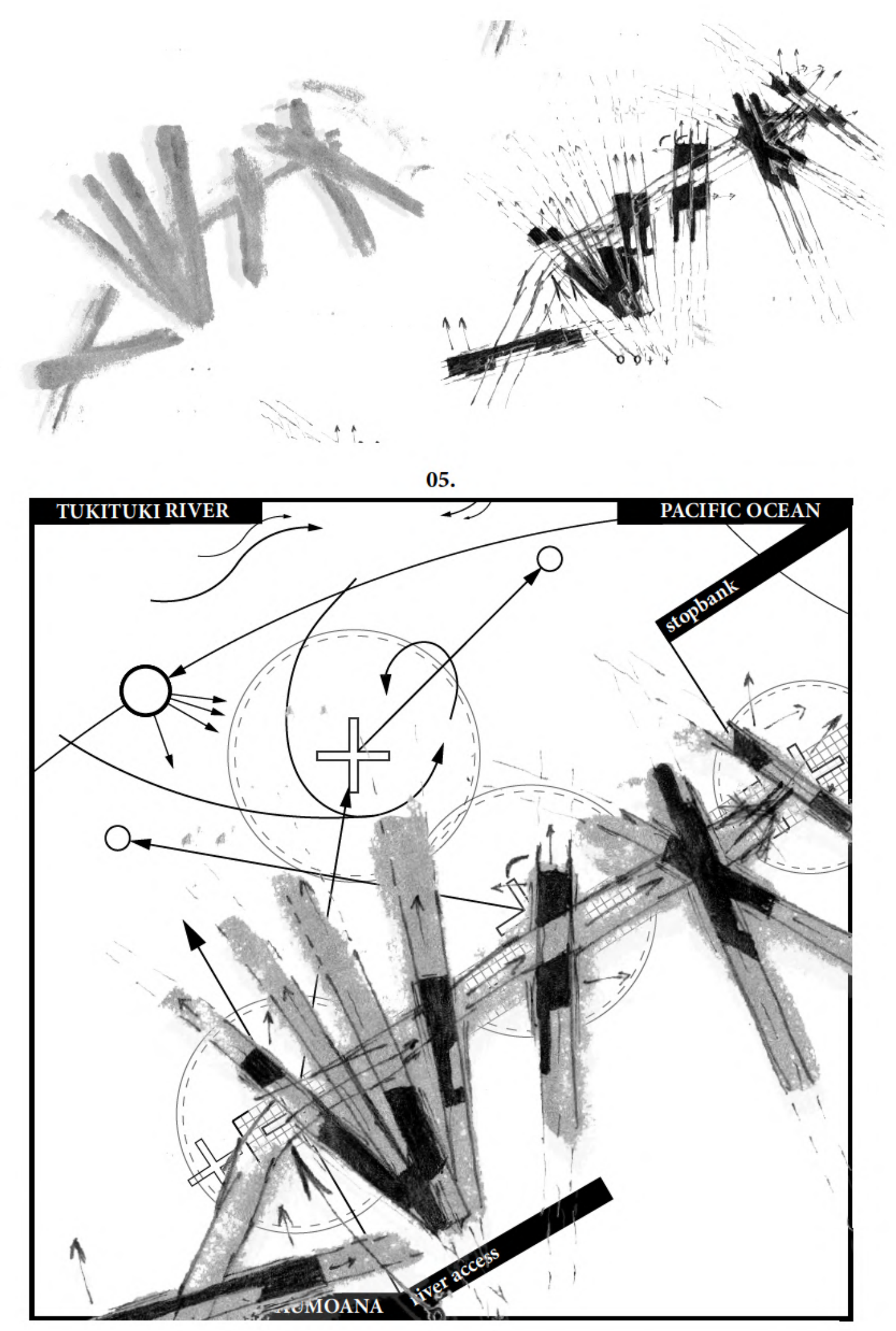

A large sweeping arm intersects the stopbank while gently connecting the existing Haumoana community with both the river and the ocean.
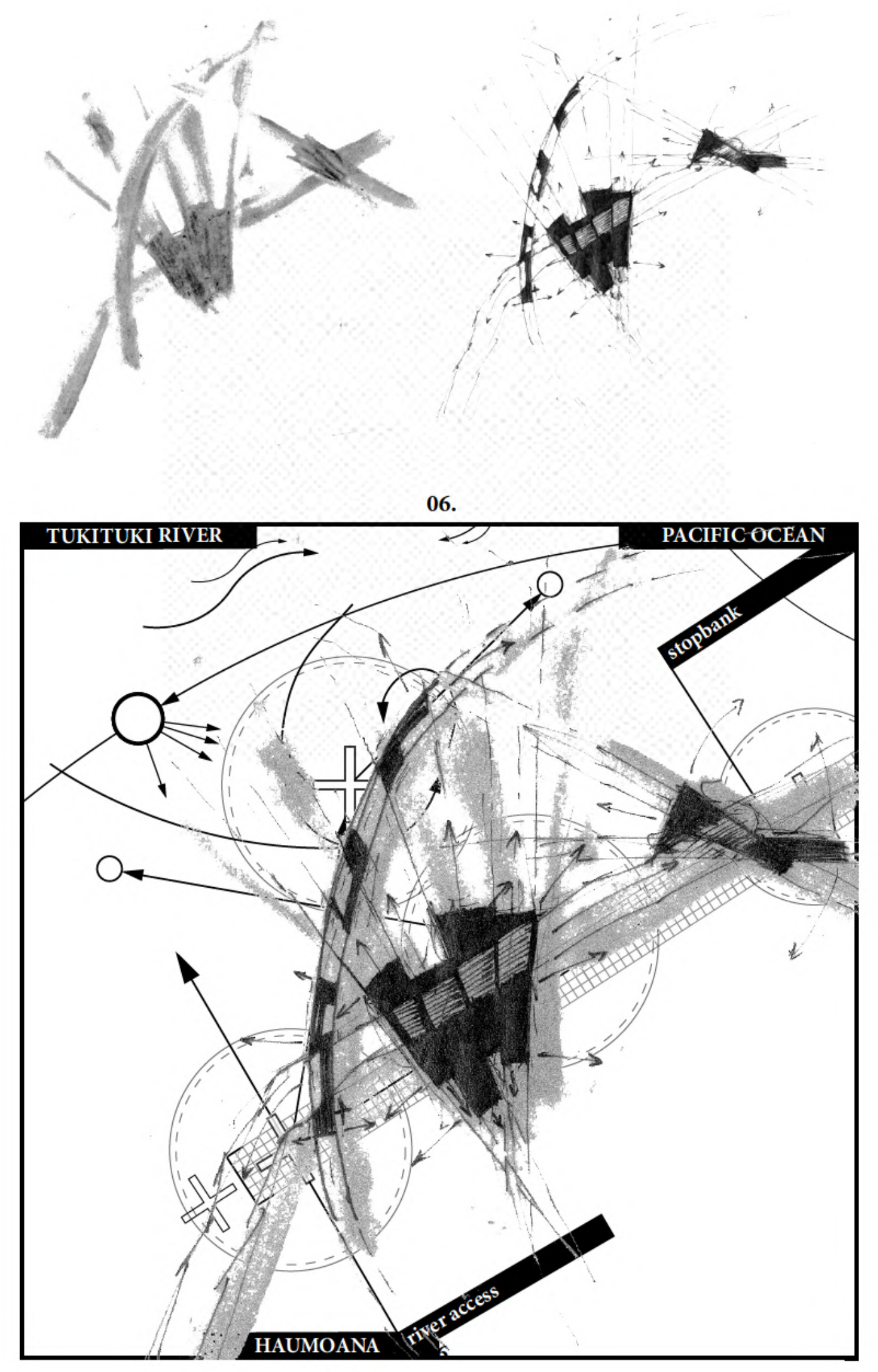
Master Plan.

$100 \quad$ Developed Wharf Design.
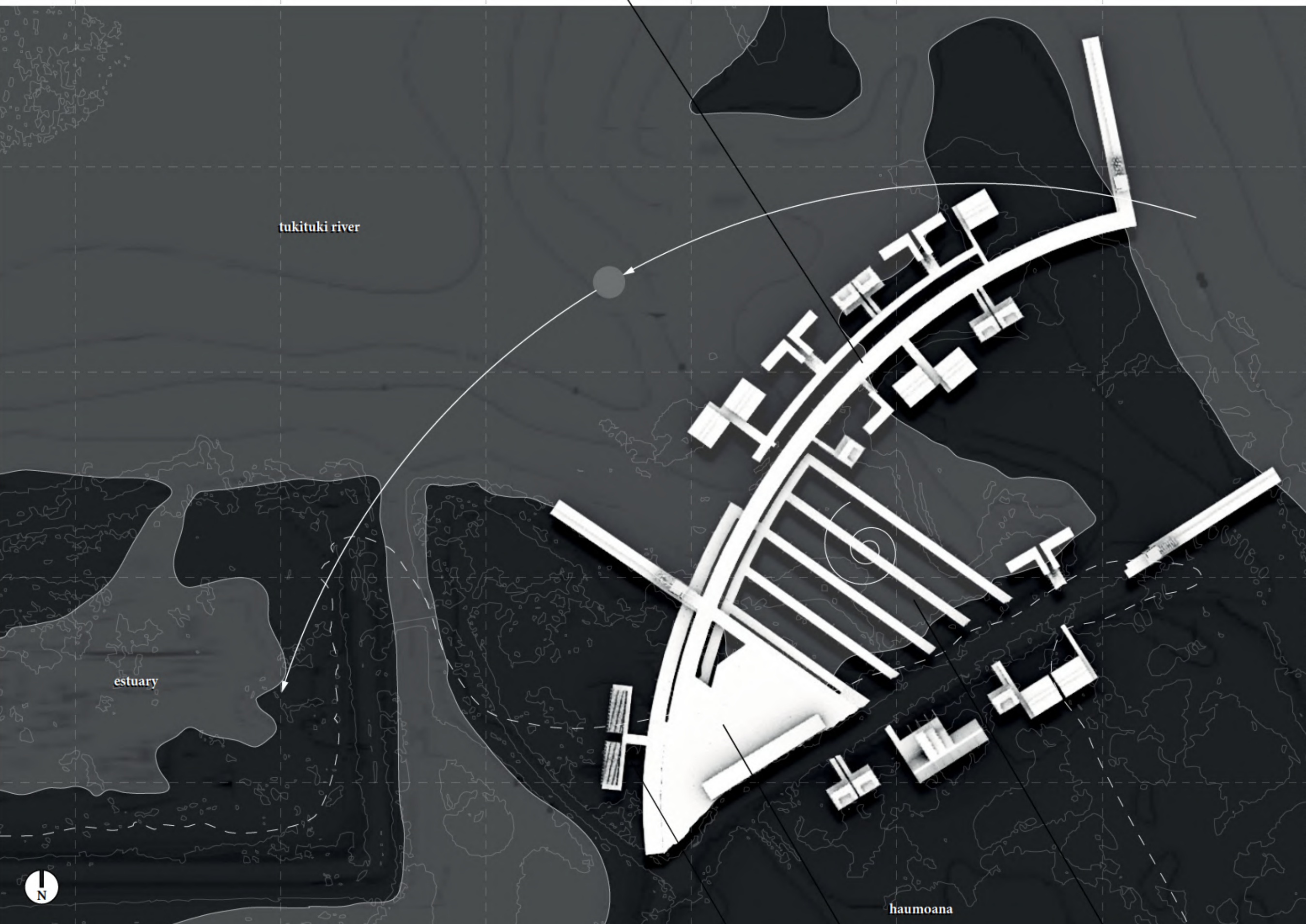

Progressing into the digital medium of 3D modelling, allows the conceptual sketches to attain further authenticity. It is here, where scale is explicit, that design gains groundedness and potential feasibility.
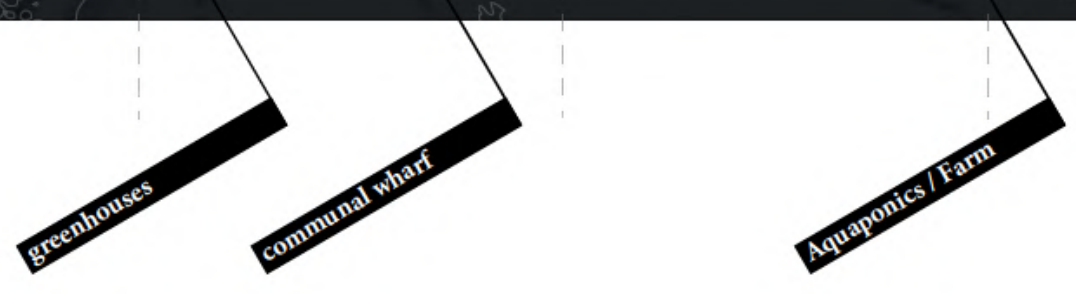


\section{Draft Atmospherics.}

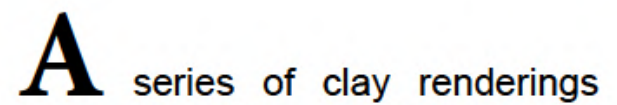
of the developed wharf layout exploring how the potential design functions as a working community, how it sits on site and impacts the surrounding environment, and

what the interventions would feel like from the view of the inhabitants.
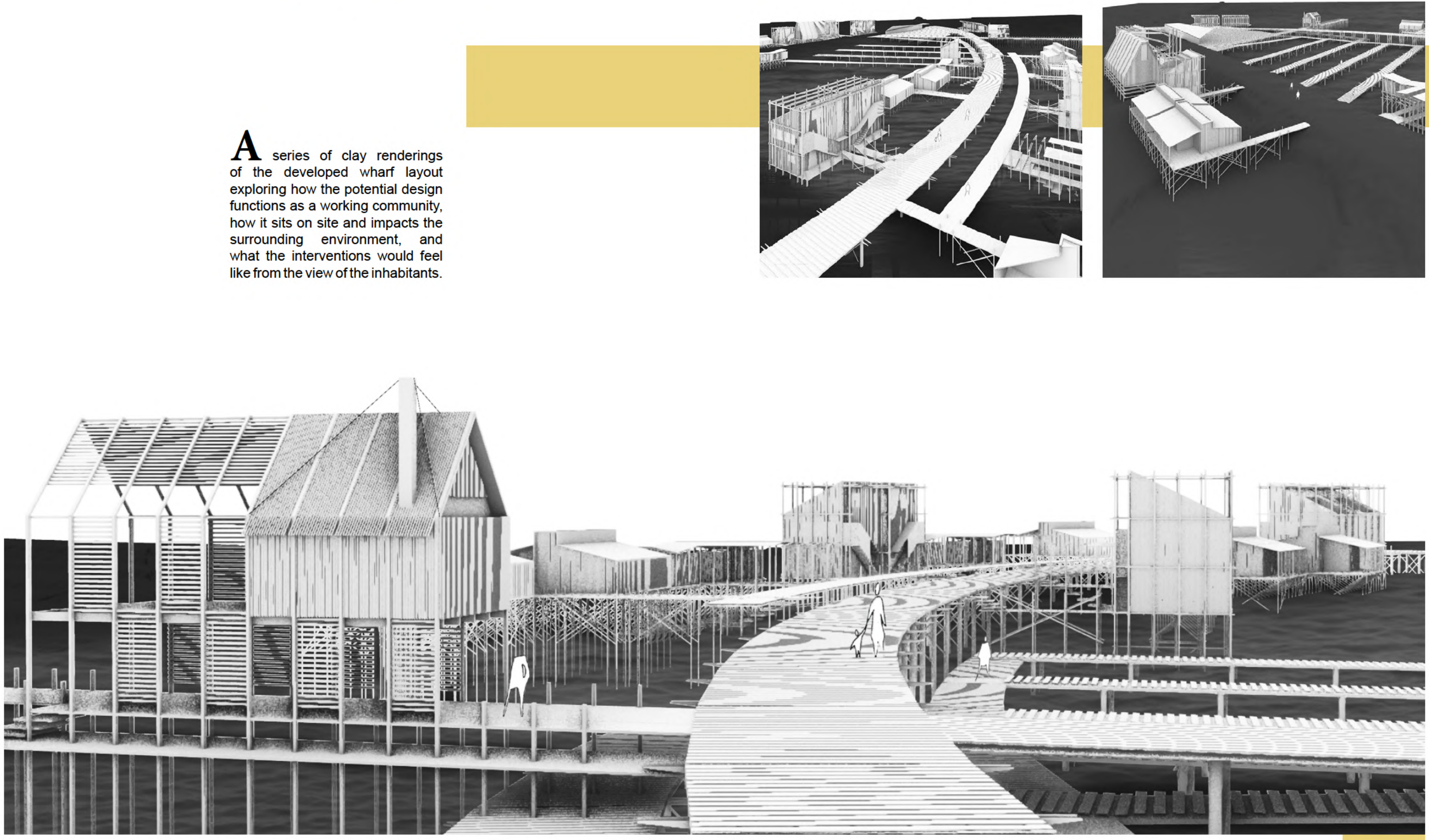

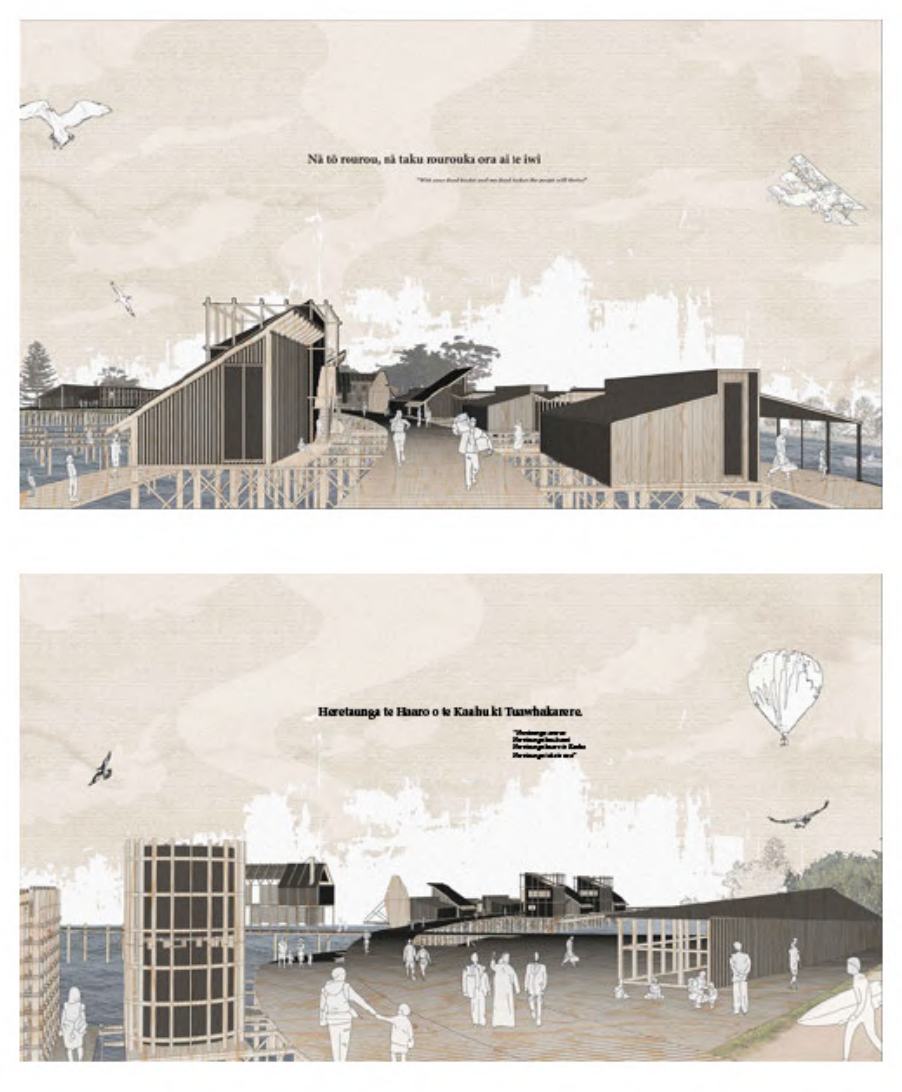

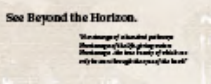

Fint

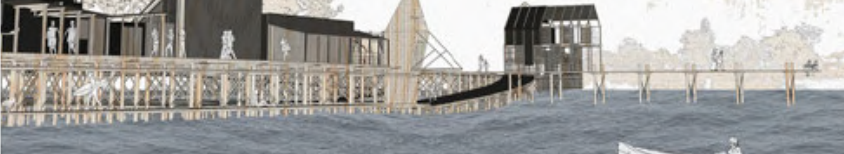

\section{OF THE ENVIRONMENT}

final design 


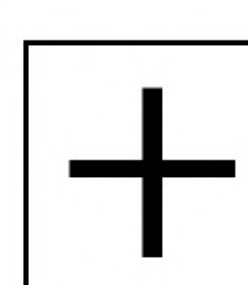

"The building is not an object, screaming for attention. It allows the environment to shape the experience with the building and at the same time the building shapes the viewer's new interaction with the environment. It is mutual and not exclusive. This building is not a didactic structure; it seem to be of the environment rather than in contrast to the environment. This is the in-between; a building that is both aware of the natural and the built form. There is a complexity that is inherent in this type of relationship

\section{Introduction.}

| final design |
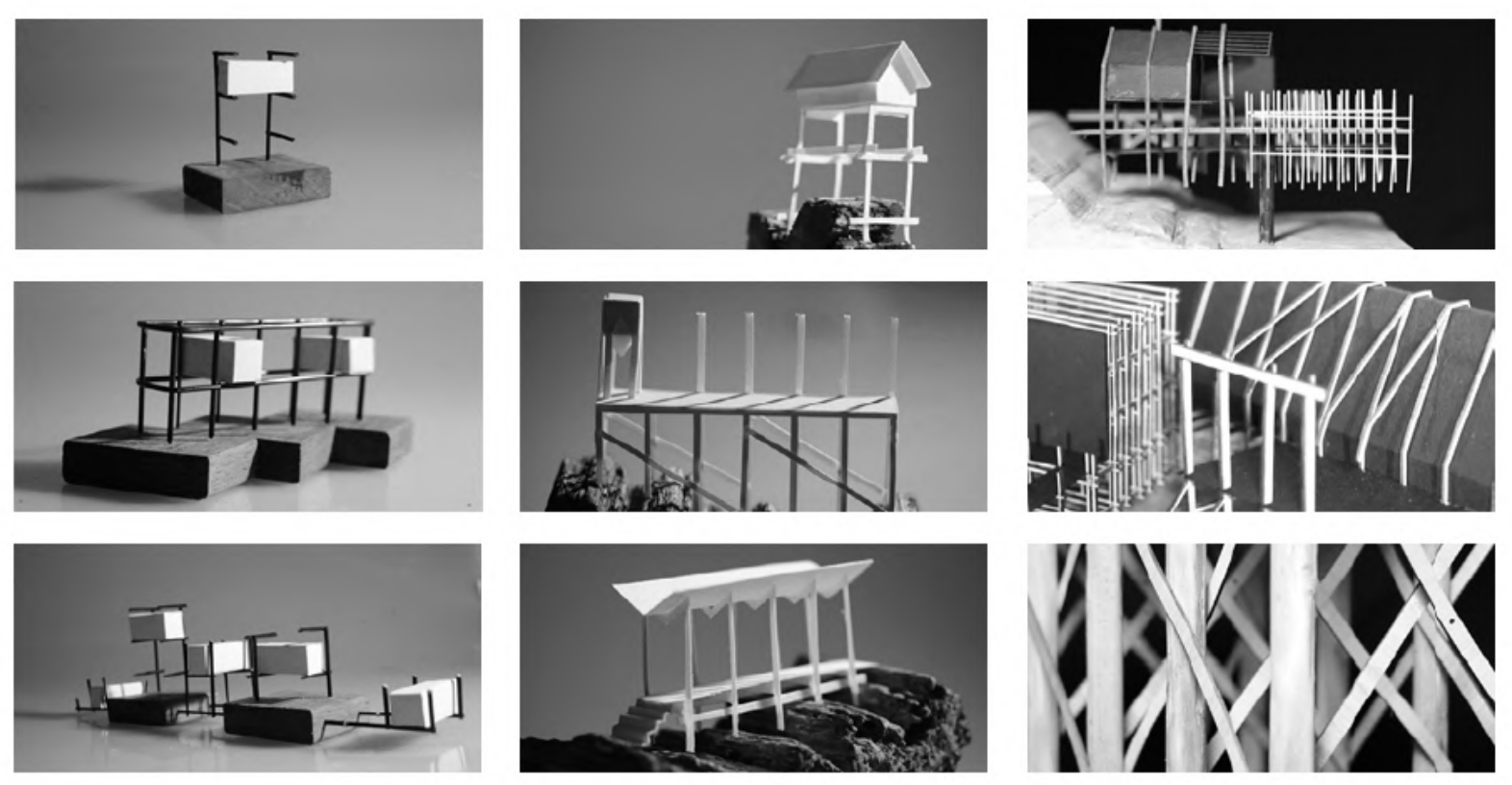

$\mathbf{T}_{\text {ne }}$

1 he final design for the To make this possible, the Haumoana community is design has adopted the stilted expressive of the values technique that was initially applied of the region, it utilises the to individual buildings, and built environment as a tool expanded upon this to explore the to strategically integrate the potential of elevating a common relationship between humans and wharf platform that buildings and nature, whilst the product of its community functions can operate response directly addresses the atop of.

natural hazards prevalent on site.
This chapter explores the macro, meso and micro scales of the intervention, reflecting the final outcome against the principles that have been established throughout this thesis. 


\section{Final Master Plan.}

$\mathbf{A}_{\mathrm{t} \text { the macro scale, the design, }}$ curving with the flow of the river, sits delicately on the site embracing all aspects of its locale. Elevating the design assures maximum liveability without interrupting the natural processes of the river below.

The most robust part of the design, is the large open platform at the base of where the wharf structure and the stopbank meet. This is the most protected region of the site and as such, is home to the community buildings and amenities.

Being contained between the stopbank, gravel barrier, and the structural members of the promenade the aquaponics / aquaculture farm sits low to the water and consists of four long piers overtop of the calm, nutrient rich waters of the river.

The dwellings exploit the true beauty of the coastal edge, they embrace the northern sun while having direct access to the waters below. Protected by the gravel barrier beach, with an incredible view over Hawkes Bay, the undoubtedly redefine the definition of und coastal living.

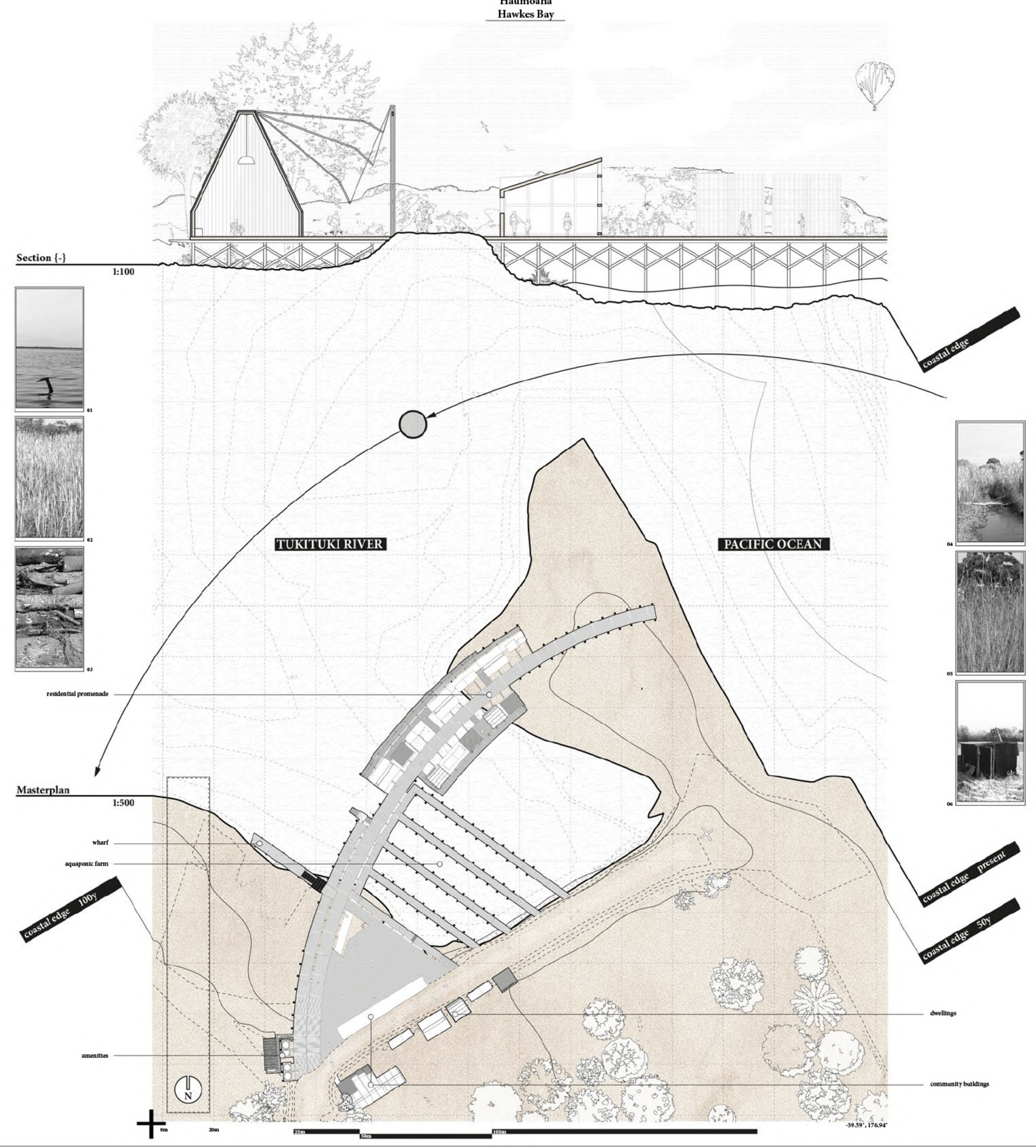


Buildings

Acollection of dwellings, amenities and community buildings that house all the basic functions of the community. They are all of simple form and minimal footprint, ensuring they are easy to install or ensuring they are easy to install or remove. The external dimensions are designed witht he structural dimensions in mind to fit atop the marine poles perfectly, preserveing stability and interchangeability.

wharf acts as a base A simple and efficient arrangement platform that connects all of of marine poles with a traditiona the buildings and intergrates Asian joist profile.

\section{Exploded Isometric.}

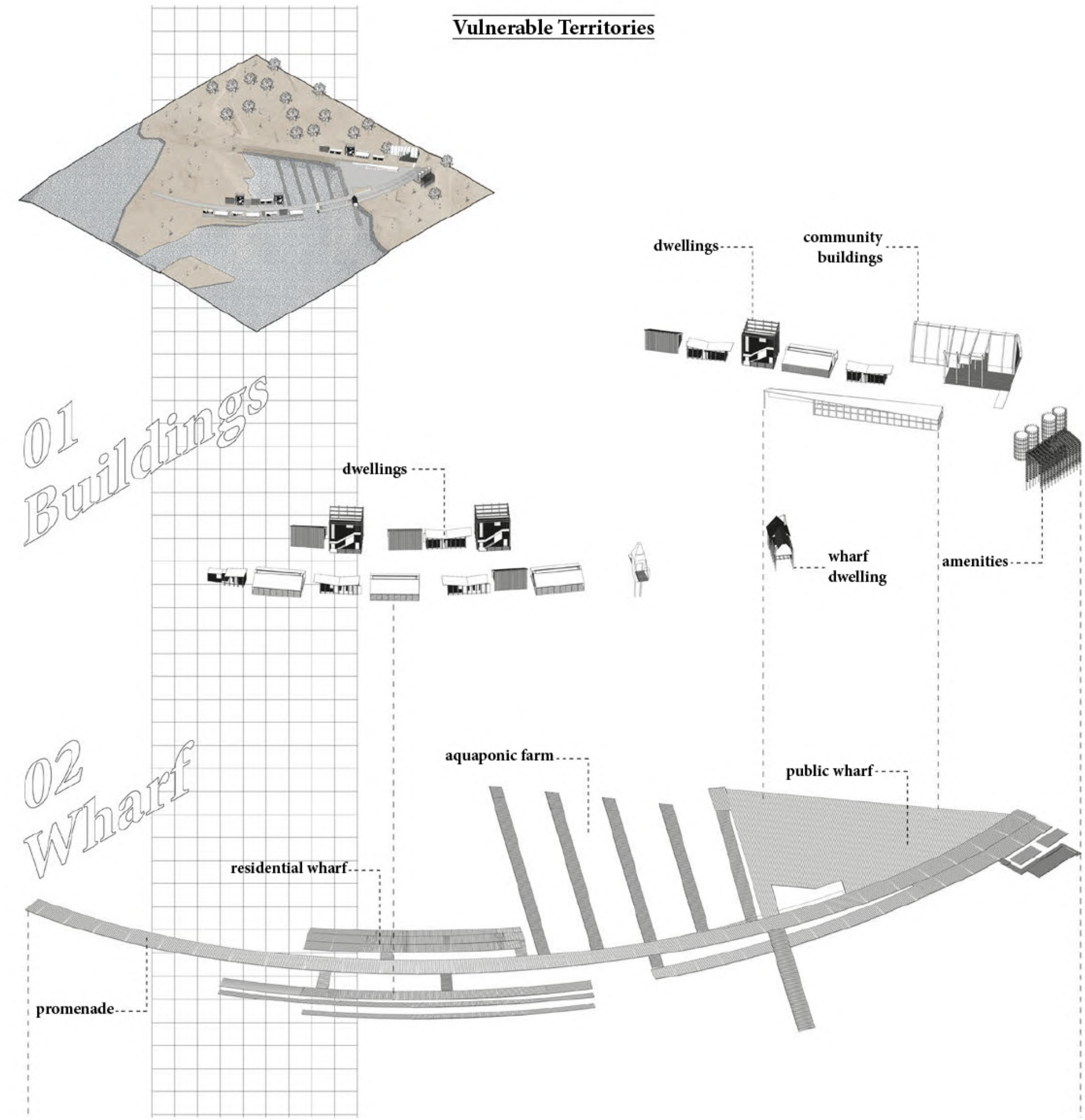$$
\text { need for digging or foundations. }
$$

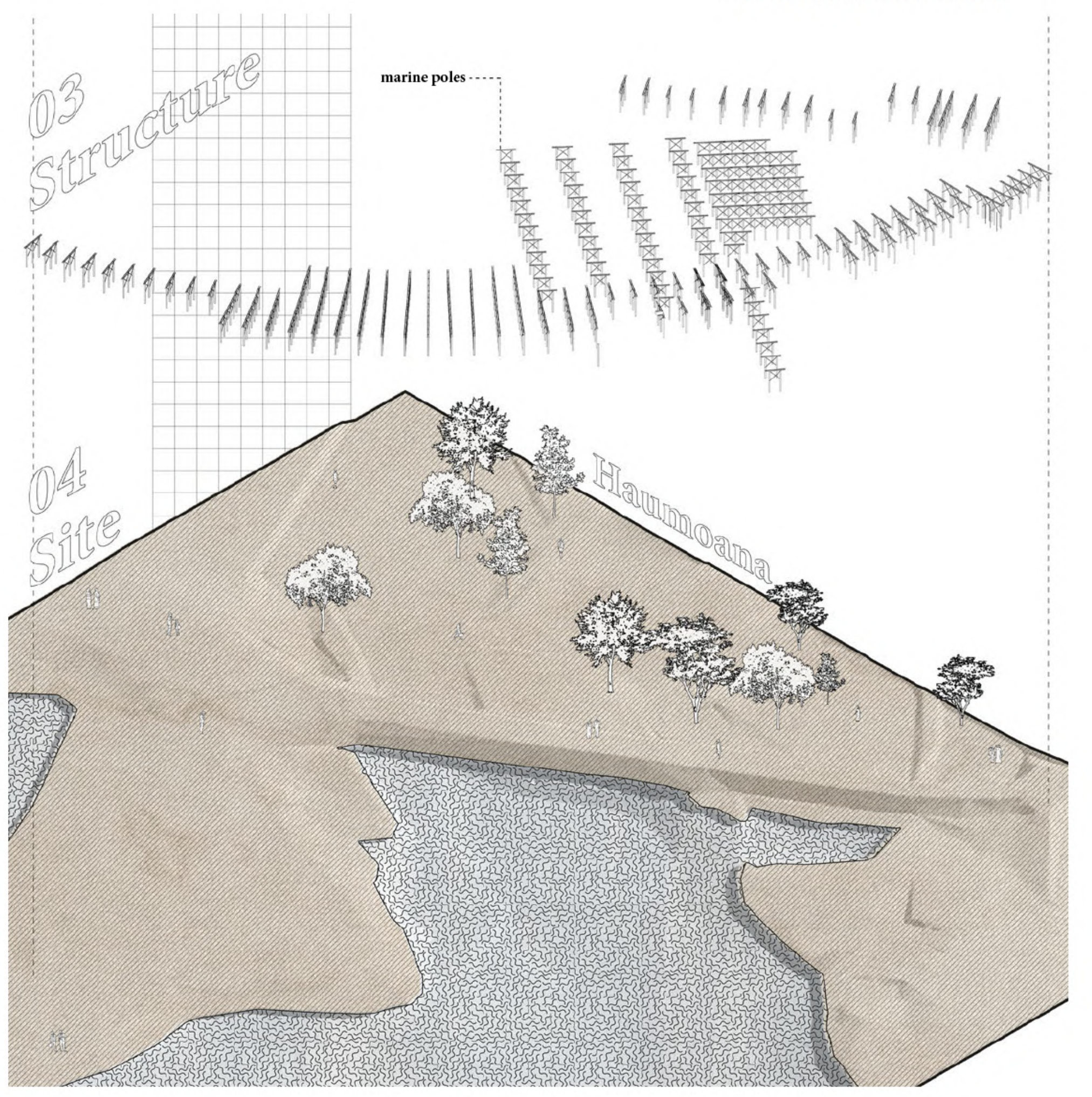




\section{Community Buildings.}

\author{
$B_{\text {eiv }}$ \\ dwellings, than the \\ dwellings, the community and \\ to the base of the where the wharf boats, access to the water for \\ meets the stopbank ensuring small boats, kayaks, Waka Ama \\ that they are more protected and a place for fishing. \\ from the hazards of the site, and \\ act as introductory buildings that (03) Amenities buildings for \\ welcome the community and housing fresh water supplies and \\ fer \\ grey water through \\ The buildings that were deemed \\ essential to the design are: \\ a greenhouse. \\ building that opens onto the \\ (01) A large community hall / communal wharf, intended for \\ events centre that opens to its own functions such as the weekend \\ wharf platform that can double as markets.
}
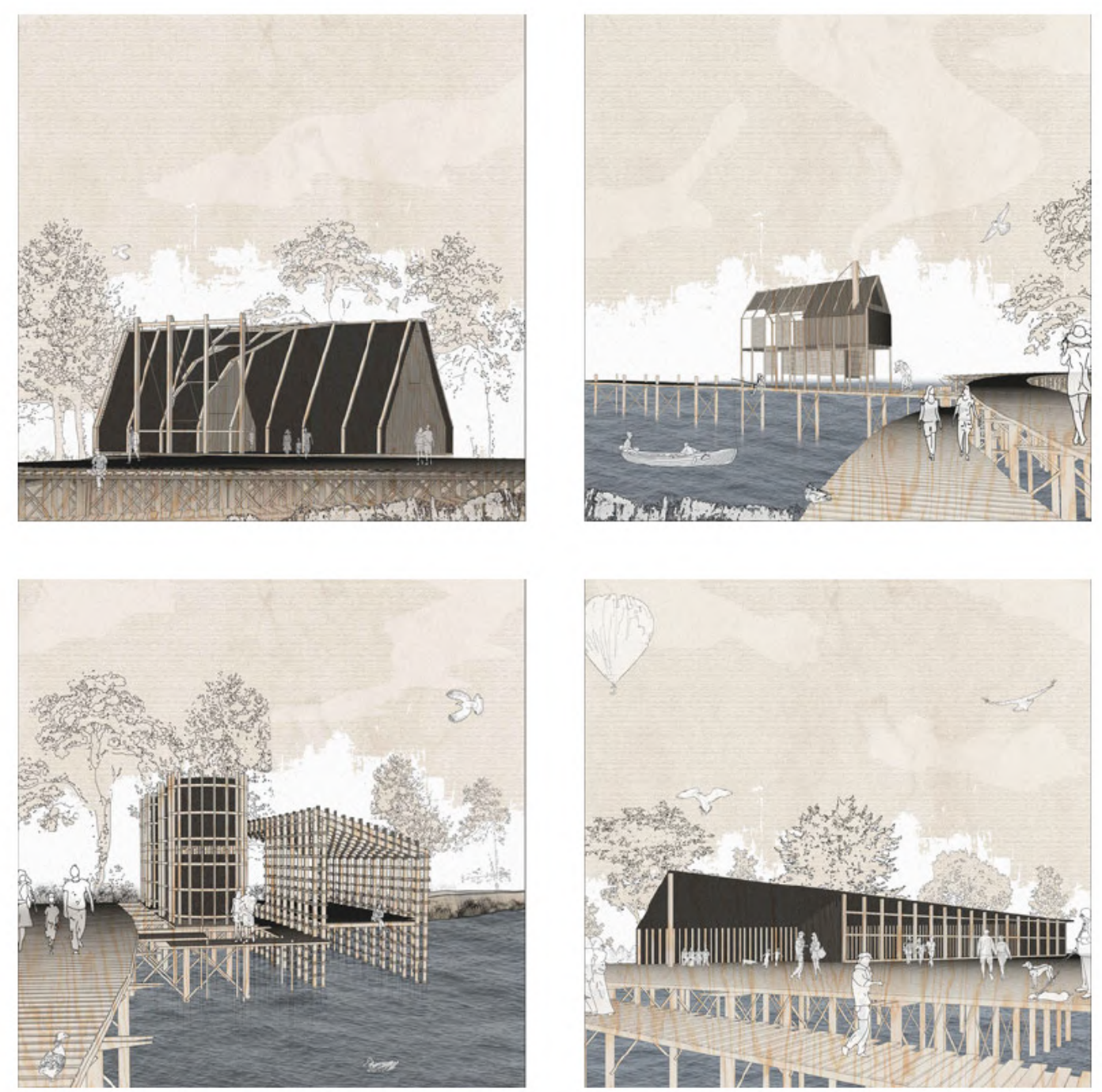
community building.

1

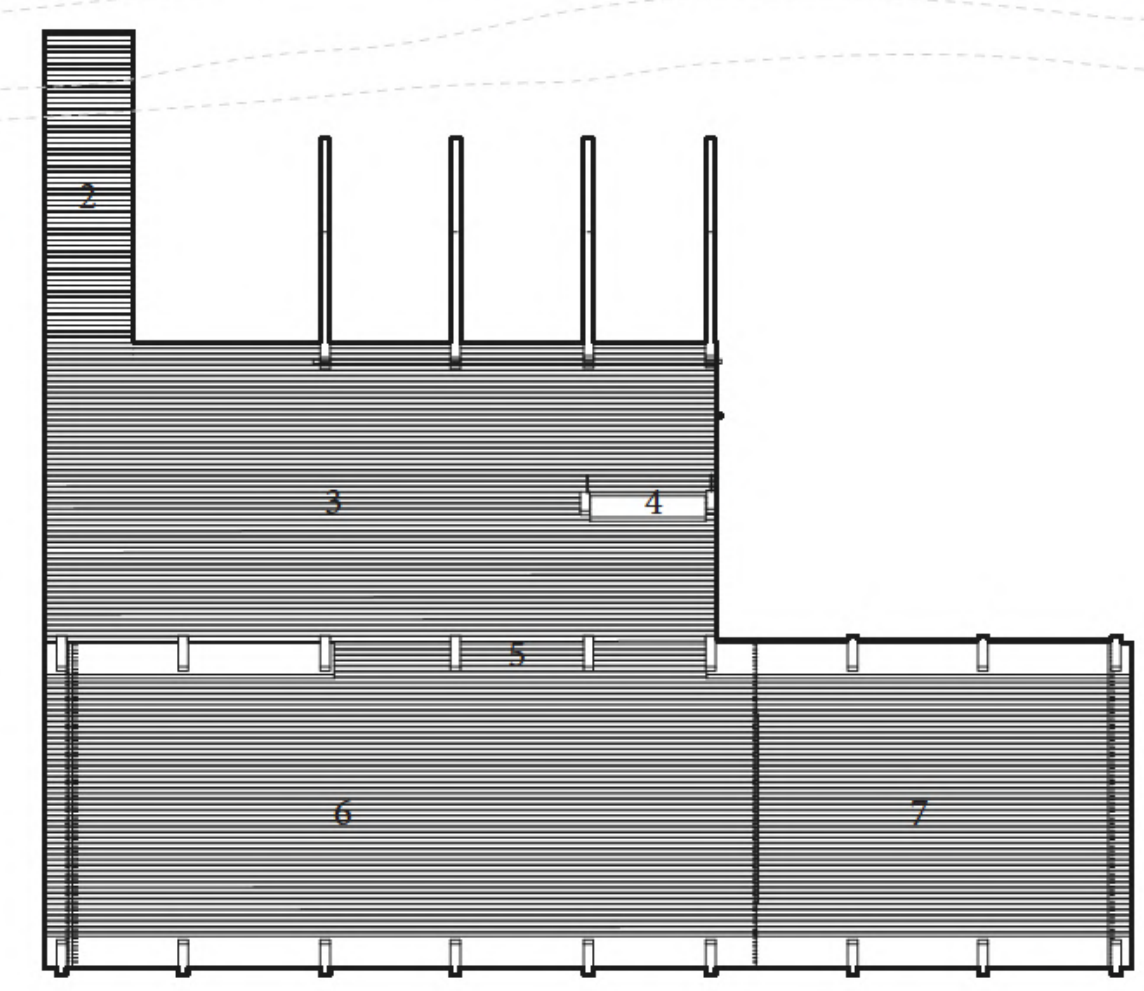

1 - stopbank

2 - wharf

3 - decked space

4 - opening screens

5 - transition space

6 - open hall

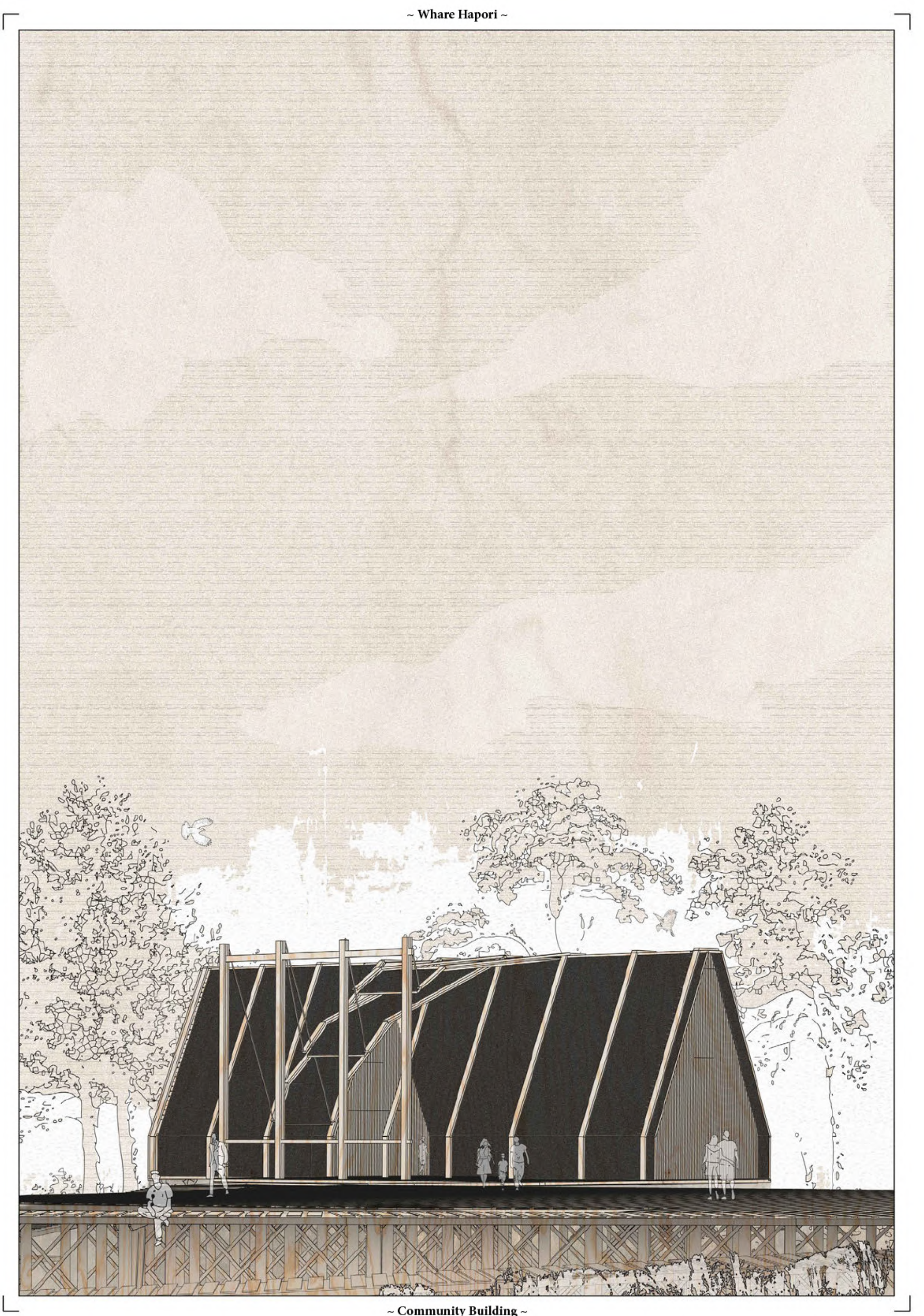


wharf.

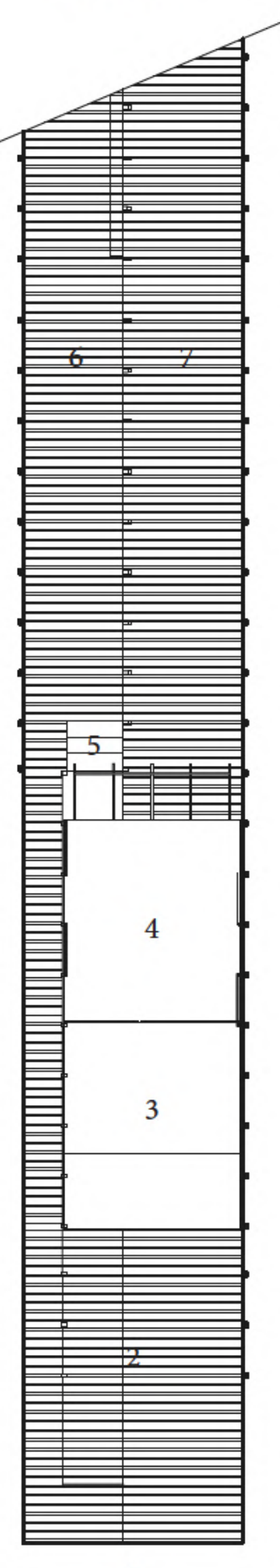

1 - promenade

2 - wharf

3 - wharf dwelling

4 - dwelling deck

5 - stair

7 - high pier

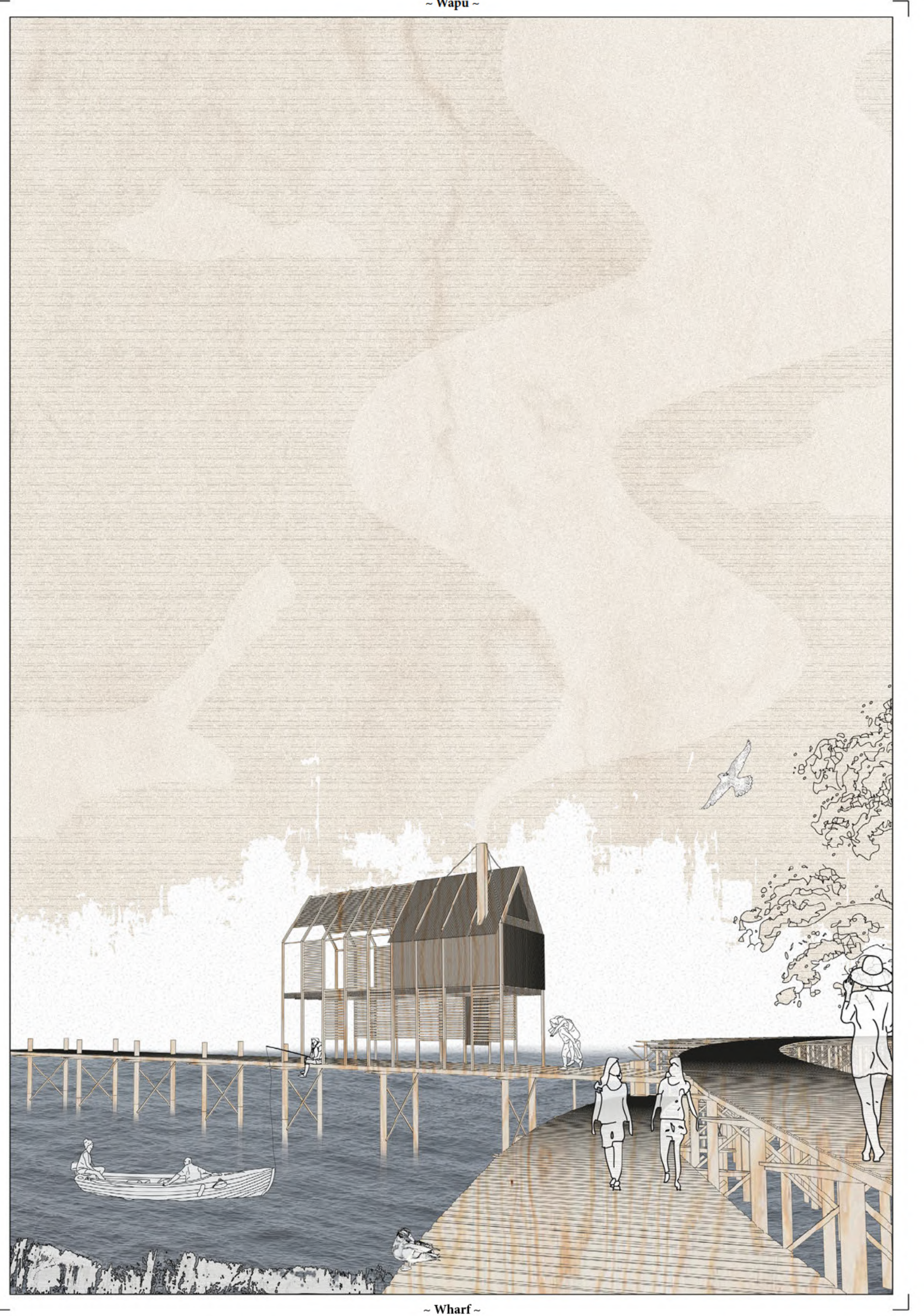


amenities.

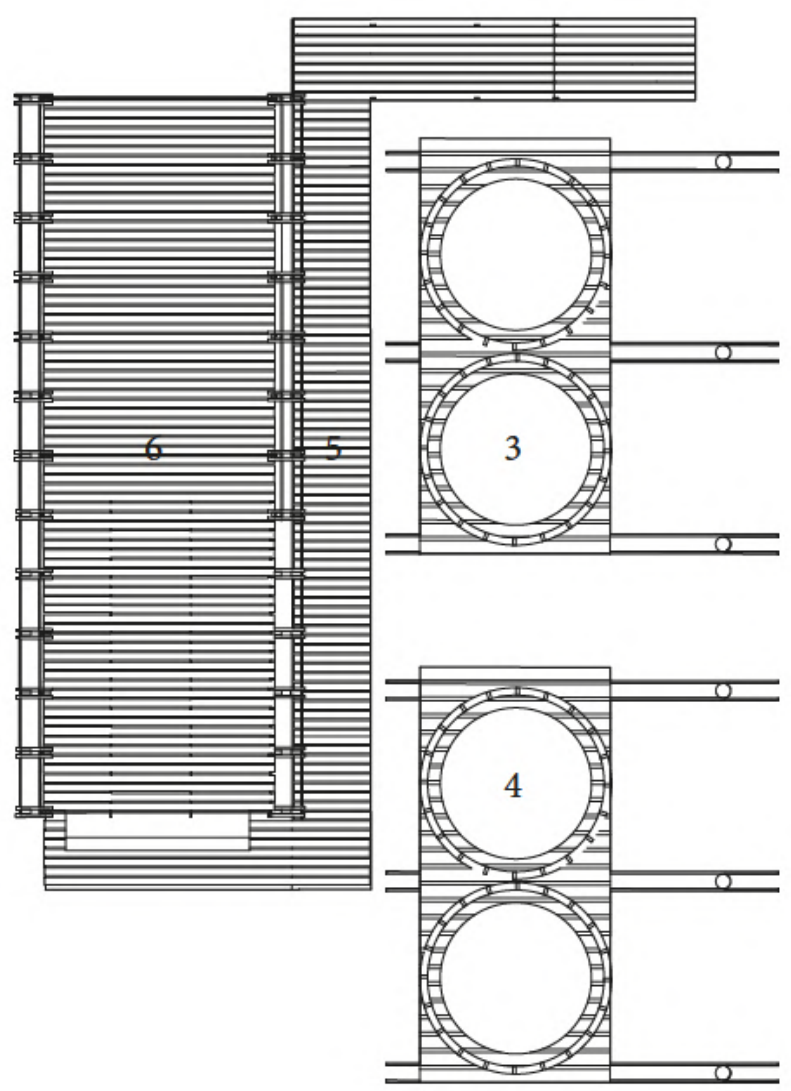

1 - stopbank

2 - wharf

3 - fresh water sortage

4 - grey water storag

- walkway

6 - communal greenhouse

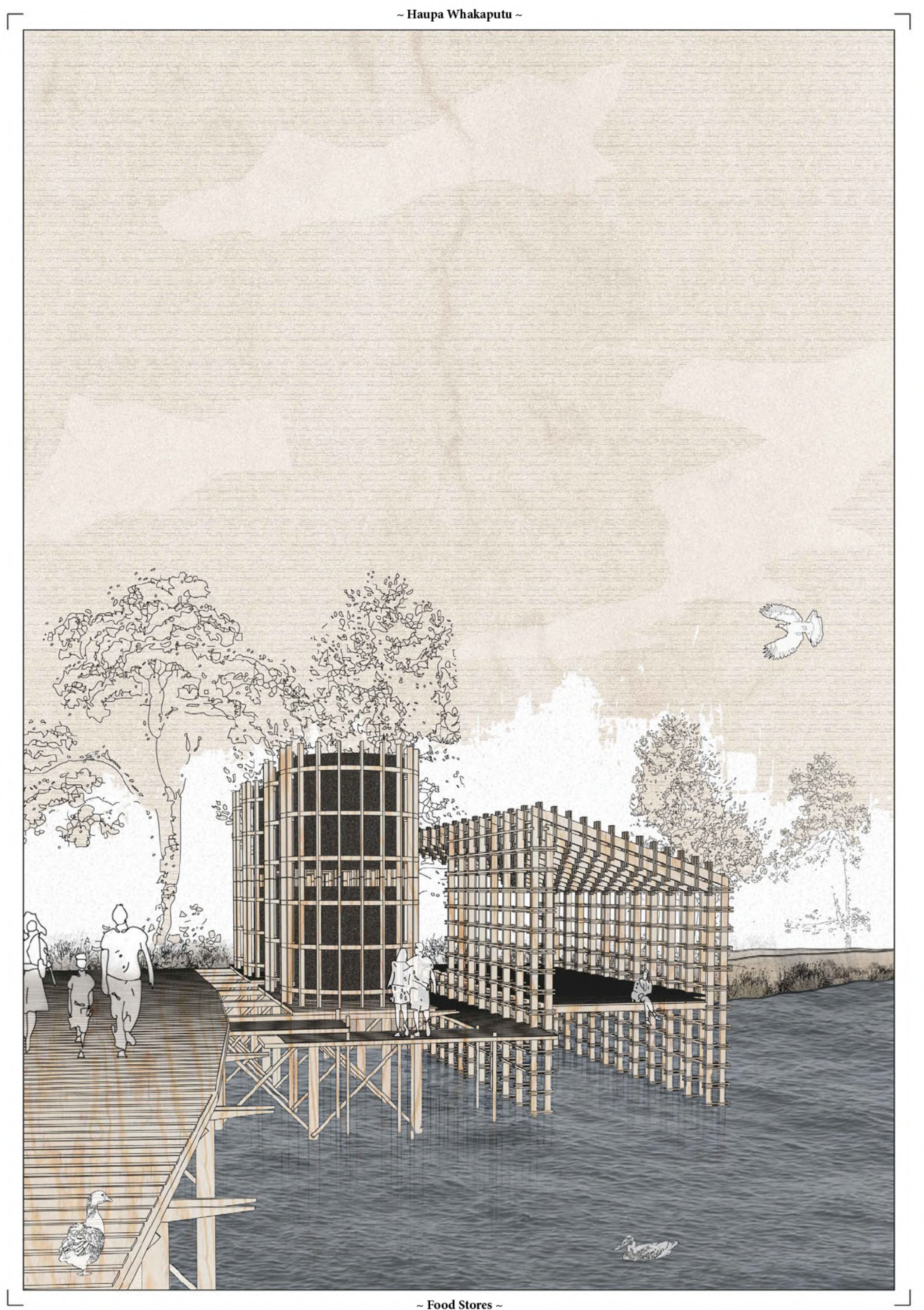




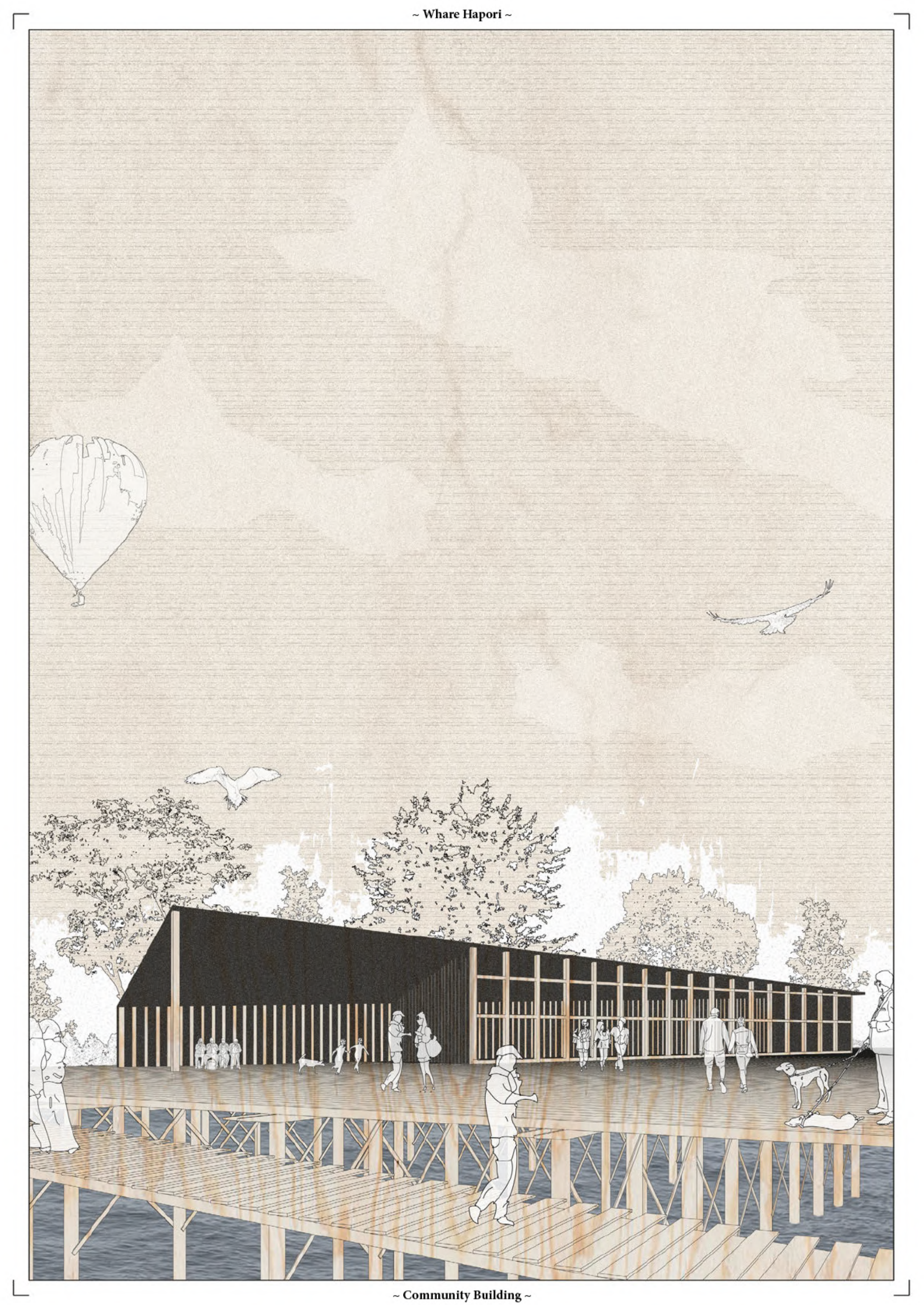




\section{Dwellings.}

$T_{\text {ne }}$ of several buildings of varying a lower wharf that encourages formal qualities, but all aspire to communal interaction with the follow the established principles natural environment, providing demonstrated by the humble New access to the river and gravel Zealand bach

While there are a series that attach They will remain protected by the themselves to the backside of the gravel barrier beach and clam stopbank, the majority are situated waters of the river for the entirety out on the arcing promenade. of their expected life span, and The dwellings are all connected and uniform shapes, they are by an access wharf running designed to be easily dismantled perpendicular to the main and removed when required.
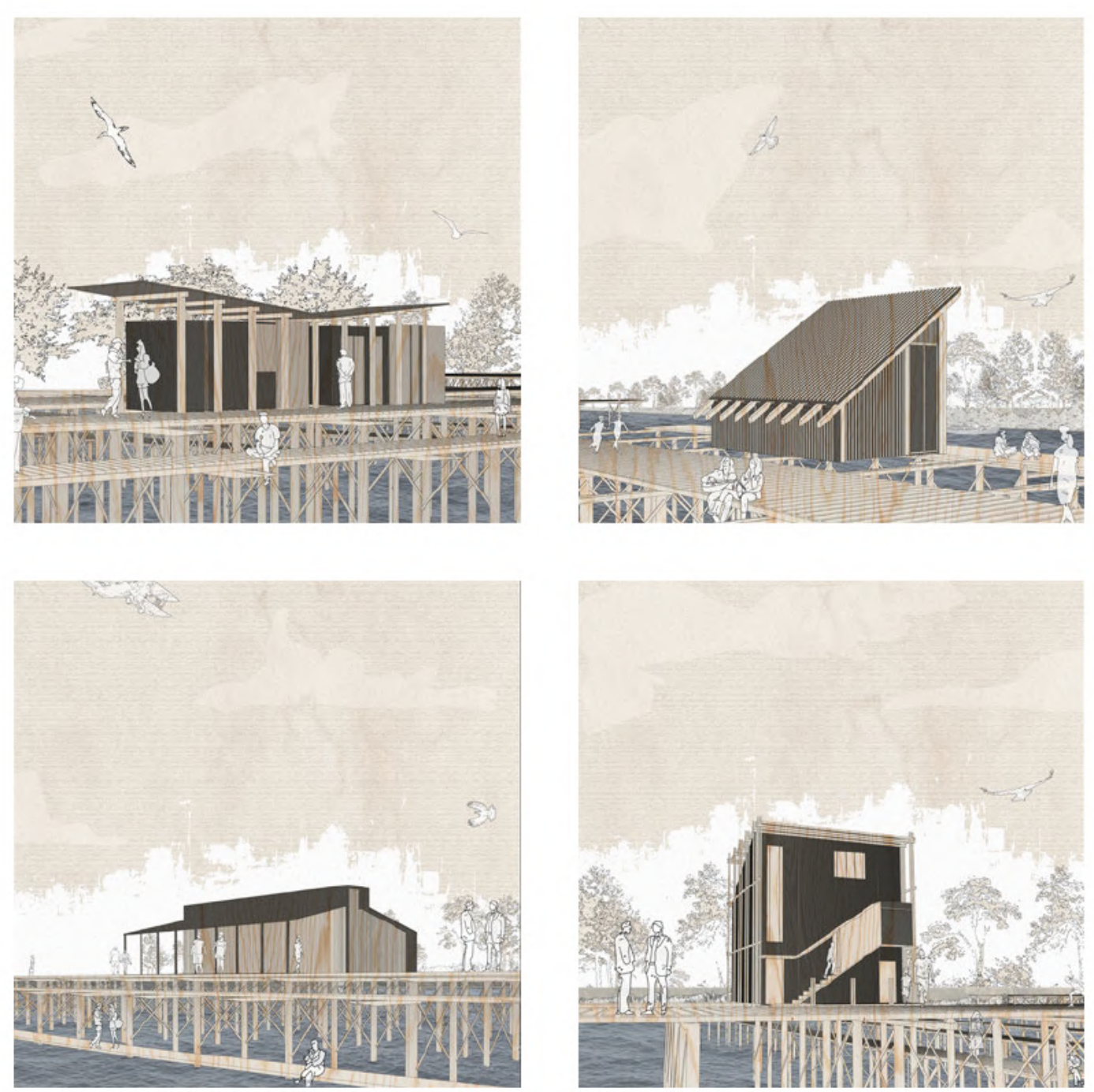


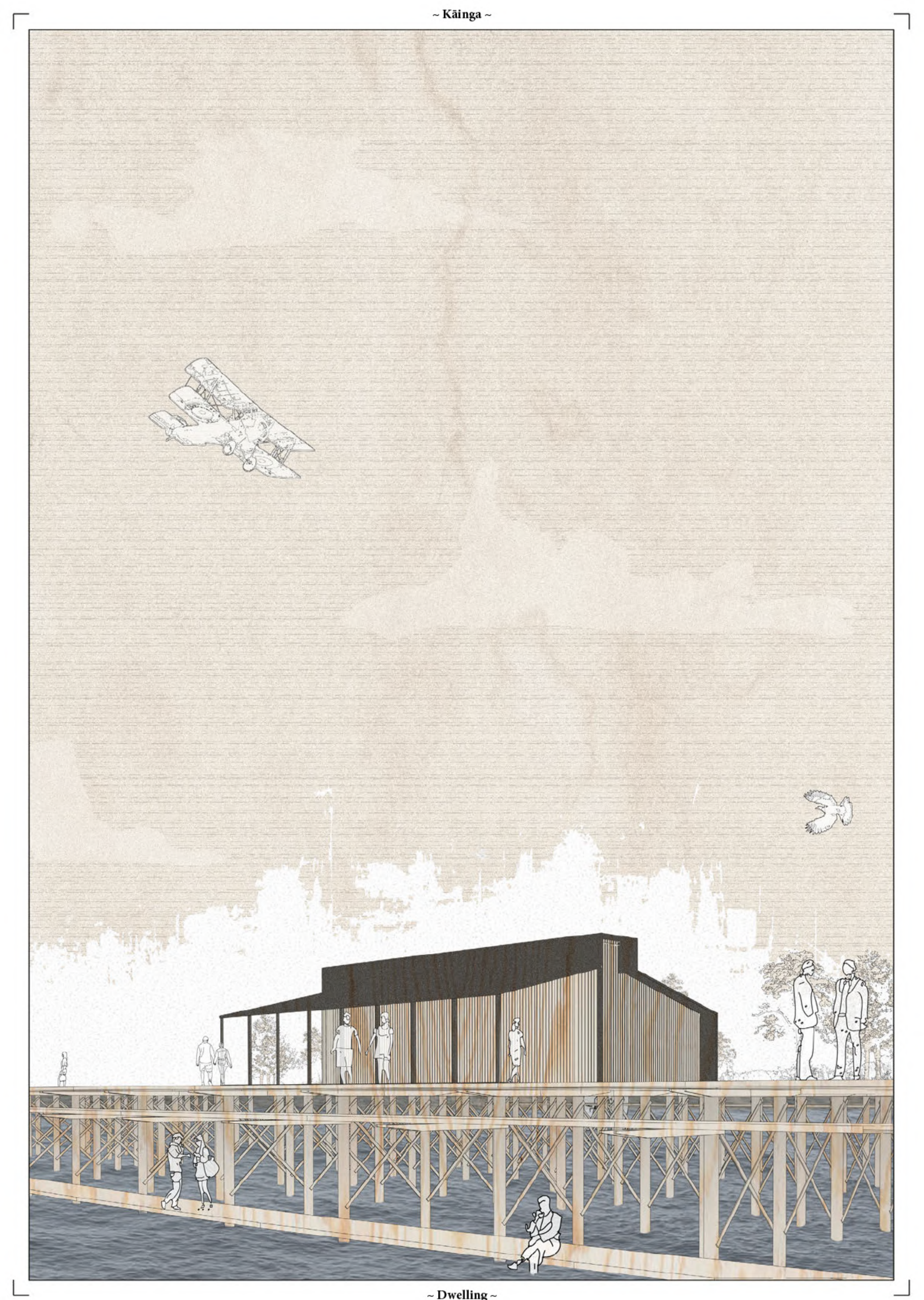




\section{$+$}

dwelling.
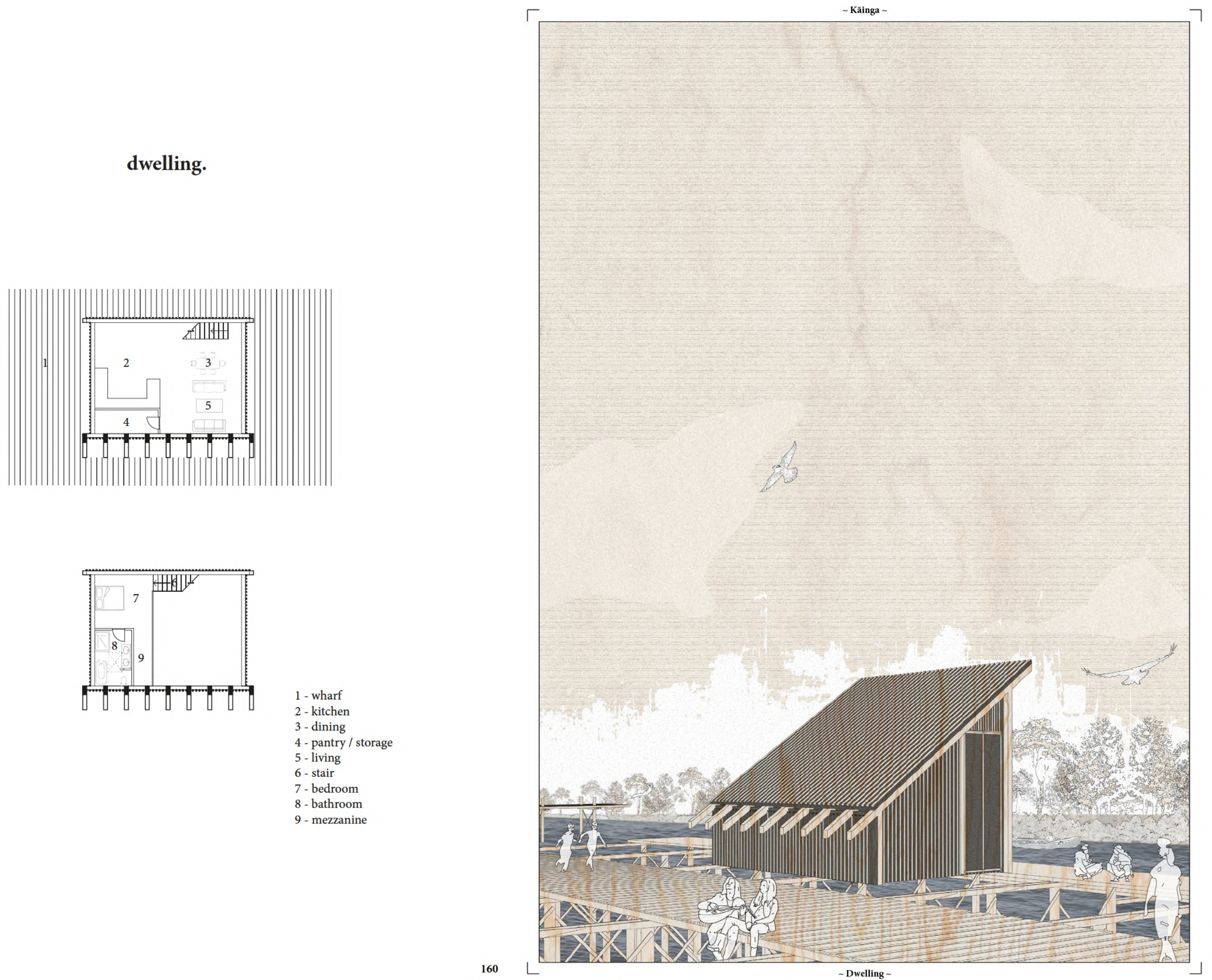
dwelling.

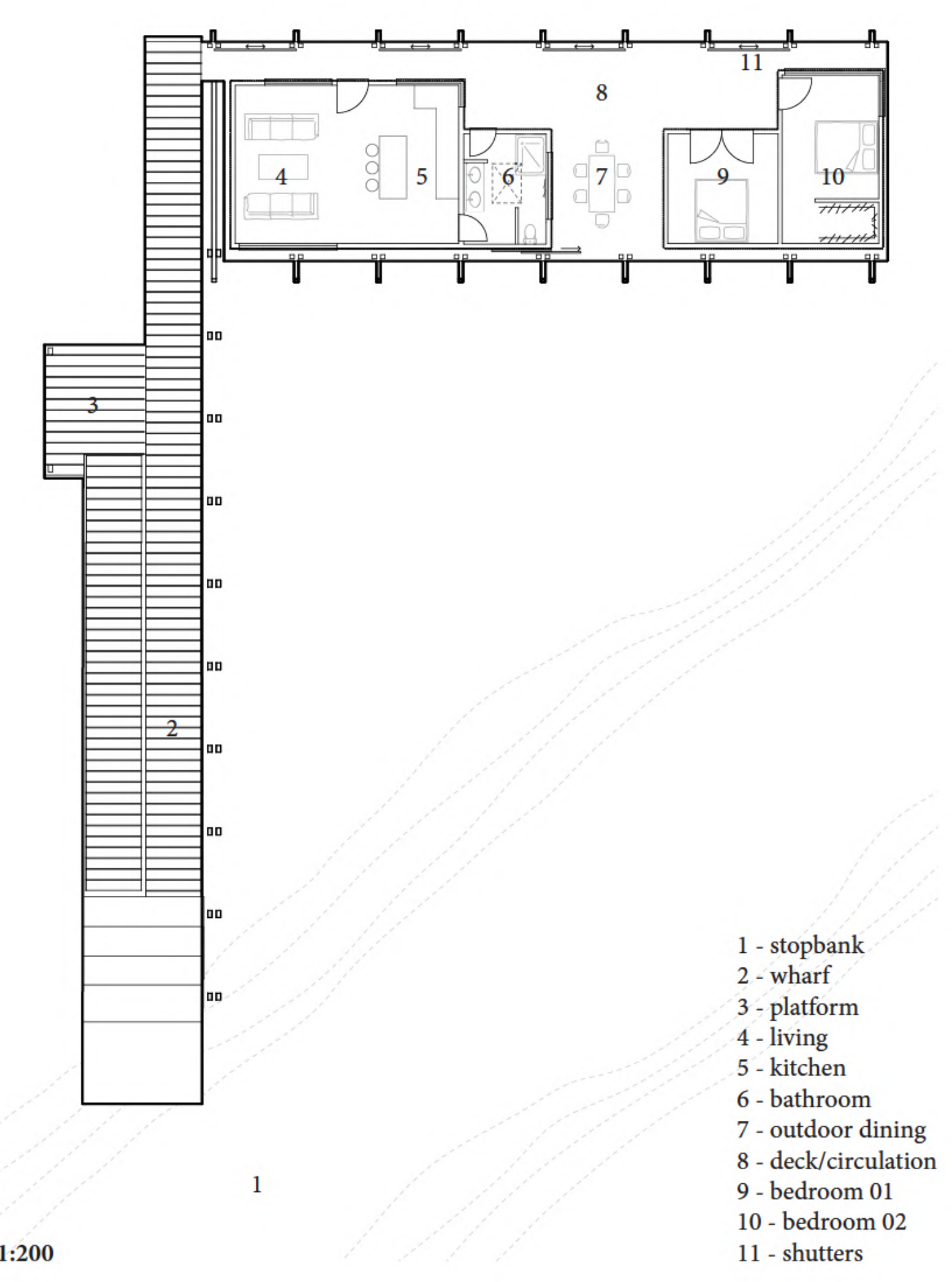

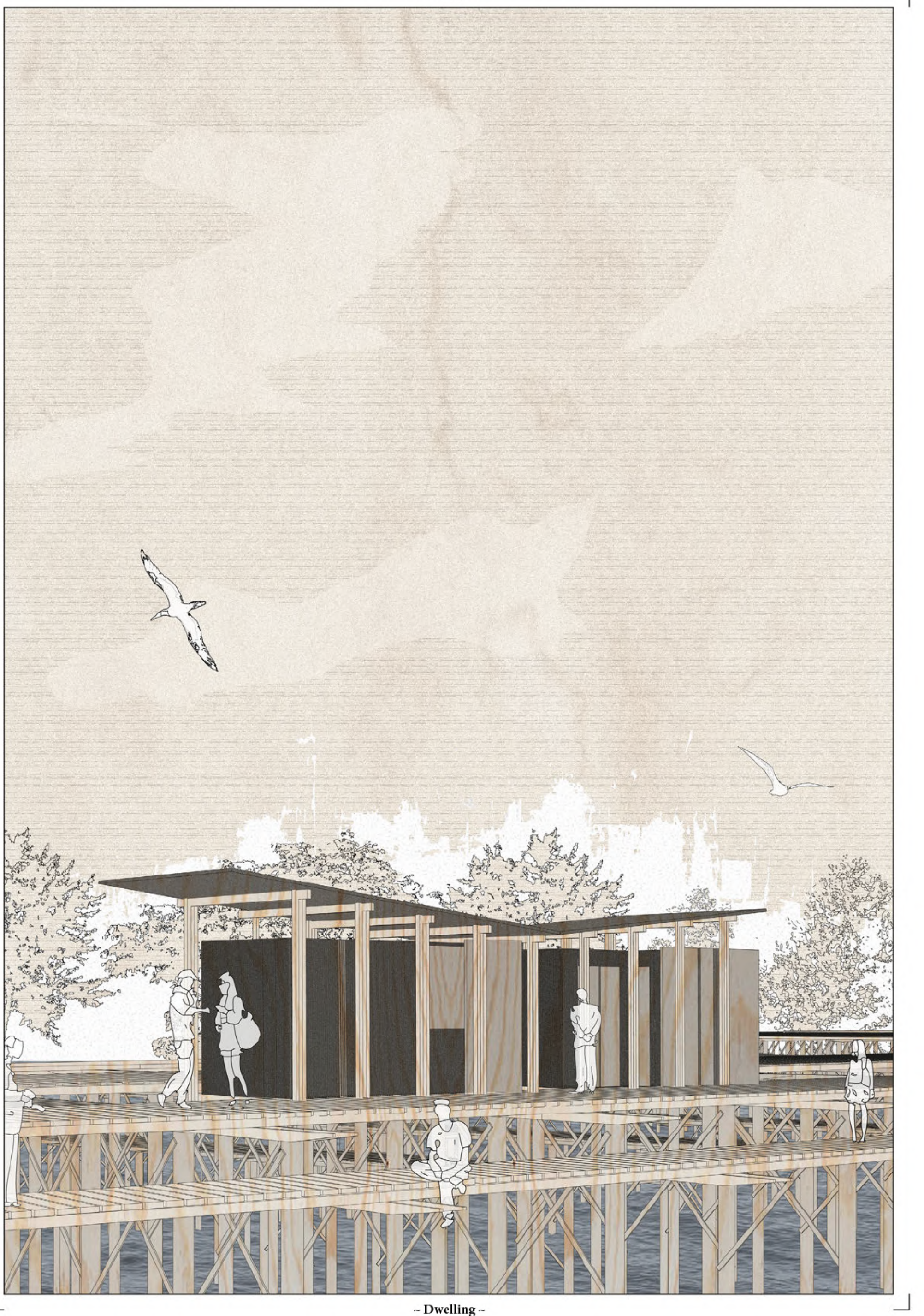

$\sim$ Dwelling $\sim$ 


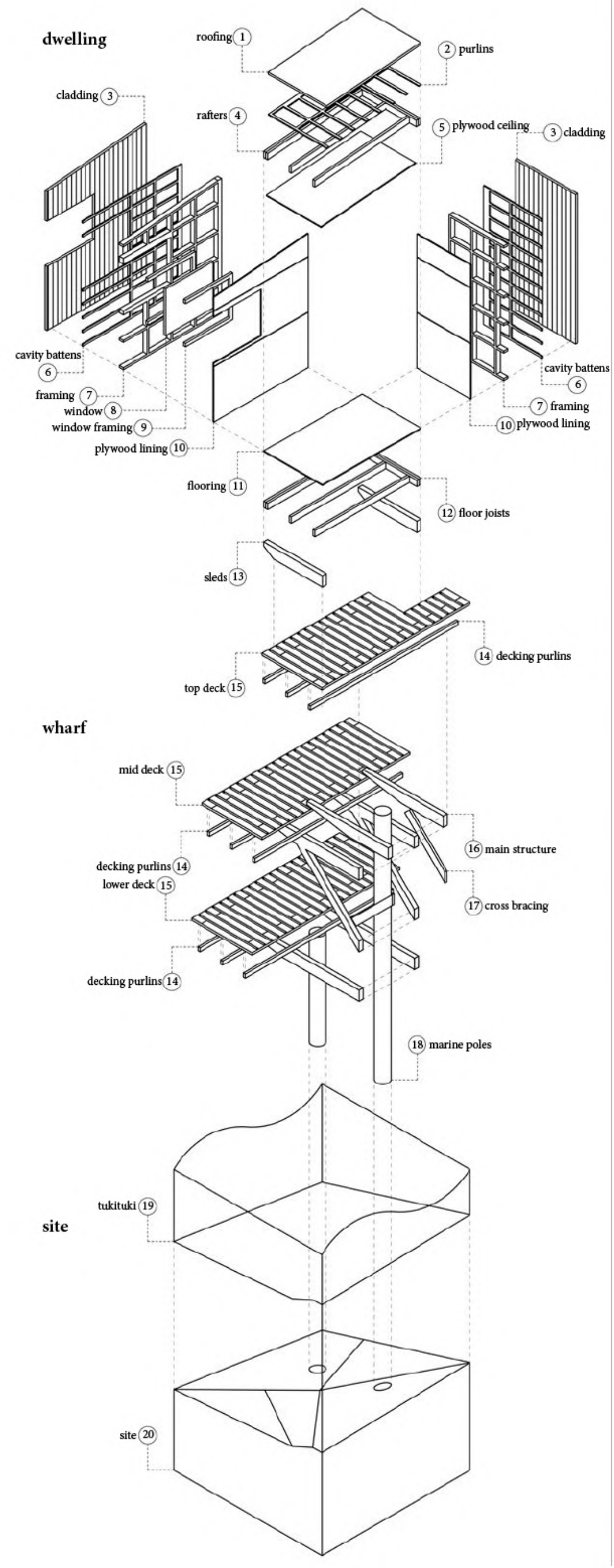

B intion at the macro scale of the masterplan, the meso scale of the experience, and this micro scale of specified materials and finishes, the design further manoeuvers itself to the realm of possibility. All materials were heavily inspired by the established precedent material, along with hints towards the building methods of traditional stilted architecture.

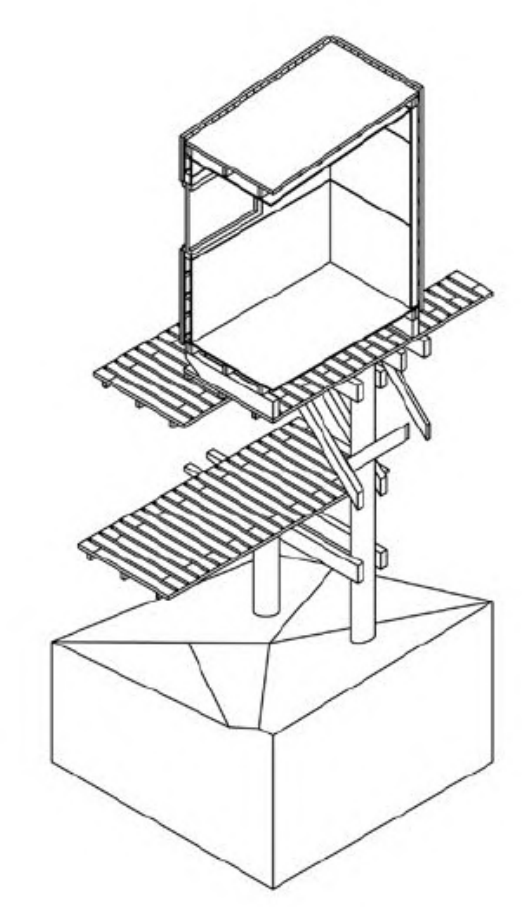

1 - zincalume corrugate roofing 2 - $75 \times 50$ timber purlins 3 - $140 \times 20$ vulcan cladding

4 - $150 \times 50$ timber rafters 5 - 18mm plywood ceiling 6 - $45 \times 25$ cavity battens 7 - $90 \times 45$ timber framing 8 - double glazed windows

9 - aluminium window framing 10 - 12m plywood lining
11 - 25mm plywood flooring 12 - $150 \times 50$ flor joists

13 - $300 \times 100$ timber sleds 14 - $90 \times 45$ decking joists 15 - $140 \times 45$ decking timber 16 - $300 \times 100$ timber structure 17 - $140 \times 45$ cross bracing 18 - 300mm H6 marine poles 19 - tukituki river

20 - site 


\section{Nā tō rourou, nā taku rourouka ora ai te iwi}

"With your food basket and my food basket the people will thrive"
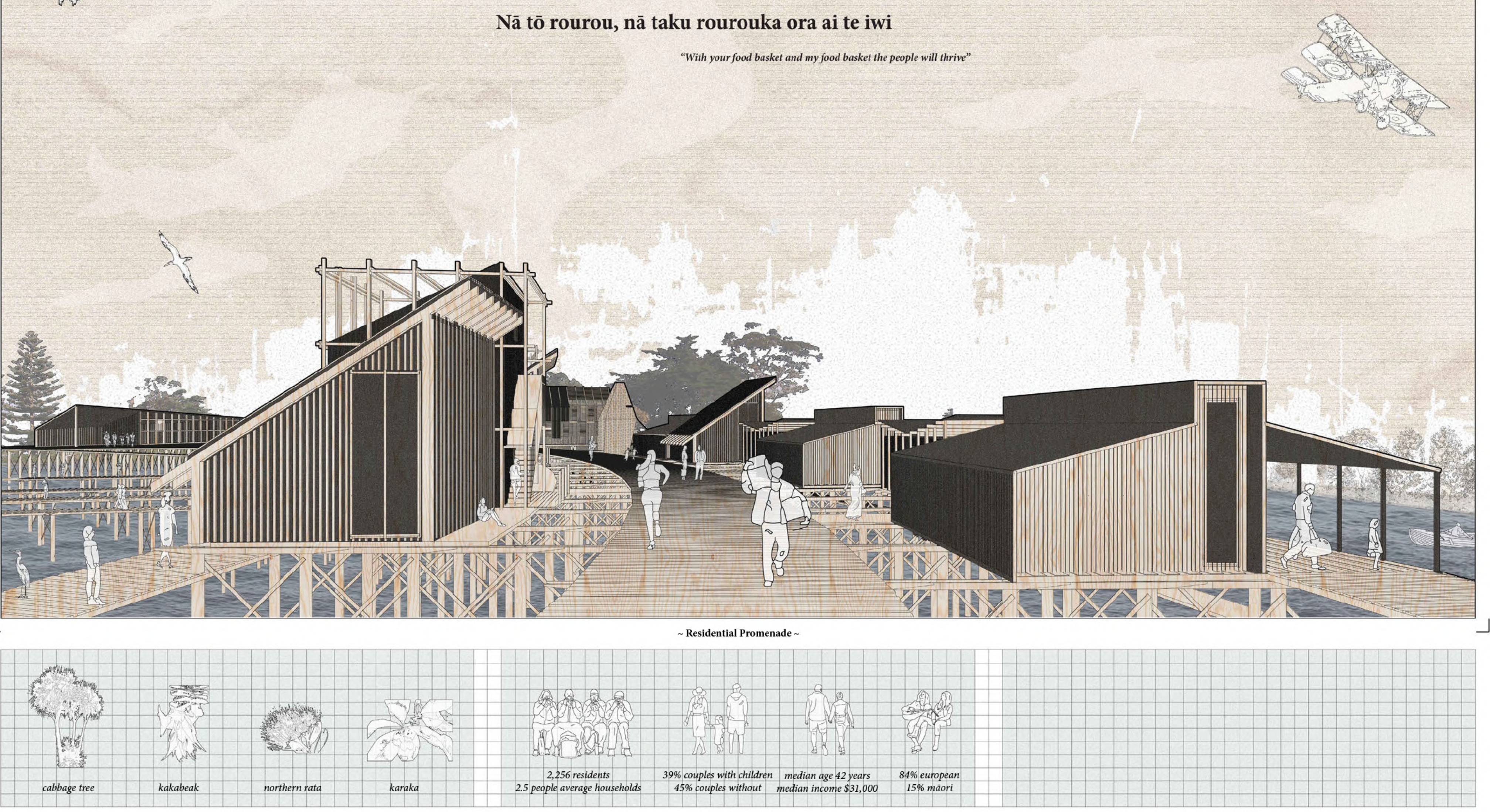
native trees 
See Beyond the Horizon.

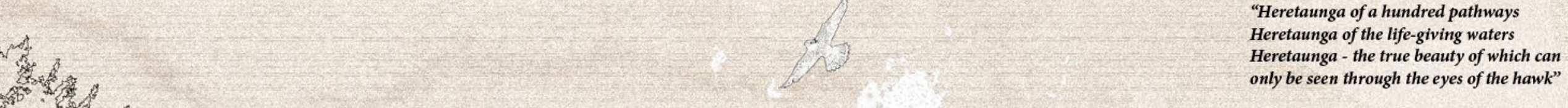

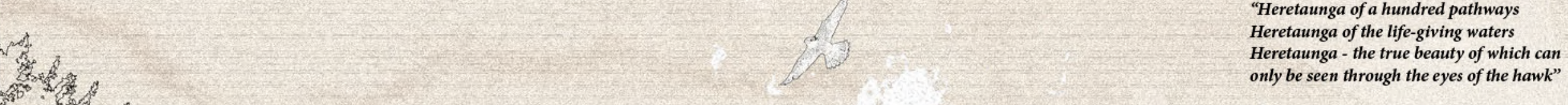

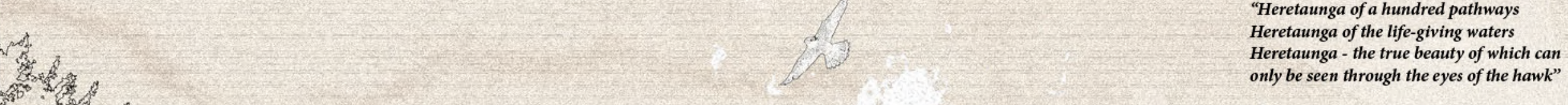

and

IIII)

1.3000

(1)

(x)
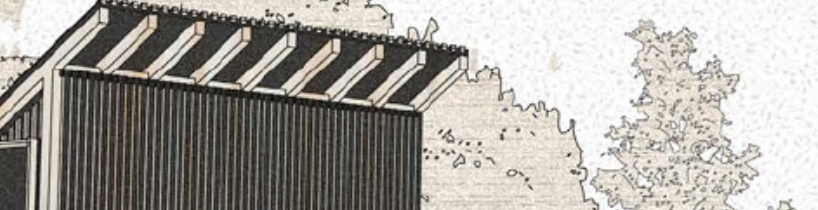

TI

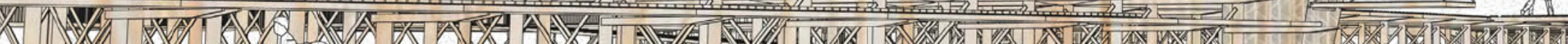

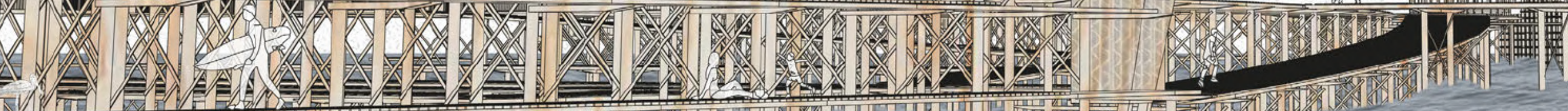

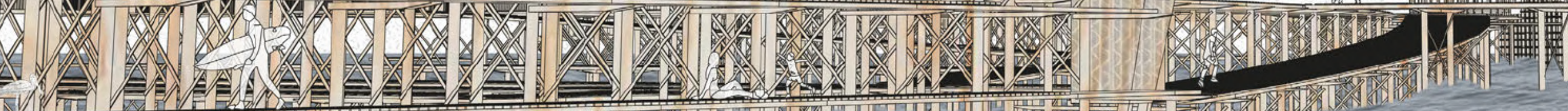
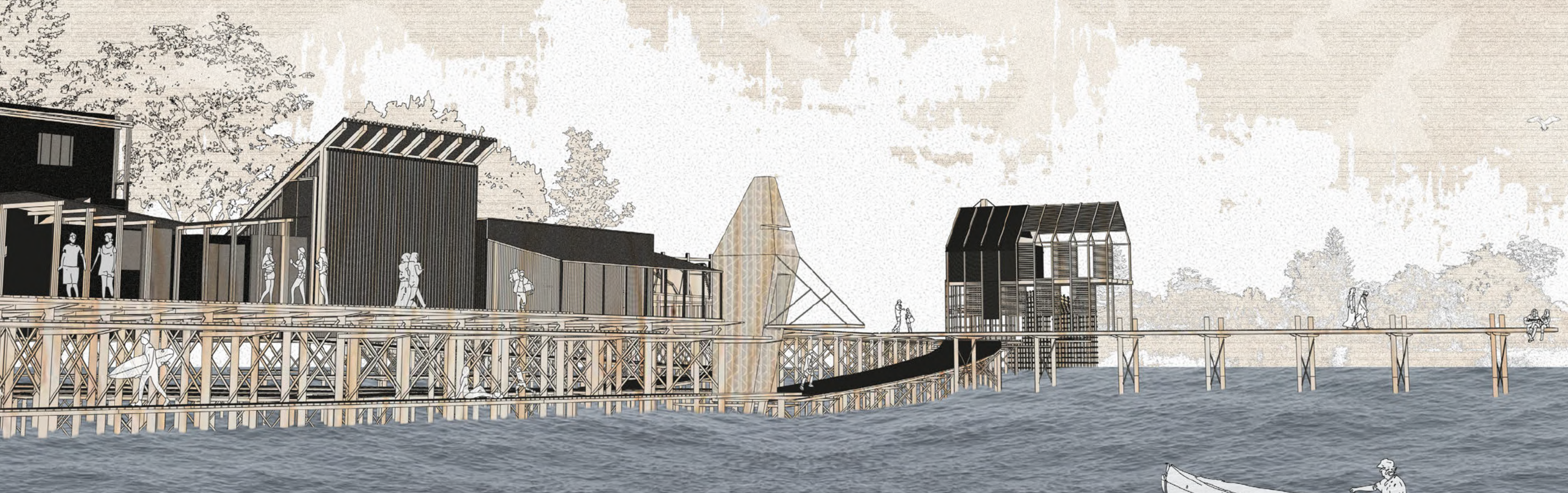

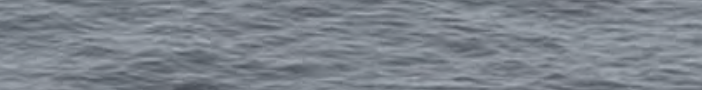

Aquaponic Farm
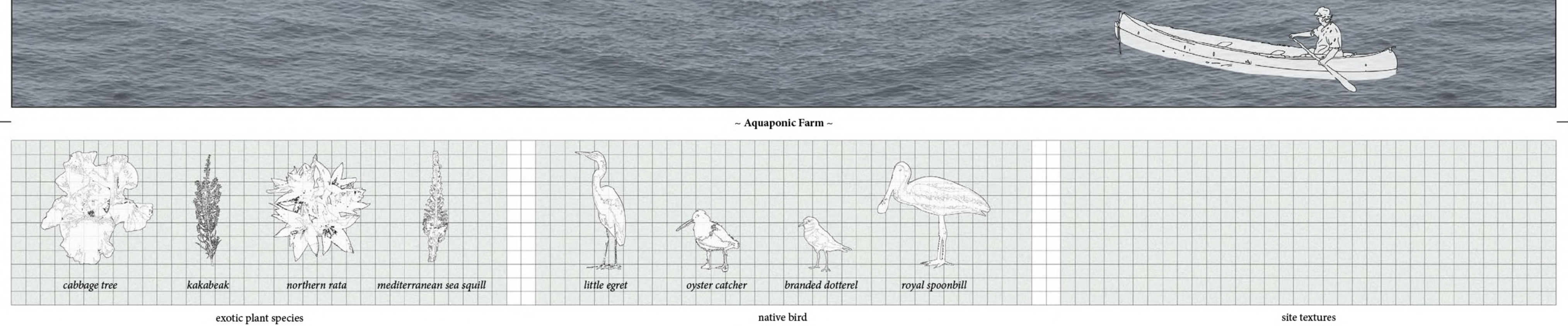


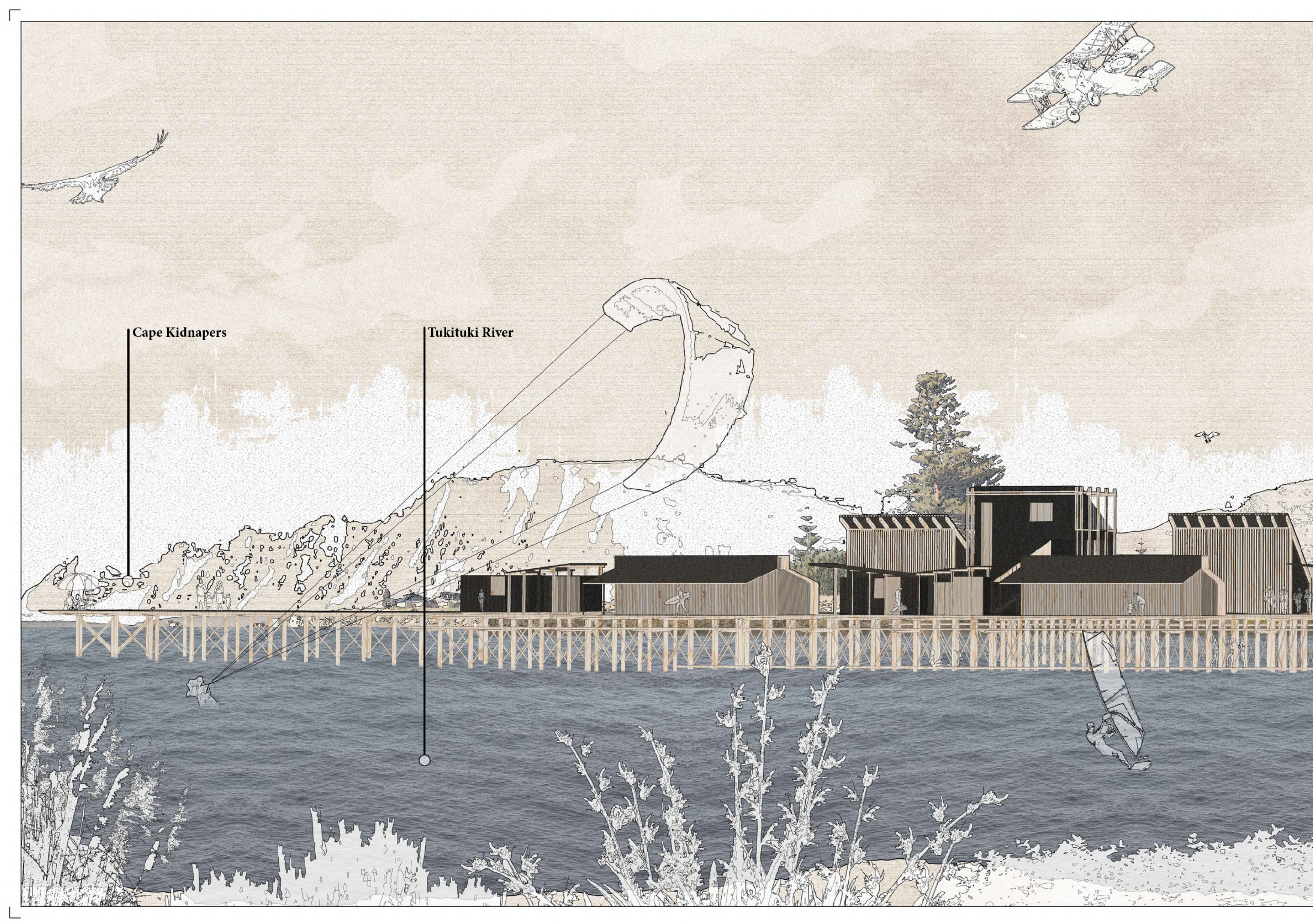




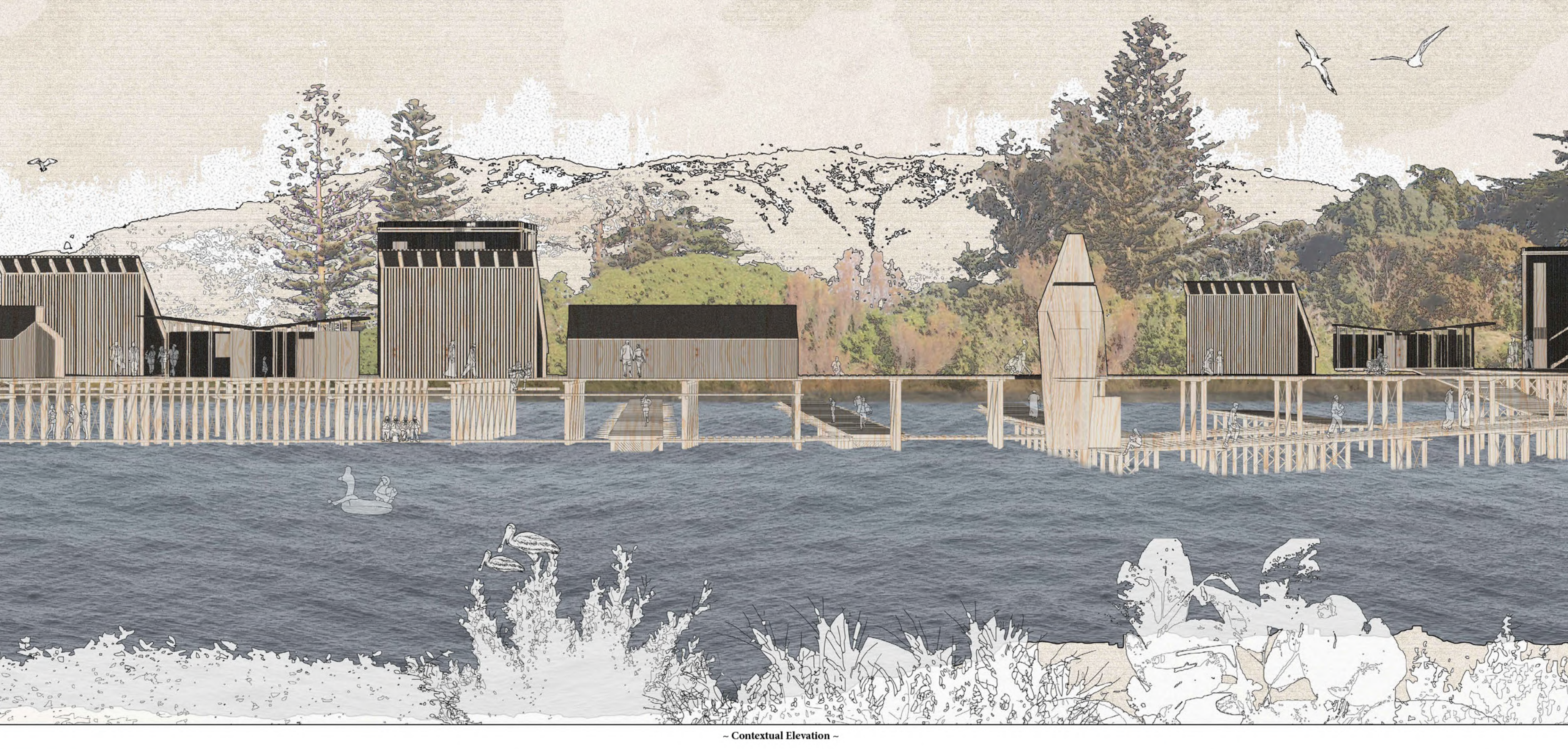




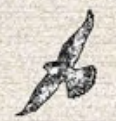

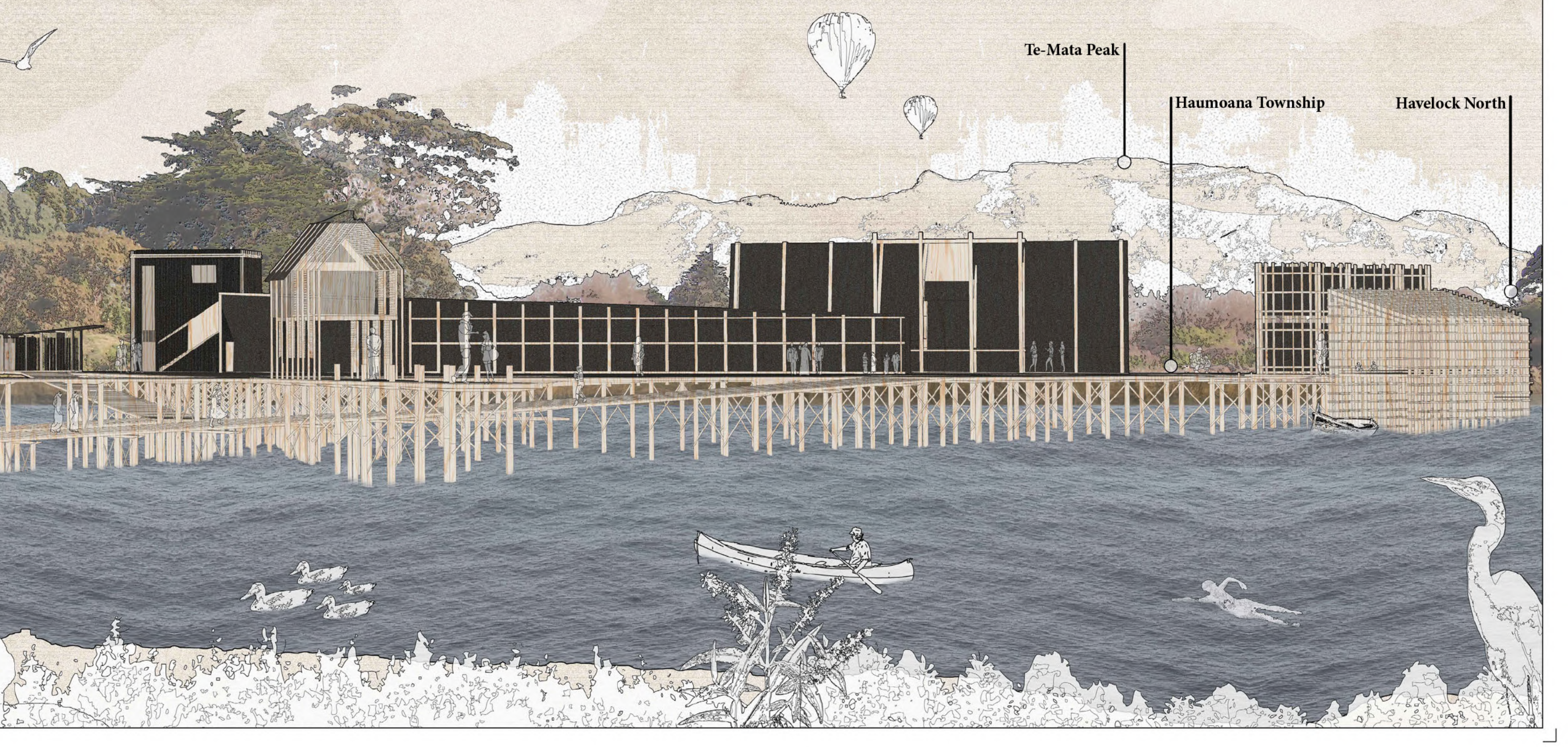




\section{Full Site.}

\section{Physical Exploration.}

\section{F}

again explored through the medium of physical modelling.

Beginning with a 1:500 Lastly, an intricatly designed representation of the entire isometric section cutting through proposed scheme. The model all aspects of the design, from has particular emphasises on dwelling to structure to territory.

the affiliation between the built

environment and the landscape sits atop.

At the next scale, a $1: 100$

callout model demonstrating the

relationship between two of the

dwellings, the wharf surrounding,
the structure that elevates it all,

This model places emphasis on the marriage between all the elements of the design vertically, the disparitys and similaritys spaces and the more communal exterior territories.

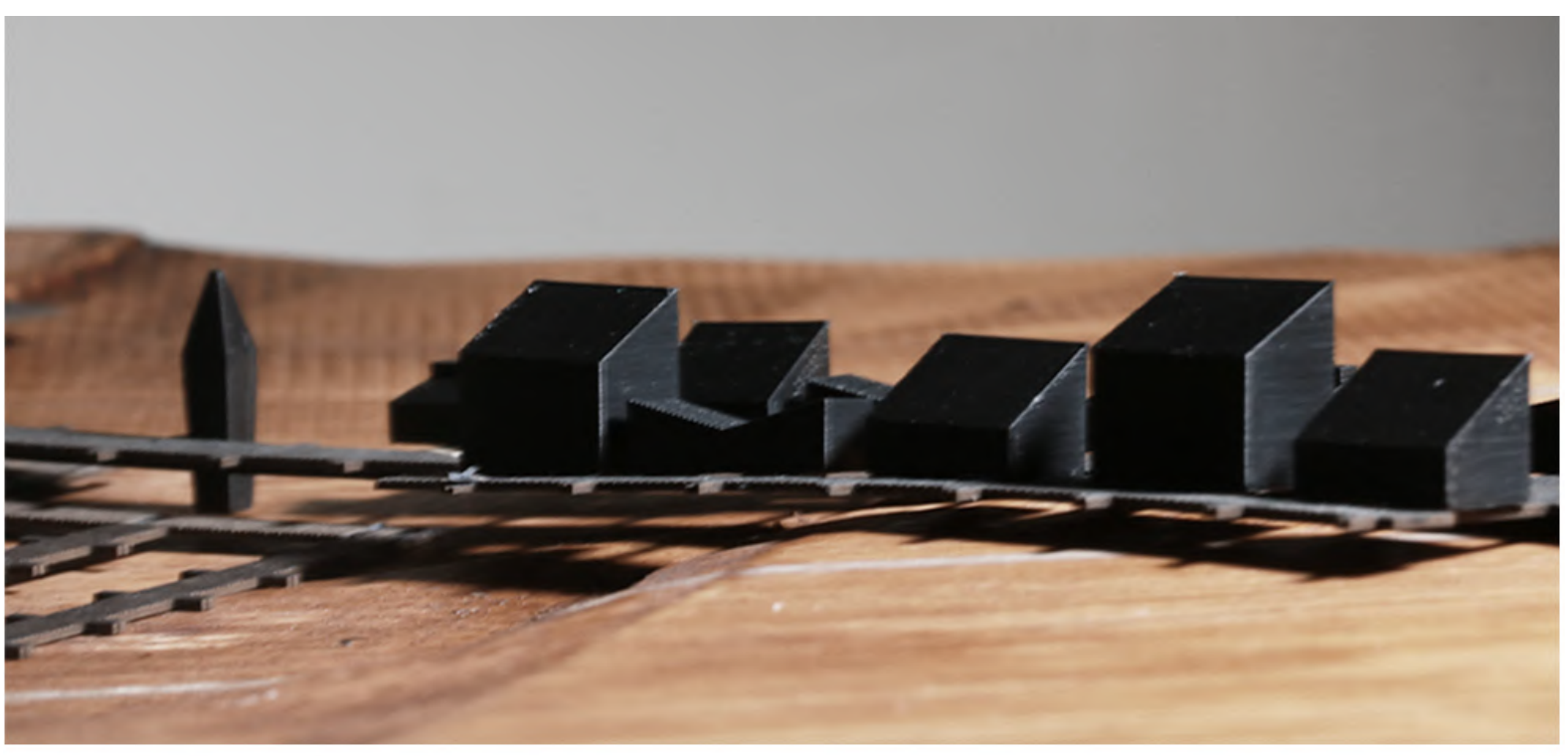
between the enclosed private
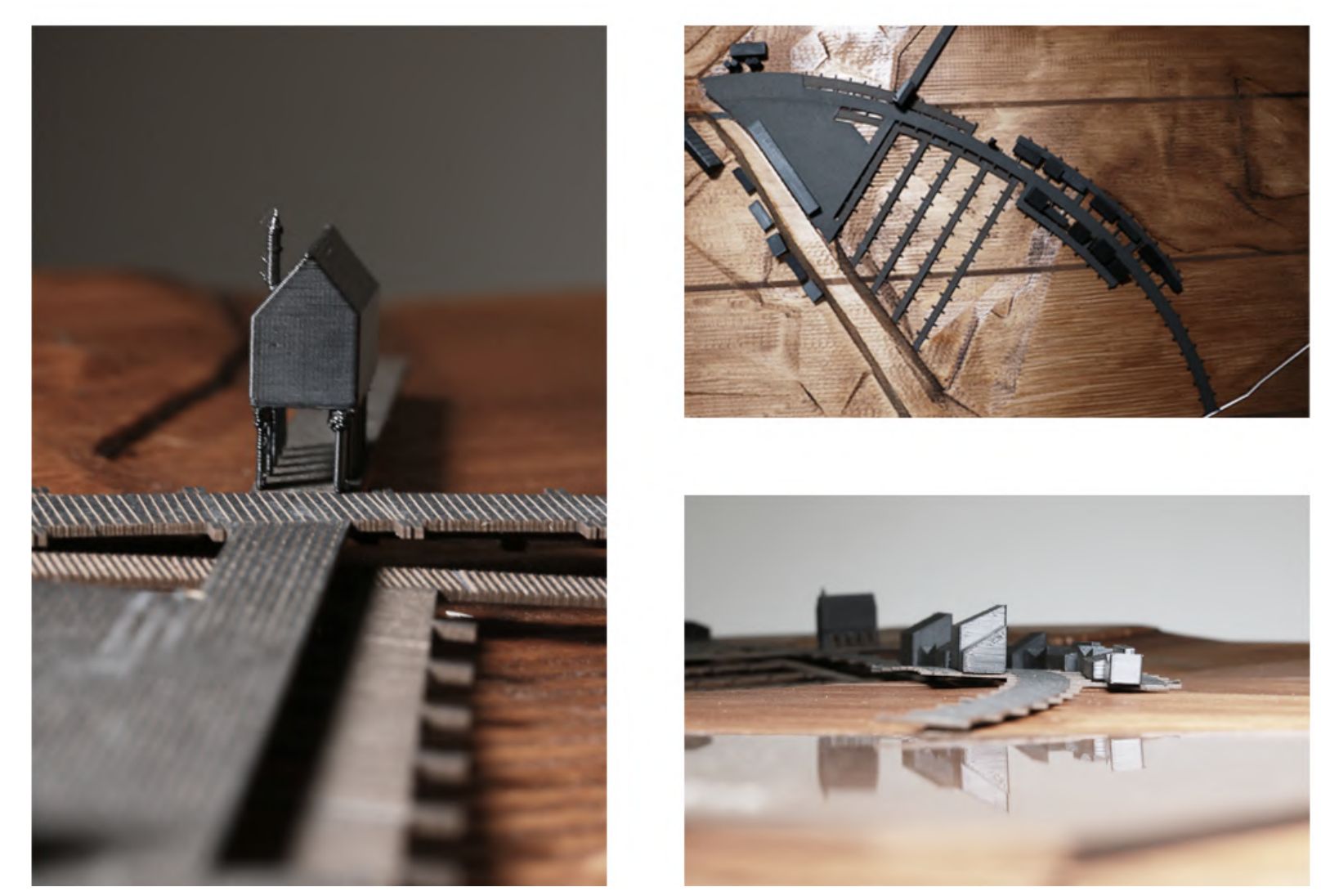


\section{Dwellings.}
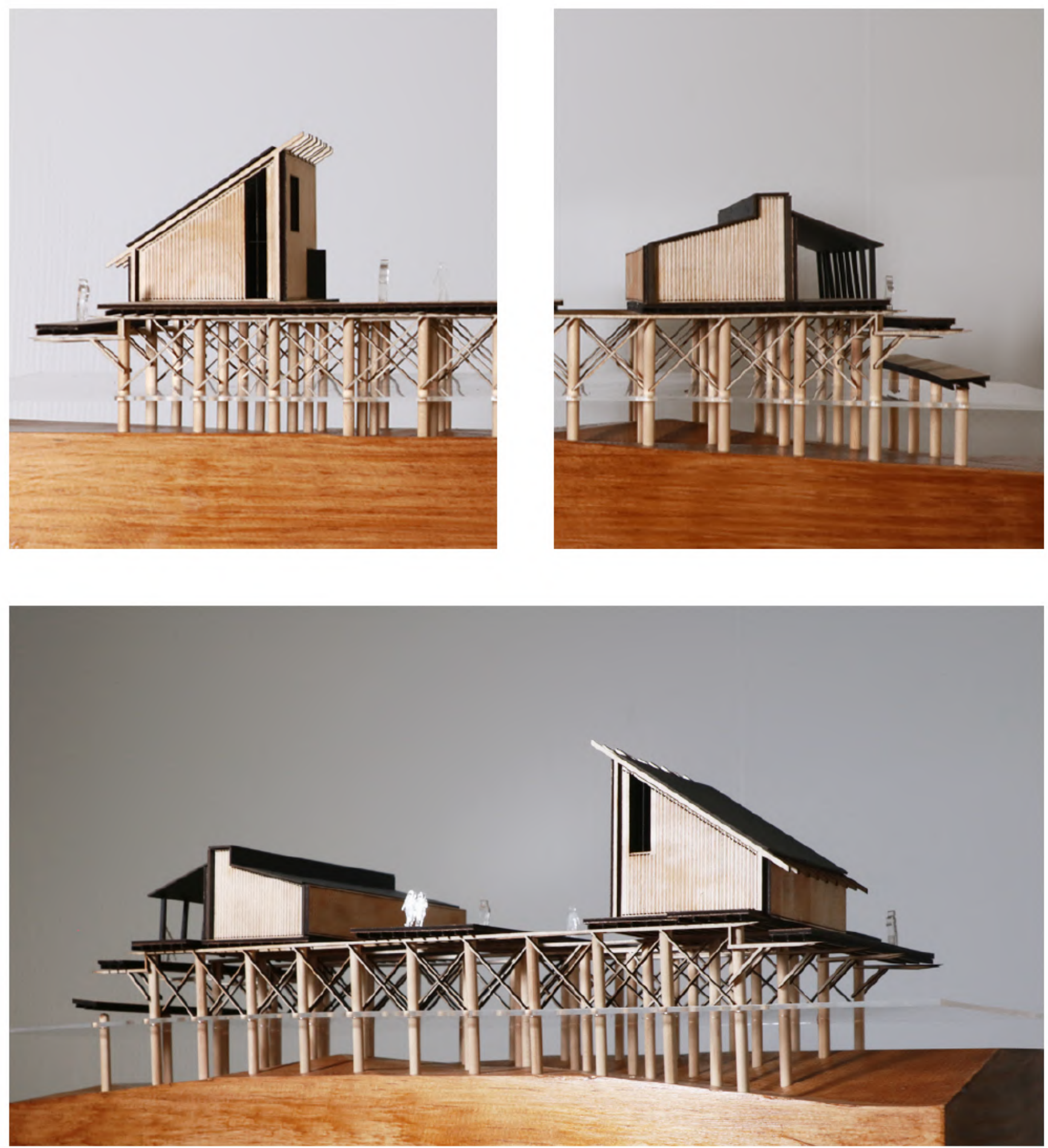

Detail Section.
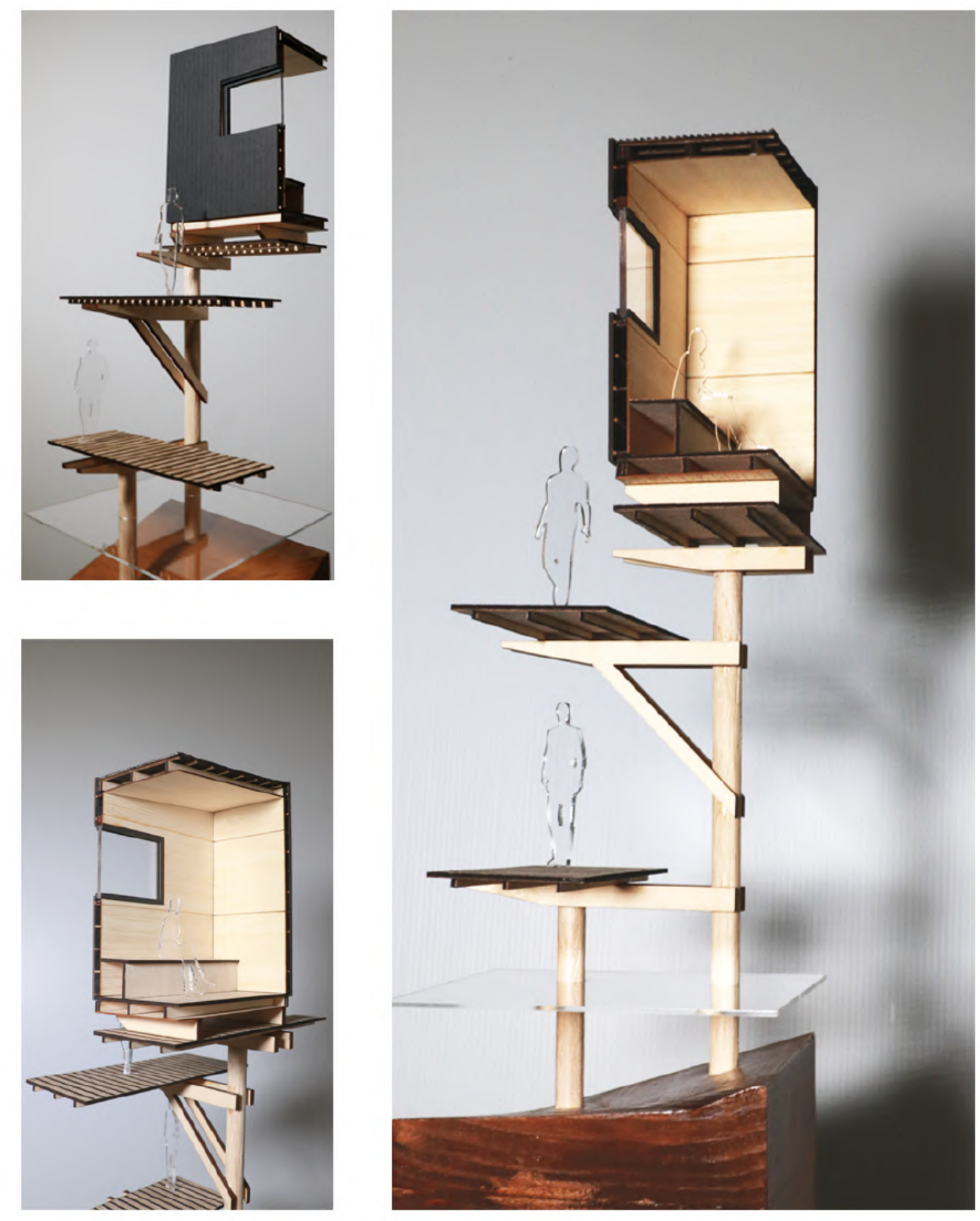

1:25 


\section{NZIA Student Design Awards.}

Jury Citation

Vulnerable Territories: The Perpetually Shifting Edge

"The thesis is a very timely response to a specific incidence of an increasingly urgent problem: the existential threat posed to coastal communities by sea-level rise induced by climate change. In a project that exhibits commendable ambition, and benefits from well-directed research into typological precedents, Joseph has produced sympathetic responses to the immediate environmental and social challenges facing the Hawkes Bay community of Haumoana. The scheme uses a coherent architectural language and demonstrates a sensitive appreciation of appropriate building scale."
This content is unavalible. Please consult the figure list for further information.

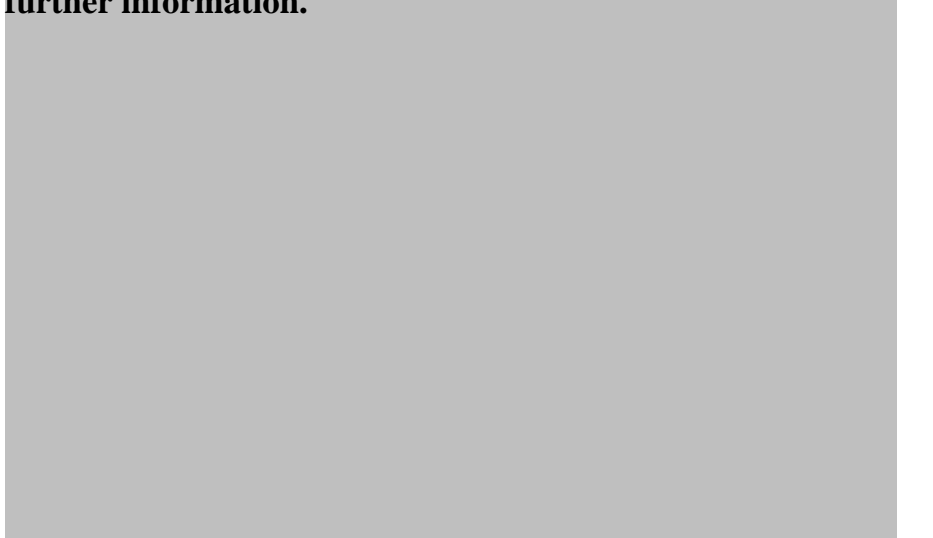

This content is unavalible. Please consult the figure list for further information. 


\section{$\begin{array}{lllllllll}0 & 01 & 02 & 03 & 04 & 05 & 06 & 07 & \mathbf{0 8}\end{array}$}

This content is unavalible. Please consult the figure list for further information.

NEVER FINISHED.

conclusions. 


\section{Project Summary.}

$\mathbf{T}$

his thesis has dedicated itself to address the growing issue of

has on the built environment of

New Zealand. Drawing attention

not only to the pressing hazards

that coastal New Zealand

communities are currently facing,

but to the flaw of humans in the

way that we have inhabited such

delicate and dynamic landscapes

by erecting structures of immense permanence.

The work covered has centred on developing the technique of stilted communities in response to these hazards. An approach that is foreign to any current coastal regions, but would allow the residents to maintain the luxury of coastal habitation while preserving the surrounding environment. A chique that has the potentia allow for humans to co-habit fynam et vulnerable landscapes.

nitially, this thesis explored the approach of elevating individua wellings and community building bove any potential threat from hazards, and for structural integrity they were anchored into the the process of design deviated and from the individual stilted dwelling, into the examination elevating an entire community.

Ultimately, the design of a full community wharf was conceived, stablishing a base platform where all the essential functions of a community can operate The design off a full wharf allows the residents of Hamoana to continue to live and collaborate in a community that they love and the general public become encouraged to frequent the region more, all while maintaining an appreciation for the areas natural character and environmental processes.

The design of the structures, dwellings, and community buildings endeavoured to follow the design principles that are exhibited in the vernacular New Zealand bach, with emphasis on simple formal qualities, and expressed structural components. 


\section{Conclusion.}

+ To enable enhanced occupation of sites that are vulnerable to coastal hazards.

+ Establish an innovative designed solution that allows the continued habitation of the Haumoana coastline.

+ Demonstrate a mutualistic relationship between nature and architecture

+ Retain the 'natural character' of Haumoana's coastal edge.

+ Use architecture as a tool to harmonise the interactions of man and nature.
$\mathbf{T}$

of both the design is a product derived from the response

hazards and demands of site,

integrated with the design

principles that were introduced

through the study of precedent design and traditional typologies.

It has been iteratively developed through a systematic conceptual investigation, and continually reflected upon and tested through the method of physical modelling.

The thesis argues that the continued habitation of New Zealand coastlines vulnerable to sea level rise and its associated hazards (mainly erosion and inundation) is advantageous if the built environment embraces an adaptive approach to community design that allows nature to retain its natural dynamics and processes.

With the designed intent to explore the considerably radical approach of stilted the village of small houses and community buildings were designed to not only retain, ut enhance the natural character of Haumoana's coastal edge. It becomes just as much of public experience as a functioning mmunity.

Being home to the fastest recedin coastline in New Zealand, this thesis focused on the Haumoan community to implement a design and test its findings. However, he potential applications of this design are not limited to the site that was explored. It was always xaumoana would act as a catalytic site for a potentially transferrable design.

As the title of this chapter suggests, the design such as this is never finished. Permitted with the luxury of more time and scope, his project would next explore the idea of easily transferable buildings atop the wharf, with the potential for a customisable or kinetic design that could be manipulated efficiently depending n the community's needs.$$
\text { the }
$$

would then continue on to address the applicability of similar designed interventions in similar vulnerable coastal environments around New Zealand such as the Coromandel or Dunedin. The project would assess what factors of the design could remain, what would change, what effect such a design would have on the environment and community.

There are some fundamental limitations to a project such as this. The architectural process and outcome followed was of personal preference, and while it was presented as a potential final intervention, design will always be open to individual interpretation, therefore many aspects of the design could take all manner of alternate forms.

It is for that reason that this thesis paid particular attention to the issues raised surrounding the current recommendation's for coastal management in New Zealand. There remains no sensible argument for the continuation of coastal habitation without an adaptive and alternative 


\section{Closing Statement.}

II've said good bye to the ove norked notion that architecture has to save the world"

Peter Zumpthor

\section{A} you must be acute to all aspects of the world, be it religious, political, environmental or any other manner of things. We are privileged enough to be in a position where the architectural community contains a diverse breadth of knowledge, creativity and influence, three things that can change the world as we know it.

It is then, in my belief that as architects, be it students, graduates, or professionals, have a responsibility to continually strive towards the creation of a superior world.

We have seen the power of architecture throughout society. Just as we often take influence from other art forms, many walks of life draw inspiration from architecture. With eve small change that the built environment makes, other aspects of society will follow, with this, architecture can be the catalysts to a sublime future.

We do not have to save the world, but we should want to even if its just one small coastal community at a time. 


\section{Bibliography.}

Ben Adams Architects. (2011). Chiquet Flood House. http://www.benadamsarchitects.co.uk/ projects/chiquet-flood-house

Bloomfield, S. (2018). Stepping back: A look at managed retreat in NZ.

Blundell, S. (2018). Rising sea levels are putting our coasts in crisis-Should we adapt or retreat? The New Zealand Listener. https://www noted. co.nz/planet/rising-sea-levels-coasts-crisis-hereswhat-we-can-do/

Britton, R. (2014). Stopbank Design and Construction Guidelines. Bay of Plenty Regional Council. https://www.boprc.govt.nz/media/395649/ stopbank-design-and-construction-guidelines.pdf

Chan, N. W., \& Parker, D. J. (1996). Response to dynamic flood hazard factors in peninsular Malaysia Geographical Journal, 313-325.

Cheyne, C., \& Freeman, C. (2006). A rising tide lifts all boats? A preliminary investigation into the impact of rising New Zealand coastal property prices on small communities. Kōtuitui: New Zealand Journal of Social Sciences Online, 1(2), 105-124.

Cooper, J. A. G., \& McKenna, J. (2008). Social justice in coastal erosion management: The temporal and spatial dimensions. Geoforum, 39(1), 294-306.

Cuny, F. C. (1991). Living with floods: Alternatives for riverine flood mitigation. Land Use Policy, 8(4) 331-342.

Federal Emergency Management Agency (2007). Selecting Appropriate Mitigatio Measures for Floodprone Structures. Washington DC: Department of Homeland Security. https://www.fema.gov/media-librarydata/20130726-1609-20490-5083/fema 551.pd
Grant-Taylor, T. L. (1996). Tukituki River. Te Ara An Encylopedia of New Zealand. https://teara. govt.nz/en/1966/tukituki-river

Gudsell, K. (2016). Wave Goodbye: Tide Rising on Haumaona. Radio New Zealand. https:// www.radionz.co.nz/news/national/309437/wavegoodbye-tide-rising-on-haumoana

HBRC. (2012). Tukituki Choices: A discussion of choices an opportunities for land and water management. Hawkes Bay Regional Council. https://www.hbrc.govt.nz/assets/DocumentLibrary/Tukituki/2012-Tukituki-Choices-discussiondocument.pd

HBRC, H. B. R. C. (2014). Hawke's Bay Regional Coastal Environmental Plan. https://www.hbrc. govt.nz/assets/Document-Library/Plans/RegionalCoastal-Environment-Plan-RCEP/HB-RegionalCoastal-Environment-Plan-excl-Schedules-andMaps.pdf

Kearns, R., \& Collins, D. (2006). 'On the rocks' New Zealand's coastal bach landscape and the case of Rangitoto Island. New Zealand Geographer, 62(3), 227-235.

Kench, P., \& Dickson, M. (2018). Living at the Edge-Transforming the Margins. Resilience to Nature's Challenges. https://resiliencechallenge. nz/edge/

. Threatening Tonle Sap. Political Geographies, 40, 29-31.

Martin, P. Y., \& Turner, B. A. (1986). Grounded Theory and Organizational Research. The Journal of Applied Behavioral Science, 22(2), 141-157. https://doi.org/10.1177/002188638602200207

Ministry of Environment, Lands and Parks. (2000). Riprap Design and Construction Guide. Provence of British Columbia, Water Management branch. http://www.env.gov.bc.ca/wsd/public safety/flood/ pdfs word/riprap guide.pdf

New Zealand Coastal Policy Statement. (2010).

New Zealand Department of Conservation.

https://www.doc.govt.nz/globalassets/documents/ conservation/marine-and-coastal/coastalmanagement/nz-coastal-policy-statement-2010. pdf

New Zealand Government. (2013). Whakataukī: Nā tō rourou, nā taku rourou ka ora ai te iwi [Educational]. Kia Eke Panuku. https://kep.org.nz module-8/1-whakatau\%C4\%81k\%C4\%AB

Norberg-Schulz, C. (1985). The Concept of Dwelling: On the way to figurative architecture. Rizzoli International Publications.

Owen, S., Lawrence, J., Ryan, E., Kench, P. Bell, R., Rennie, H., Blackett, P., \& Schneider P. (2018). ANTICIPATING STAGED MANAGED RETREAT at the coastal margins: Key questions and considerations for community and loca government evaluation of managed retreat approaches. Planning Quarterly, 209.

Parliamentary Commissioner for the Environment. (2015). Preparing New Zealand for rising seas: Certainty and Uncertainty. https://www.pce. parliament.nz/media/1390/preparing-nz-for-risingseas-web-small.pdf

Reinen-Hamill, R., Clode, G., \& Daykin, N. (2009) Coastal erosion of the Hawke Bay coastline from Napier to Cape Kidnappers. Coasts and Ports 2009: In a Dynamic Environment, 105.

Proposed Hastings District Plan. (2013). https:// eplan.hdc.govt.nz/eplan/\#Rules/0/45/1/0

Resource Management Act. (1991). Ministry for the Environment.
Ricketts, P. J. (1986). National policy and management responses to the hazard of coasta erosion in Britain and the United States. Applied Geography, 6(3), 197-221.

Sharpe, M. (2012, May 29). Haumoana groynes unlikely to get nod. The Dominion Post. http:// www.stuff.co.nz/dominion-post/business/ commercial-property/6993010/Haumoanagroynes-unlikely-to-get-nod

Sithirith, M. (2007). Fishing Economy of Stand-stilt Community in the Tonle Sap.

Soucie, G. (1973). Where beaches have been going: Into the ocean. Smithsonian Associates.

Stats NZ. (2013). 2013 QuickStats about a place: Haumoana. http://archive.stats.govt.nz/ Census/2013-census/profile-and-summaryreports/quickstats-about-a-place.aspx?request_va ue=14037\&tabname=Populationanddwellings $\#$

The Working Group I. (2013). Climate Change 2013: The Physical Science Basis. Contribution of Working Group I to the Fith Assessment Report of the Intergovernmental Panel on Climate Change. Cambridge University Press.

Wood, P. (2000). The bach: The cultural history of a local typology. Fabrications, 11(1), 44-61.

Workman, V. (2004). Mutualism in Architecture: An Architecture of the In-Between. Masters Theses. https://trace.tennessee.edu/utk gradthes/2253

Workman, V. A. (2004). Mutualism in Architecture: An Architecture of the In-Between. 


\section{Figures Cited.}

All uncaptioned images throughout this document are

the property of the author. All captioned images are

listed below, in order of appearance.

Figure 1.01. - Popov, Andrei. The Ocean is in our Hands. Niels Bugge Cartoon Award. 2014. Russia 12 April 2019 .Web. http://hae.de/nielsbuggeaward/award14.html

Figure 1.02. - Parsons-King, Rebekah. Haumoana residents build walls against the rising sea. 2016 RNZ. 18 April 2019. Web. https://www.rnz.co.nz/news/national/309437/wave-goodbyetide-rising-on-haumoana

Figure 1.03. - Whittaker, Tim. Haumoana, Hawkes Bay. 2017. Noted. 18 April 2019. Web. https://www. noted.co.nz/planet/planet-planet/rising-sea-levels-coasts-crisis-heres-what-we-can-do

Figure 1.04. - WP WATSO. Flood Protection System. Urban Green-Blue grids. 21 May 2019. Web. https://www.urbangreenbluegrids.com/measures/measures-for-separate-buildings/ sealable-buildings/

Figure 1.05. - Baca Architects. Amphibious House. 2014. Buckinghamshire, UK. 21 May 2019. Web. https://www.baca.uk.com/amphibious-house.html

Figure 1.06. - NLE Works. Minjiang Floating System. 2018. Chengdu, China. 21 May 2019. Web. https://www.nleworks.com/case/mfsiiix3-minjiang-floating-system/

Figure 1.07. - Asnida, Shutterstock. Temporary Construction in Southeast Asian Ocean. Badjao. Archdaily. 22 May 2019. Web. https://www.archdaily.com/638523/5-architecturalsecrets-of-the-badjao-21st-century-sea-people/

Figure 2.01. - Ninotaziz. Rumah Beranjung from Negri Sembilan. 2017. New Straits Times. 23 May 2019. Web. https://www.nst.com.my/lifestyle/sunday-vibes/2017/04/235069/savingkampung-house

Figure 2.02. - Green Era Travel. Tonle Sap Lake and Kampong Phluk. Trip Advisor. 23 May 2019. Web. https://www.tripadvisor.com.sg/AttractionProductReview-g297390-d12979807Tonle_Sap_Lake_and_Kampong_Phluk_Private_Half_Day_tour_from_Siem_ReapSiem_Reap_Si.htm

Figure 2.03. - Green Era Travel. Half-Day Kompong Phluk. On The Go Tours. 28 May 2019. Web. https://www.onthegotours.com/nz/Cambodia/Best-Places-To-Visit/Siem-Reap/Half-DayKompong-Phluk-Tonle-Sap-Lake-Tour

Figure 2.04. - Unknown Author. Angkor Wat Kampong Klieng. 28 May 2019. Web.http://angkorwatservices.com/Thailand/tours-package/angkor-wat-beng-melea-guided-tour-75-tours. angkorwat-services

Figure 2.05-06- Ben Adams Architects. Chiquet Flood House. 2011. Weybridge, United Kingdom. 2 June 2019. Web. http://www.benadamsarchitects.co.uk/projects/chiquet-floodhouse?sector_id=home
Figure 2.07-08- Oliver, Francis. Grand designs NZ 2017: Black House. 2017. Newshub. 4 June 2019. Web https://www.newshub.co.nz/home/entertainment/2017/10/grand-designs-nz-2017black-house.html

Figure 3.01. - Google Maps. 2017. 24 June 2019. Web. https://www.google.co.nz/maps/place/ Haumoana/@-39.5982714,176.9435893,546m/data=!3m1!1e3!4m5!3m4!1 s0x6d68358 3cbbfac6f:0x500ef6143a2ca70!8m2!3d-39.6034908!4d176.9465597

Figure 3.02. - Unknown Author. Rip Rap Gallery. Kroeger Marine. 20 June 2019. Web. http://www. kroegermarine.com/photos/rip-rap-gallery/

Figure 3.03. - Unknown Author. Woven \& Welded Gabions Protect River Bank from Erosion Control. 21 June 2019. ENZAR. Web. https://www.gabionbarriers.com/application/gabion-bank. html

Figure 3.04. - Hu, Edward. Flood Walls in New Orleans with raised streets. Scope Project. 23 June 2019. Web. https://www.scopeproject.org/hurricane-irma-and-harvey

Figure 4.01-04- EFFEKT. Regen Villages. 2016. Almere, The Netherlands. Regen Villages Holding B.V. 12 July 2019. Web. https://www.effekt.dk/regenvillages

Figure 4.05. - Unknown Author. Rangitoto Island Abandoned Vessels and Baches. 2014. Rangitoto Archaeology 14. 12 July 2019. Web. https://rangitotoarchaeology14.wordpress.com/ about/location-2/

Figure 4.06. - Double Whirler. A Traditional Bach. 2013. 21 December 2019. Web. https:// doublewhirler.wordpress.com/2013/05/08/lifes-a-bach-the-new-zealand-beach-house/

Figure 4.07. - Unknown Author. Svetlai Rangitoto Bach. 2011. Rangitoto, Auckland. 21 December 2019. Web. https://jobryantnz.files.wordpress.com/2011/08/svetlai-rangitoto-bach.jpg

Figure 4.08-10- Crosson Architects. Hut On Sleds. 2012. Crosson. Whangapoura, Corromandel. 21 August 2019. Web. http://crosson.co.nz/hut-on-sleds-whangapoua/

Figure 4.11-15- Amoretti, Aldo. The Nobel Simplicity of Peter Zumthor's Zinc Mine Museum. 2017. Arch Daily. 14 July 2019. Web. https://www.archdaily.com/803691/the-noble-simplicity-ofpeter-zumthors-allmannajuvet-zinc-mine-museum

Figure 4.16-20- Andernach, Dennis. Landschaftshäuser, Landscape for Houses. Von Dennis Andernach. Web. http://www.denis-andernach.de/

Figure 6.01. - Green Era Travel. Half-Day Kompong Phluk. On The Go Tours. 28 May 2019. Web. https://www.onthegotours.com/nz/Cambodia/Best-Places-To-Visit/Siem-Reap/Half-DayKompong-Phluk-Tonle-Sap-Lake-Tour 
Figure 6.02. - Kampong Phluk, Cambodia. Google Maps. 28 May 2019. Web. https://www.google. co.nz/maps/place/Kampong+Phluk,+Cambodia/@13.2099181,103.9731825,969m/data

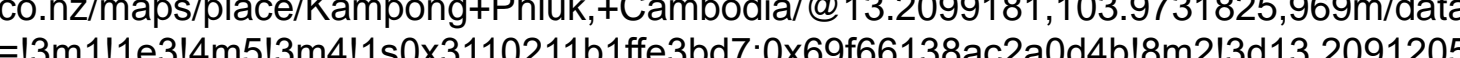
$4 d 103.9738648$

Figure 6.03. - Unknown Author. Kampong Khleang. Siem Reap Plus. 7 August 2019. Web. https:// siemreapplus.com/trip/kampong-khleang/

Figure 6.04. - Kampong Khelang, Cambodia. Google Maps. 7 August 2019. Web. https://www.google co.nz/maps/place/\%E1\%9E\%80\%E1\%9F\%86\%E1\%9E\%96\%E1\%9E\%84\%E1\%9F\%8 B\%E1\%9E\%83\%E1\%9F\%92\%E1\%9E\%9B\%E1\%9E\%B6\%E1\%9F\%86\%E1\%9E\%84, +Cambodia/@13.1052992,104.1167049,3876m/data=!3m2!1e3!4b1!4m5!3m4!1 s0x310 d793835b5099:0x5d0401bd503eb296!8m2!3d13.1052996!4d104.1254811

Figure 6.05. - Takahashi, Satoshi. Kompong Luong Floating Village on Tonle Sap Lake. 2015. Getty Images. 8 August 2019. Web. https://www.gettyimages.co.nz/detail/news-photo/ kompong-luong-floating-village-on-tonle-sap-lake-the-news-photo/627322418

Figure 6.06. - Kampong Luong, Cambodia. Google Maps. 8 August 2019. Web. https://www.google. co.nz/maps/place/Kampong+Luong,+Cambodia/@12.563222,104.1947694,7769m/data $=! 3 \mathrm{~m} 1 ! 1 \mathrm{e} 3$ !4m5!3m4!1s0x310fb274a6d0a54d:0x495617ac2b30dc6b!8m2!3d12.549379 $5 ! 4 \mathrm{~d} 104.189484$

Figure 6.07. - Cockrem, Tom. Stilt Village. 2010. Semporna, Sabah, Malaysia. Age Foto Stock 8 August 2019. Web. https://www.agefotostock.com/age/en/Stock-Images/RightsManaged/U75-1162261

Figure 6.08. - Semporna, Malaysia. Google Maps. 8 August 2019. Web. https://www.google.co.nz/ maps/place/Semporna/@4.4882457,118.5987416,1986m/data=!3m1!1e3!4m5!3m4!1s0 x323fe8cc43dbc6f1:0xc9437d364cbf136a!8m2!3d4.6252899!4d118.3891075

Figure 6.09. - Unkown Author. Malaysia Semporna Borneo Aerial shot. Semporna Island. Wallpapers 13. 5 December 2019. Web. https://www.wallpapers13.com/malaysia-sempornaborneo-aerial-shot-of-semporna-island-1920x1200/

Figure 6.10. - Bodgaya Island, Malaysia. Google Maps. 5 December 2019. Web. https://www.google. co.nz/maps/place/Semporna/@4.4882457,118.5987416,1986m/data=!3m1!1e3!4m5!3 $\mathrm{m} 4 ! 1 \mathrm{~s} 0 \times 323 \mathrm{fe} 8 \mathrm{cc} 43 \mathrm{dbc6f1}: 0 \times \mathrm{xc} 9437 \mathrm{~d} 364 \mathrm{cbf} 136 \mathrm{a} ! 8 \mathrm{~m} 2 ! 3 \mathrm{~d} 4.6252899 ! 4 \mathrm{~d} 118.3891075$

Figure 6.11. - Steamer, James. Nzulenzu Amansuri Village Lake Western Region. 2016. Ghana. Mp3ew.com. 8 December 2019.Web. http://mp3ew.com/audio/view/0sKCzyZY1oU.html

Figure 6.12. - Nzulenzu Village, Ghana. Google Maps. 8 December 2019. Web. https://www.google. co.nz/maps/place/Nzulenzu,+Ghana/@5.020885,-2.5988433,496m/data=!3m1!1e3!4m5 3m4!1s0xfe802e7753e56d5:0x5bedb75c6b4fc578!8m2!3d5.0208275!4d-2.59792 
"It's kind of fun to do the impossible" Walt Disney 